Leonardo Barra Santana de Souza

\title{
ESTUDO EXPERIMENTAL E MODELAGEM NUMÉRICA DO ESCOAMENTO E DO ASSOREAMENTO EM UMA ARMADILHA DE SEDIMENTOS
}

Tese apresentada à Escola de Engenharia de São Carlos da Universidade de São Paulo, como parte dos requisitos para obtenção do Título de Doutor em Engenharia - Área de concentração: Hidráulica e Saneamento.

ORIENTADOR: Professor Titular Swami Marcondes Villela 
Ficha catalográfica preparada pela Seção de Tratamento da Informação do Serviço de Biblioteca - EESC/USP

Souza, Leonardo Barra Santana de
Estudo experimental e modelagem numérica do escoamento
e do assoreamento em uma armadilha de sedimentos /
Leonardo Barra Santana de Souza. - - São Carlos, 2006.
Tese (Doutorado) -- Escola de Engenharia de São
Carlos-Universidade de São Paulo, 2006.
Área: Hidráulica e Saneamento.
Orientador: Prof. Tit. Swami Marcondes Villela.
1. Assoreamento de reservatórios. 2. Simulação
numérica. 3. Velocimetria a laser. I. Título.


FOLHA DE JULGAMENTO

Candidato: Engenheiro LEONARDO BARRA SANTANA DE SOUZA

Tese defendida e julgada em 06-02-2006 perante a Comissão Julgadora:

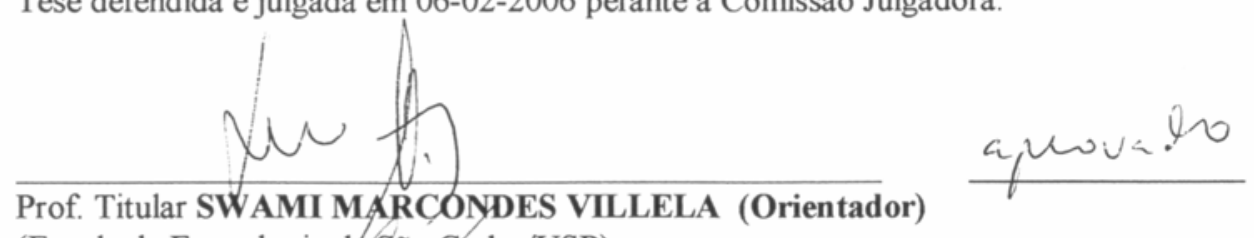

(Escola de Engenharia de São Carlos/USP)
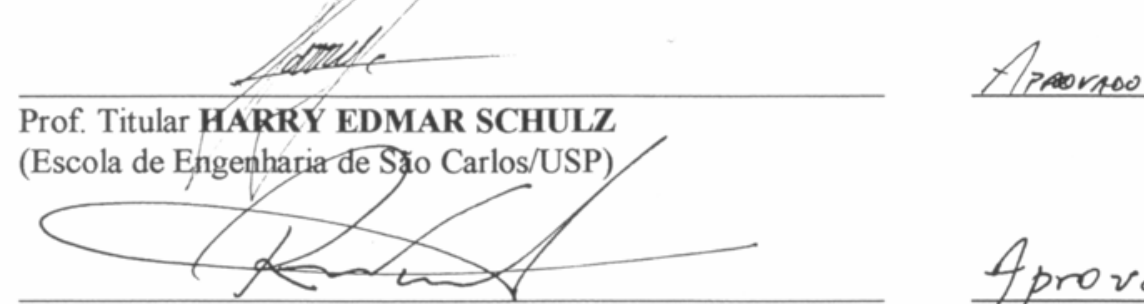

Prof. Associado RODRIGO DE MELO PORTO

(Escola de Engenharia de São Carlos/USP)
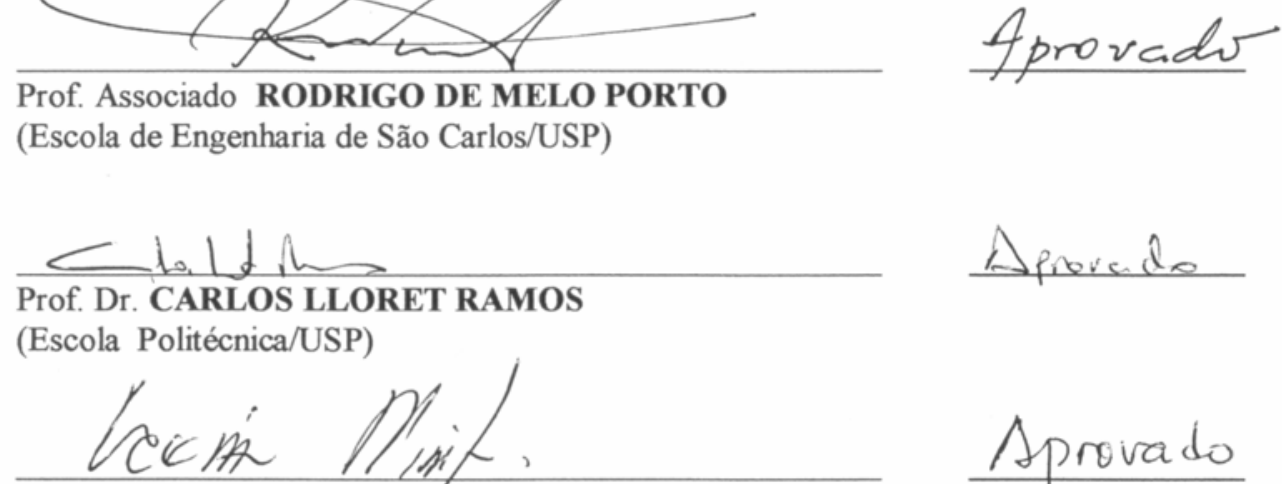

Prof. Dr. LUIS CESAR DE SOUZA PINTO

(Escola Politécnica/USP)

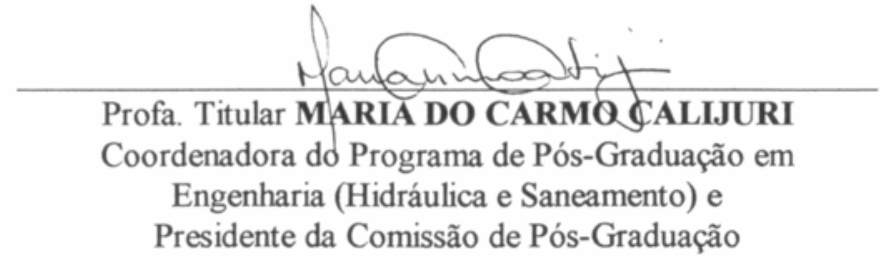


Dedicado aos meus pais, à Jaq e ao Leandro, pelo amor, apoio e paciência. 


\section{AGRADECIMENTOS}

Agradeço à Fundação Coordenação de Aperfeiçoamento de Pessoal de Nível Superior CAPES, pela bolsa de doutorado;

à Financiadora de Estudos e Projetos - FINEP, pelo auxílio financeiro concedido através do convênio n ${ }^{\mathrm{o}}$ 23.01.0606.00;

à Fundação para o Incremento da Pesquisa e o Aperfeiçoamento Industrial - FIPAI, pela administração do auxílio financeiro;

ao meu orientador, Professor Swami Marcondes Villela, pelos ensinamentos que não se limitaram à pesquisa e pelo exemplo de ser humano e bondade;

ao Professor Dr. Harry Edmar Schulz, pelo apoio de sempre e por tudo que me ensinou desde o meu primeiro dia como aluno de mestrado no SHS;

ao Professor Dr. Rodrigo de Melo Porto, pelos ensinamentos preciosos e toda a contribuição ao trabalho;

aos Professores Dr. Carlos Lloret Ramos e Dr. Luis Cesar de Souza Pinto, pela contribuição ao trabalho quando da participação da banca;

à coordenação e a todos os professores, técnicos, funcionários e colegas do SHS-EESCUSP que direta ou indiretamente participaram deste trabalho;

a todos da empresa DHI Water and Environment, em especial ao engenheiro $\mathrm{PhD}$ Bo Brahtz Christensen, por todo o suporte técnico ao trabalho de simulação;

aos engenheiros M.Sc. Jaqueline Costa Martins e M.Sc. Stênio de Sousa Venâncio, pela ajuda na condução do trabalho experimental;

ao programador Leandro Barra Santana de Souza e ao técnico em computação gráfica Daniel de Souza Dutra, pela colaboração nos trabalhos de programação e edição dos vídeos;

à Tuquinha (in memoriam), ao Byron e à Fancy, pela alegria e paz que me proporcionaram, me recebendo em casa sempre com muita felicidade nos dias mais duros de trabalho, e pela companhia fiel nas noites sem fim em frente ao computador;

a toda minha família e aos meus amigos, por tudo.

Muito obrigado! 


\section{RESUMO}

SOUZA, L. B. S. Estudo experimental e modelagem numérica do escoamento e do assoreamento em uma armadilha de sedimentos. 2006. 154 p. Tese de Doutorado Escola de Engenharia de São Carlos, Universidade de São Paulo, São Carlos.

Os sedimentos transportados por cursos de água, quando depositados nos reservatórios, podem lhes causar danos, como redução do seu volume de água, prejuízos à navegação, danificação de turbinas e bloqueio de tomadas de água e comportas. Para que medidas preventivas possam ser tomadas nesse sentido, a capacidade de predizer taxas de sedimentação e sua distribuição não-uniforme em reservatórios é muito importante, ainda em sua fase de projeto. Este trabalho compreende a construção e o assoreamento de uma armadilha de sedimentos em laboratório, bem como a utilização de um programa computacional para reprodução numérica do assoreamento. A comparação satisfatória entre resultados experimentais e simulados, tanto para o padrão do escoamento no interior da armadilha quanto para a deposição de sedimentos, permitiu avaliar o programa MIKE $21 \mathrm{C}$ como ferramenta útil no estudo e na estimativa do assoreamento de reservatórios.

Palavras-chave: assoreamento de reservatórios, simulação numérica, velocimetria a laser. 


\section{ABSTRACT}

SOUZA, L. B. S. Estudo experimental e modelagem numérica do escoamento e do assoreamento em uma armadilha de sedimentos. 2006. 154p. Tese de Doutorado Escola de Engenharia de São Carlos, Universidade de São Paulo, São Carlos.

Sediment transport in alluvial rivers may cause serious problems to reservoirs, such as decrease in storage volume, impairment of navigability, damage to hydropower turbines, and blockage of gates and intakes. The capacity of predicting sedimentation and its non-uniform distribution inside reservoirs is very important, still in their phase of planning and design. This work comprehends the construction of a sand trap in a laboratory and its experimental sedimentation, as well as the use of a computational program to reproduce numerically the experiment. The satisfactory comparison between experimental and numerical results, for the flow pattern inside the trap and for the sediment deposition, validated the program MIKE $21 \mathrm{C}$ as a useful tool in the study and prediction of reservoir sedimentation.

Key-words: reservoir sedimentation, numerical simulation, laser velocimetry. 


\section{SUMÁRIO}

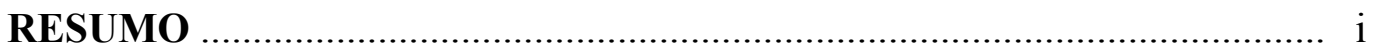

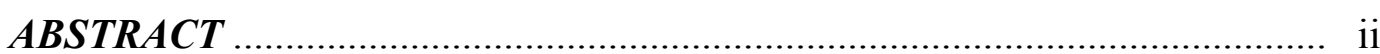

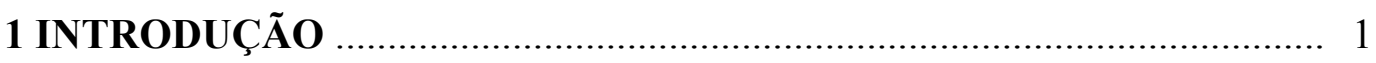

2 OBJETIVO

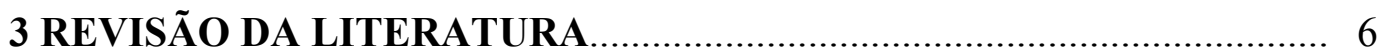

3.1 Trabalhos de modelagem numérica do assoreamento de reservatórios.......... 7

3.2 Modelagem no Brasil............................................................................. 12

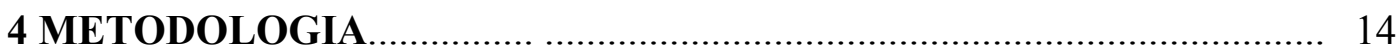

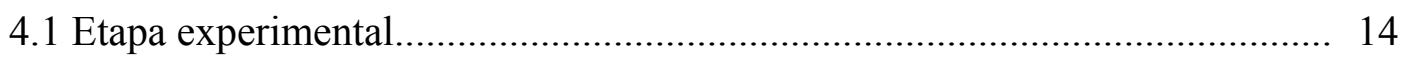

4.1.1 Projeto e construção da armadilha de sedimentos.................................... 14

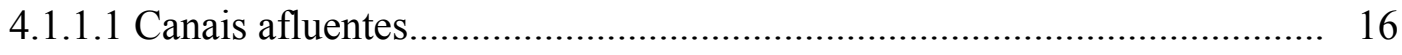

4.1.1.2 Reservatório elevado e sistema de descarga de sedimento..................... 18

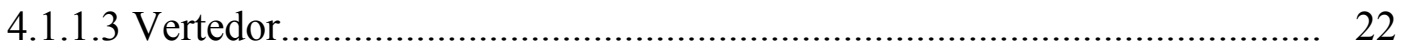

4.1.2 Campos de velocidade na armadilha..................................................... 23

4.1.2.1 Técnica de velocimetria a laser.......................................................... 25

4.1.2.2 Campos de velocidade média.............................................................. 31

4.1.3 Assoreamento da armadilha............................................................... 31

4.1.3.1 Características da areia...................................................................... 31

4.1.3.2 Medição do assoreamento.................................................................... 34

4.2 Etapa de simulação numérica....................................................................... 35

4.2.1 Equacionamento do modelo hidrodinâmico............................................... 36

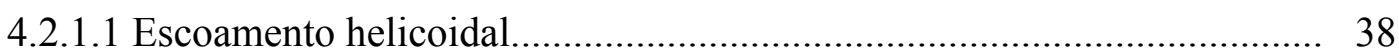

4.2.1.2 Modelagem da turbulência................................................................ 40

4.2.2 Modelo de transporte de sedimentos .................................................. 40

4.2.2.1 Transporte em suspensão................................................................... 41

4.2.2.2 Transporte de fundo....................................................................... 42

4.2.2.3 Equações de transporte de sedimentos................................................... 42

4.2.3 Simulação hidrodinâmica......................................................................... 43

4.2.4 Simulação do assoreamento............................................................... 51

5 RESULTADOS E DISCUSSÃO........................................................ 57

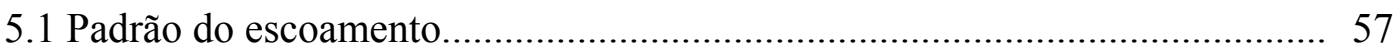

5.1.1 Configuração 1.................................................................................. 57 


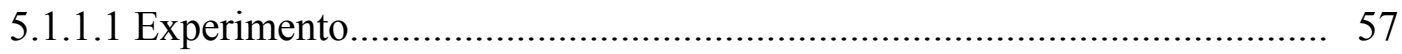

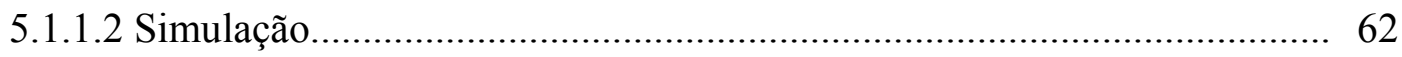

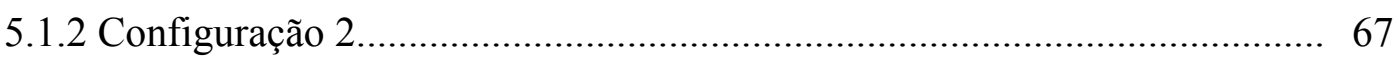

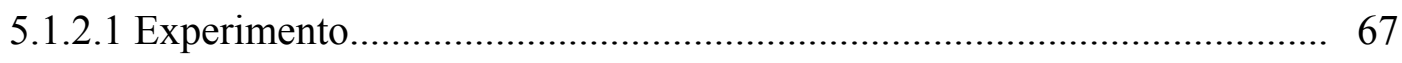

5.1.2.2 Simulação.................................................................................. 71

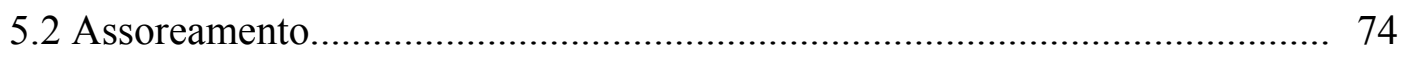

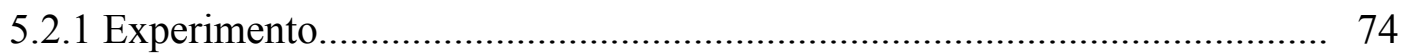

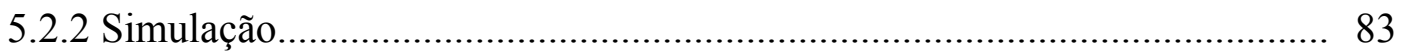

5.2.3 Comparação de seções transversais...................................................... 95

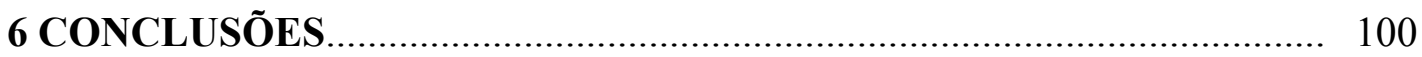

7 SUGESTÕES PARA TRABALHOS FUTUROS..................................... 103

8 REFERÊNCIAS BIBLIOGRÁFICAS................................................. 104

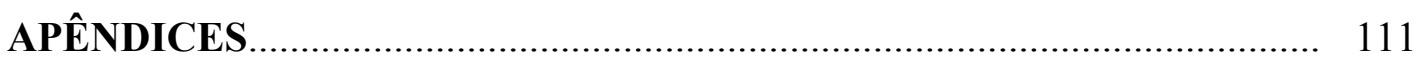

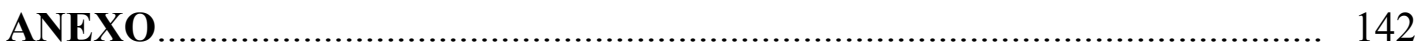




\section{INTRODUÇÃO}

Uma das maneiras mais antigas que a humanidade conhece de aproveitar a água, da melhor forma possível para seu abastecimento, é a sua reservação. O armazenamento de água em reservatórios formados por barragens tem uma história própria e milenar, com registros apontando, por exemplo, a barragem de Sadd-el-Kaffara, construída no Egito por volta de 2600 a.C., com $14 \mathrm{~m}$ de altura e $113 \mathrm{~m}$ de comprimento na crista, como a mais antiga de seu porte (SMITH, 1971; SCHNITTER, 1994). Para que a construção de um reservatório garanta um bom aproveitamento de um curso de água, fornecendo água regularmente tanto nos períodos de abundância quanto nos períodos de seca, certo volume para armazenamento (o volume do reservatório), devidamente calculado, faz-se necessário.

Ao longo dos anos de seu funcionamento, um reservatório recebe sedimentos transportados por cursos de água. Grande parte desses sedimentos, formados por partículas que podem estar em suspensão ou no leito do rio, percorre longas distâncias e

é geralmente depositada na entrada ou ao longo do reservatório, onde a velocidade do escoamento e a capacidade de transporte de material diminuem consideravelmente. Uma vez depositadas, essas partículas se consolidam, aumentam sua resistência à erosão e se tornam difíceis de ser carreadas (MOHAMMAD, 2000). A acumulação de sedimentos em reservatórios é denominada assoreamento, um fenômeno natural causado por enchentes e erosões, mas que tem sido agravado e acelerado por atividades humanas, tais como uso indevido do solo, desmatamento, urbanização, etc. O assoreamento causa diversos problemas ao reservatório, por vezes irreparáveis, e à população por ele abastecida, dentre os quais cita-se:

- elevação do nível de água e alagamento de regiões próximas;

- obstrução de tomadas de água para geração de energia elétrica;

- danificação de rotores de turbinas e outras estruturas, por abrasão;

- formação de bancos de areia que alteram e dificultam as rotas de navegação; 
- diminuição do volume útil do reservatório, destinado a abastecimento, irrigação, geração de energia, controle de enchentes, etc.;

- e por fim, a inutilização completa do reservatório.

A capacidade de predizer taxas de sedimentação é muito importante ainda na fase de projeto de reservatórios, como comentado por Ziegler e Nisbet (1995). No seu planejamento, engenheiros precisam antecipar problemas de assoreamento e incorporar aos projetos medidas para regular a acumulação de sedimentos no lago. Se projetistas desprezam ou subestimam esses problemas, podem falhar na adoção de medidas apropriadas e a capacidade dos reservatórios diminuirá continuamente (FAN e MORRIS, 1992).

Como caso extremo de assoreamento, cita-se Lake Powell no rio Colorado, que de acordo com Morris \& Fan (1998) apud Nicklow e Mays (2000), necessitaria de U\$83 bilhões para recuperação de seu volume inicial de $33 \mathrm{~km}^{3}$, completamente tomado por sedimentos.

Um estudo para estimativa do assoreamento pode ser feito através de medições diretas de vazão do rio e concentração de sedimentos, realizadas simultaneamente em locais próximos à entrada dos reservatórios. Os dados obtidos produzem a chamada curva-chave de sedimentos, relacionando a vazão de água à descarga de sedimentos. De posse de uma série de vazões de água e da curva, para determinado rio que abastece um reservatório, faz-se uma previsão do assoreamento ao longo do tempo, causado pela descarga de sedimentos do rio em questão. Com o reservatório já construído e em operação, batimetrias podem ser realizadas periodicamente para acompanhamento do assoreamento.

A partir dessas técnicas de avaliação da deposição de material nos reservatórios, existem medidas preventivas e corretivas que podem ser tomadas no combate ao assoreamento e são importantes para o prolongamento da vida útil da obra. Das medidas preventivas, cita-se controle de erosão na bacia, proteção das margens do reservatório e construção de desarenadores em canais de adução para abastecimento e geração de energia. Como medidas corretivas, tem-se as dragagens (operações de retirada de sedimentos dos reservatórios) e as lavagens (do inglês flushing), que compreendem a liberação de sedimentos através de comportas de fundo na barragem (descarregadores de fundo).

Caso houvesse uma estimativa espaço-temporal do assoreamento, com estudo do volume de material a ser sedimentado ao passar dos anos e de sua distribuição não- 
uniforme no reservatório, tanto medidas preventivas quanto corretivas poderiam ser tomadas de forma mais eficiente. Por exemplo, descarregadores de fundo poderiam ser mais bem dimensionados e localizados, para que lavagens periódicas do reservatório pudessem ser programadas e executadas com eficiência; e as dragagens realizadas em períodos e locais pré-estabelecidos.

A estimativa espaço-temporal do assoreamento pode ser auxiliada por um estudo mais detalhado do movimento do fluido (água) e do transporte de sedimentos no interior do reservatório, realizado através de modelagem física, numérica, ou de ambas. A modelagem física do assoreamento de um reservatório envolve considerável consumo de tempo na construção de modelos reduzidos e na execução de experimentos, mas tem sido tradicionalmente usada e útil em pesquisas de fenômenos hidráulicos. Sua precisão na representação do fenômeno é limitada pela incompatibilidade dos adimensionais envolvidos na análise de escoamentos livres e pela distorção de escala geométrica, quase inevitável quando transporte de sedimentos é considerado.

A modelagem numérica tem crescido substancialmente e se tornado ferramenta importante no estudo de escoamentos de fluidos, apoiada pelo avanço da capacidade dos computadores e das técnicas numéricas para solução de equações. Como os reais parâmetros do problema estudado (dimensões do reservatório, propriedades do fluido, do escoamento e dos sedimentos, etc.) são introduzidos nessa modelagem, a distorção de escala geométrica inexiste (apesar de haver distorção de escala relacionada a discretização das equações diferenciais que representam o fenômeno). Em contrapartida, o escoamento de um fluido carregado de sedimentos envolve um número alto de variáveis que os modelos atuais não conseguem representar. Como resultado, modelos matemáticos hidrodinâmicos e de transporte de sedimentos possuem hipóteses simplificadoras do fenômeno e precisam ser calibrados, através de dados obtidos a partir do próprio fenômeno real estudado ou de um modelo físico que o represente. Observase então que estas duas modelagens, física e numérica, apresentam limitações próprias, mas juntas podem gerar resultados e conclusões mais representativos do fenômeno pesquisado.

No Brasil, as medições diretas de descarga de sedimentos em reservatórios ainda são raras, como também são os levantamentos batimétricos periódicos (por serem de alto custo), necessários à obtenção da distribuição espacial dos sedimentos depositados e sua evolução no tempo. Essa falta de dados de campo faz com que reservatórios sejam operados como se seu volume útil fosse ainda aquele referente ao início de sua 
operação. Exemplificando, quando se diz que um reservatório está operando com $10 \%$ de sua capacidade, essa porcentagem diz respeito ao volume inicial de projeto, mas que na realidade foi reduzido ao longo dos anos pelo assoreamento. Pela falta de acompanhamento da redução do volume dos reservatórios, não apenas reservatórios isolados são operados de forma ineficiente, mas redes de reservatórios são gerenciadas sem otimização. Enfatiza-se assim a importância do desenvolvimento de trabalhos experimentais e simulações numéricas, no âmbito nacional, para auxílio no entendimento do complexo fenômeno do assoreamento de reservatórios.

Esta pesquisa de Doutorado compreende trabalhos experimental e de simulação numérica que visam contribuir no estudo do assoreamento de reservatórios. No Capítulo 2, apresenta-se os objetivos deste trabalho, desenvolvido no Departamento de Hidráulica e Saneamento da Escola de Engenharia de São Carlos, da Universidade de São Paulo (SHS-EESC-USP). Na seqüência, faz-se uma breve revisão da literatura no Capítulo 3, citando-se trabalhos de modelagem física e numérica de assoreamento. $\mathrm{O}$ Capítulo 4 detalha os materiais e métodos usados. Nesse capítulo, apresenta-se para a etapa experimental a construção da armadilha de sedimentos em laboratório e a metodologia adotada para determinação do padrão do escoamento de água e do assoreamento em seu interior. Para a etapa de simulação, mostra-se o programa computacional adquirido, MIKE 21C, e sua utilização nas modelagens hidrodinâmica e do assoreamento. No Capítulo 5, os resultados experimentais e numéricos são apresentados, discutidos e comparados. Nos demais capítulos seguem as conclusões, as sugestões para trabalhos futuros, as referências bibliográficas e apêndices. Junto a este texto encontra-se um DVD (Digital Vídeo Disc) com gravação de fotos e vídeos dos experimentos e simulações realizados, essenciais para o bom entendimento desta pesquisa. Os arquivos são organizados como mostrado no APÊNDICE A_ORGANIZAÇÃO DOS VÍDEOS E FOTOS NO DVD. 


\section{OBJETIVO DO TRABALHO}

Este trabalho tem como objetivo específico reproduzir numericamente o processo de assoreamento em uma armadilha de sedimentos. Sua etapa experimental compreende o projeto e a construção da armadilha em laboratório, bem como a realização de experimentos para conhecimento do padrão do escoamento e da deposição de sedimentos em seu interior. A etapa de simulação numérica consiste em aquisição e uso de um programa de modelagem morfológica de escoamentos fluviais, para reprodução do experimento. A avaliação satisfatória dos resultados numéricos, a partir de sua comparação com os dados experimentais, viabiliza a utilização do programa em trabalhos seguintes, contribuindo para que o objetivo maior desta linha de pesquisa seja atingido: o uso confiável de simulações numéricas para estudo e estimativa do assoreamento de reservatórios de água formados por barragens. 
3 REVISÃO DA LITERATURA

A importância de pesquisas e trabalhos para melhor entendimento, acompanhamento e controle do assoreamento de reservatórios no Brasil é evidenciada em Carvalho (1994), que apresenta uma série de reservatórios que já foram afetados por esse fenômeno (Tabela 1).

Tabela 1 - Alguns reservatórios no Brasil parcial ou totalmente assoreados. Fonte: Carvalho (1994).

\begin{tabular}{|c|c|c|c|}
\hline RESERVATÓRIO & CURSO DE ÁGUA & PROPRIETÁRIO & FINALIDADE \\
\hline \multicolumn{4}{|l|}{ Bacia do São Francisco } \\
\hline Rio das Pedras & Velhas & CEMIG & UHE - $10 \mathrm{MW}$ \\
\hline Paraúna & Paraúna & CEMIG & UHE - $30 \mathrm{MW}$ \\
\hline Pandeiros & Pandeiros & CEMIG & UHE - 4,2 MW \\
\hline Acabamundo & Acabamundo & DNOS & Controle de cheias \\
\hline Arrudas & Arrudas & DNOS & Controle de cheias \\
\hline Pampulha & Pampulha & DNOS & Controle de cheias \\
\hline \multicolumn{4}{|l|}{ Bacia Atlântico/Leste } \\
\hline Funil & Contas & CHESF & UHE - $30 \mathrm{MW}$ \\
\hline Pedras & Contas & CHESF & UHE - $23 \mathrm{MW}$ \\
\hline Peti & Santa Bárbara & CEMIG & UHE - 9,4 MW \\
\hline Brecha & Piranga & - & UHE - 10,5 MW \\
\hline Piracicaba & Piracicaba & Belgo - Mineira & UHE - - \\
\hline Sá Carvalho & Piracicaba & Acesita & UHE - $50 \mathrm{MW}$ \\
\hline Dona Rita & Tanque & - & UHE - 2,41 MW \\
\hline Salto Grande & Santo Antônio & CEMIG & UHE - $104 \mathrm{MW}$ \\
\hline Tronqueiras & Tronqueiras & - & UHE - 7,87 MW \\
\hline Bretas & Suaçuí Pequeno & - & - \\
\hline Mascarenhas & Rio Doce & ESCELSA & UHE - $120 \mathrm{MW}$ \\
\hline Paraitinga & Paraitinga & CESP & UHE - $85 \mathrm{MW}$ \\
\hline Jaguari & Jaguari & CESP & UHE - 27,6 MW \\
\hline Una & Una & PM Taubaté & Abastecimento de água \\
\hline \multicolumn{4}{|l|}{ Bacia do Paraná } \\
\hline Caconde & Pardo & CESP & UHE - 80,4 MW \\
\hline Euclides da Cunha & Pardo & CESP & UHE - 108,8 MW \\
\hline Americana & Atibaia & CPFL & UHE - $34 \mathrm{MW}$ \\
\hline Jurumirim & Paranapanema & CESP & UHE - $22 \mathrm{MW}$ \\
\hline Piraju & Paranapanema & CPFL & UHE - $120 \mathrm{MW}$ \\
\hline Presidente Vargas & Tibaji & Klabin & UHE - 22,5 MW \\
\hline Poxoréu & Poxoréu & CEMAT & UHE - - \\
\hline São Gabriel & Coxim & ENERSUL & UHE - 7,5 MW \\
\hline Ribeirão das Pedras & Descoberto & CAESB & Abastecimento de água \\
\hline São João & São João & ENRSUL & UHE - 3,2 MW \\
\hline Bacia do Uruguai & & & \\
\hline
\end{tabular}




continuação
\begin{tabular}{|l|l|l|l|}
\hline Caveiras & Caveiras & CELESC & UHE - 4,3 MW \\
\hline Silveira & Santa Cruz & CELESC & UHE - - \\
\hline Celso Ramos & Chapecozinho & CELESC & UHE - 5,76 MW \\
\hline Furnas do Segredo & Jaguari & CEEE & UHE - - \\
\hline Bacia Atlântico/Sudeste & Tacanica & & \\
\hline Santa Cruz & Piraí & CCPRB & UHE - 1,4 MW \\
\hline Piraí & Jacuí & CELESC & UHE - 1,37 MW \\
\hline Ernestina & Jacuí & CEEE & UHE - 1,0 MW \\
\hline Passo Real & & CEEE & UHE - 125 MW \\
\hline
\end{tabular}

O cálculo de escoamento e transporte de sedimentos, tanto em rios quanto em reservatórios, é tarefa importante na hidráulica fluvial. A estimativa desses processos tem sido realizada através de trabalhos de campo, de laboratório e de simulação numérica. De interesse particular deste trabalho, enfatiza-se neste capítulo a apresentação de estudos de simulação numérica de transporte de sedimentos e assoreamento de reservatórios, mas que envolvem também, em sua maioria, experimentos de laboratório e dados de campo para avaliação e validação dos resultados computacionais. Algumas das simulações foram realizadas com programas computacionais desenvolvidos em pesquisas no meio acadêmico ou por agências governamentais, enquanto outras são resultados de pacotes comerciais, desenvolvidos por empresas particulares. Existem, ainda, programas desenvolvidos em trabalho conjunto dessas instituições (academia, governo e empresa).

\subsection{Trabalhos de modelagem numérica do assoreamento de reservatórios}

Ziegler e Nisbet (1995) fizeram uma simulação de 30 anos (de 1961 a 1991) de transporte de sedimentos finos, coesivos, no reservatório de Watts Bar, localizado no Tennessee e que faz parte do sistema de reservatórios Tennessee Valley Authority. Demonstrou-se que o modelo SEDZL reproduziu bem deposição e erosão neste grande reservatório. O modelo foi calibrado com dados de batimetrias realizadas em 1946, 1951, 1956, 1961 e 1991 . Uma comparação quantitativa da variação do nível do fundo acusou um erro relativo médio de $46 \%$ e foi considerada satisfatória pelos autores. $\mathrm{O}$ modelo predisse que $76 \%$ do sedimento que entra no reservatório em 30 anos é mantido no reservatório, contra 72\% $( \pm 6 \%)$ observado. As batimetrias foram realizadas em 64 seções transversais no reservatório (as mesmas em todas as medições). A batimetria de 1991 usou equipamento Acoustic Depth Finder (precisão de \pm 0,03 metros) com Global Positioning System (GPS). 
O trabalho preocupou-se com o tempo de permanência de sedimentos finos e coesivos no reservatório, muitas vezes carregados de compostos químicos e metais pesados, prejudiciais ao meio ambiente. A pequena profundidade do reservatório em questão, associada aos pequenos efeitos de estratificação térmica, indicou que a coluna de água pôde ser assumida misturada verticalmente, isto é, as correntes de velocidades horizontais e concentrações de sedimentos são aproximadamente uniformes na direção vertical. Essas condições permitiram que o processo físico fosse aproximado por uma modelagem bidimensional, com equações integradas na vertical. A malha computacional continha 157 elementos. Os resultados mostraram-se coerentes com a realidade, com sedimentos de maior diâmetro, não coesivos, depositados na entrada do reservatório; e sedimentos finos e coesivos (silte e argila) em maior quantidade na medida em que se aproxima da barragem. O SEDZL também foi usado em simulações de transporte de sedimentos finos em outros sistemas aquáticos, como Fox River, em Wisconsin (GAILANI et al. 1991); Pawtuxet River, em Rhode Island (ZIEGLER e NISBET, 1994) e Lake Irie (LICK et al., 1994).

Chang et al. (1996) discutiram a acumulação de sedimentos em reservatórios ao longo do rio North Feather, fenômeno que afetará num futuro próximo a geração de energia elétrica. Para controle do assoreamento, descargas de fundo têm sido consideradas, para que os sedimentos atravessem os reservatórios. O objetivo é manter o balanço de sedimentos sem erosão ou assoreamento resultante nos reservatórios, em um extenso ciclo de operação. A velocidade do escoamento para que os sedimentos sejam transportados e passem por cada reservatório seria atingida com o rebaixamento do nível de água, usando descargas de fundo durante períodos de cheia.

Um estudo com modelagem numérica, usando o programa FLUVIAL-12, foi realizado para se avaliar a viabilidade e eficiência dessa operação. O FLUVIAL-12, segundo Chang (1988), tem sido formulado e desenvolvido desde 1972 para modelagem de escoamento e transporte de sedimentos fluviais.

Em Gessler (1999), descreve-se o modelo tridimensional (3D) de escoamento e transporte de sedimentos CH3D-SED; e sua aplicação no Projeto Deep Draft Navigation, no baixo Mississipi. A capacidade do programa em simular transporte de sedimentos (apenas areia) em canais de fundo móvel foi desenvolvida em conjunto pelo Laboratório de Hidráulica do U.S. Army Corps of Engineers e a Waterways Experiment Station, no Iowa Institute of Hydraulic Research. 
Olsen e Kjellesvig (1999) modelaram numericamente, em três dimensões, o funcionamento de uma armadilha de sedimentos, com geometria semelhante àquelas encontradas em canais de adução. A eficiência da armadilha é importante no projeto para se estimar, nos casos em que a água é usada para propósitos de geração de energia por exemplo, a quantidade de sedimentos que atinge as turbinas. Ao longo dos anos de uso da armadilha, o material capturado diminui sua seção transversal, aumentando a velocidade do escoamento e diminuindo sua eficiência. Cálculos numéricos envolvendo variações de fundo, isto é, levando-se em consideração a morfologia da armadilha, são então importantes para diferentes propósitos: cálculo da variação da eficiência com o aumento do volume de material sedimentado; informações a respeito da periodicidade da limpeza da armadilha; e no caso de modelagem com sedimentos de diâmetros variados (melhor representação da realidade), a localização de sedimentos de maior diâmetro na armadilha é importante para o design do sistema de limpeza, através de descarga de fundo. Aplicou-se a simulação ao modelo físico reduzido, já existente, de uma armadilha de sedimentos do Svartisen Hydropower Project, Noruega. Construído em acrílico, o modelo teve partículas de diâmetro médio de 3 milímetros ( $\mathrm{mm}$ ) coladas às placas para representação da rugosidade causada por rochas não alinhadas na armadilha real. Cinco diâmetros diferentes foram usados para simular a distribuição granulométrica. O uso periódico da descarga de fundo é apontado, também nesse trabalho, como medida de engenharia para reduzir o problema do assoreamento. $\mathrm{O}$ texto aponta que o efeito da lavagem varia substancialmente em diferentes reservatórios, dependendo de sua geometria, tamanho dos sedimentos, magnitude dos depósitos, vazão, altura de água e capacidade das comportas. Dessa forma, o design de uma comporta deve incluir uma análise do tipo: custo de sua construção e operação versus valor econômico do aumento do volume do reservatório com a possível lavagem. $\mathrm{O}$ conhecimento do processo de lavagem é, portanto, importante no projeto do reservatório e pode ser modelado numericamente.

Olsen (1999) avaliou um modelo numérico a partir da comparação com dados obtidos em um modelo físico reduzido de reservatório, construído em concreto, no Norwegian Hydrotechnical Laboratory. Com 12 metros (m) de comprimento e $6 \mathrm{~m}$ de largura, representa o Kali Gandaki Hydropower Reservoir, no Nepal, na escala 1:50. O reservatório possui volume de 0,4 milhões de metros cúbicos. O estudo estimou que o reservatório seria preenchido completamente em curto período de tempo caso não ocorresse a lavagem. 
O trabalho de $\mathrm{Wu}$ et al. (2000) apresentou um modelo numérico em três dimensões para cálculo de escoamento e transporte de sedimentos em uma canal de laboratório em forma de $U$, com modelo $\kappa-\varepsilon$ de turbulência e discretização das equações por método de volumes finitos. O trabalho defendeu a necessidade da simulação em 3D, para a captação dos escoamentos secundários na reprodução de escoamentos reais, negligenciada pelas simulações $1 \mathrm{D}$ e $2 \mathrm{D}$, maioria nessa linha de pesquisa.

Nas últimas décadas, as simulações em 3D têm se tornado mais comuns. Cita-se Wang \& Adeff (1986), baseado em elementos finitos, e Lin \& Falconer (1996), com um modelo para regiões costeiras e estuários, nos quais adotou-se um modelo simples de viscosidade turbulenta (constante). Van Rijn (1987) estabeleceu um modelo no qual o transporte de sedimentos é calculado com uma aproximação 3D e a hipótese de escoamento com integração na vertical, em combinação com um perfil logarítmico de velocidade. Demuren \& Rodi (1986) usaram o modelo $\kappa-\varepsilon$ em simulações 3D de canais meandrados. Demuren (1989) estendeu este trabalho, incluindo transporte de sedimentos em suspensão. Em 1991, Demuren incluiu também um modelo de transporte de sedimentos junto ao leito (transporte de fundo) e simulou o trabalho experimental de Odgaard e Bergs (1988), de um canal em forma de U. Demuren (1991) usou o modelo 3D de escoamento e transporte de sedimentos FAST3D, desenvolvido na Universidade de Karlsruhe, com adaptação para escoamentos livres.

Em Molino, Greco e Rowan (2001), aplicou-se um modelo bidimensional ao estudo de caso do reservatório Abbeystead, no Reino Unido. Os resultados simulados foram comparados e mostraram boa concordância com os dados de 7 batimetrias realizadas entre 1851 e 1991, representando satisfatoriamente o crescimento do delta no reservatório. Raramente são encontrados reservatórios com essa quantidade de levantamentos batimétricos.

Guo e Jin (2002) modelaram o transporte de sedimentos em suspensão com vários diâmetros de sedimento, mais condizente com a realidade. A maior parte dos trabalhos têm apresentado simulações para um diâmetro médio de sedimento, o $\mathrm{d}_{50}$. Foi aplicado aos experimentos conduzidos por Van Rijn, 1986, do Delft Hydraulic Laboratory, em um canal de $30 \mathrm{~m}$ de comprimento, $0,5 \mathrm{~m}$ de largura e $0,7 \mathrm{~m}$ de profundidade; escoamento com velocidade igual a 0,51 metros por segundo $(\mathrm{m} / \mathrm{s})$ e profundidade de $0,39 \mathrm{~m}$. O sedimento utilizado foi areia fina com $\mathrm{d}_{50}=0,16 \mathrm{~mm}$ e velocidade de queda $0,013 \mathrm{~m} / \mathrm{s}$, a 15 graus Celcius $\left({ }^{\circ} \mathrm{C}\right)$. A simulação usou malha com diferentes tamanhos de célula, variando de $0,2 \mathrm{~m}$ a $0,4 \mathrm{~m}$ na direção do escoamento e de 
$0,03 \mathrm{~m}$ e $0,05 \mathrm{~m}$ na direção transversal. A atualização do fundo (batimetria) era feita a cada 15min de tempo computacional. Segundo os autores, os resultados comparativos evidenciaram a boa capacidade do modelo em simular variações de fundo em canais.

Sloff et al. (2004) apresentou um modelo bidimensional e integrado na profundidade para estudo de morfologia fluvial, denominado Delft3D, aplicado ao reservatório Senbiri no rio Toshibetsu, em Hokkaido, região do Japão. Simulações foram realizadas para comparação, separadamente, com os dados de campo e aqueles obtidos em modelo físico reduzido. Estudou-se a formação de canal no interior do reservatório, durante a erosão que ocorre em épocas de cheia e aumento da vazão de água. O trabalho teve como objetivo investigar as causas da formação do canal, por erosão, no lado esquerdo do reservatório, apesar da localização da saída de água na barragem do lado direito. $O$ trabalho focou a localização da formação do canal e não suas dimensões.

O experimento no modelo físico foi realizado na J-POWER - Chigasaki R\&D Center, Japão e consiste em um reservatório de $2 \mathrm{~m}$ de largura, $7 \mathrm{~m}$ de comprimento e declividade 1/600. O canal afluente tem posição central e 40 centímetros $(\mathrm{cm})$ de comprimento. A vazão foi estabelecida em $0,025 \mathrm{~m}^{3} / \mathrm{s}$, com altura do escoamento de $0,15 \mathrm{~m}$. A modelagem numérica usou uma malha com células de $20 \mathrm{~cm}$ na direção longitudinal por $10 \mathrm{~cm}$ na transversal. O coeficiente de resistência de Chezy foi fixado em $60 \mathrm{~m}^{1 / 2} / \mathrm{s}$, para uma rugosidade de $0,05 \mathrm{~mm}$ e $\mathrm{d}_{50}$ igual a $0,26 \mathrm{~mm}$ para o sedimento. Concluiu-se ser difícil prever a localização do canal, que depende da sensitividade do padrão do escoamento às condições de contorno, condições iniciais e geometria. Para quantificar o sedimento erodido na formação do canal, o conhecimento atual do fenômeno é restrito e pesquisas mais avançadas com simulações mais precisas são necessárias.

O trabalho de Nicklow e Mays (2000) diferencia-se dos demais citados por apresentar uma metodologia de otimização junto à simulação de transporte de sedimentos, para minimizar a erosão e o assoreamento em sistemas de múltiplos reservatórios, englobando tomadas de decisões no gerenciamento do sistema. A otimização é trabalhada com o programa HEC-6, modelo de simulação de transporte de sedimentos, do U.S. Army Corps of Engineers, aplicado a um hipotético sistema de três reservatórios, bem como a um sistema real de reservatórios do rio Mississipi.

A realização de novos trabalhos aliando gerenciamento de sistemas de reservatórios a simulações de transporte de sedimentos parece ser o próximo passo a ser 
dado, após validação e consagração de modelos numéricos capazes de representar assoreamentos de reservatórios.

\subsection{Modelagem no Brasil}

Ainda são raras no Brasil as aplicações de simulações numéricas à hidráulica fluvial, considerando-se a quantidade de trabalhos em outros países. Restringindo-se ao estudo de morfologia de reservatórios, no qual leva-se em conta a dinâmica do processo de transporte de sedimentos, o número de trabalhos nacionais é ainda menor. No caso ainda mais particular, em que as simulações são realizadas com base na solução das equações hidrodinâmicas e de transporte de sedimentos em duas ou três dimensões (simulações não apenas unidimensionais), não se encontrou na bibliografia pesquisada um trabalho nacional de modelagem computacional aplicada ao assoreamento de reservatórios.

Em 1987, no Departamento de Hidráulica e Saneamento da Escola de Engenharia de São Carlos - Universidade de São Paulo (SHS-EESC-USP), Alvim (1987) apresentou um modelo matemático para estudo do processo de assoreamento de reservatórios, utilizando equacionamento unidimensional para o transporte do fluido. Em 1988, Cogollo e Villela aplicaram o modelo matemático de escoamento também unidimensional, desenvolvido por Lopes (1978), na estimativa do assoreamento do Reservatório de Urra II no Rio Sinu, Colômbia. Os resultados mostraram uma deposição na entrada do reservatório, representando o delta, e foram considerados satisfatórios. Atualmente, desenvolve-se no SHS-EESC-USP um modelo tridimensional de transporte de sedimentos, com Simulação de Grandes Escalas de turbulência (SGE) e Método de Fronteira Imersa (MFI) para simulação do escoamento sobre a superfície irregular do leito. O desenvolvimento desse trabalho é apresentado em Alamy Filho e Schulz (2005).

Collischonn e Merten (2001) apresentaram o modelo computacional HIDROSED e sua aplicação na análise do transporte de sedimentos no rio Taquari, no Pantanal Matogrossense. O módulo hidrodinâmico do modelo é unidimensional e semelhante àquele encontrado nos programas DAMBRK (FREAD, 1991) e FLDWAV (FREAD, 1993). O módulo de transporte de sedimentos foi adaptado do programa FLUVIAL-12 (CHANG, 1993).

Como modelagem apenas hidrodinâmica, sem transporte de sedimentos, têm-se as aplicações do modelo numérico bidimensional IPH-A em Botelho (2000), para 
determinação da circulação e transporte de constituintes no reservatório Billings, no estado de São Paulo ; e em Paz et al. (2003), na análise do comportamento hidrodinâmico do Banhado do Taim, no Rio Grande do Sul, sob influência da vegetação no banhado, da lagoa Mangueira e do vento. O modelo foi desenvolvido pelo Instituto de Pesquisas Hidráulicas d Universidade Federal do Rio Grande do Sul (IPH UFRGS).

Friedrich e Ota (2003) mostraram os efeitos de alguns parâmetros e condições de contorno sobre resultados de modelagem numérica do escoamento em regime permanente, de um trecho do rio Jacuí, a jusante da Usina Hidrelétrica Dona Francisca, no estado do Rio Grande do Sul. O programa utilizado foi o RMA2 V4.3, bidimensional em planta e com distribuição uniforme de velocidades na vertical, desenvolvido pelo U.S. Army Corps of Engineers. A calibração do modelo numérico foi auxiliada por um modelo físico reduzido, construído em concreto, no qual realizou-se medições de altura de água e velocidade; e visualização das linhas de corrente com partículas flutuantes.

No que diz respeito à modelagem física de assoreamento de reservatórios, destaca-se o trabalho experimental de Chella et al.(2003). Construiu-se um modelo físico reduzido, na escala 1:50, da Usina Hidrelétrica Melissa, localizada na Região Sudoeste do Estado do Paraná, no Rio Melissa, Bacia do Rio Paraná, Município de Corbélia. Essa usina é uma pequena central hidrelétrica, com potência instalada de 1,0 MW, pertencente à Companhia Paranaense de Energia (COPEL). Iniciou sua operação em 1962 e desde então, já passou por diversas dragagens do material depositado em seu reservatório. Porém, em poucos anos, o acúmulo de lodo e folhas torna-se crítico novamente, pois o processo de erosão a montante continua ocorrendo de forma crescente devido, principalmente, a práticas incorretas de cultivo e manejo do solo nas lavouras da região (COPEL, 1999). O trabalho no modelo foi desenvolvido no Centro de Hidráulica e Hidrologia Prof. Parigot de Souza (CEHPAR). O material móvel utilizado nos testes foi serragem de imbuia selecionada e tratada, material que já havia sido utilizado nos estudos em modelos reduzidos (CEHPAR, 1981). As dificuldades encontradas no decorrer dos experimentos foram relatadas no texto e serviram de referência à construção da armadilha de sedimentos deste trabalho. 


\section{METODOLOGIA}

Neste capítulo, apresenta-se os materiais e métodos empregados nas diferentes etapas do trabalho, organizadas no texto da forma:

\section{Etapa experimental}

Compreende:

- o projeto e a construção de uma armadilha de sedimentos em laboratório.

- o conhecimento do padrão do escoamento de água na armadilha, através de campos de velocidade obtidos com técnica de velocimetria a laser;

- o assoreamento na armadilha.

Etapa de simulação numérica:

Abrange:

- apresentação do um programa computacional MIKE 21 C, adquirido neste trabalho;

- simulação hidrodinâmica, para obtenção de campos de velocidade do escoamento de água na armadilha;

- simulação do assoreamento.

\subsection{Etapa experimental}

Realizada no Laboratório de Hidráulica Ambiental do SHS-EESC-USP, é detalhada a seguir.

\subsubsection{Projeto e construção da armadilha de sedimentos}

Inicialmente, propôs-se o projeto e a construção de uma armadilha de sedimentos em concreto armado e alvenaria, com $5 \mathrm{~m}$ de largura, $20 \mathrm{~m}$ de comprimento e altura de $1 \mathrm{~m}$. Porém, optou-se por uma armadilha de menores dimensões, em acrílico, aproveitando-se em parte o equipamento construído durante o trabalho de Barbosa 
(1998), utilizado e modificado por Silva (2002), no Laboratório de Hidráulica Ambiental. Os trabalhos citados desenvolveram estudos de correntes de densidade em reservatórios.

Uma armadilha de sedimentos com paredes e fundo em acrílico (paredes construídas nos trabalhos citados acima) permitiria a observação da deposição de areia (sedimento usado no trabalho experimental) através de fotografias tiradas de diferentes ângulos, ao longo do processo de assoreamento. Já no caso da construção em concreto e alvenaria, externa ao laboratório e proposta inicialmente, a visualização dos sedimentos apenas seria possível ao final do experimento, após o esvaziamento da armadilha. A construção realizada no interior do laboratório possibilitaria ainda o uso do equipamento de velocimetria a laser, disponível no laboratório mencionado, para obtenção de campos de velocidade instantânea em várias regiões da armadilha e o então conhecimento do padrão do escoamento de água para cada vazão afluente experimentada.

Uma vista geral da armadilha, já construída e em operação, é apresentada na Figura 1 e de forma simplificada na Figura 2, que ilustra seu projeto com omissão de toda estrutura metálica de sustentação. Os detalhes construtivos são apresentados posteriormente. Neste trabalho, o termo "armadilha de sedimentos" refere-se a toda estrutura construída no laboratório, que inclui o reservatório de acrílico em que a areia é depositada (armadilha propriamente dita), o reservatório elevado e o sistema de transporte de areia; e o sistema de recirculação de água, este composto por caixas de água, bomba e tubulação.

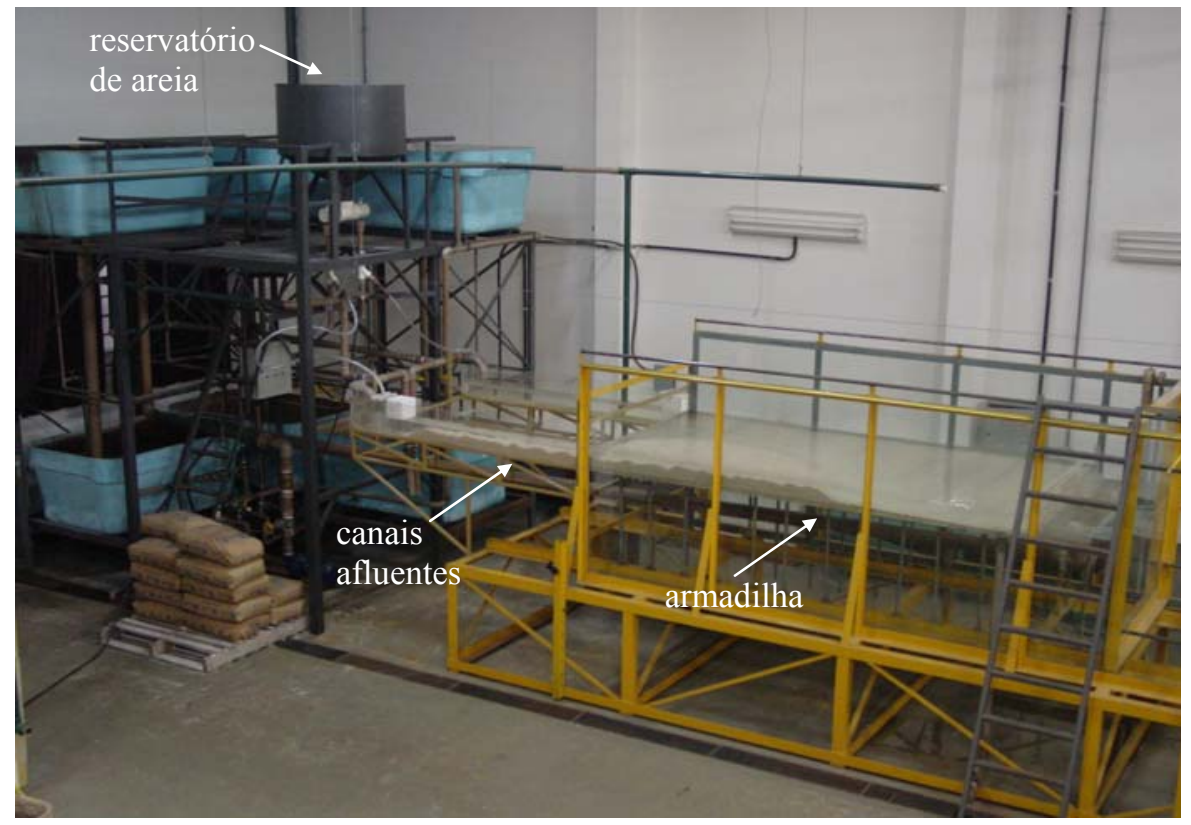

Figura 1 - Vista geral da armadilha de sedimentos, construída com base na estrutura desenvolvida nos trabalhos de Barbosa (1998) e Silva (2002). 


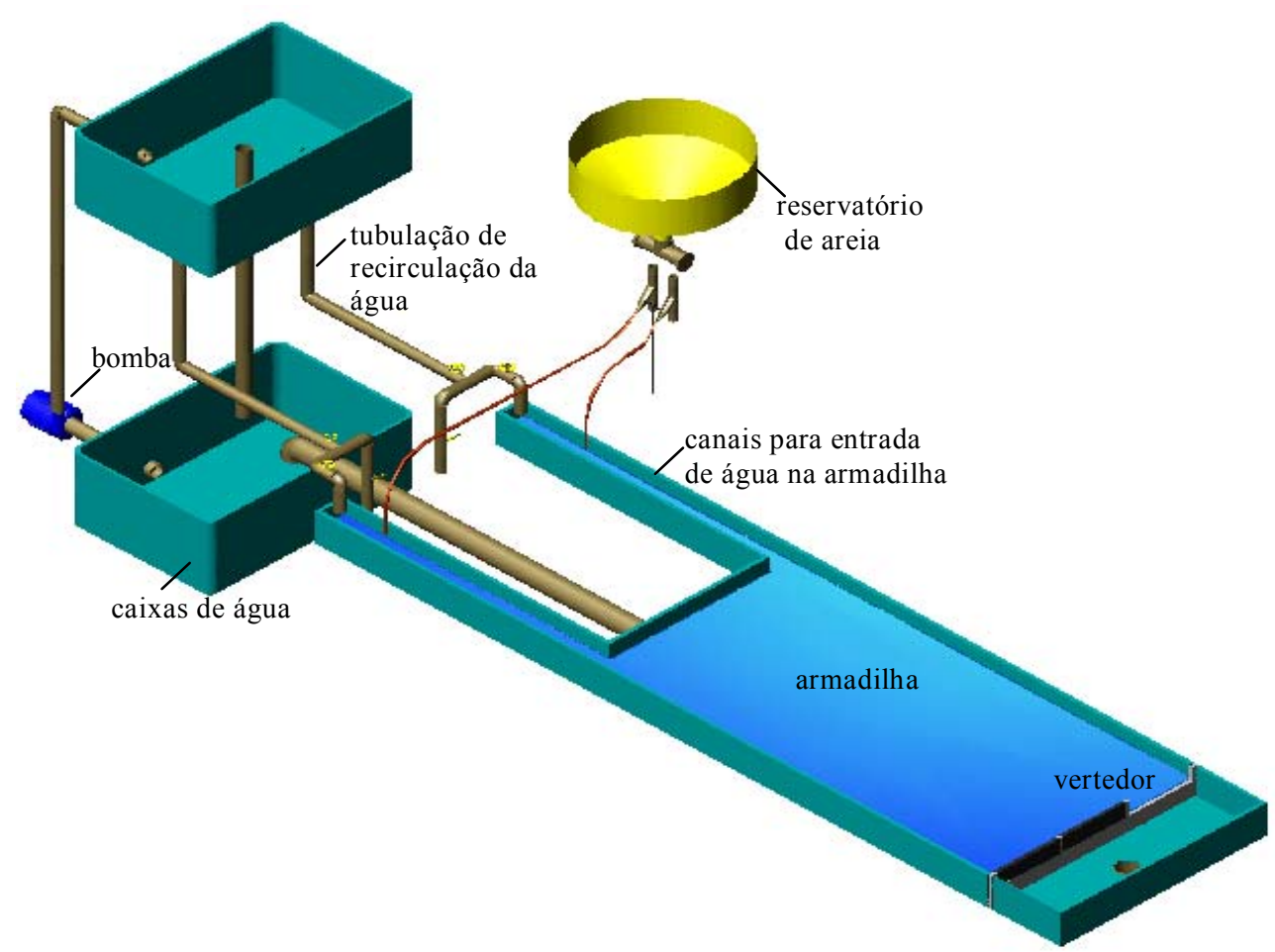

Figura 2 - Projeto simplificado da armadilha.

Com referência à Figura 1, tem-se as seguintes partes do equipamento de Barbosa (1998) e Silva (2002) aproveitadas no equipamento: a estrutura metálica de sustentação da armadilha; suas paredes laterais e o fundo em acrílico, fundo este construído com várias placas, o que possibilita sua montagem com diferentes ângulos de inclinação ao longo do comprimento da armadilha, para melhor representação de um reservatório real, formado por barragem; e as caixas de água, com sua estrutura metálica de sustentação.

Apresenta-se agora a construção realizada neste trabalho, compreendendo os canais afluentes, o reservatório elevado, o sistema de descarga de areia, o vertedor e todo o sistema de recirculação de água, que substituiu o já existente para se adaptar à armadilha e aumentar a capacidade de vazão.

\subsubsection{Canais afluentes}

O abastecimento da armadilha é feito através de dois canais prismáticos, em acrílico, de seção retangular com $0,15 \mathrm{~m}$ de largura, $0,25 \mathrm{~m}$ de altura e $2 \mathrm{~m}$ de comprimento (Figura 3). Na extremidade de montante de cada canal, a tubulação descarrega uma vazão de água regulável de até $0,005 \mathrm{~m}^{3} / \mathrm{s}$. Logo a jusante do lançamento de água nos canais, cubos de isopor foram fixados de forma a funcionar 
como quebra-ondas, impedindo que a agitação gerada nessa região pela descarga de água se propagasse à armadilha.

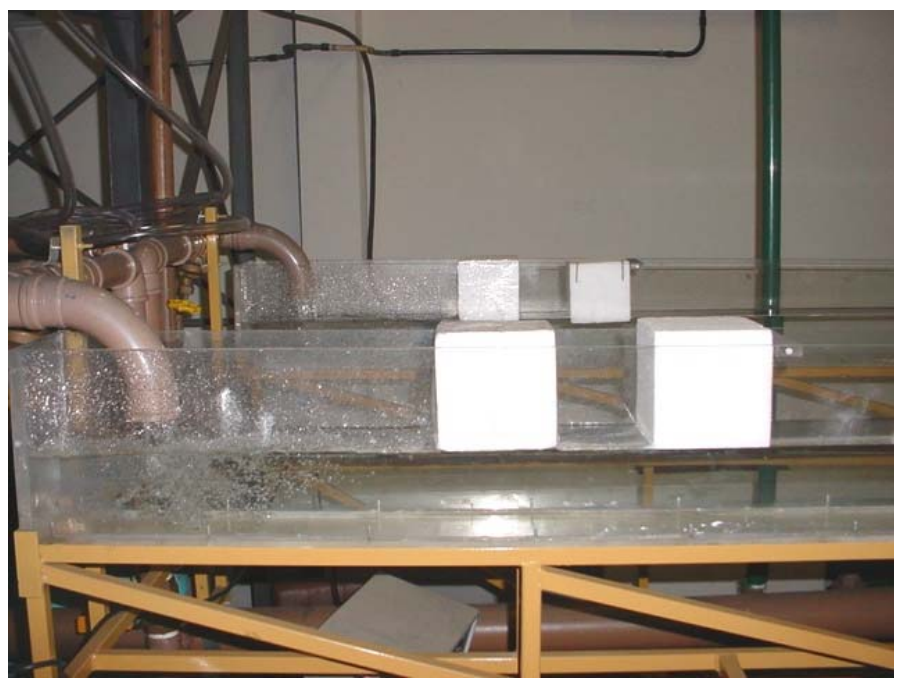

Figura 3 - Canais afluentes da armadilha.

A medição da vazão é feita através de uma ramificação da tubulação que descarrega água nos canais, levando o fluido a uma caixa de água posicionada sobre uma balança eletrônica. Registros localizados nesse ponto de ramificação permitem que a mesma vazão que abastece a caixa de água seja transferida para os canais. As Figuras 4 e 5 ilustram o exposto.

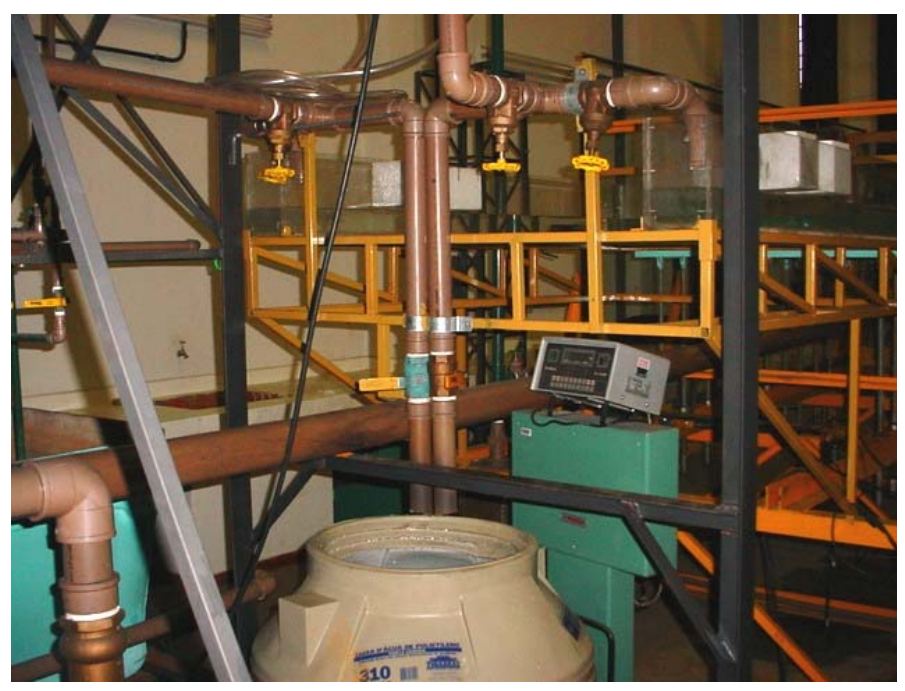

Figura 4 - Sistema de medição de vazão afluente nos canais. 


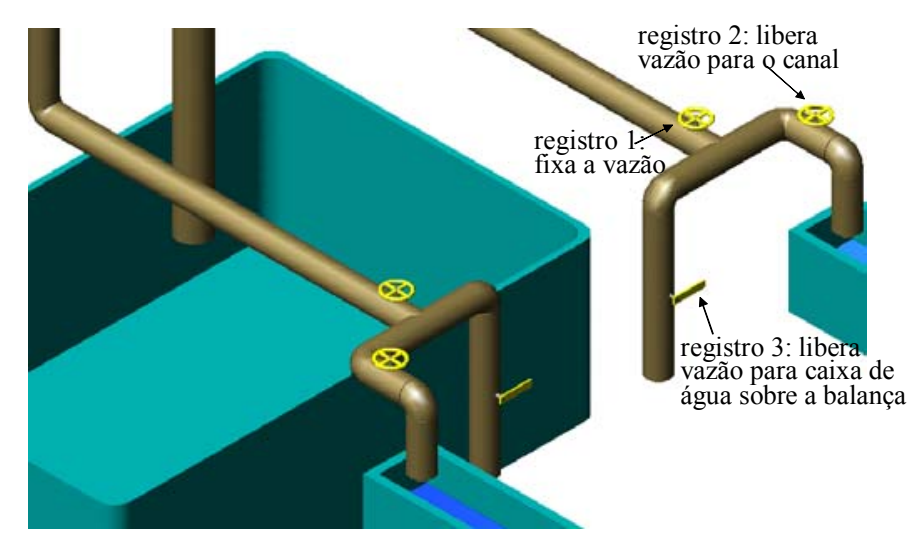

Figura 5 - Parte do projeto da armadilha com detalhe do sistema de medição de vazão.

De acordo com a Figura 5, a vazão é fixada da seguinte maneira: com o registro 3 totalmente aberto e o registro 2 fechado, ajusta-se o registro 1 para a vazão desejada, com uso da caixa de água posicionada sobre a balança. Então, fechando-se o registro 3 e abrindo-se totalmente o registro 2 , tem-se praticamente a mesma vazão direcionada ao canal, pois a diferença entre as perdas de carga ao longo dos trechos ramificados a partir do registro 1 mostrou-se desprezível em testes anteriores aos experimentos.

\subsubsection{Reservatório elevado e sistema de descarga de sedimento}

Ao longo da construção da armadilha, a revisão da literatura abrangeu a busca por diferentes sistemas de descarga de sedimento apresentados em trabalhos experimentais. Poucos desses trabalhos apresentaram abertamente, como Chella et al. (2003), as dificuldades encontradas em seus experimentos para que uma descarga de sedimentos constante fosse atingida. Na ausência de um sistema de alimentação de sedimentos eficiente e consagrado na literatura, testes com diferentes tubulações que transportavam por gravidade a areia do seu reservatório aos canais adutores foram executados sem sucesso. Finalmente, um sistema de escoamento bifásico, ar e areia, não encontrado na bibliografia pesquisada, foi adotado com êxito. A injeção de ar comprimido na mangueira flexível que ligava o reservatório de sedimento a cada canal impedia qualquer interrupção no transporte de areia e conseqüente variação indesejável na descarga.

Durante os experimentos de assoreamento, o reservatório de areia elevado foi abastecido continuamente. Com capacidade para $0,4 \mathrm{~m}^{3}$, o reservatório foi mantido, em média, com $0,2 \mathrm{~m}^{3}$ (Figura 6). 


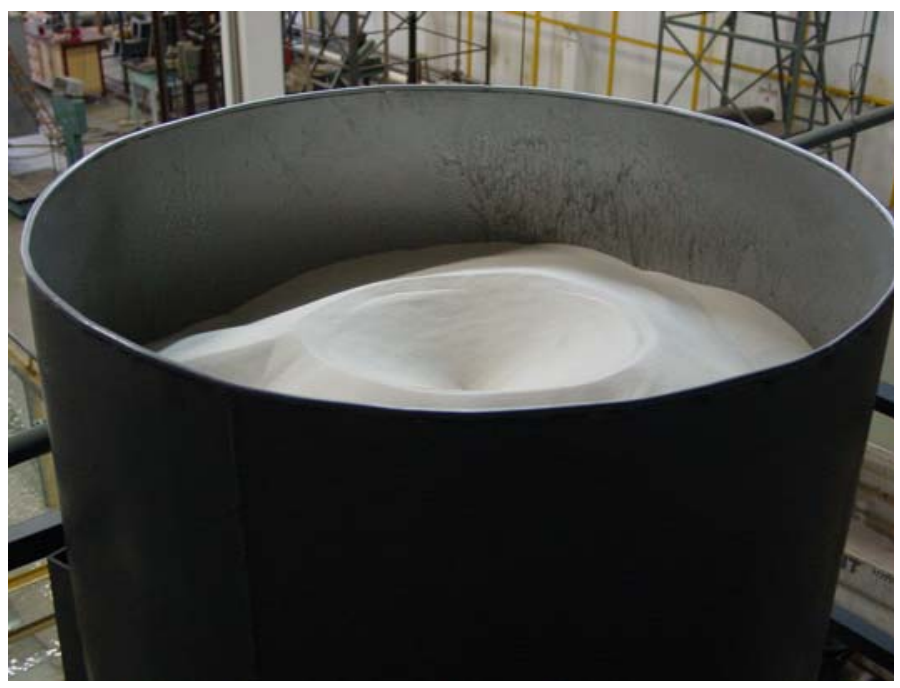

Figura 6 - Reservatório de areia elevado.

A Figura 7 apresenta o sistema de descarga de areia e a Figura 8 ilustra seu projeto, com a tubulação seccionada para exibição de detalhes construtivos. O sistema foi dimensionado para possibilitar uma descarga de até 15 gramas por segundo $(\mathrm{g} / \mathrm{s})$, ajustável através do registro ilustrado na Figura 8.

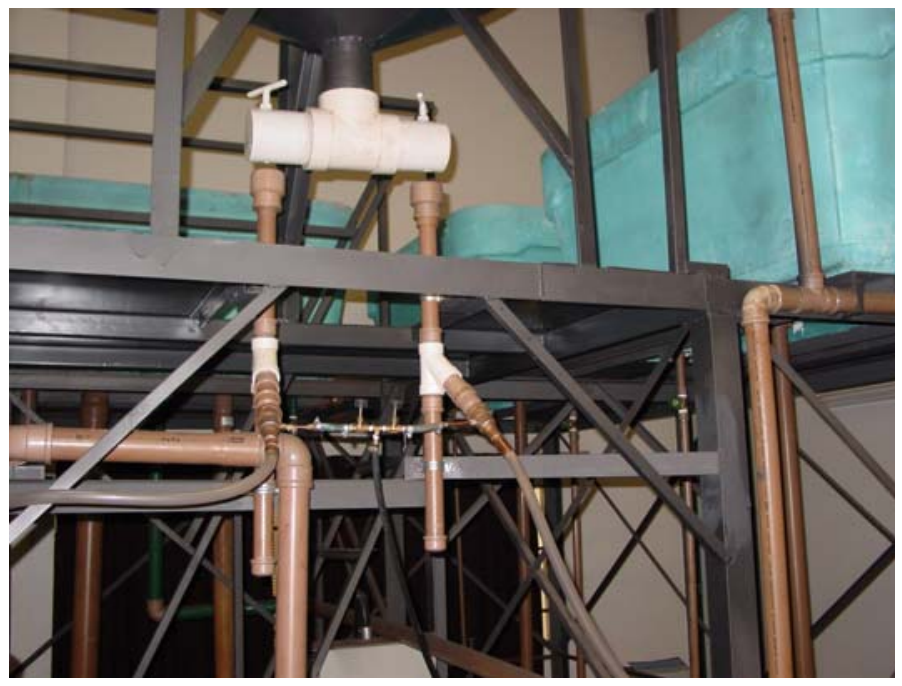

Figura 7 - Sistema de ar comprimido. 


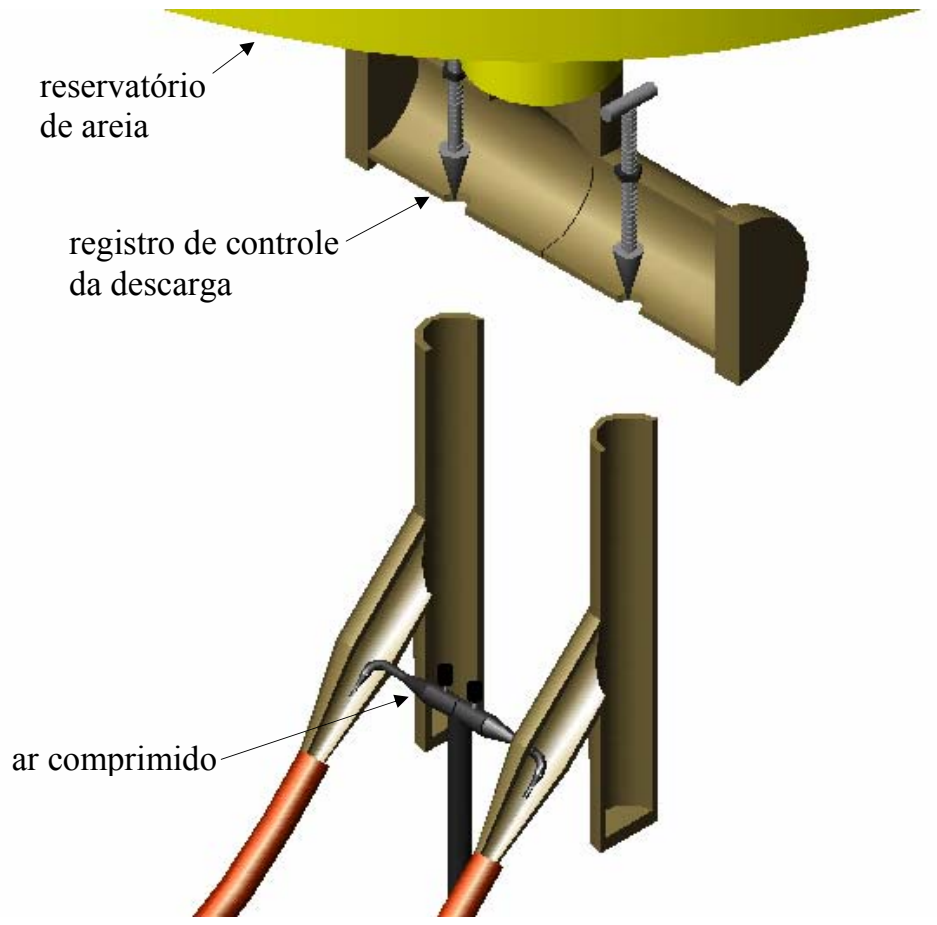

Figura 8 - Detalhe em projeto do sistema de descarga de sedimento.

Com o sistema de descarga de sedimento em funcionamento, ilustrado na Figura 9, o "fio de areia" pode ser observado, na descarga de $2 \mathrm{~g} / \mathrm{s}$ definida para o experimento. O transporte de areia até cada um dos canais é feito em uma mangueira transparente e flexível. Assim, o escoamento no interior da mangueira é monitorado (Figura 10) - para que não haja acúmulo de material ao longo do percurso - e o lançamento de areia pode ser realizado em qualquer trecho desejado do canal (Figura 11).

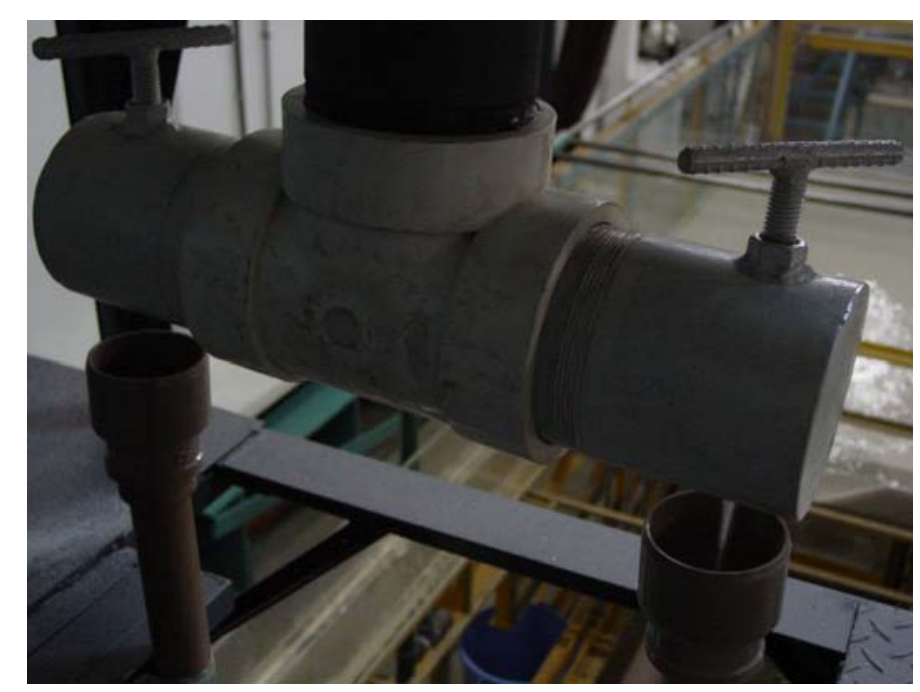

Figura 9 - Detalhe dos registros ligados à base do reservatório de areia, para fixação da descarga. 


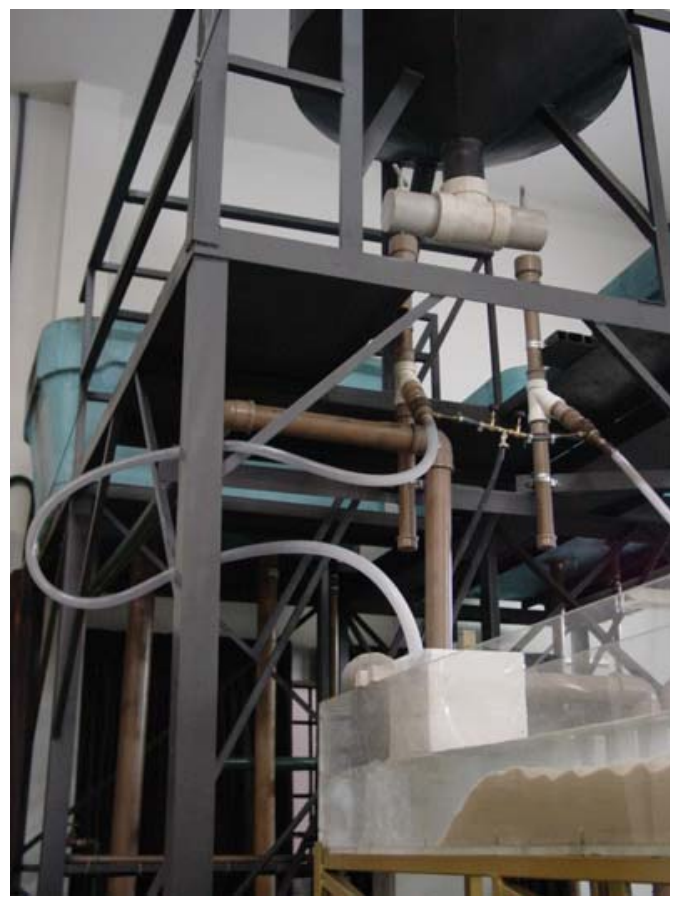

Figura 10 - Mangueira transparente para monitoramento do transporte de areia até cada um dos canais.

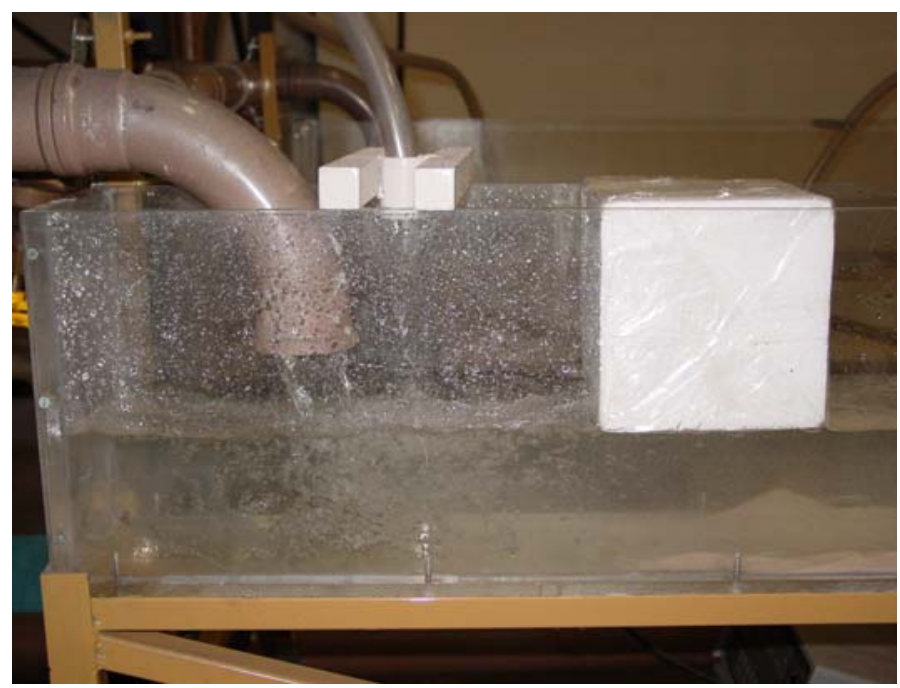

Figura 11 - Lançamento de areia no início do canal.

Observa-se na figura acima que o lançamento de areia é realizado na extremidade de montante do canal, para que a agitação da água no local de seu lançamento produza mistura completa de fluido e sedimento. Desta forma, uma distribuição vertical da concentração de areia, semelhante àquela encontrada nos escoamentos fluviais, decrescente no sentido da superfície, se forma ao longo dos $2 \mathrm{~m}$ de canal e atinge a armadilha com melhor representação de situações naturais. 


\subsubsection{Vertedor}

Foi construído com uma base de $0,10 \mathrm{~m}$ de altura ao longo de toda a largura da armadilha. Sobre essa base, o vertedor foi dividido em três seções, nas quais pranchas são colocadas para se obter diferentes configurações dessa estrutura. O vertedor é mostrado na Figura 12, com o fundo da armadilha sustentado pela estrutura metálica em azul a montante (lado esquerdo da Figura) e a tubulação para recirculação da água vertida, a jusante.

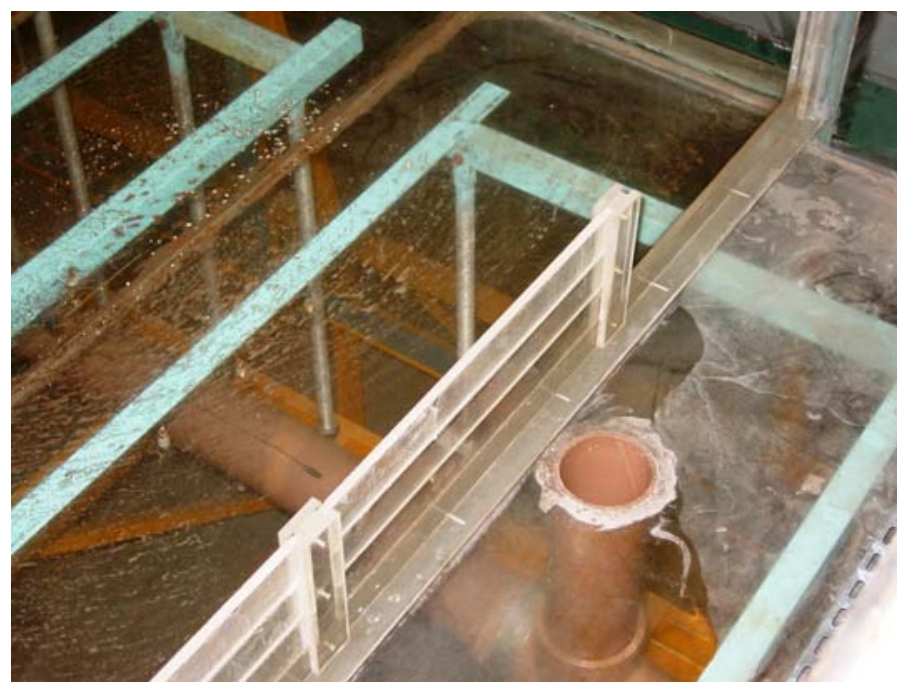

Figura 12 - Vertedor construído em acrílico.

Todo a estrutura apresentada no item 4.1.1 representa dois rios e um reservatório formado por barragem. A armadilha de sedimentos construída permite que diferentes configurações (combinações) de vazão nos canais, descarga de sedimento e abertura do vertedor possam ser usadas para estudo, em laboratório, do assoreamento de reservatórios. Além de possibilitar uma observação física do fenômeno, essa armadilha também auxilia na validação de simulações numéricas de transporte de sedimentos, para que programas computacionais possam ser usados como ferramentas confiáveis na estimativa da distribuição espacial e temporal de sedimentos em reservatórios reais, ao longo dos seus anos de operação.

Nota-se que o equipamento construído apenas representa um reservatório de água abastecido por dois rios e tem por função permitir um trabalho experimental que auxilie na pesquisa do assoreamento de reservatórios. Não se estuda neste trabalho nenhum reservatório real em particular, cuja geometria se assemelhe àquela da armadilha e justifique a denominação desta de modelo reduzido. Ainda, mesmo que essa semelhança geométrica existisse, as pequenas dimensões do equipamento 
impediriam que se obtivesse semelhança entre modelo construído e protótipo (reservatório real) com relação aos adimensionais importantes para o fenômeno estudado. Diferentemente do estudo de modelagem física de vertedores, em que se despreza a semelhança com relação ao número de Reynolds e se mantém apenas a semelhança do número de Froude, ambos adimensionais são fundamentais no presente estudo. O número de Froude representa a relação entre a força de inércia e a força de gravidade e é importante no estudo de escoamentos com superfície livre. O número de Reynolds, representando a relação entre a força de inércia e a força viscosa, tem relação direta com a intensidade turbulenta no escoamento, esta por sua vez relacionada aos fenômenos de erosão, deposição e dispersão dos sedimentos em um curso de água.

\subsubsection{Campos de velocidade na armadilha}

O conhecimento do escoamento no interior da armadilha é fundamental para o entendimento do processo de assoreamento. As partículas de areia são transportadas pelo fluido segundo fenômenos de advecção e dispersão (ou convecção e difusão, como são também chamados, apesar da diferença conceitual entre difusão e dispersão), portanto com dependência das propriedades do escoamento, como velocidade média e intensidade turbulenta.

Durante o assoreamento, as condições de contorno do escoamento variam continuamente. A deposição de areia faz com que a seção do escoamento diminua e a velocidade do fluido aumente. Assim, elevam-se também as tensões de cisalhamento junto ao fundo, o número de Reynolds local e a capacidade de transporte de sedimentos. Com o aumento das tensões, a resistência ao escoamento é elevada e o fluido pode então seguir outro caminho, que apresente menor resistência. Esse processo dinâmico deve ser conhecido para estudo do assoreamento na armadilha.

Entretanto, a técnica de velocimetria a laser empregada para obtenção de campos de velocidade na armadilha não é adequada para uso enquanto o assoreamento evolui. A obtenção de imagens do escoamento necessárias à geração dos campos de velocidade é feita, como detalhada posteriormente, com uma câmera fotográfica digital instalada sob o fundo da armadilha. A deposição de areia impede que essas imagens sejam registradas.

Por esse motivo, obtiveram-se campos de velocidade instantânea e média em várias regiões da armadilha, com uso de técnica de velocimetria a laser, para o 
escoamento apenas de água, ainda sem a adição de areia. Esses campos de velocidade permitem que se faça um estudo da relação entre o escoamento e o início do assoreamento, enquanto as condições de contorno não se alteram de forma significativa. Adicionalmente, os campos de velocidade obtidos nesse trabalho experimental são úteis na validação do campo de velocidade da simulação numérica hidrodinâmica da armadilha sem sedimento, fundamental para o início da simulação posterior, do assoreamento na armadilha.

Por não ser viável a obtenção dos campos em todo o volume da armadilha, devido ao extenso trabalho experimental requerido para isso, algumas regiões foram analisadas, dando uma idéia geral do padrão do escoamento. Cada região, um plano de forma quadrada e lado igual a $15 \mathrm{~cm}$, foi posicionada horizontalmente a $6 \mathrm{~cm}$ do fundo da armadilha. Com a altura da superfície da água na armadilha variando entre $11,5 \mathrm{~cm}$ e $12,5 \mathrm{~cm}$ (em toda a área da armadilha), a posição do plano é igual a aproximadamente $50 \%$ da altura do escoamento. Assim, tem-se que a velocidade obtida em cada ponto de uma região provavelmente não corresponde exatamente à velocidade média do perfil vertical de velocidade naquele ponto, mas está na mesma escala de grandeza e fornece, juntamente com as velocidades de todas as regiões, uma boa representação do complexo padrão do escoamento.

$\mathrm{Na}$ Figura 13, as regiões analisadas estão ilustradas em vermelho e enumeradas no interior da armadilha, em azul. A unidade das cotas é o centímetro.

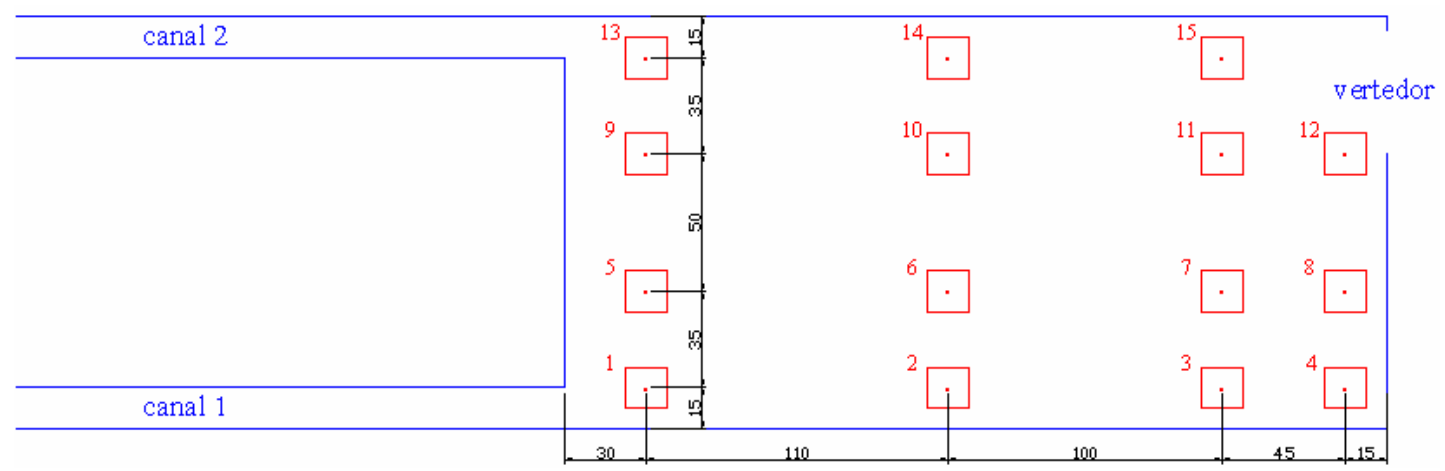

Figura 13 - Localização das regiões onde campos de velocidade foram obtidos.

Os campos de velocidade foram obtidos em 15 regiões da armadilha, para cada uma das duas configurações de vazão experimentadas. Na primeira das configurações, chamada de Configuração 1 , definiu-se uma vazão de $0,002 \mathrm{~m}^{3} / \mathrm{s}$ no canal 1 . O canal 2 foi fechado na sua ligação com a armadilha. Para a Configuração 2, usou-se vazão de $0,002 \mathrm{~m}^{3} / \mathrm{s}$ em ambos os canais. 
Em cada região, de cada configuração, obteve-se 315 imagens em 321s (como explicado no item 4.1.2.1 Técnica de velocimetria a laser), para geração dos campos de velocidade instantânea. Com 15 regiões e 2 configurações experimentadas, 9450 imagens do escoamento foram capturadas e analisadas neste trabalho.

A Configuração 2 de vazão dos canais afluentes, diferentemente da Configuração 1, não foi usada para assoreamento na armadilha. A obtenção dos campos de velocidade nessa configuração teve como propósito:

- observar a modificação do padrão do escoamento na armadilha para uma variação de vazões afluentes, com uso dos dois canais. Um trabalho seguinte a este, de assoreamento na armadilha, poderia usar esta configuração;

- validar uma simulação numérica hidrodinâmica de escoamento diferente daquele da Configuração 1, testando desta forma a capacidade do programa computacional em reproduzir diferentes padrões de escoamentos. Bons resultados comparativos entre experimento e simulação para dois padrões de escoamento - e não apenas para um, da Configuração 1 - aumentariam a confiabilidade dos resultados obtidos com o programa computacional adquirido neste trabalho.

\subsubsection{Técnica de velocimetria a laser}

O equipamento laser DPIV (Digital Particle Image Velocimetry) e a metodologia usada na geração dos campos de velocidade são descritos a seguir:

\section{Laser Oxford, modelo LS20}

Dispõe-se de um laser a vapor de cobre, responsável pela produção do plano de luz inserido no volume de água da armadilha para obtenção dos campos. Sua potência média, de 20watts (W) a 10 quilohertz $(\mathrm{kHz})$, é suficiente para dispensar a adição de partículas traçadoras, pois as partículas de impurezas em suspensão na água, iluminadas pela luz do laser, já possibilitam boa visualização do escoamento do fluido. Os comprimentos de onda de emissão de luz são de 510,6 nanometros (nm) (luz verde) e $578,2 \mathrm{~nm}$ (luz amarela), com 1/3 emitido em amarelo e 2/3 em verde. A luz produzida pelo equipamento (Figura 14) é concentrada em fibra ótica e levada ao ponto de utilização, onde é convertida em plano (ou folha) de luz de espessura média de $3 \mathrm{~mm}$ por um conjunto de lentes esféricas, côncavas e convexas (Figura 15). O plano de luz iluminando o escoamento de água na armadilha é ilustrado na Figura 16. 


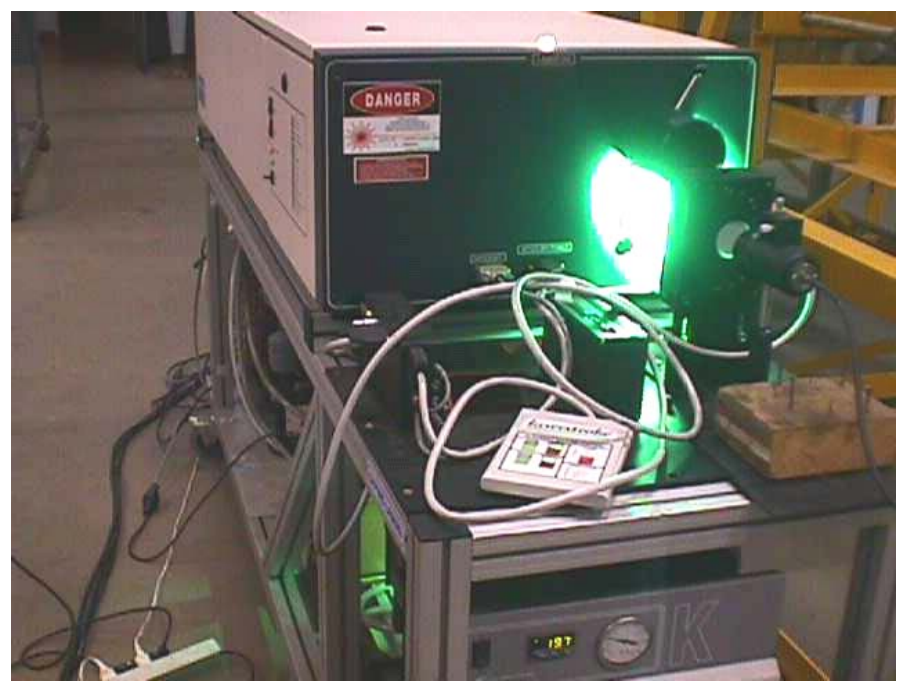

Figura 14 - Luz gerada pelo equipamento laser. Fonte: Souza (2002).

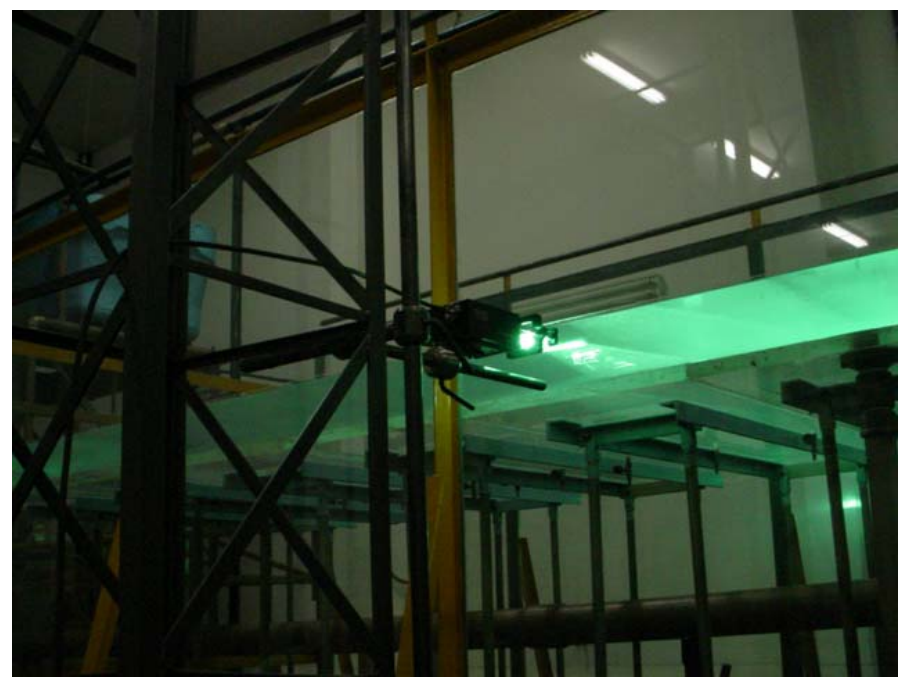

Figura 15 - Conjunto de lentes posicionado ao lado da armadilha, inserindo o plano de luz no escoamento através de uma parede lateral.

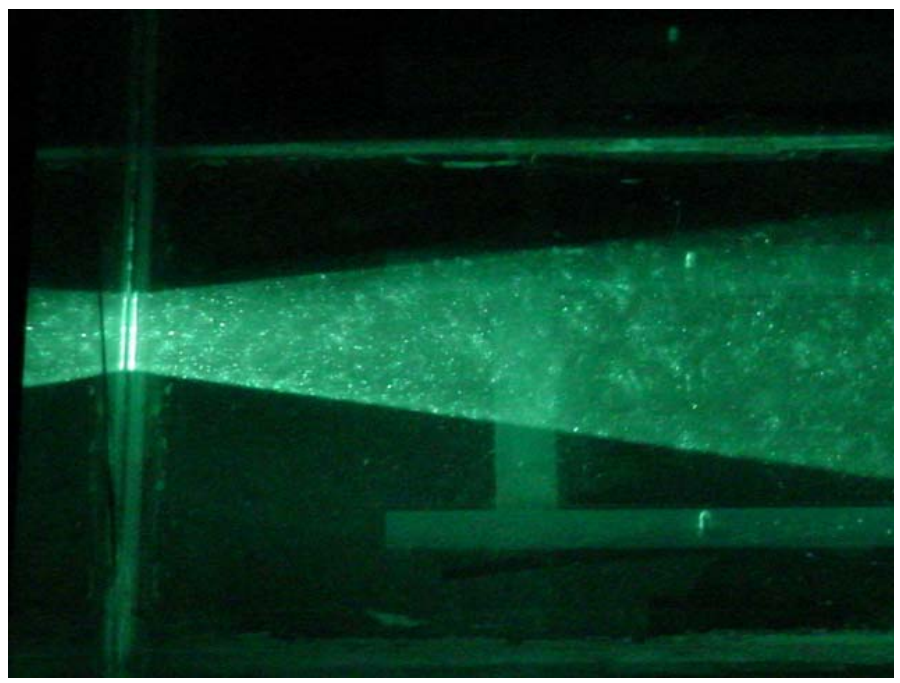

Figura 16 - Plano de luz no escoamento na armadilha, iluminando as partículas em suspensão na água. 
Câmera CCD Kodak Megaplus modelo ES 1.0

Essa câmera fotográfica digital captura, em escala de cinza, as imagens do plano de fluido iluminado pelo laser. O controle de obtenção de imagens é feito via comunicação serial com um microcomputador. A freqüência de captação de imagens possível durante os experimentos foi de 15 exposições (fotos) por segundo, pois a câmera apresentou problemas técnicos e sua freqüência original de 30 exposições por segundo não foi atingida. Na Figura 17, mostra-se a câmera instalada perpendicularmente ao plano de luz do laser, sob o fundo em acrílico da armadilha. Uma base móvel posiciona a câmera sob a região a ser analisada (Figura 18).

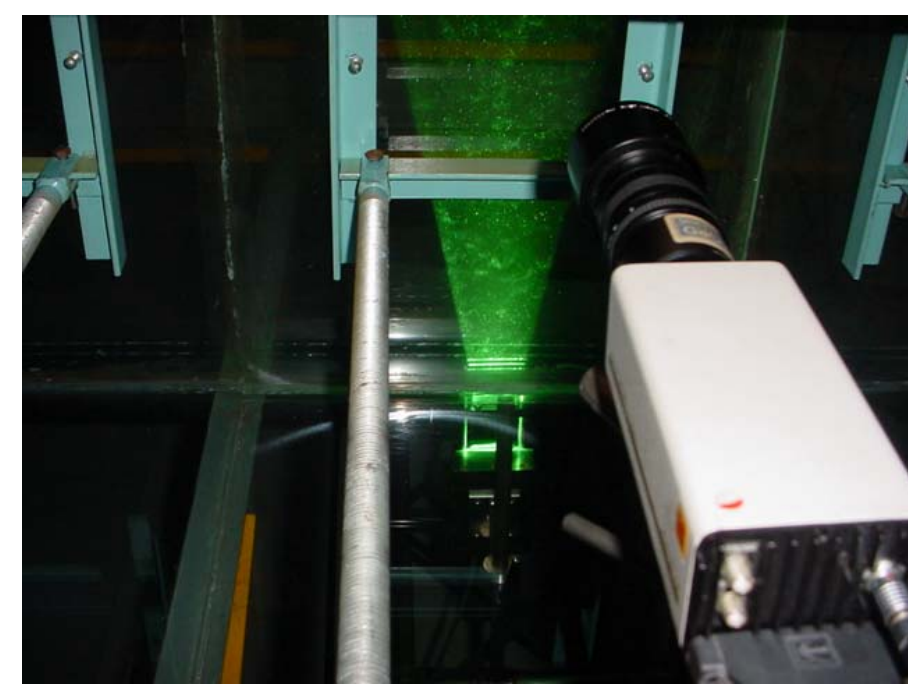

Figura 17 - Câmera digital posicionada sob a armadilha, para captura de imagens do escoamento.

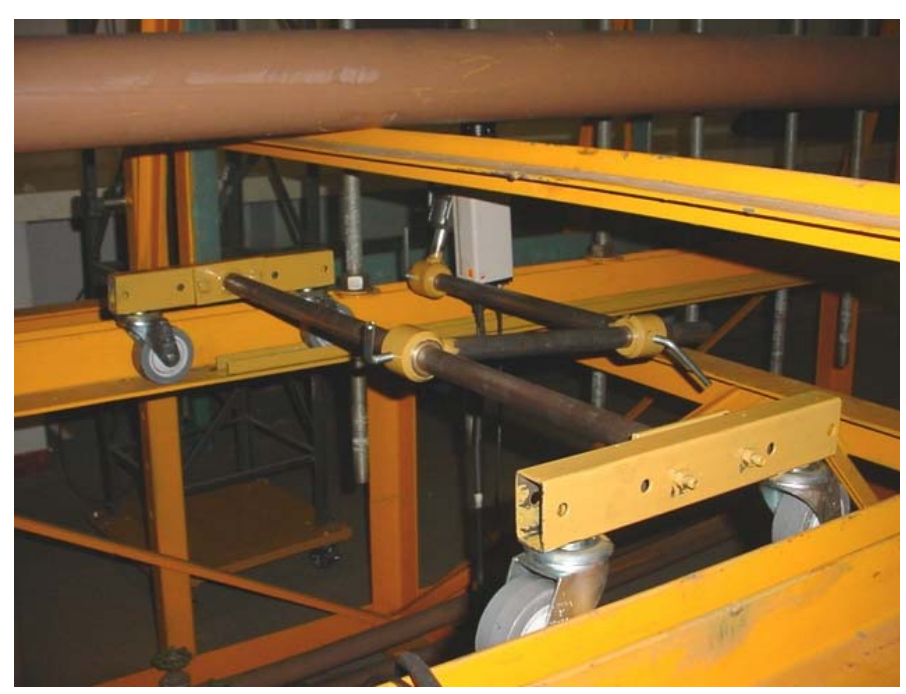

Figura 18 - Base móvel para deslocamento da câmera. 


\section{Programa Visiflow}

As fotos capturadas pela câmera são armazenadas em sua memória e enviadas para o disco rígido do microcomputador. O procedimento é gerenciado pela versão 6.14, adquirida em Souza (2002), do programa Visiflow, da AEA Technology. Esse programa, através de técnica DPIV, divide cada imagem em pequenas células e, dentro de cada célula, analisa o deslocamento das partículas iluminadas pelo laser para cada par de fotos consecutivas. A partir desse deslocamento e do intervalo de tempo entre as duas fotos, um tratamento estatístico das imagens é feito e um vetor velocidade instantânea é obtido para cada célula. Com o conjunto de várias células, um campo de velocidade instantânea é então gerado para cada par de fotos. Com a freqüência de obtenção de 15 imagens por segundo pela câmera, o intervalo de tempo entre duas fotos consecutivas é de $1 / 15 \mathrm{~s}$. Esse intervalo, para as velocidades do escoamento analisado, ainda mostrou-se suficiente para que um número significativo de partículas se mantivesse na mesma célula, nas duas fotos, para que cada vetor velocidade fosse gerado corretamente.

Apesar da obtenção de 15 imagens por segundo, 321 segundos foram necessários para obtenção das 315 imagens em cada região, tempo suficiente para englobar possíveis flutuações de velocidade em maiores escalas de tempo da turbulência, para o experimento em questão. Isso aconteceu porque a memória da câmera digital se esgotava com 15 fotos, suficientes para geração de 14 campos de velocidade. Um intervalo de $15 \mathrm{~s}$ era então necessário para descarregamento das fotos no microcomputador e liberação da memória da câmera para nova aquisição de imagens.

Um exemplo de seqüência de 03 fotos e 02 campos gerados é apresentado nas Figuras 19 e 20. As fotos registram imagens de uma região quadrada do escoamento, de $15 \mathrm{~cm}$ de lado (Figura 19). Aplicada aos campos calculados da Figura 20, a escala de cores da Figura 21 refere-se à componente dos vetores velocidade na direção longitudinal da armadilha (direção horizontal nas figuras). Na escala, a unidade da velocidade é o metro por segundo. A seqüência de fotos é mostrada na vertical, para que se possa observar o deslocamento horizontal de uma determinada partícula, direção esta predominante na região em questão. A partícula é marcada pela seta amarela. Os campos gerados são, consecutivamente, referentes aos pares de fotos 1-2 e 2-3, da Figura 19. 

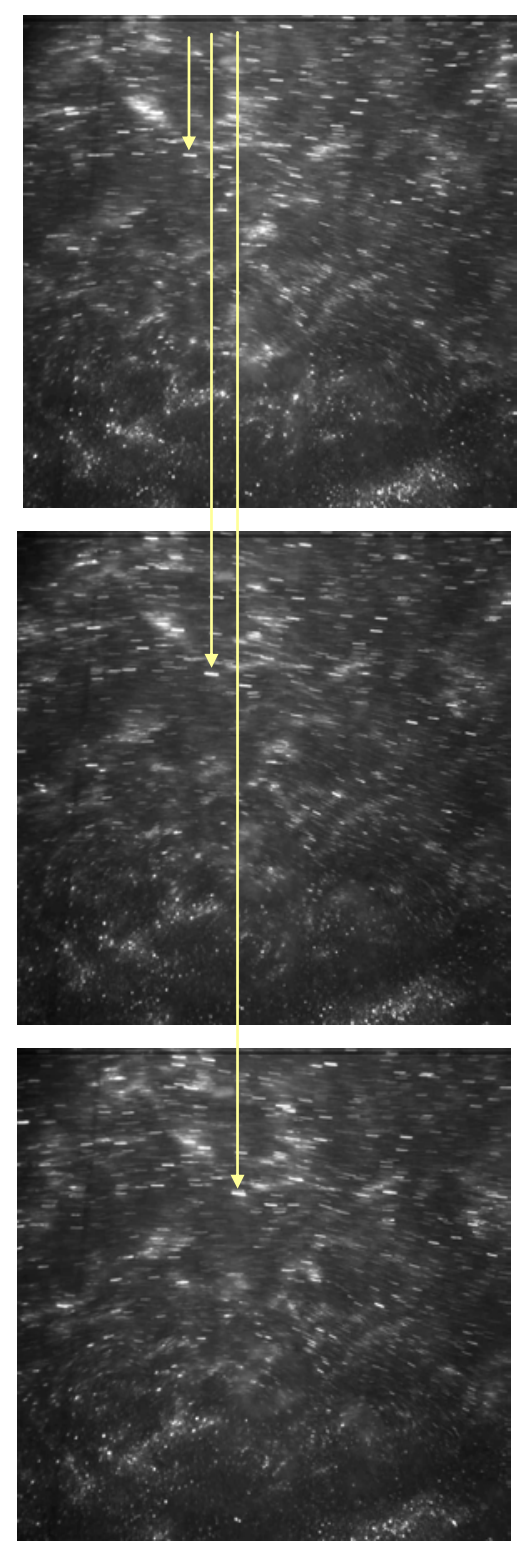

Figura 19 - Sequência de fotos de uma região do escoamento, com acompanhamento de uma partícula.
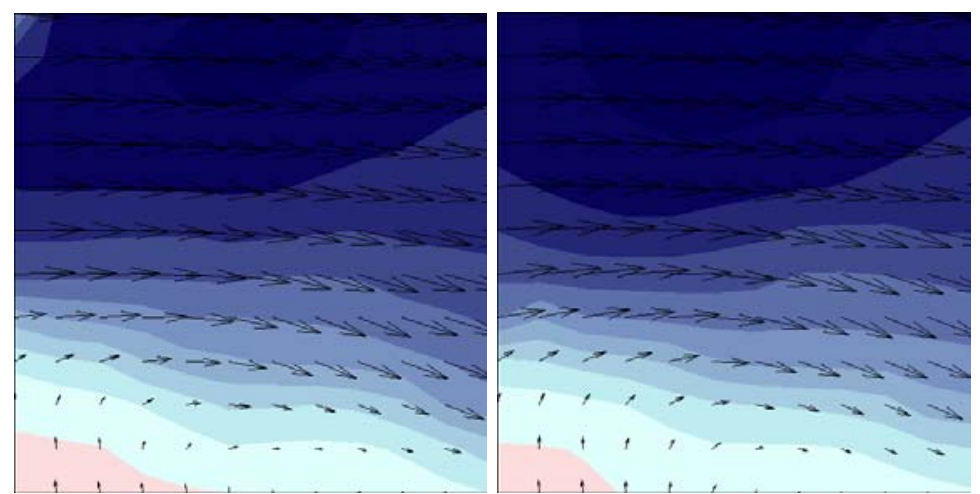

Figura 20 - Campos de velocidade instantânea obtidos a partir da análise das imagens do escoamento. 


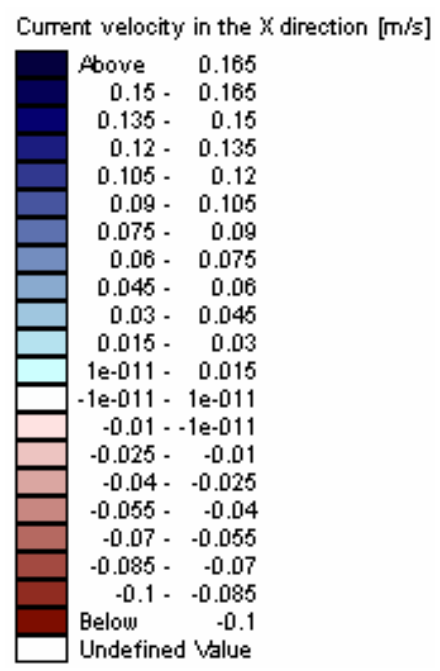

Figura 21 - Escala de cores dos campos da Figura 20, referente à componente da velocidade na direção longitudinal da armadilha (direção horizontal na Figura 20).

Em cada configuração, as 315 imagens do escoamento obtidas para cada uma das 15 regiões estudadas geraram 314 campos de velocidade instantânea. As seqüências (uma para cada região) no tempo dessas imagens (como as mostradas na Figura 19) e dos seus respectivos campos (Figura 20) podem ser observadas através de vídeos, apresentados em gravação digital, na PASTA 1_EXPERIMENTO_VÍDEOS DO ESCOAMENTO e na PASTA 2_EXPERIMENTO_VÍDEOS DOS CAMPOS DE VELOCIDADE INSTANTÂNEA, do DVD em anexo. Os vídeos foram editados em programas computacionais específicos; e sua organização no DVD é mostrada no APÊNDICE A deste texto.

Nota-se que os 9420 arquivos com dados de velocidade instantânea (314 campos x 15 regiões x 2 configurações), gerados pelo programa VISIFLOW a partir das imagens do escoamento, não se encontram adequadamente formatados para a geração dos vídeos. Fez-se sua formatação através de programação em linguagem FORTRAN. Como exemplo de arquivo original gerado no VISIFLOW, apresenta-se no APÊNDICE B_ARQUIVO GERADO PELO PROGRAMA VISIFLOW aquele referente à região 1 da Configuração 1 do escoamento, seguido pelo código do programa em FORTRAN.

Para observação no presente texto dos resultados de velocidade instantânea, expõe-se no capítulo seguinte gráficos de variação temporal das componentes da velocidade nas direções longitudinal e transversal da armadilha, referentes ao ponto (à célula) central de cada região, de cada uma das duas configurações. 


\subsubsection{Campos de velocidade média}

Para obtenção dos campos de velocidade média, calculou-se a média temporal dos 314 campos de velocidade instantânea para cada região. Esses campos, importantes para o conhecimento do padrão do escoamento médio na armadilha, são mostrados no capítulo RESULTADOS E DISCUSSÃO.

\subsubsection{Assoreamento da armadilha}

O trabalho de assoreamento na armadilha foi realizado com a Configuração 1 do escoamento, isto é, o canal 1 recebeu uma vazão constante de $0,002 \mathrm{~m}^{3} / \mathrm{s}$ e o canal 2 foi fechado na entrada da armadilha. A descarga de areia foi definida em $2 \mathrm{~g} / \mathrm{s}$, o que representa uma concentração de 1 grama por litro $(\mathrm{g} / \mathrm{L})$ na extremidade de montante do canal 1, local de lançamento.

A escolha dessa descarga, encontrada em rios naturais, fez com que o assoreamento de grande parte da armadilha acontecesse em 72 horas. Uma média diária de 6 horas e meia de trabalho de assoreamento resultou em um total de 11 dias de experimentação. Em cada parada do experimento, a armadilha era mantida cheia, com altura de água nivelada pelo vertedor (com base de $10 \mathrm{~cm}$ de altura, em relação ao fundo da armadilha). A cada reinício diário, teve-se a preocupação de se restabelecer o escoamento, sem descarga de sedimento, de forma lenta o suficiente para que não houvesse modificação brusca no assoreamento já formado, por desmoronamento de dunas e taludes. Por outro lado, preocupou-se também em se fazer esse restabelecimento rápido o bastante para que considerável quantidade de sedimentos do assoreamento já formado não fosse transportada. Durante o reinício, o padrão do escoamento varia consideravelmente e a areia é depositada, de forma indesejável, em locais que não aqueles em condição de escoamento estabelecido.

\subsubsection{Características da areia}

A areia usada possui distribuição granulométrica mostrada na Tabela 2 e graficamente na Figura 22. A escolha de uma areia fina, com diâmetro médio $\left(\mathrm{d}_{50}\right)$ igual a $0,12 \mathrm{~mm}$, teve como motivo a baixa capacidade de transporte de sedimento do escoamento na armadilha. Caso uma areia mais grossa fosse escolhida, o assoreamento se concentraria na entrada do reservatório, podendo até mesmo superar a altura de água 
definida pelo vertedor. Isso causaria uma descontinuidade no escoamento, comprometendo experimento e simulação computacional.

Tabela 2 - Resultado do ensaio granulométrico da areia usada nos experimentos.

\begin{tabular}{|cccc|}
\hline Peneiras & \% Retida & \% Retida acumulada & Diâmetro $(\mathrm{mm})$ \\
\hline 6 & 0 & 100 & 3,36 \\
12 & 0 & 100 & 1,68 \\
20 & 0 & 100 & 0,84 \\
30 & 0 & 100 & 0,59 \\
40 & 0,5 & 100 & 0,42 \\
50 & 5,4 & 99,5 & 0,297 \\
70 & 24,3 & 94,1 & 0,21 \\
100 & 34,1 & 69,8 & 0,149 \\
140 & 27,7 & 35,7 & 0,105 \\
200 & 5,7 & 8 & 0,074 \\
270 & 2,1 & 2,3 & 0,053 \\
fundo & 0,2 & 0,2 & 0,037 \\
Total & 100 & & \\
\hline
\end{tabular}




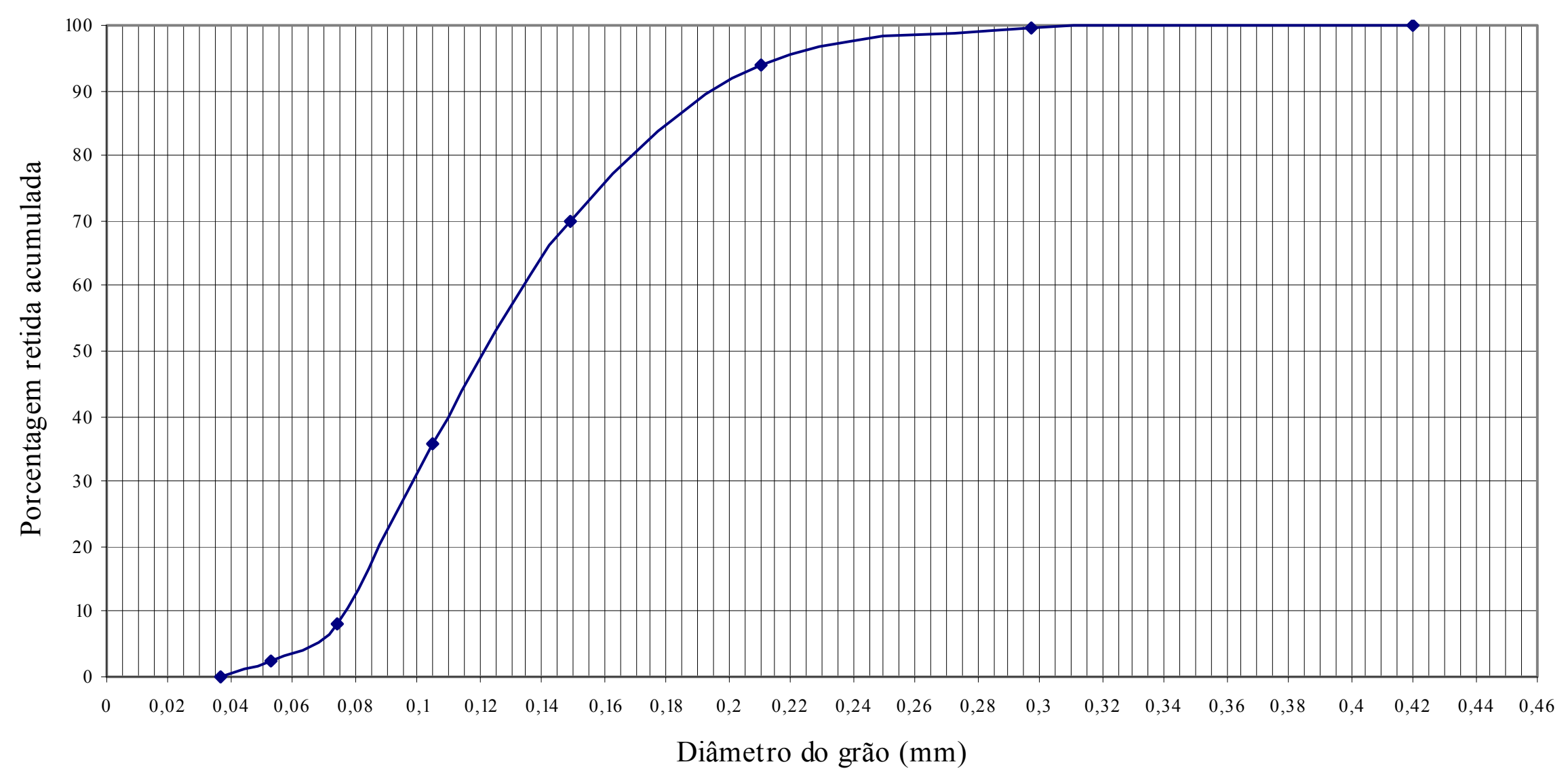

Figura 22 - Distribuição granulométrica da areia. 


\subsubsection{Medição do assoreamento}

O desenvolvimento do assoreamento ao longo das 72 horas foi registrado em aproximadamente 2000 fotos e alguns vídeos com duração de até 20 minutos. O transporte de fundo, predominante no caso de areia como sedimento, é visível nos vídeos através da movimentação das dunas formadas sobre o fundo dos canais e da armadilha. Algumas fotos são mostradas no Capítulo 5. As demais e os vídeos encontram-se no DVD, na PASTA 3_EXPERIMENTO_FOTOS DO ASSOREAMENTO e na PASTA 4_EXPERIMENTO_VÍDEOS DO ASSOREAMENTO.

Esta metodologia usada para registro do assoreamento (fotos e vídeos), apesar de simples, mostrou-se satisfatória para se obter um bom acompanhamento da deposição, no tempo e no espaço, de areia na armadilha. O equipamento montado e destinado inicialmente à medição do assoreamento mostrou-se ineficiente. O paquímetro digital, preso a uma mesa móvel sobre a armadilha (Figura 35), não possibilita medições instantâneas do assoreamento em várias posições. Além disso, uma malha extremamente fina de pontos de medição seria necessária para registro, com uso desse instrumento, das ravinas (sulcos formados pelo escoamento sobre o leito) e das variações de altura nas dunas.

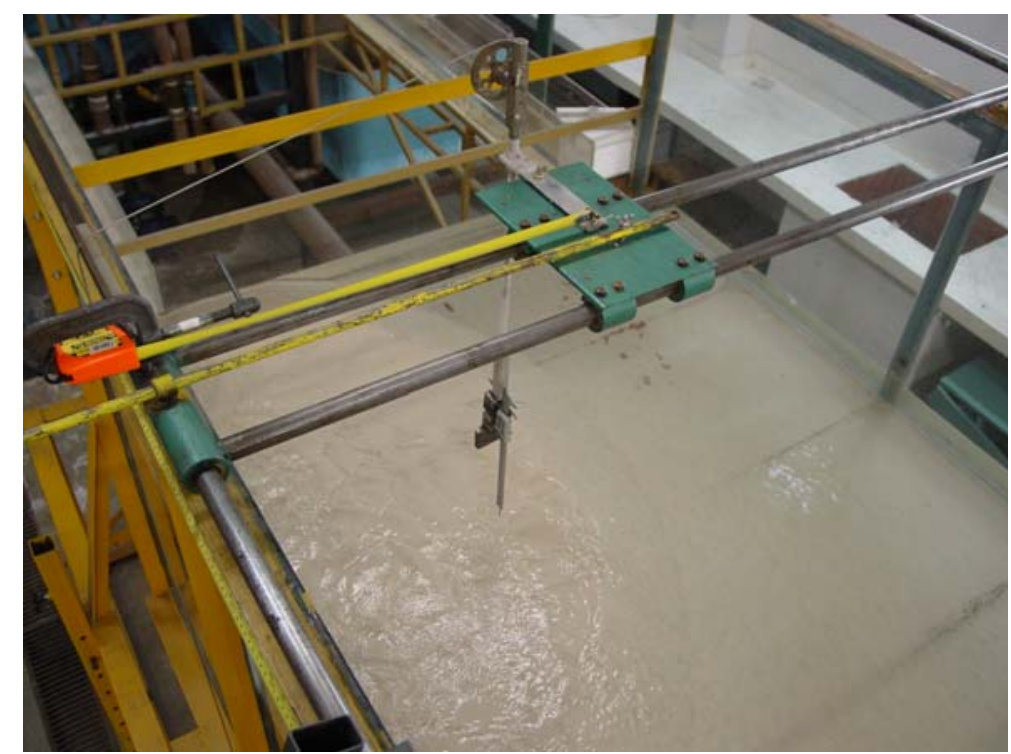

Figura 23 - Equipamento inicialmente montado para medição do assoreamento, com paquímetro fixado à mesa móvel acima da armadilha. 


\subsection{Etapa de simulação numérica}

Apresenta-se a seguir o programa computacional MIKE 21C, da empresa dinamarquesa DHI Water and Environment (DHI vem do antigo nome da empresa, Danish Hydraulic Institute), adquirido para este trabalho de pesquisa e usado para modelagem numérica do escoamento e do assoreamento na armadilha. A decisão por esse programa deveu-se à existência de trabalhos de validação do modelo, desenvolvidos na Delft University of Technology, como Olesen (1987) e Talmon (1992), bem como às aplicações em casos reais de transporte de sedimentos. Das aplicações, realizadas pela própria DHI Water and Environment, cita-se as modelagens:

- das condições hidrodinâmicas e morfológicas do Rio Jamuna, durante a construção da Ponte Jamuna, no período de 1995 a 1998. Contratante: World Bank;

- do comportamento de um canal, criado em 1996 para funcionamento durante poucos meses, conectando o Rio Jamuna e o Rio Dhaleswari. A modelagem visou o estudo da probabilidade de erosão do canal e desmoronamento das encostas. Contratante: Jamuna Multipurpose Bridge Authority;

- hidrodinâmica e de transporte de sedimentos no Estuário Loire, na França, durante um ciclo de maré durante a primavera. Contratante: BCEOM, 1997;

- do padrão do escoamento no estreito entre Suécia e Dinamarca, definido pela diferença entre os níveis de água do mar Báltico e do Mar do Norte. Contratante: Øresundskonsortiet;

- do transporte de sedimentos no Rio Gorai e no Rio Ganges, em Bangladesh, para estudo e combate ao assoreamento desses rios, em 1998-1999. Contratantes: Surface Water Modelling Centre, Ministry of Water Resources de Bangladesh e World Bank;

- do transporte de sedimentos e assoreamento do Rio Karnaphuli e na Baía de Bengal, em Bangladesh, 1991. Contratante: DANIDA.

Os trabalhos de validação e aplicação do MIKE 21C podem ser encontrados resumidamente em DHI Water and Environment (2005).

O MIKE 21C é descrito de forma bastante resumida neste texto, juntamente com sua configuração para uso nas simulações do trabalho. Detalhamento de suas informações técnicas, suas ferramentas e seus equacionamentos pode ser encontrado em DHI (2004) e DHI (2005), também disponíveis em DHI Water and Environment (2005). 


\subsubsection{Equacionamento do modelo hidrodinâmico}

A hidrodinâmica de escoamentos com fundo móvel é caracterizada por padrões tridimensionais complexos. Isso tem que ser levado em consideração quando se estuda morfologia de rios e assoreamento de reservatórios. Por outro lado, a aplicação de um modelo hidrodinâmico tridimensional a simulações de grande escala de tempo (décadas, no caso de assoreamento de reservatórios) requer um grande trabalho computacional, muitas vezes inviável. Por isso, nesse programa, as equações de Navier-Stokes (conservação de massa e quantidade de movimento) são reduzidas a equações bidimensionais, no plano horizontal e integradas na vertical. Efeitos tridimensionais, chamados de escoamentos secundários, são mantidos através de um modelo de escoamento helicoidal. O equacionamento também adota hipóteses de distribuição hidrostática de pressão na vertical e ausência da condição de não-escorregamento (velocidade zero) junto às paredes, fazendo com que o modelo seja aplicável a escoamentos de águas rasas (pequena profundidade com relação à largura do canal) e gradualmente variados.

Apesar de o programa permitir a elaboração de uma malha computacional ortogonal e curvilínea para discretização do domínio a ser estudado, como exemplificado na Figura 24 e ideal para escoamentos em rios e reservatórios, sua aplicação neste trabalho não utilizou essa ferramenta. A malha foi gerada em coordenadas cartesianas, devido à geometria retangular dos canais afluentes e da armadilha de sedimentos.

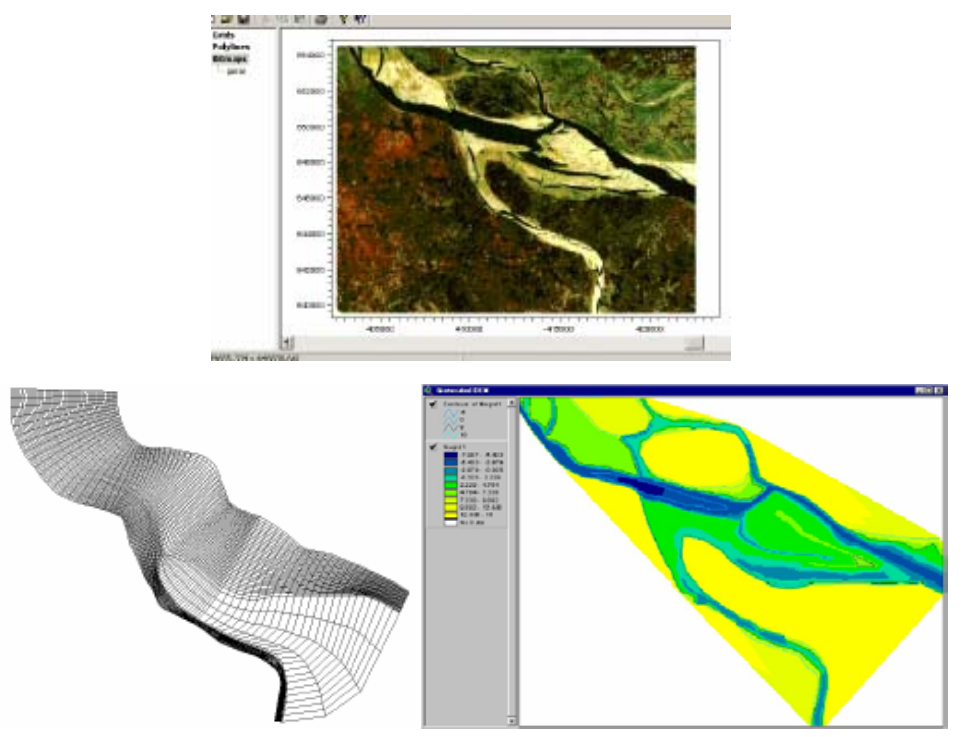

Figura 24 - Na ilustração superior, a imagem de satélite mostra a bifurcação de um rio, que corre da esquerda para a direita. Abaixo, as duas ilustrações apresentam o trabalho de geração da malha curvilínea e de batimetria com uso do MIKE 21C. Fonte - DHI (2005). 
As equações governantes do modelo, de conservação de massa e quantidade de movimento, descrevem o comportamento do escoamento em resposta às diferentes forças atuantes, referentes, por exemplo, às diferenças de nível da superfície da água e às condições de contorno do problema. Essas equações, para malhas cartesianas, são resolvidas através de um método de diferenças finitas, Alternating Direction Implicit Technique. Com as hipóteses adotadas, são também conhecidas como equações de Saint-Venant em duas direções, na forma como se segue:

Conservação da massa:

$\frac{\partial \zeta}{\partial \mathrm{t}}+\frac{\partial \mathrm{p}}{\partial \mathrm{x}}+\frac{\partial \mathrm{q}}{\partial \mathrm{y}}=\frac{\partial \mathrm{d}}{\partial \mathrm{t}}$

Quantidade de movimento na direção x:

$$
\begin{aligned}
& \frac{\partial p}{\partial t}+\frac{\partial}{\partial x}\left(\frac{p^{2}}{h}\right)+\frac{\partial}{\partial y}\left(\frac{p q}{h}\right)+g h \frac{\partial \zeta}{\partial x}+\frac{g p \sqrt{p^{2}+q^{2}}}{C^{2} h^{2}}- \\
& \frac{1}{\rho_{w}}\left[\frac{\partial}{\partial x}\left(h \tau_{x x}\right)+\frac{\partial}{\partial y}\left(h \tau_{x y}\right)\right]-\Omega q-f V V_{x}+\frac{h}{\rho_{w}} \frac{\partial}{\partial x}\left(p_{a}\right)=0
\end{aligned}
$$

Quantidade de movimento na direção y:

$$
\begin{aligned}
& \frac{\partial \mathrm{q}}{\partial \mathrm{t}}+\frac{\partial}{\partial \mathrm{y}}\left(\frac{\mathrm{q}^{2}}{\mathrm{~h}}\right)+\frac{\partial}{\partial \mathrm{x}}\left(\frac{\mathrm{pq}}{\mathrm{h}}\right)+\mathrm{gh} \frac{\partial \zeta}{\partial \mathrm{y}}+\frac{\mathrm{gq} \sqrt{\mathrm{p}^{2}+\mathrm{q}^{2}}}{\mathrm{C}^{2} \mathrm{~h}^{2}}- \\
& \frac{1}{\rho_{\mathrm{w}}}\left[\frac{\partial}{\partial \mathrm{y}}\left(\mathrm{h} \tau_{\mathrm{yy}}\right)+\frac{\partial}{\partial \mathrm{x}}\left(\mathrm{h} \tau_{\mathrm{xy}}\right)\right]-\Omega \mathrm{p}-\mathrm{fVV}_{\mathrm{y}}+\frac{\mathrm{h}}{\rho_{\mathrm{w}}} \frac{\partial}{\partial y}\left(\mathrm{p}_{\mathrm{a}}\right)=0
\end{aligned}
$$

onde:

$$
\begin{array}{ll}
\mathrm{h}(\mathrm{x}, \mathrm{y}, \mathrm{t}) & \text { profundidade do escoamento }=\zeta-\mathrm{d}(\mathrm{m}) ; \\
\mathrm{d}(\mathrm{x}, \mathrm{y}, \mathrm{t}) & \text { altura do leito variando no tempo }(\mathrm{m}) ; \\
\zeta(\mathrm{x}, \mathrm{y}, \mathrm{t}) & \text { elevação da superfície }(\mathrm{m}) ; \\
\mathrm{p}, \mathrm{q}(\mathrm{x}, \mathrm{y}, \mathrm{t}) & \text { vazão específica nas direções x e y }=\mathrm{uh}, \mathrm{vh}\left(\mathrm{m}^{3} / \mathrm{s} / \mathrm{m}\right) ; \\
\mathrm{u}, \mathrm{v}(\mathrm{x}, \mathrm{y}, \mathrm{t}) & \text { velocidades médias na profundidade, nas direções x e y }(\mathrm{m} / \mathrm{s}) ; \\
\mathrm{C}(\mathrm{x}, \mathrm{y}) & \text { coeficiente de Chezy }\left(\mathrm{m}^{1 / 2} / \mathrm{s}\right) ; \\
\mathrm{g} & \text { aceleração da gravidade }\left(\mathrm{m} / \mathrm{s}^{2}\right) ; \\
\mathrm{f}(\mathrm{V}) & \text { fator de cisalhamento do vento; }
\end{array}
$$




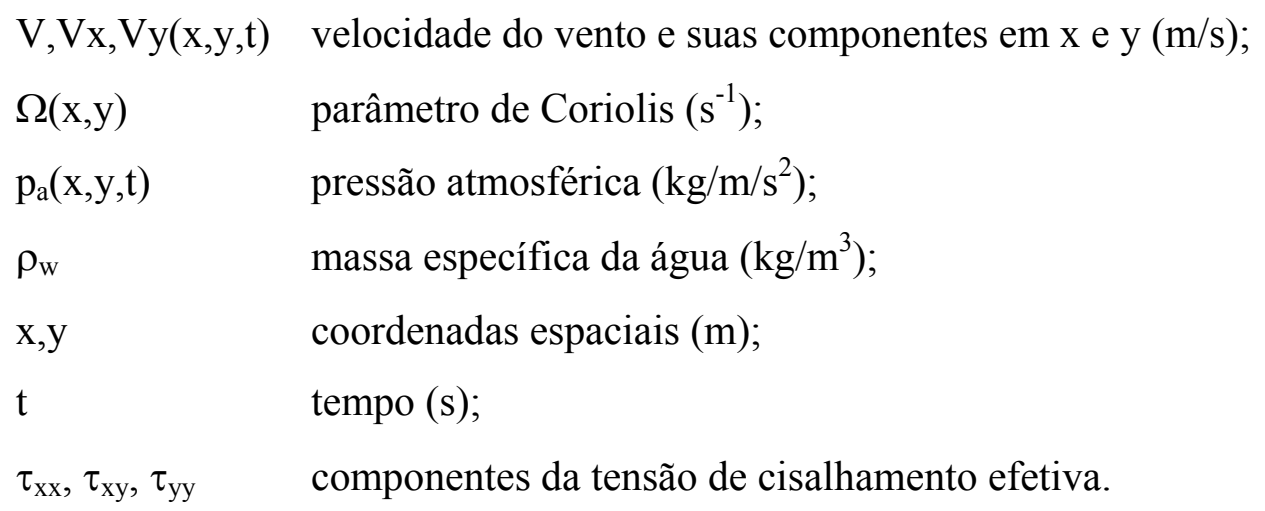

\subsubsection{Escoamento helicoidal}

Quando o escoamento livre muda de direção, um desbalanço de força centrípeta gera um movimento para fora da curva junto à superfície e para dentro da curva junto ao fundo. A razão disso é que, de acordo com a distribuição de velocidade vertical para escoamentos livres, a parte superior do escoamento tem maior velocidade. Em conseqüência, partículas na parte superior seguem um caminho com maior raio de curvatura para manter aproximadamente constante a força centrípeta ao longo da profundidade (a aceleração centrípeta é igual à razão entre o quadrado da velocidade e o raio de curvatura). A forma do escoamento pode ser considerada como a soma da componente longitudinal do escoamento com o movimento helicoidal, como mostrado na Figura 25.

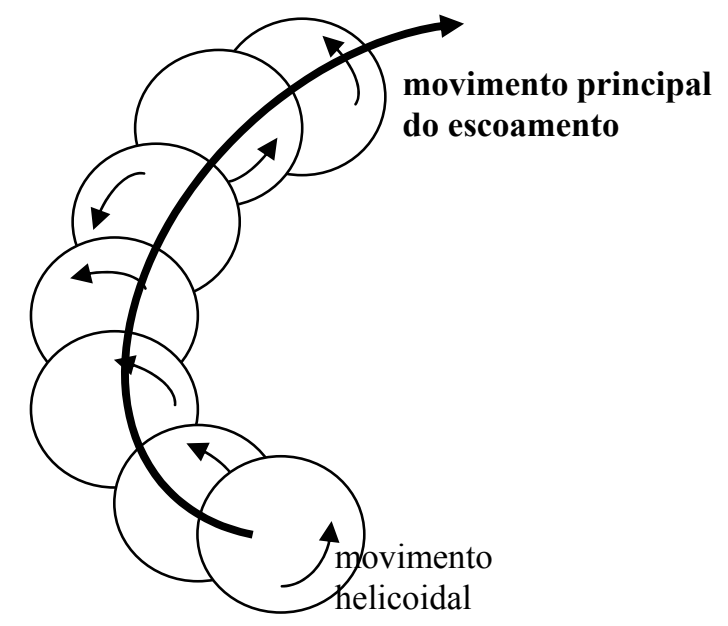

Figura 25 - Movimento principal (longitudinal) somado ao movimento helicoidal, de um escoamento com superfície livre em uma curva.

Figura adaptada de DHI (2004) 
A intensidade do movimento helicoidal é a magnitude da componente transversal da velocidade, como definido por Vriend (1981):

$\mathrm{i}_{\mathrm{s}}=\mathrm{u} \cdot \frac{\mathrm{h}}{\mathrm{R}_{\mathrm{s}}}$

onde:

u velocidade do escoamento longitudinal;

h profundidade do escoamento;

$\mathrm{R}_{\mathrm{S}} \quad$ raio de curvatura das linhas de corrente;

$i_{\mathrm{s}} \quad$ intensidade do movimento helicoidal.

O movimento helicoidal causa uma pequena variação na direção do escoamento principal junto ao fundo. Em conseqüência, ocorrem também mudanças na direção da tensão de cisalhamento, no transporte de sedimentos em suspensão e na topografia do fundo móvel. A modelagem proposta por Rozovskii (1957) para a nova direção da tensão de cisalhamento junto ao fundo é incluída no programa. As novas direções do escoamento junto à superfície, junto ao fundo e da tensão de cisalhamento são ilustradas, simplificadamente e sem apresentação do extenso equacionamento, na Figura 26.

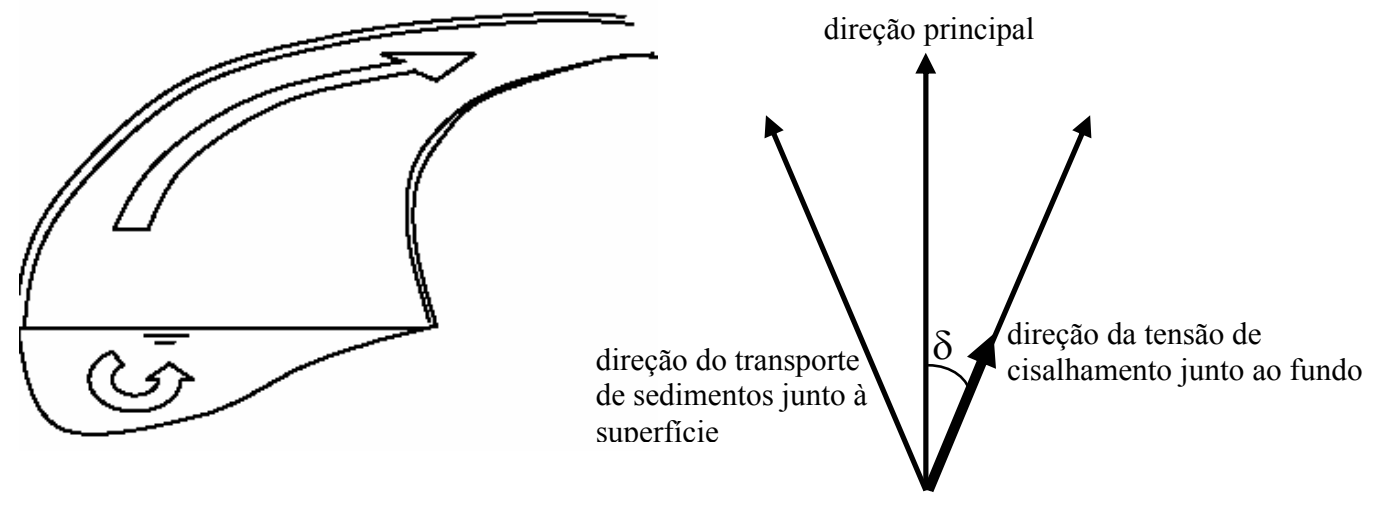

Figura 26 - Direções do escoamento junto à superfície, junto ao fundo e da tensão de cisalhamento. Figura adaptada de DHI (2004).

Embora o movimento helicoidal não modifique consideravelmente o padrão de escoamento de águas rasas, sua influência no transporte de sedimentos e na morfologia pode ser significativa. 


\subsubsection{Modelagem da turbulência}

A viscosidade turbulenta pode ser introduzida ou não nos escoamentos simulados, de diferentes formas:

- Escoamento invíscido: a viscosidade é desprezada.

- Viscosidade constante: um valor constante pode ser aplicado para todo o domínio ou diferentes valores podem ser especificados para as células da malha computacional.

- Formulação de Smagorisnky: modelo dinâmico com uma equação de fechamento para turbulência. Esse equacionamento é baseado no conceito de Smagorinsky (1963), para cálculo do coeficiente de viscosidade turbulenta (E), da forma:

$$
\mathrm{E}=\mathrm{C}_{\mathrm{s}}^{2} \Delta^{2}\left[\left(\frac{\partial \mathrm{U}}{\partial \mathrm{x}}\right)^{2}+\frac{1}{2}\left(\frac{\partial \mathrm{U}}{\partial \mathrm{y}}+\frac{\partial \mathrm{V}}{\partial \mathrm{x}}\right)^{2}+\left(\frac{\partial \mathrm{V}}{\partial \mathrm{y}}\right)^{2}\right]
$$

onde :

$\mathrm{C}_{\mathrm{s}} \quad$ parâmetro de calibração, definido entre 0,25 e 1,0;

$\Delta \quad$ espaçamento de grade (na malha computacional).

Detalhes do equacionamento podem ser obtidos em Lilly (1966), Leonard (1974), Aupoix (1984) e Horiuti (1987).

\subsubsection{Modelo de transporte de sedimentos}

Uma das formas tradicionais de se classificar o transporte de sedimentos em escoamentos fluviais pode ser encontrada em Jansen et al. (1979) e é dividida em transporte de fundo (bed load transport) e transporte em suspensão (suspended load). Transporte de fundo compreende o transporte do material que forma o leito e que desliza, rola ou salta próximo ao leito. O transporte em suspensão engloba tanto sedimentos que fazem parte do material encontrado no leito (sedimentos mantidos suspensos no fluido por certo período, mas que são também encontrados no leito) quanto sedimentos finos, com diâmetro máximo em torno de $0,062 \mathrm{~mm}$ e que são mantidos em suspensão durante todo o tempo devido ao movimento turbulento do fluido (compreende o wash load, nessa classificação). Essa classificação de transporte é 
ilustrada na Figura 27. Os transportes de fundo e em suspensão são chamados também de descarga de arrasto e descarga em suspensão, como em Carvalho (1994).

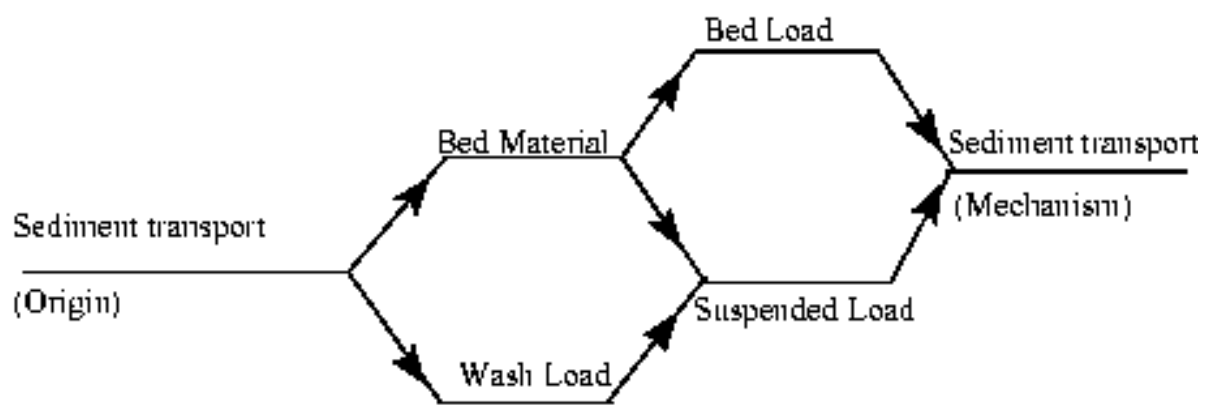

Figura 27 - Classificação do transporte de sedimentos.

Fonte - Jansen et al. (1979)

No presente trabalho, onde estuda-se o desenvolvimento do assoreamento, com interação entre batimetria e hidrodinâmica, apenas o transporte de material do leito é importante. Assim, o transporte de fundo e parte do transporte em suspensão são considerados. Enquanto isso, os sedimentos finos (e coesivos) em suspensão, cuja ocorrência não influencia consideravelmente a capacidade de transporte dos sedimentos de interesse no escoamento, são desprezados.

O comportamento do transporte em suspensão é fundamentalmente diferente do transporte de fundo, o que deve ser considerado na modelagem do assoreamento. A seguir, os dois tipos de transporte são tratados separadamente, de forma simplificada. Posteriormente, equacionamentos clássicos da literatura para quantificação desses transportes e implementados no modelo (do programa MIKE 21C) são citados.

\subsubsection{Transporte em suspensão}

O modelo para transporte em suspensão é baseado na teoria descrita por Galappatti (1983). O transporte é representado por uma equação de advecção dispersão, dada por:

$\frac{\partial c}{\partial t}+u \frac{\partial c}{\partial x}+v \frac{\partial c}{\partial y}+w \frac{\partial c}{\partial z}=w_{s} \frac{\partial c}{\partial z}+\frac{\partial}{\partial x}\left(E \frac{\partial c}{\partial x}\right)+\frac{\partial}{\partial y}\left(E \frac{\partial c}{\partial y}\right)+\frac{\partial}{\partial z}\left(E \frac{\partial c}{\partial z}\right)$

onde:

z coordenada vertical;

c concentração dos sedimentos em suspensão; 
E coeficiente de difusão turbulenta;

ws velocidade de queda da partícula em suspensão;

$\mathrm{u}, \mathrm{v}, \mathrm{w} \quad$ velocidade do escoamento nas direções $\mathrm{x}, \mathrm{y}$ and $\mathrm{z}$, respectivamente.

As condições de contorno especificam fluxo zero na superfície e certa concentração para uma altura logo acima do leito, que divide as regiões de transportes de fundo e em suspensão. Nessa teoria, esta altura é igual $2 \%$ da profundidade do escoamento.

Apesar de o modelo hidrodinâmico ser baseado na integração vertical da velocidade, informação a respeito da distribuição vertical dessa propriedade (velocidade) é necessária para determinação da tensão de cisalhamento junto ao fundo e para cálculo do transporte de sedimentos em suspensão. Por esse motivo, perfis de concentração de sedimentos e de distribuição vertical de velocidade são incorporados no equacionamento.

\subsubsection{Transporte de fundo}

A modelagem do transporte de fundo é fundamental para uma boa representação do assoreamento realizado em laboratório, pois tem-se que esse tipo de transporte mostrou-se predominante nos experimentos, para as condições de escoamento e o sedimento utilizado. Em contraste com o transporte em suspensão, assume-se na modelagem que o transporte de fundo responde imediatamente às mudanças hidrodinâmicas locais. Assim, não há necessidade de uma equação de convecçãodifusão. Porém, leva-se em consideração a mudança de direção da tensão de cisalhamento junto ao leito, devido ao movimento helicoidal, e a alteração no transporte em conseqüência da declividade do leito. Estudos relacionando declividade do leito e transporte de fundo podem ser encontrados em Lane (1953), Koch (1980), Ikeda (1980) e Olesen (1987).

\subsubsection{Equações de transporte de sedimentos}

O modelo usa fórmulas de transporte de sedimentos, consagradas na literatura, para cálculo da capacidade de transporte de fundo e em suspensão. Uma das fórmulas, desenvolvida por Engelund and Hansen (1967), estima somente o transporte total (de fundo + em suspensão). Dois fatores, $\mathbf{k}_{\mathbf{b}}$ e $\mathbf{k}_{\mathbf{s}}$, são inseridos na modelagem a partir de 
calibração, como parâmetros de entrada, cada um multiplicando o transporte total, para determinação das frações representativas de cada tipo de transporte. Por exemplo, caso se especifique $\mathbf{k}_{\mathbf{b}}=0,9$ e $\mathbf{k}_{\mathbf{s}}=0,1,90 \%$ do transporte será considerado de fundo e $10 \%$ em suspensão. As demais fórmulas, de Rijn (1984) e Engelund and Fredsøe (1976), apresentam, separadamente, cálculos para transporte de fundo e em suspensão. Esta última foi usada neste trabalho por apresentar os melhores resultados na reprodução do assoreamento experimental. O trabalho de Engelund and Fredsøe (1976) é reproduzido neste texto no ANEXO; e traz o transporte de fundo como $\mathbf{q}_{\mathbf{b}}$ e o transporte em suspensão como $\mathbf{q}_{\mathbf{s}}$.

\subsubsection{Simulação hidrodinâmica}

Usou-se o programa primeiramente para simulação hidrodinâmica das configurações 1 e 2 de escoamento, cujos campos de velocidade foram obtidos experimentalmente por velocimetria a laser. A simulação da Configuração 1 foi usada em seguida para dar início à simulação do assoreamento no reservatório.

Discretizou-se o domínio computacional com uma malha de 152 células ao longo da largura da armadilha e 340 ao longo do comprimento, em um total de 51680 células. Cada célula quadrada possui $1 \mathrm{~cm}$ de lado e é suficientemente pequena para se obter detalhes do escoamento na escala de comprimento desejada. A relação entre as escalas de comprimento da armadilha e da malha pode ser observada na Figura 28. A malha é apresentada na cor preta e o contorno da armadilha em vermelho. A unidade das cotas é o metro. Na direção horizontal (direção longitudinal da armadilha), o zero coincide com o início da armadilha. Os $30 \mathrm{~cm}$ anteriores correspondem aos canais afluentes. Apesar de os canais possuírem na realidade $2 \mathrm{~m}$ de comprimento, apenas um trecho foi simulado, para redução da malha e conseqüentemente do esforço computacional no cálculo do escoamento. 


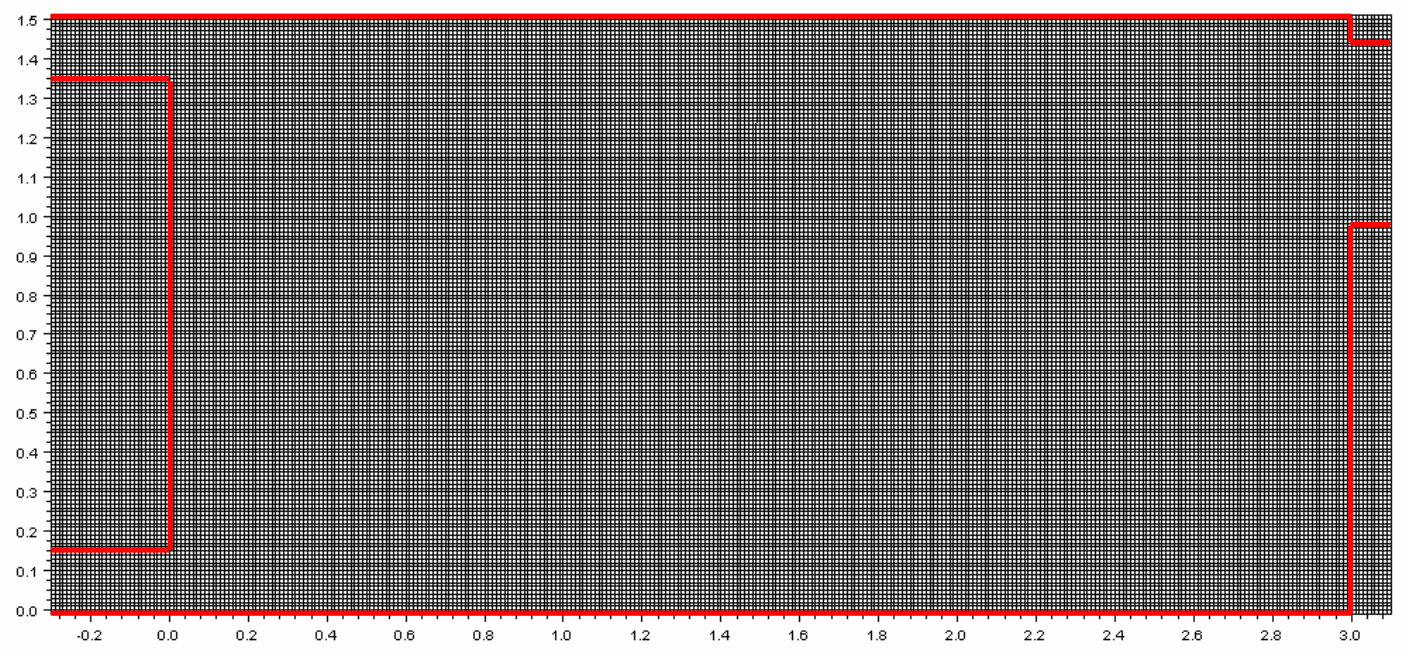

Figura 28- Discretização do domínio. A malha computacional é apresentada na cor preta e o contorno da armadilha em vermelho.

A geometria simulada coincide com a geometria da armadilha do laboratório, com exceção do comprimento dos canais e altura das paredes laterais. Estas, com $20 \mathrm{~cm}$ de altura na simulação, não correm o risco de ser inundadas pela água durante o assoreamento se o modelo representar satisfatoriamente o experimento do laboratório (que teve altura de água em torno de $12 \mathrm{~cm}$ ). Caso o nível de água ultrapasse os $20 \mathrm{~cm}$, a simulação foi realizada de forma que o escoamento não ultrapassasse os limites laterais dos canais e armadilha. O programa MIKE $21 \mathrm{C}$ oferece a opção de inundação (de áreas secas), caso ela seja desejada.

Os ângulos retos presentes na entrada da armadilha, ou seja, na ligação da armadilha com os canais afluentes, não são usualmente encontrados em reservatórios de água reais, formados por barragem. Esses ângulos dificultam o cálculo numérico realizado na simulação, mas, por outro lado, testa a capacidade do modelo para situações críticas de geometria. Após detalhamento do contorno e da batimetria da armadilha, sua geometria é visualizada no programa, como mostrado nas Figuras 29 e 30 abaixo, respectivamente para as Configurações 1 e 2 de escoamento. 


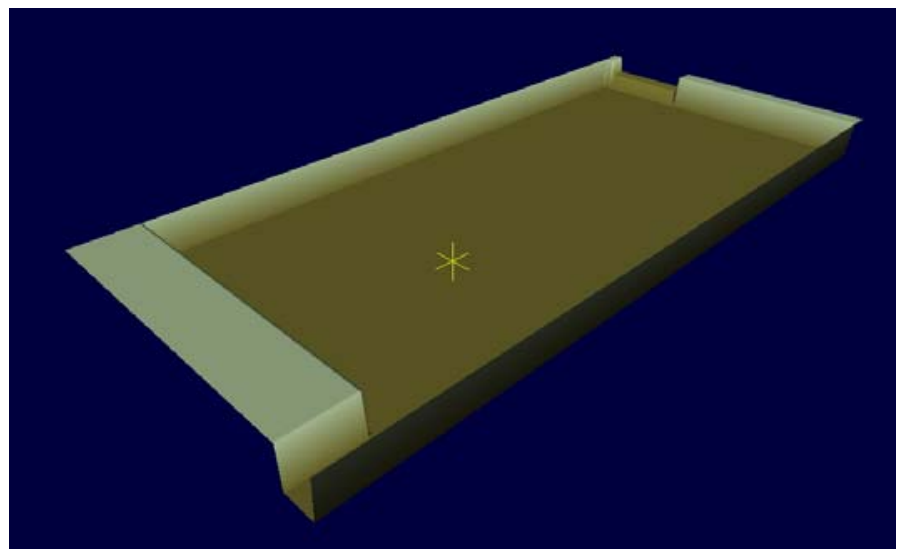

Figura 29 - Geometria da armadilha na configuração 1 do escoamento, com apenas um canal afluente.

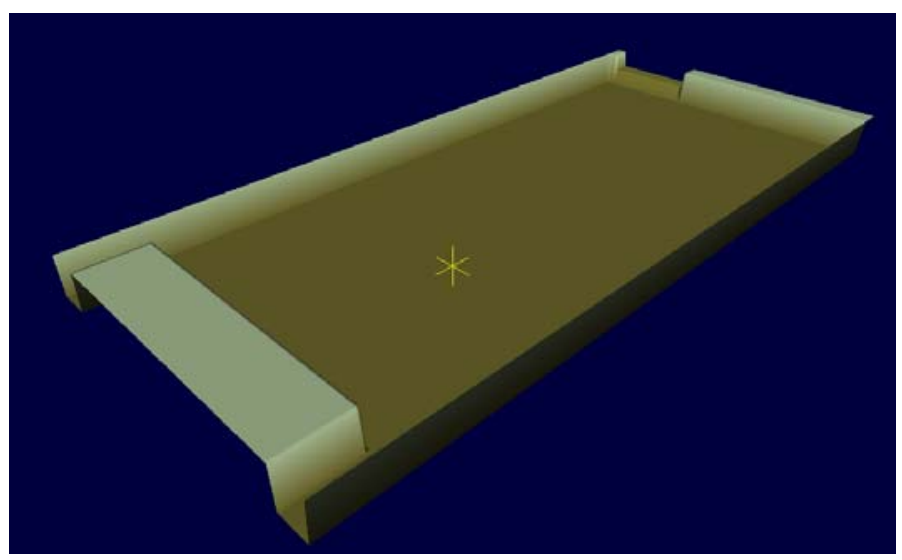

Figura 30 - Geometria da armadilha na configuração 2 do escoamento, com dois canais afluentes.

Para permitir conhecimento prévio da interface gráfica do programa, principalmente por parte dos autores de trabalhos seguintes, os parâmetros definidos para a etapa de simulação são apresentados juntamente com ilustrações das principais "janelas" do MIKE 21C. A seguir, descreve-se os passos para a simulação hidrodinâmica.

Defini-se inicialmente o tipo de simulação desejada, que no momento é apenas para a hidrodinâmica do escoamento (Figura 31). 


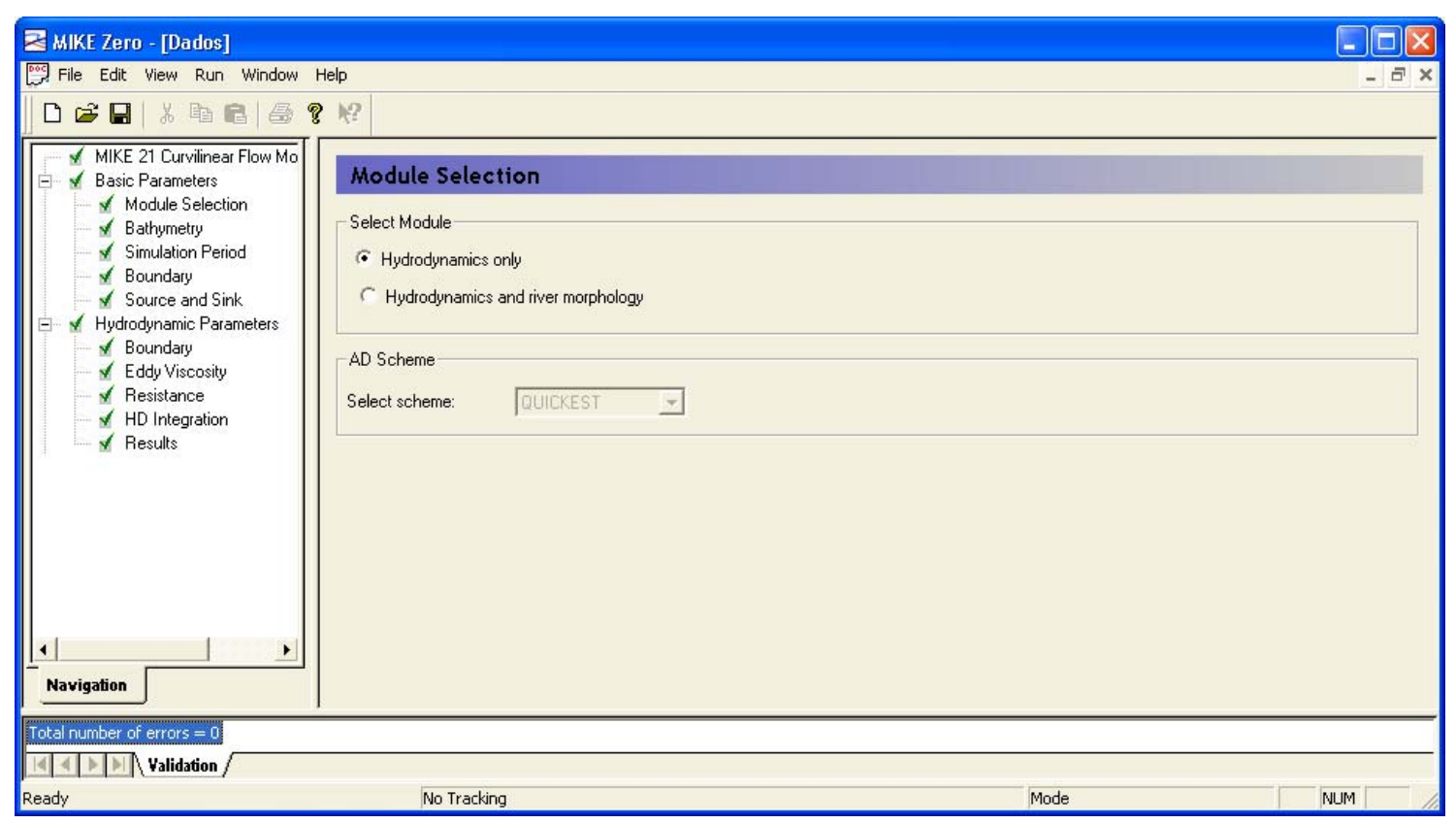

Figura 31 - Seleção do tipo de simulação. No caso, apenas hidrodinâmica.

Os arquivos já criados de batimetria e malha do domínio em estudo são inseridos (Figura 32).

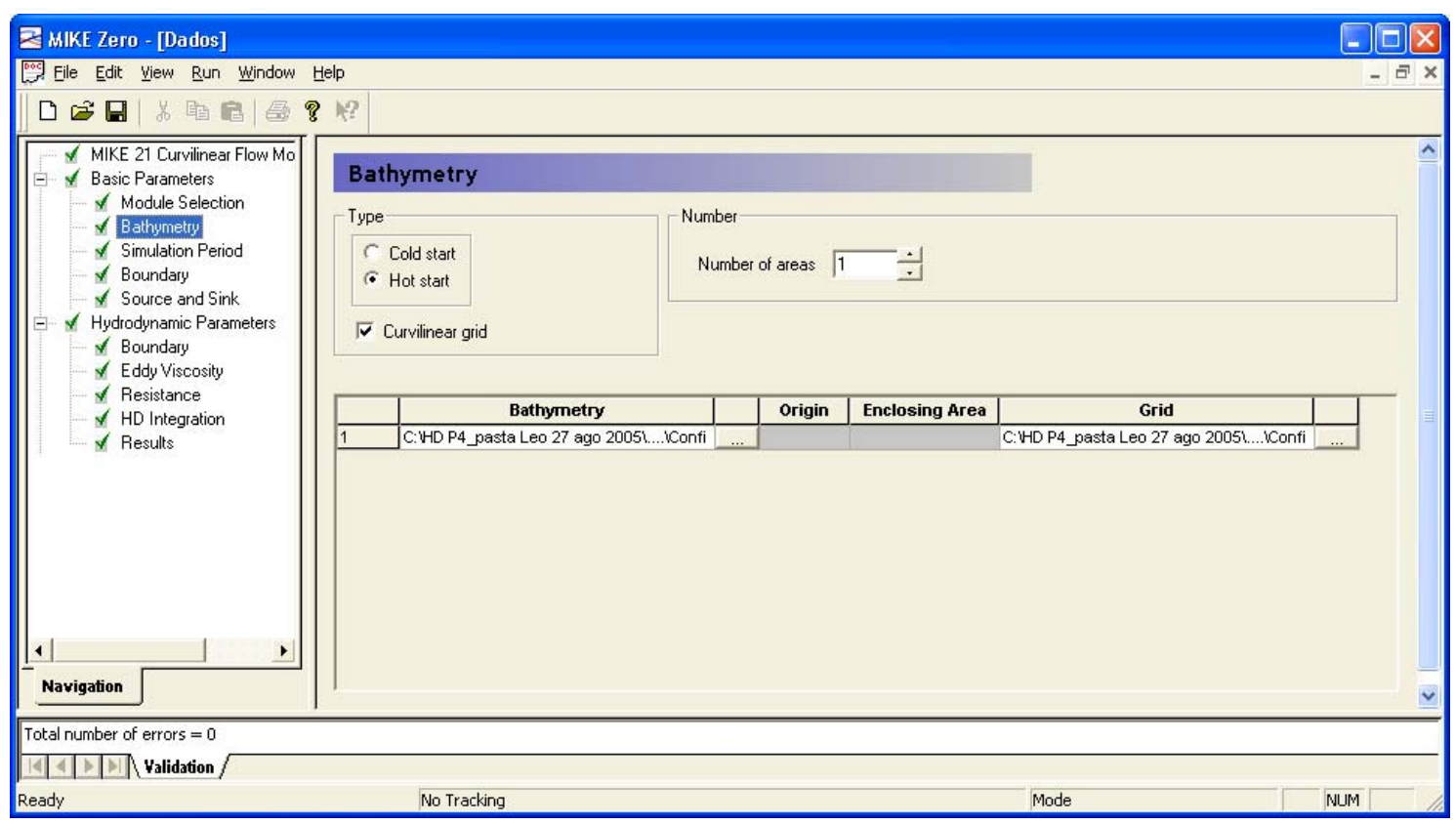

Figura 32 - Carregamento dos arquivos já criados de batimetria e malha computacional.

O período de simulação é definido. Adotou-se um passo no tempo de $0,01 \mathrm{~s}$, coerente com a malha computacional e a velocidade do fluido na armadilha. Com esse passo, o número de Courant se manteve em torno da unidade, o que é fundamental para que se mantenha estabilidade numérica durante o processo de cálculo. A simulação foi 
completada após 100.000 passos no tempo (16minutos e 40 segundos de escoamento real), para que o escoamento atingisse regime permanente. Na Figura 33, apenas 10.000 passos são observados, pois o trecho mostrado na figura foi realizado após 90.000 passos já simulados anteriormente.

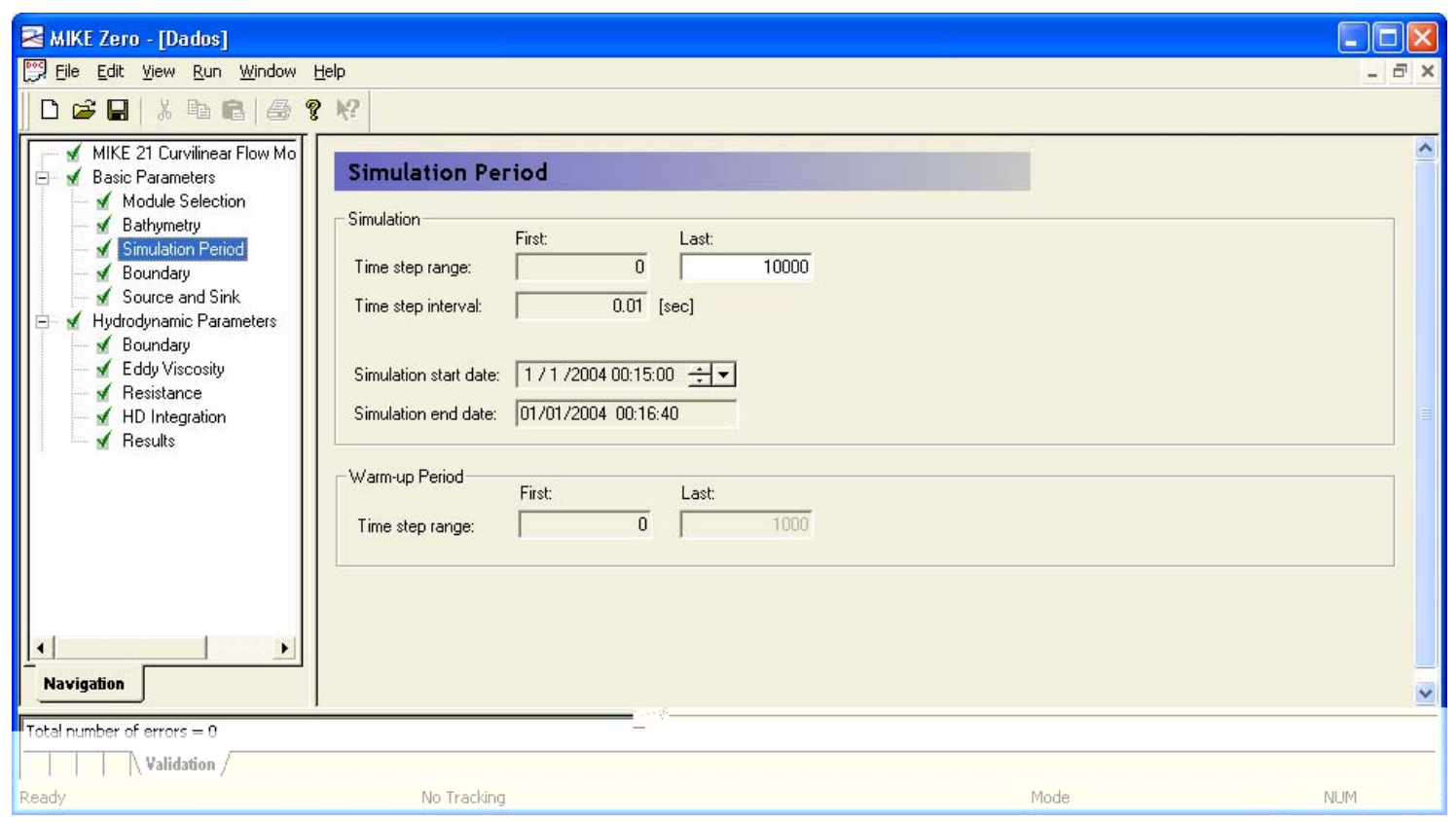

Figura 33 - Estabelecimento do período de simulação e do passo no tempo.

Não existe, na armadilha, pontos de fonte ou sumidouro de massa, a não ser no contorno referente aos canais de entrada e o vertedor (Figura 34).

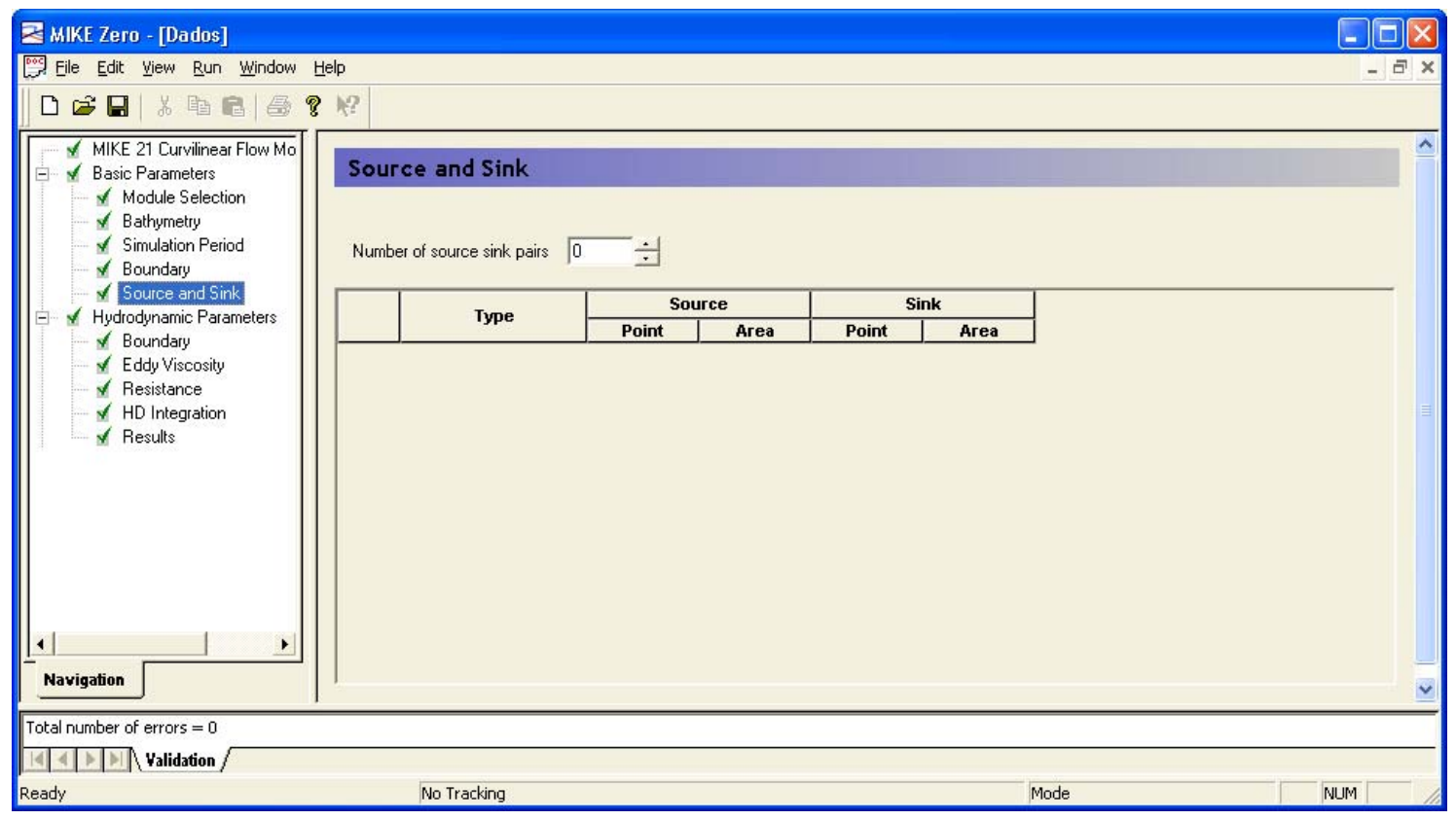

Figura 34 - Pontos de fonte ou sumidouro de massa. Não há no problema. 
As condições de contorno do problema foram definidas, como geralmente faz-se para escoamentos livres em regime fluvial, com a profundidade do escoamento a jusante e vazão a montante. A vazão afluente estabelecida foi de $0,002 \mathrm{~m}^{3} / \mathrm{s}$ e a profundidade do escoamento igual à altura crítica de água no vertedor, de $0,113 \mathrm{~m}(0,10 \mathrm{~m}$ da base do vertedor mais $0,013 \mathrm{~m}$ de lâmina de água), como ilustrado na Figura 35.

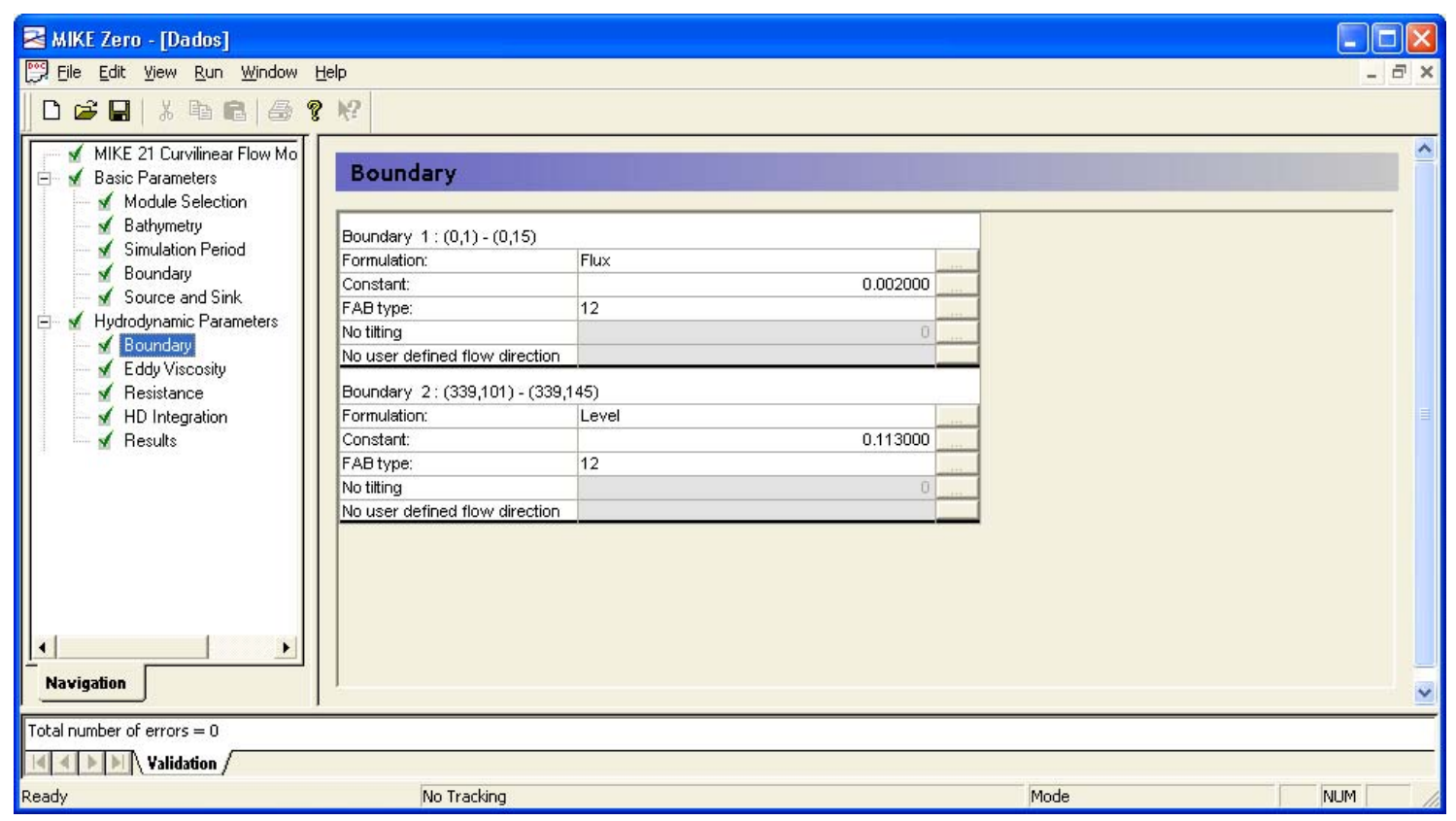

Figura 35 - Condições de contorno do problema.

A viscosidade turbulenta foi modelada a partir da formulação de Smagorinsky (1963). O parâmetro de calibração, compreendido entre 0,25 e 1,0, não modificou consideravelmente o padrão do escoamento, mesmo quando se testou modelagens com os valores extremos do parâmetro. Adotou-se, por isso, o valor 0,5 (Figura 36). 


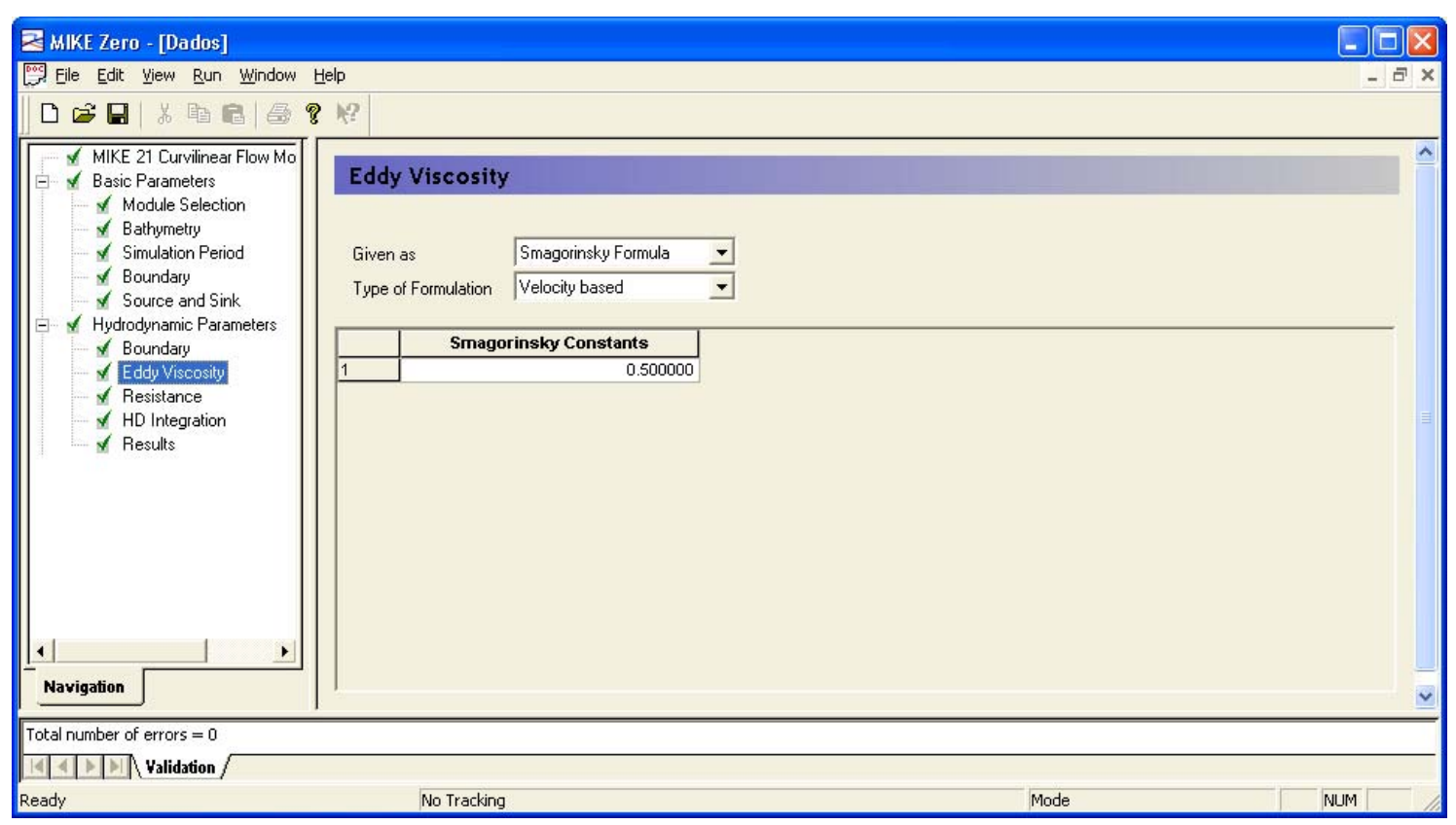

Figura 36 - Escolha do modelo de turbulência. Optou-se pela formulação de Smagorinsky.

A formulação de Chezy é usada para se calcular a perda de carga do escoamento (equações de resistência). A calibração é feita a partir do parâmetro de entrada, que pode ser o próprio coeficiente de Chezy ou o coeficiente $M$ de Strickler (= $1 / n$, com n sendo o coeficiente de Manning). Um arquivo com parâmetro constante para cada célula da malha também pode ser adotado. Neste trabalho, um valor constante foi adotado para o coeficiente de Strickler, contudo a resistência é atualizada através da equação

$$
\mathrm{C}=\mathrm{M} \cdot \mathrm{h}^{1 / 6}
$$

onde:

M coeficiente de Strickler (no programa, M é considerado coeficiente de Manning);

h profundidade do escoamento;

C coeficiente de Chezy, usado no cálculo da resistência.

Nota-se que, neste trabalho, o escoamento desenvolvido anteriormente ao processo de assoreamento, tanto experimental como simulado, foi atingido com um parâmetro de resistência para materiais como vidro e plástico. O ideal, para melhor representação de um assoreamento real, seria que o fundo da armadilha fosse construído ou coberto com o mesmo material do sedimento usado para assoreamento, ou ao menos com material de parâmetro de resistência semelhante. Isso seria possível caso grãos de 
areia (usada no assoreamento) fossem colados ao fundo e às paredes da armadilha, como uma rugosidade artificial. Essa metodologia não foi usada, pois impediria o uso da técnica de velocimetria a laser para observação do padrão do escoamento na armadilha. Como já comentado, nessa técnica, uma câmera digital é posicionada sob o fundo da armadilha e necessita da transparência do fundo para capturar imagens do escoamento.

Adotou-se, para a armadilha em acrílico, $\mathrm{M}=100$, com $\mathrm{M}=1 / \mathrm{n}$ e $\mathrm{n}=0,010$ para vidro ou plástico (CHANG, 1998), como mostrado na Figura 37.

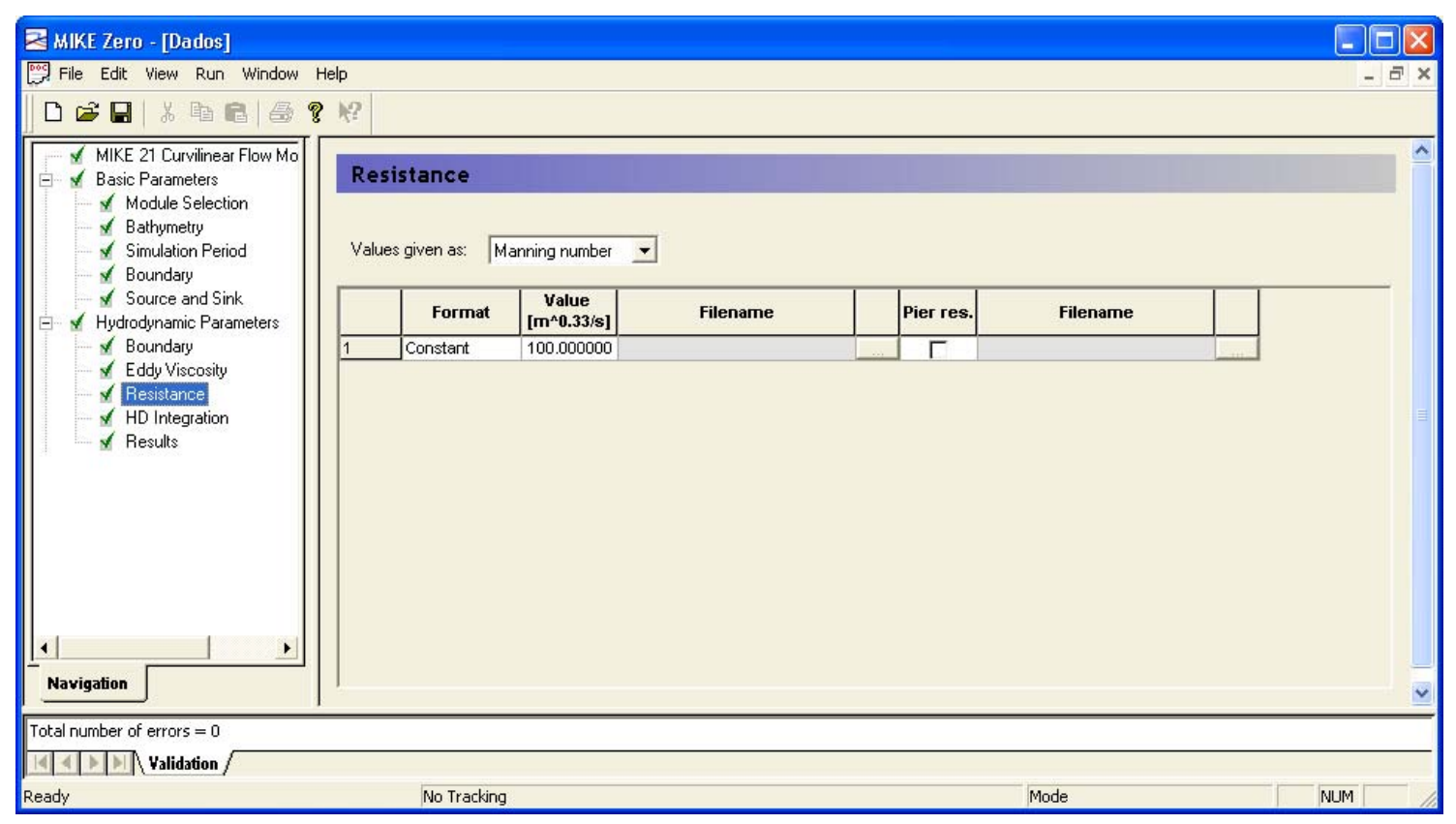

Figura 37 - Parâmetro de resistência do escoamento.

Os resultados da simulação são gravados a cada 100 passos (10s), para diminuição dos arquivos armazenados. A tela de configuração do arquivo de resultados é apresentada na Figura 38. 


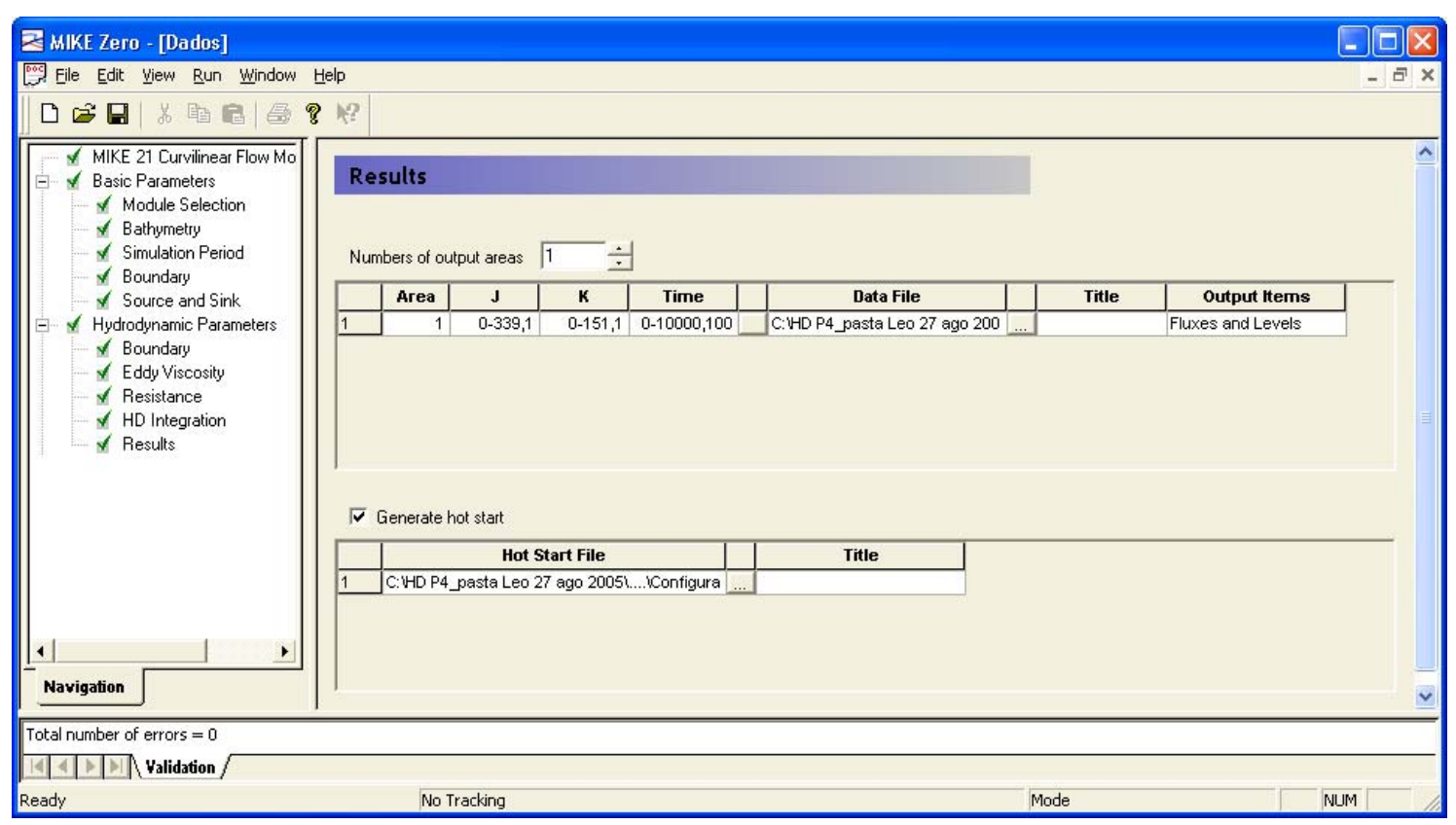

Figura 38- Tela de configuração do arquivo de resultados da simulação.

\subsubsection{Simulação do assoreamento}

Nessa etapa, a simulação hidrodinâmica da Configuração 1 foi usada para dar início à simulação do assoreamento. Porém, com a malha de discretização do domínio com $1 \mathrm{~cm}$ de lado, o tempo de trabalho computacional mostrou-se muito longo, visto que para cada atualização da geometria da armadilha, a hidrodinâmica do escoamento é recalculada na simulação do assoreamento. A simulação hidrodinâmica foi então refeita para uma malha de $3 \mathrm{~cm}$ de lado. $O$ padrão do escoamento resultante não foi alterado, quando comparado com àquele realizado com a malha de $1 \mathrm{~cm}$, significando que, mesmo com uma malha mais grosseira, o padrão do escoamento real foi bem representado. Outro fato que levou ao uso de uma malha menos refinada foi o grande número de simulações preliminares, da ordem de centenas, necessárias para conhecimento do programa, análise de sensibilidade e calibração dos parâmetros de entrada do MIKE $21 \mathrm{C}$.

Com a nova malha, de 5250 células, pôde-se incluir na simulação todo o trecho de $1,5 \mathrm{~m}$ do canal de entrada afetado pelo assoreamento, sem aumento significativo do tempo de processamento. A nova malha é ilustrada na Figura 39. 


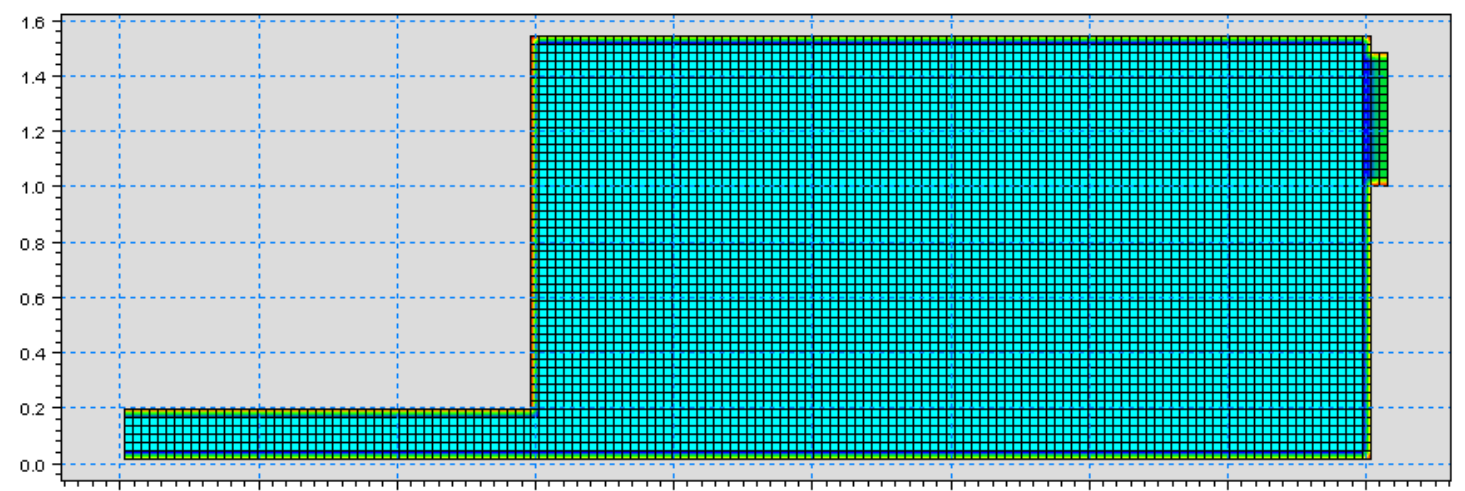

Figura 39- Malha usada na simulação do assoreamento, com células de $3 \mathrm{~cm}$ de lado.

Esta malha ainda é relativamente fina, se comparada às malhas das modelagens de transporte de sedimentos apresentadas na revisão da literatura.

Os parâmetros de entrada do MIKE 21C para essa etapa da simulação são apresentados a seguir, acompanhados de ilustrações da interface do programa.

Incluiu-se o módulo morfológico na simulação do assoreamento, com o esquema Ultimate para a equação de advecção-dispersão de sedimentos (Figura 40). O esquema Quickest, apresentado como padrão quando se inicia o programa, apresentou certa instabilidade numérica, com valores de transporte de sedimentos em algumas regiões da armadilha não condizentes com a realidade.

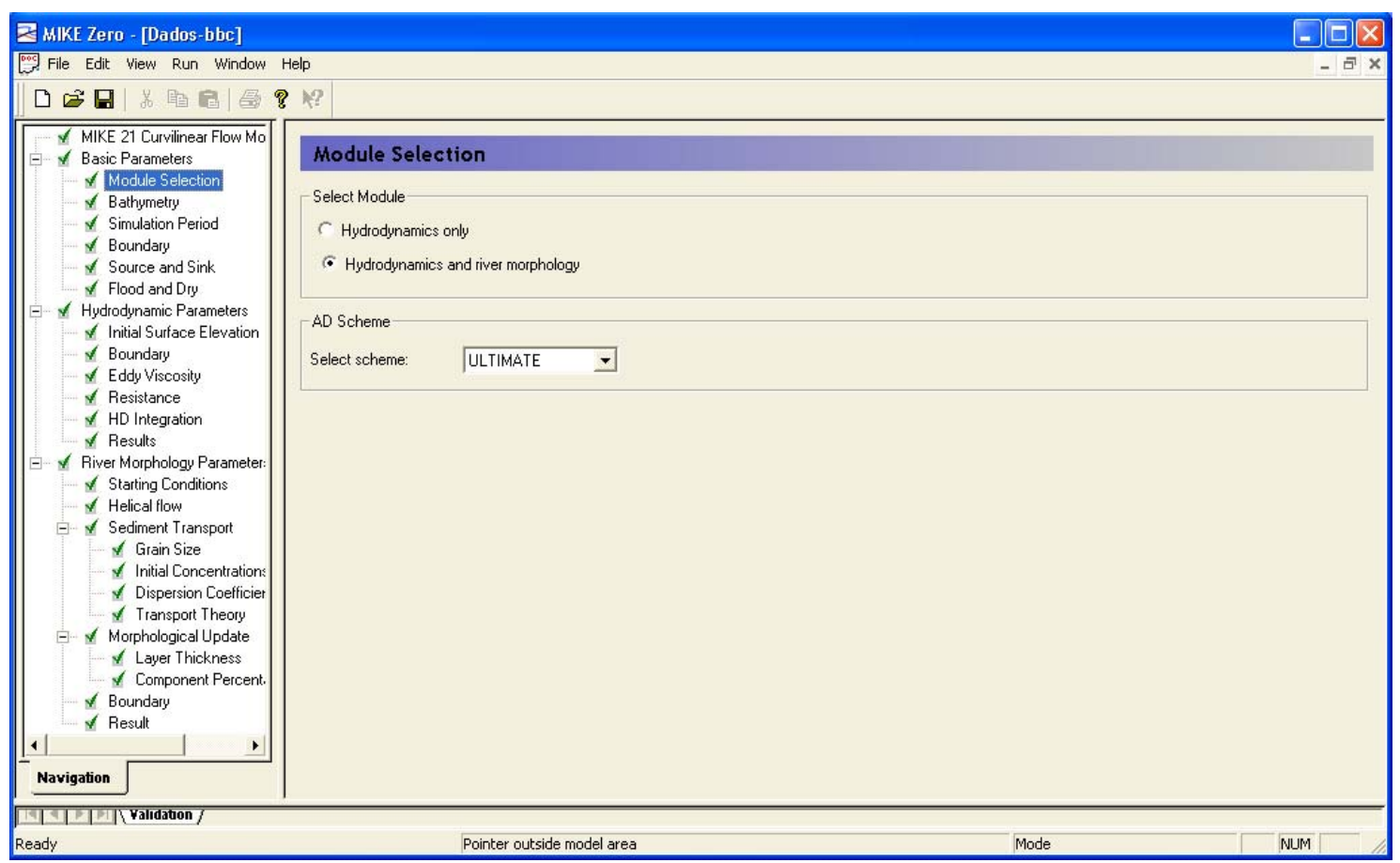

Figura 40 - Módulo morfológico na simulação do assoreamento, com o esquema Ultimate para solução da equação de advecção-dispersão de sedimentos. 
O passo de tempo para a solução das equações hidrodinâmicas do escoamento continuou igual a $0,01 \mathrm{~s}$. O passo de tempo para o equacionamento do transporte de sedimentos foi definido 10s. Isso significa que a geometria (batimetria) da armadilha é atualizada a cada 1000 passos de cálculo do escoamento. A simulação foi realizada para um tempo real de assoreamento de $72 \mathrm{~h}$, como mostrado na Figura 41.

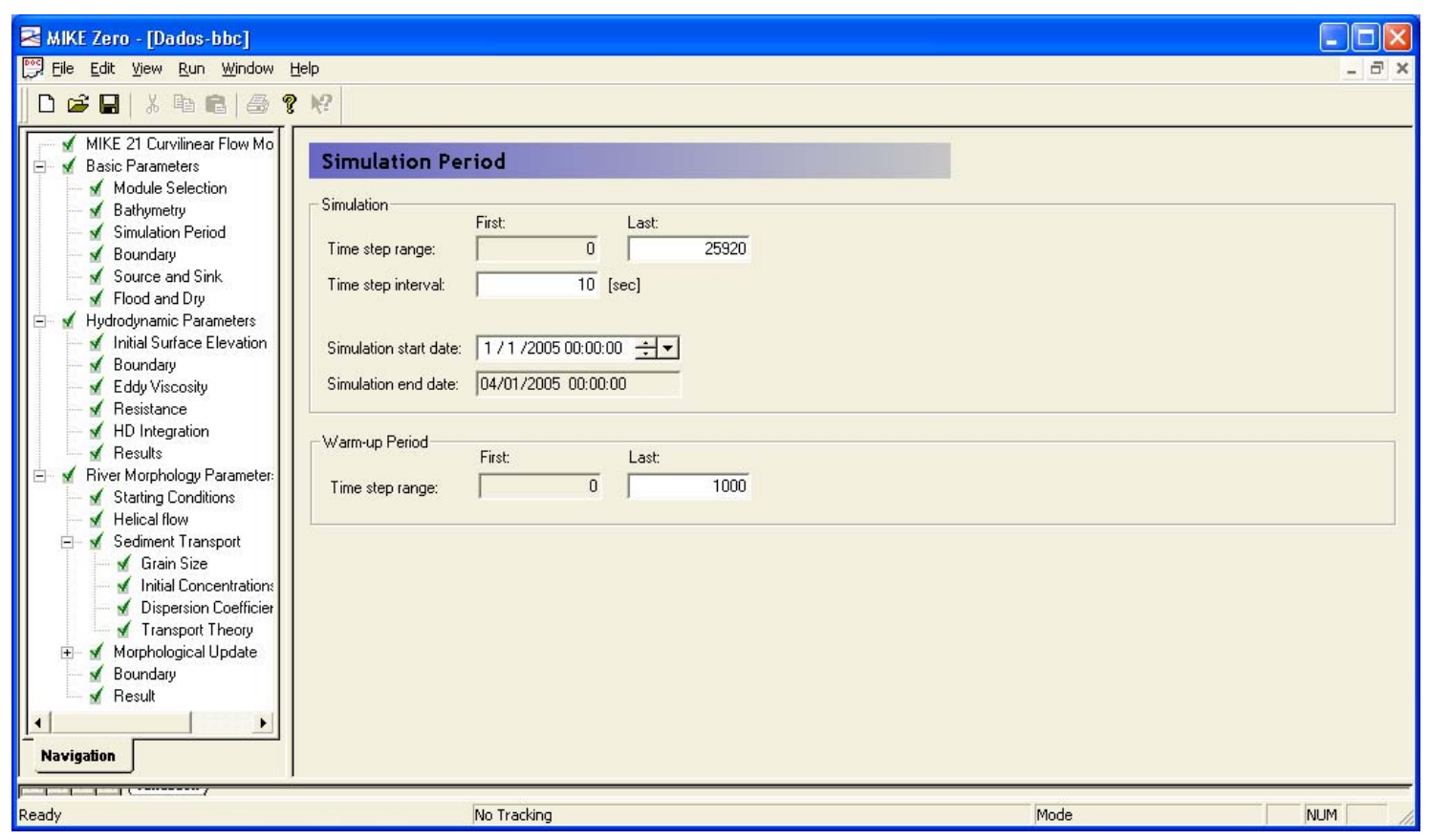

Figura 41 - Definição do período de simulação e do passo no tempo do transporte de sedimentos.

A ferramenta flood and dry (Figura 42) foi acionada para que regiões da armadilha pudessem ser consideradas secas, caso a altura do escoamento de tornasse inferior a $0,002 \mathrm{~m}$, e ser consideradas molhadas, caso a altura do escoamento sobre regiões secas superasse $0,003 \mathrm{~m}$. Esses parâmetros definem quando uma célula será excluída ou incluída no cálculo computacional, e são diferentes para se evitar instabilidades no modelo. 


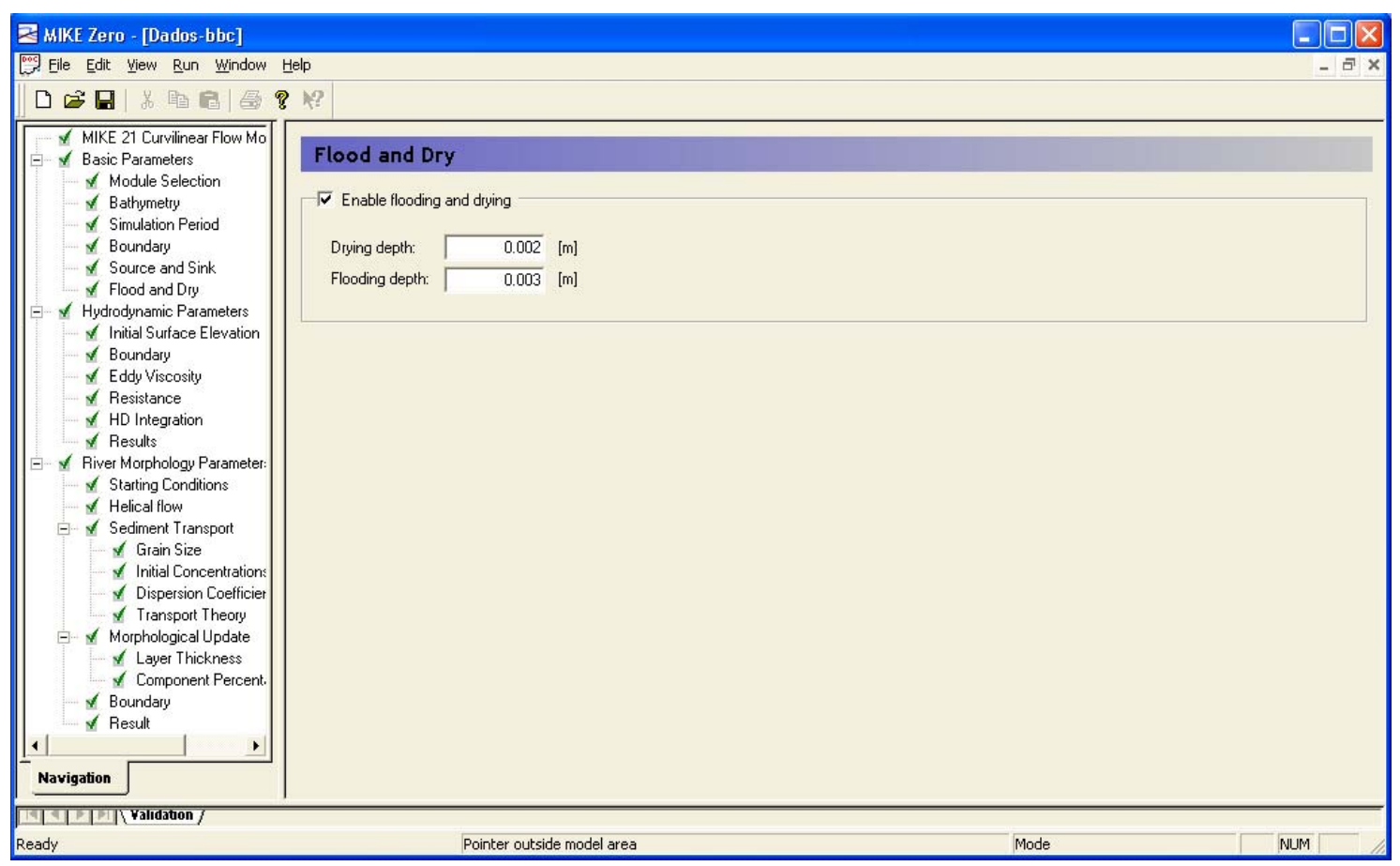

Figura 42 - Ferramenta flood and dry, usada para que uma célula seja excluída ou incluída no cálculo computacional, de acordo com a altura de água.

A definição da viscosidade cinemática turbulenta do escoamento é um dois parâmetros de maior influência nos resultados da simulação. Para a etapa de simulação hidrodinâmica, anterior ao processo do assoreamento, a viscosidade foi calculada pelo modelo de turbulência de Smagorinsky (Figura 36). Inicialmente, a simulação do assoreamento foi realizada com a viscosidade calculada também dessa forma. Porém, observou-se nos resultados que a variação da viscosidade turbulenta simulada não acompanhou o aumento da viscosidade turbulenta experimental. Na realidade, o aumento da intensidade turbulenta foi causado pelo aumento da velocidade do escoamento (menor seção transversal devido ao assoreamento) e pelas dunas de areia formadas. Na modelagem, um assoreamento médio foi gerado, e o aumento da intensidade turbulenta (relacionada à viscosidade turbulenta) levou em consideração apenas o aumento da velocidade e não a agitação do fluido causada pelo escoamento sobre as dunas. Impôs-se, por isso, uma viscosidade cinemática turbulenta constante e igual a $0,01 \mathrm{~m}^{2} / \mathrm{s}$, para todo o período de simulação do assoreamento (Figura 43).

Nota-se que, a partir deste ponto do trabalho, a etapa de simulação hidrodinâmica com uso do modelo de Smagorinsky, realizada a princípio para dar início à simulação do assoreamento, passou a ser usada apenas para avaliação da capacidade do programa em representar os padrões da Configuração 1 e da Configuração 2 de escoamento, sem 
sedimento. Imagens do assoreamento com o modelo de Smagorinsky são mostradas no capítulo de resultados, apesar de não fazerem parte dos resultados finais do trabalho.

$\mathrm{O}$ uso de viscosidade constante tem sido feito para escoamentos turbulentos e gerado bons resultados não apenas neste trabalho, mas também nos trabalhos de transporte de sedimentos desenvolvidos pela DHI Water and Environment, apresentados em DHI (2005).

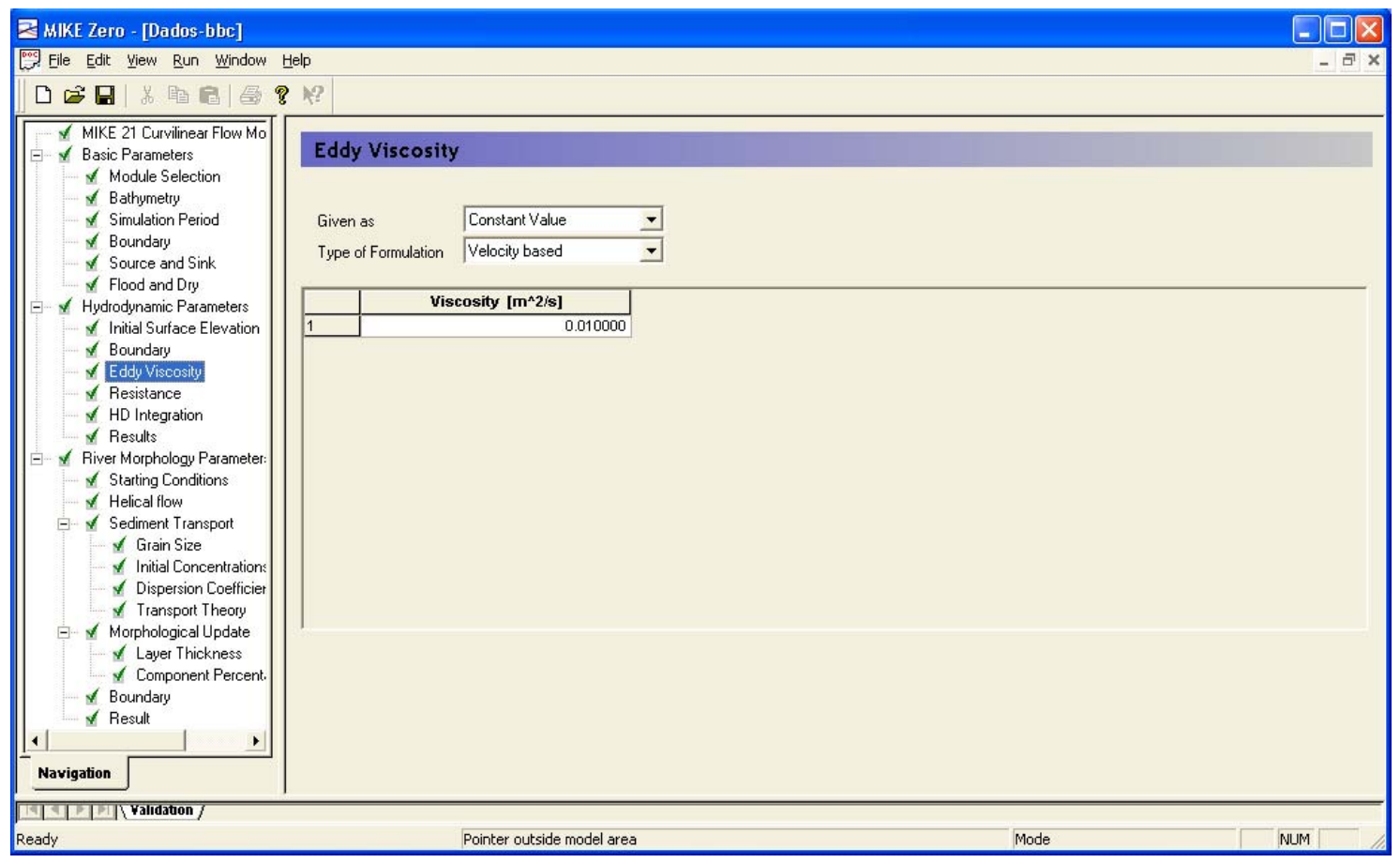

Figura 43 - Viscosidade turbulenta constante e igual a $0,01 \mathrm{~m}^{2} / \mathrm{s}$, para a simulação do assoreamento.

A resistência ao escoamento foi especificada através do coeficiente de Strickler, definido em $50 \mathrm{~m}^{1 / 3} / \mathrm{s}$, por calibração. Essa resistência é aumentada com a elevação do fundo e diminuição da altura de água, na forma da Equação (7). O escoamento helicoidal foi incorporado à modelagem através de um parâmetro que mede sua influência no cálculo do transporte de sedimentos. Definiu-se o valor 1 (um) para esse parâmetro, através de calibração, correspondente a 100\% de intensidade e mostrando sua importância no auxílio da modelagem bidimensional para representação de escoamentos reais (tridimensionais) envolvendo transporte de sedimentos.

A granulometria da areia foi especificada através do $d_{50}$ igual a $0,12 \mathrm{~mm}$. A equação de transporte que mais se adequou ao trabalho foi Engelund and Fredsøe (1976). O uso de qualquer outra equação disponível no programa, de transporte total ou com equacionamentos separados para sedimentos de fundo e em suspensão, modificou 
consideravelmente os resultados, que não mostraram semelhança satisfatória com os resultados experimentais.

As condições de contorno para entrada de sedimentos na estrutura (Figura 44) foram concentração constante no canal de entrada, de $1000 \mathrm{~g} / \mathrm{m}^{3}$, e concentração nula no vertedor, caso haja fluido entrando na armadilha pelo vertedor. Nada impede, contudo, que qualquer concentração saia no escoamento sobre essa estrutura.

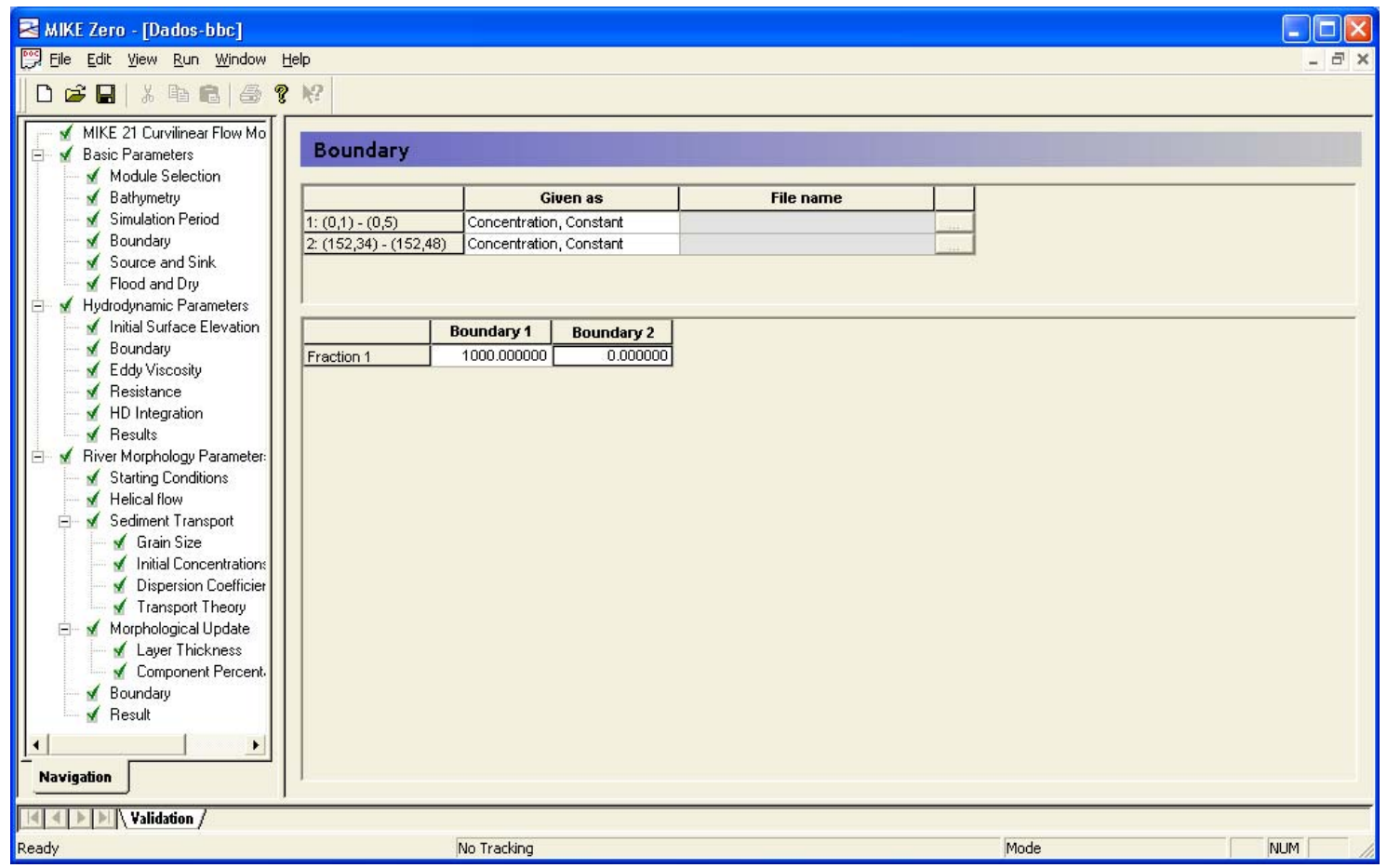

Figura 44 - Condições de contorno do problema, para o transporte de sedimentos. Concentração de areia constante no canal de entrada, de 1000g/L. 


\section{RESULTADOS E DISCUSSÃO}

Neste capítulo, os resultados referentes ao padrão do escoamento e ao assoreamento da armadilha, obtidos experimentalmente e numericamente, são discutidos e comparados.

\subsection{Padrão do escoamento}

Analisa-se duas configurações de escoamento: a Configuração 1, usada posteriormente para assoreamento da armadilha, e a Configuração 2, apenas para testar a capacidade do programa MIKE 21C em simular diferentes padrões de escoamento.

\subsubsection{Configuração 1}

Os resultados referentes a experimento e simulação do escoamento para apenas um canal afluente, com vazão constante de $2 \mathrm{~L} / \mathrm{s}$, são apresentados e discutidos.

\subsubsection{Experimento}

Os campos de velocidade média obtidos para as regiões de estudo com velocimetria permitem que se faça uma análise do campo em toda a armadilha. Pode-se com isso estimar o início do assoreamento, pois o campo de velocidade durante as primeiras horas desse processo não se altera consideravelmente com um pequeno volume de sedimentos depositado. Adicionalmente, esses campos são úteis na validação da simulação hidrodinâmica realizada para a Configuração 1 do escoamento, que antecede a simulação do assoreamento. Os campos de velocidade média são ilustrados nas Figuras 45 - 52. A escala de cores da componente longitudinal da velocidade, ilustrada na Figura 21, é repetida a seguir. 


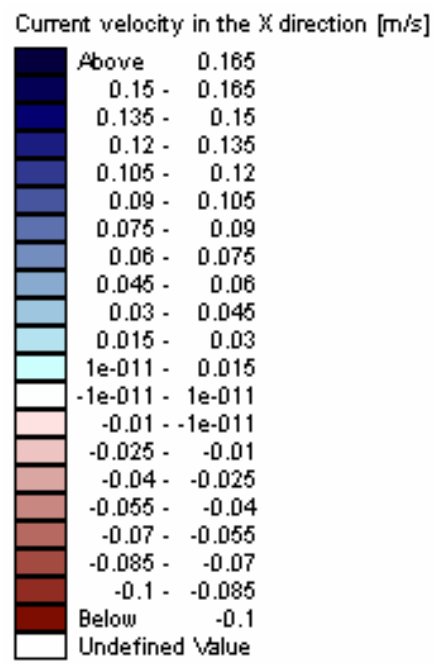

Figura 21 - Escala de cores dos campos da Figura 20, referente à componente da velocidade na direção longitudinal da armadilha (direção horizontal nas figuras).

Na região 1 (Figura 45), observa-se em sua parte inferior (da figura, pois na realidade a região está no plano horizontal) um escoamento de velocidade horizontal relativamente grande, bem como uma mudança de direção do escoamento que chega da parte superior e passa a seguir para a direita. Na região 2, nota-se um escoamento com linhas de corrente paralelas e horizontais, com um gradiente vertical de velocidade.
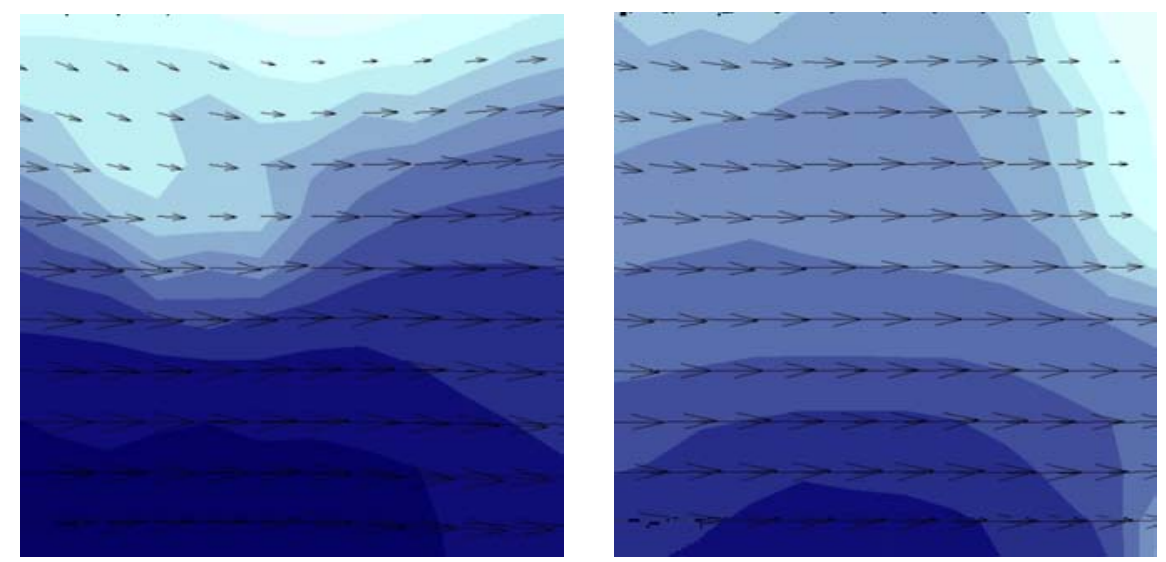

Figura 45 - Campos de velocidade média das regiões 1 e 2 , respectivamente, para a Configuração 1 do escoamento.

Nas regiões 3 e 4 da Figura 46 tem-se, para a região 3, linhas de corrente paralelas, porém com uma pequena mudança de direção do escoamento, para cima, no lado direito da figura. Há também uma diminuição da velocidade do escoamento da esquerda para a direita. $\mathrm{Na}$ região 4 , próxima à união das paredes da armadilha, em ângulo reto, existe uma recirculação do fluido no sentido horário. 

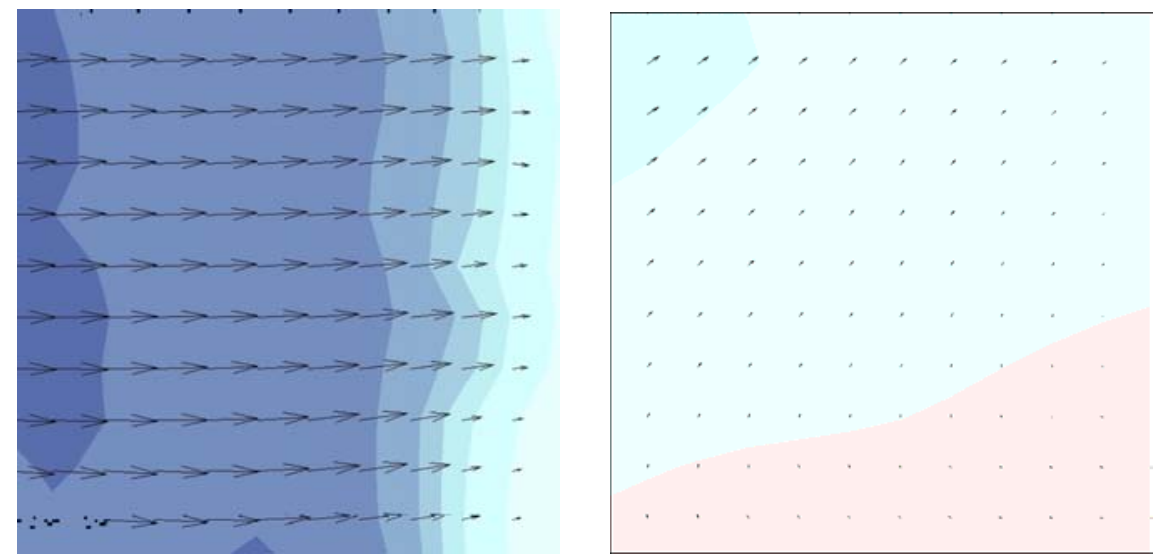

Figura 46 - Campos de velocidade média das regiões 3 e 4, respectivamente, para a Configuração 1 do escoamento.

Na Figura 47, tem-se um escoamento descendente na região 5, fazendo uma curva para a direita para atingir o escoamento praticamente horizontal da região 6. As regiões 7 e 8, da Figura 48, demonstram a continuação dessa grande zona de recirculação de fluido no sentido horário.
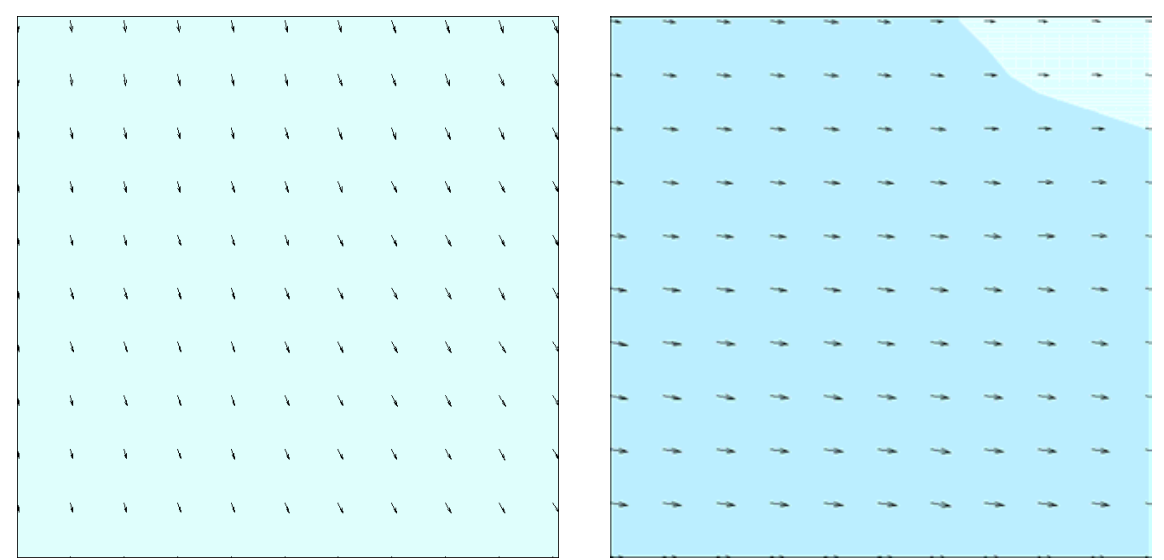

Figura 47 - Campos de velocidade média das regiões 5 e 6 , respectivamente, para a Configuração 1 do escoamento.
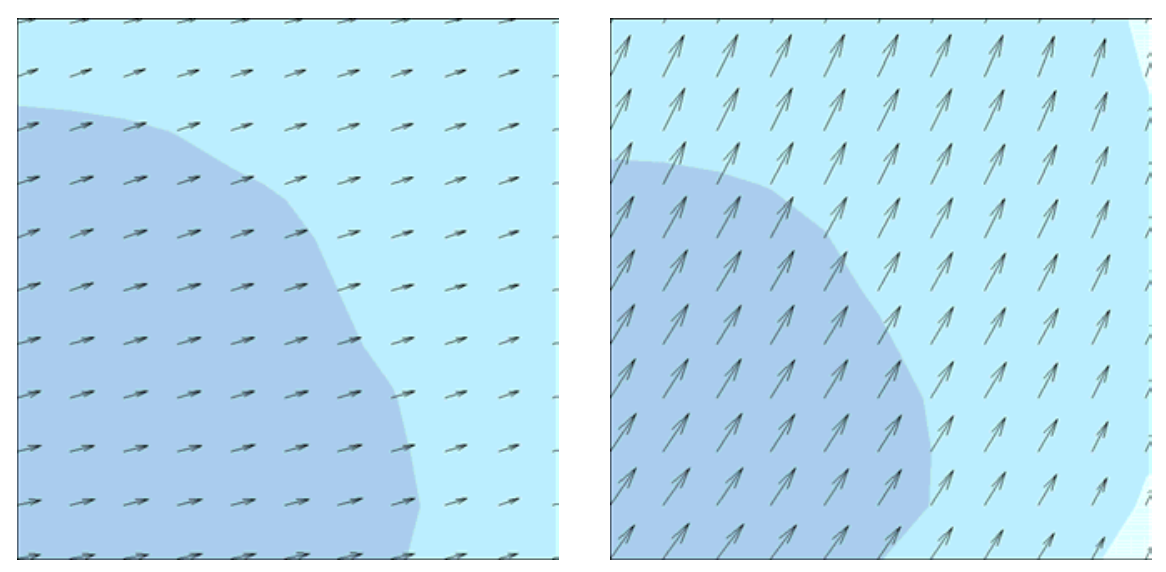

Figura 48 - Campos de velocidade média das regiões 7 e 8 , respectivamente, para a Configuração 1 do escoamento. 
Acompanhando o escoamento proveniente da região 8 e não seguindo a numeração crescente das regiões, nota-se que as regiões 11, 10 e 9 (Figuras 49 e 50) ilustram bem o fechamento dessa grande zona de recirculação.
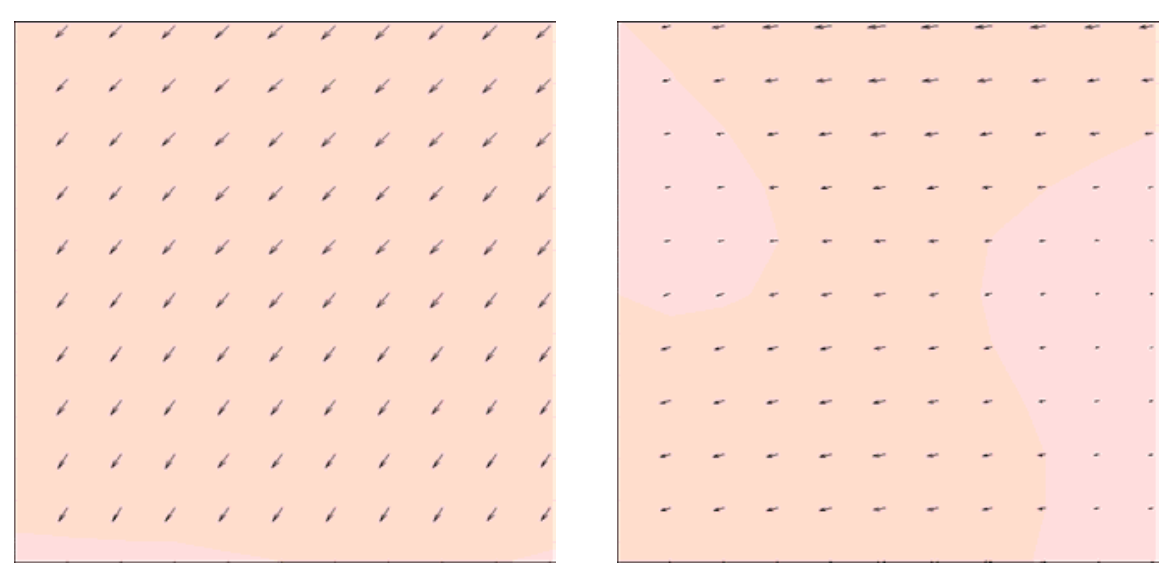

Figura 49 - Campos de velocidade média das regiões 9 e 10, respectivamente, para a Configuração 1 do escoamento.

Na região 12 (Figura 50), há parte do escoamento se dirigindo para a direita, em direção ao vertedor. A porção de fluido do lado esquerdo da região segue, em média, uma caminho vertical para se dirigir ás regiões 15, 14 e 13, nesta ordem, e fazer parte da grande zona de recirculação. A Figura 51 ilustra, para a região 13, uma pequena recirculação de fluido no sentido horário, causada pela junção de duas paredes da armadilha, como na região 4.
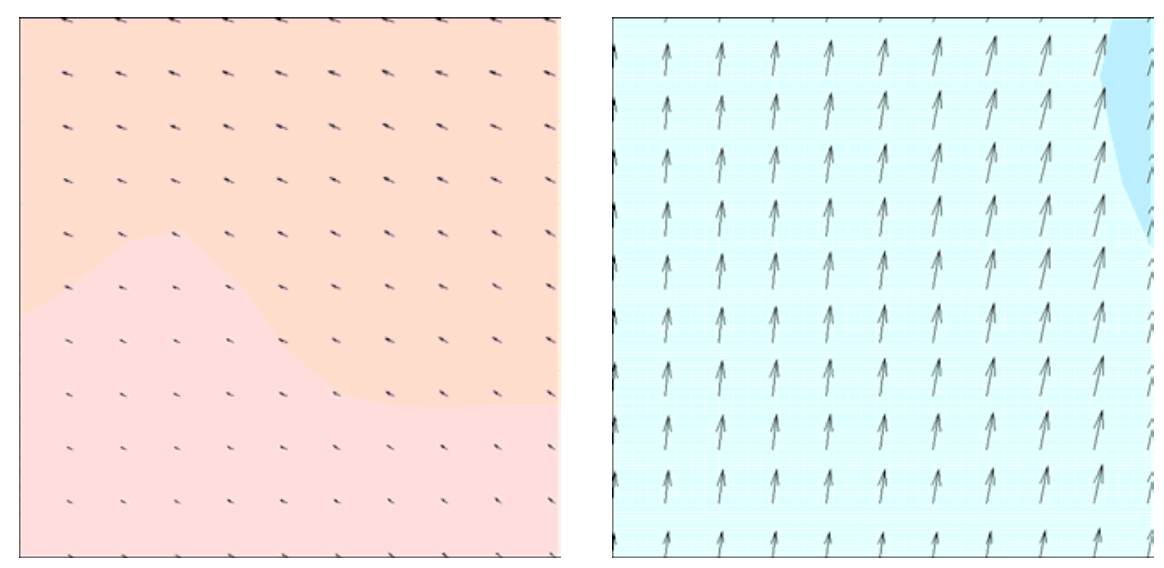

Figura 50 - Campos de velocidade média das regiões 11 e 12, respectivamente, para a Configuração 1 do escoamento. 

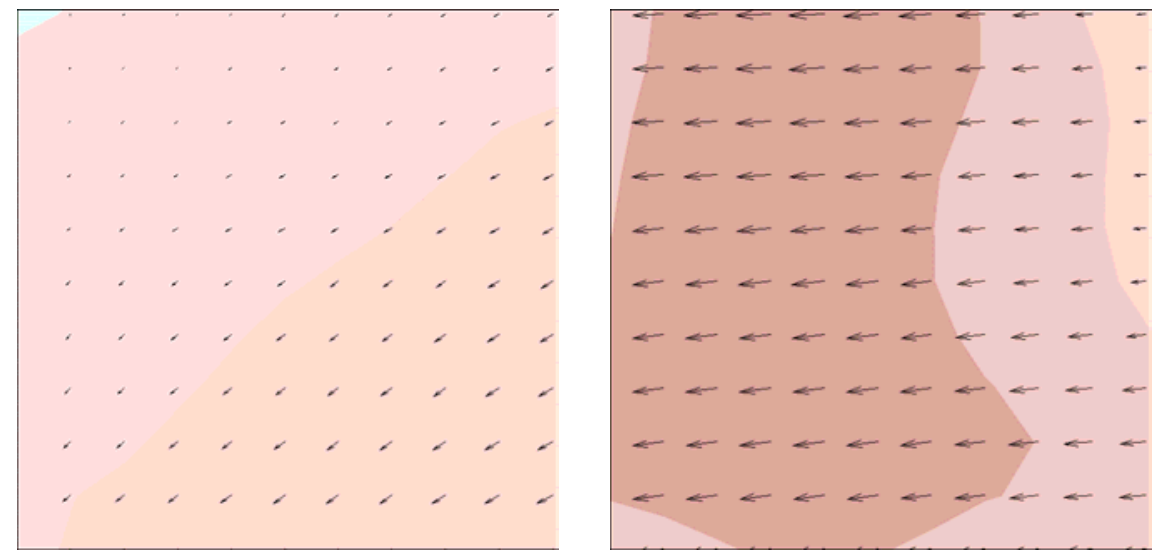

Figura 51 - Campos de velocidade média das regiões 13 e 14, respectivamente, para a Configuração 1 do escoamento.

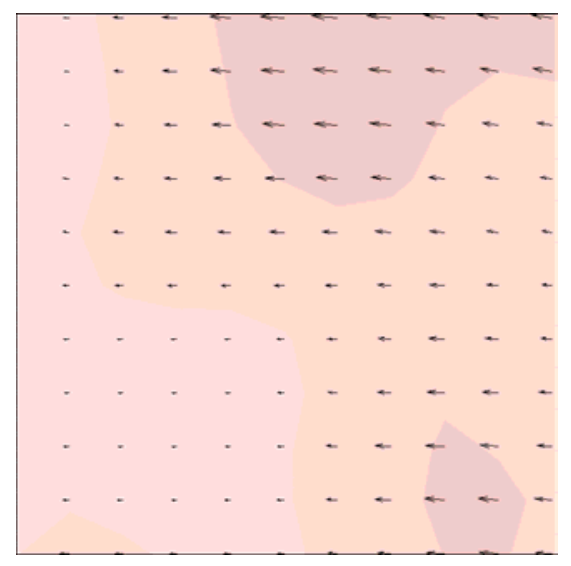

Figura 52 - Campo de velocidade média da região 15 , para a Configuração 1 do escoamento.

Com base nos campos de velocidade média, o padrão do escoamento médio em toda a armadilha é esboçado na Figura 53. Os vetores velocidade média são representados, de forma simplificada, sobre cada região.

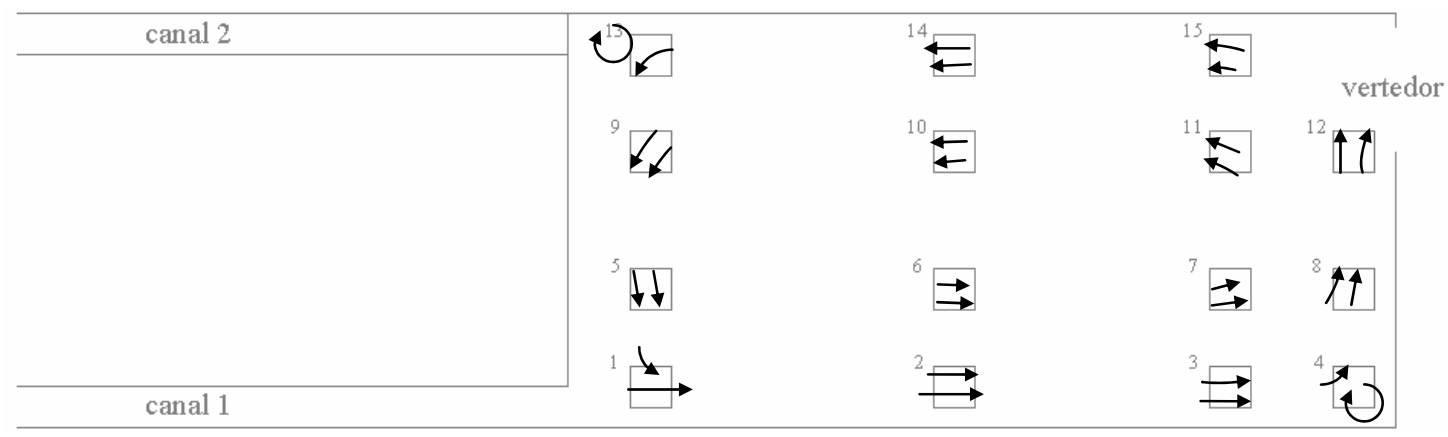

Figura 53 - Padrão do escoamento médio na armadilha, para a Configuração 1. 
Observa-se que o caminho preferencial do fluido, a partir de sua entrada na armadilha através do canal 1, não segue a linha de menor distância entre o canal 1 e o vertedor, para a vazão definida no experimento. Seu caminho passa pelas regiões 1, 2, 3, 8 e 12. Próximas às regiões 4 e 13 encontram-se duas pequenas áreas de recirculação de fluido, conseqüência do ângulo formado pela junção das paredes. A área formada pelas outras regiões mantém uma grande zona de recirculação, um vórtice da escala de comprimento da geometria da armadilha.

\subsubsection{Simulação}

A simulação hidrodinâmica foi realizada partindo-se com o fluido em repouso na armadilha até que o escoamento atingisse regime permanente. Nota-se que, mesmo durante regime permanente, há variação de velocidade, resultado da flutuação da velocidade instantânea em torno de uma média temporal. Assim, tem-se que o regime permanente é atingido para o escoamento médio na armadilha; e as flutuações de velocidade são geradas pelo modelo de turbulência de Smagorinsky. As Figuras 54-56 mostram instantes da simulação da Configuração 1, para 80000, 90000 e 100000 passos no tempo, referindo-se respectivamente a $13 \mathrm{~min} 20 \mathrm{~s}$, $15 \mathrm{~min}$ e $16 \mathrm{~min} 40 \mathrm{~s}$ de escoamento, quando já se havia estabelecido o regime permanente. O padrão médio do escoamento (Figura 57) foi obtido a partir dos dados de velocidade instantânea da simulação, através de trabalho de programação. As regiões analisadas em laboratório são sobrepostas na Figura 57 para que experimento e simulação possam ser comparados.

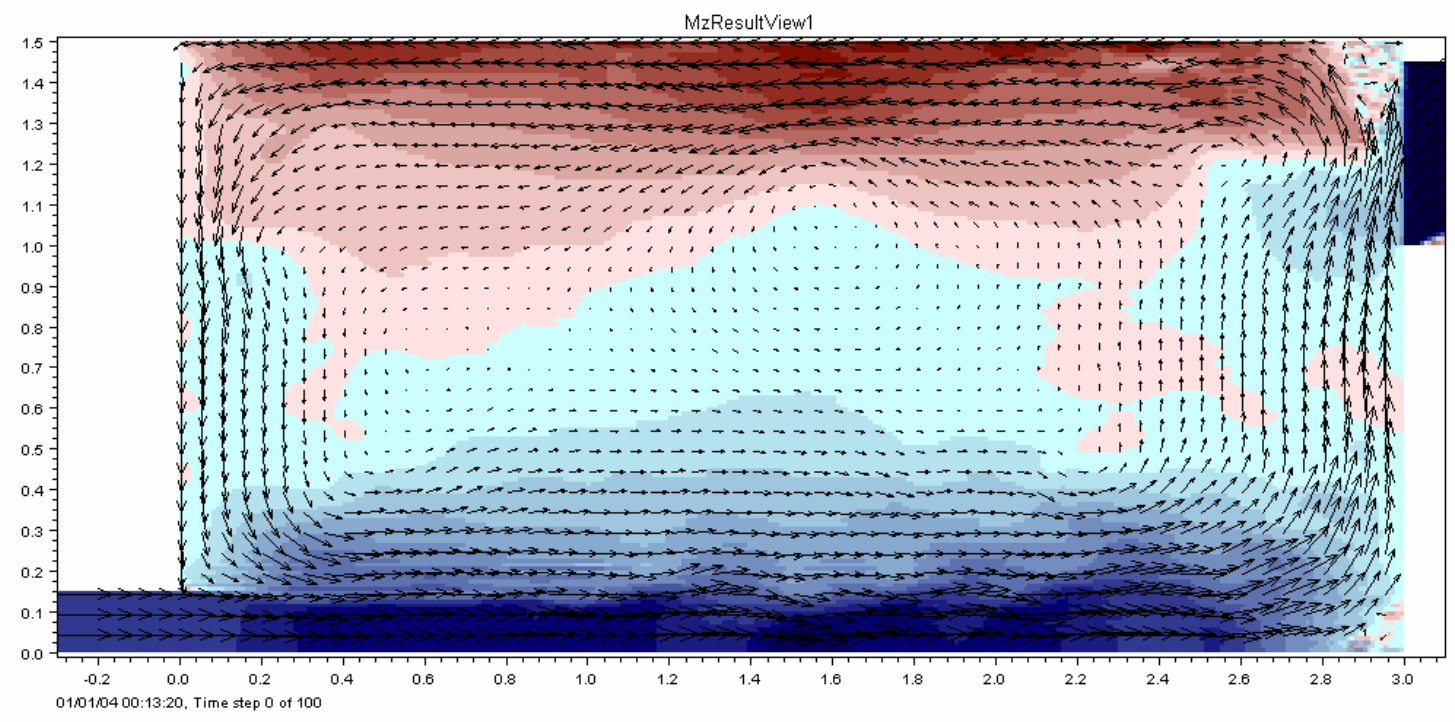

Figura 54 - Instante da simulação computacional para a Configuração 1, referente a $13 \mathrm{~min} 20 \mathrm{~s}$ de escoamento. 


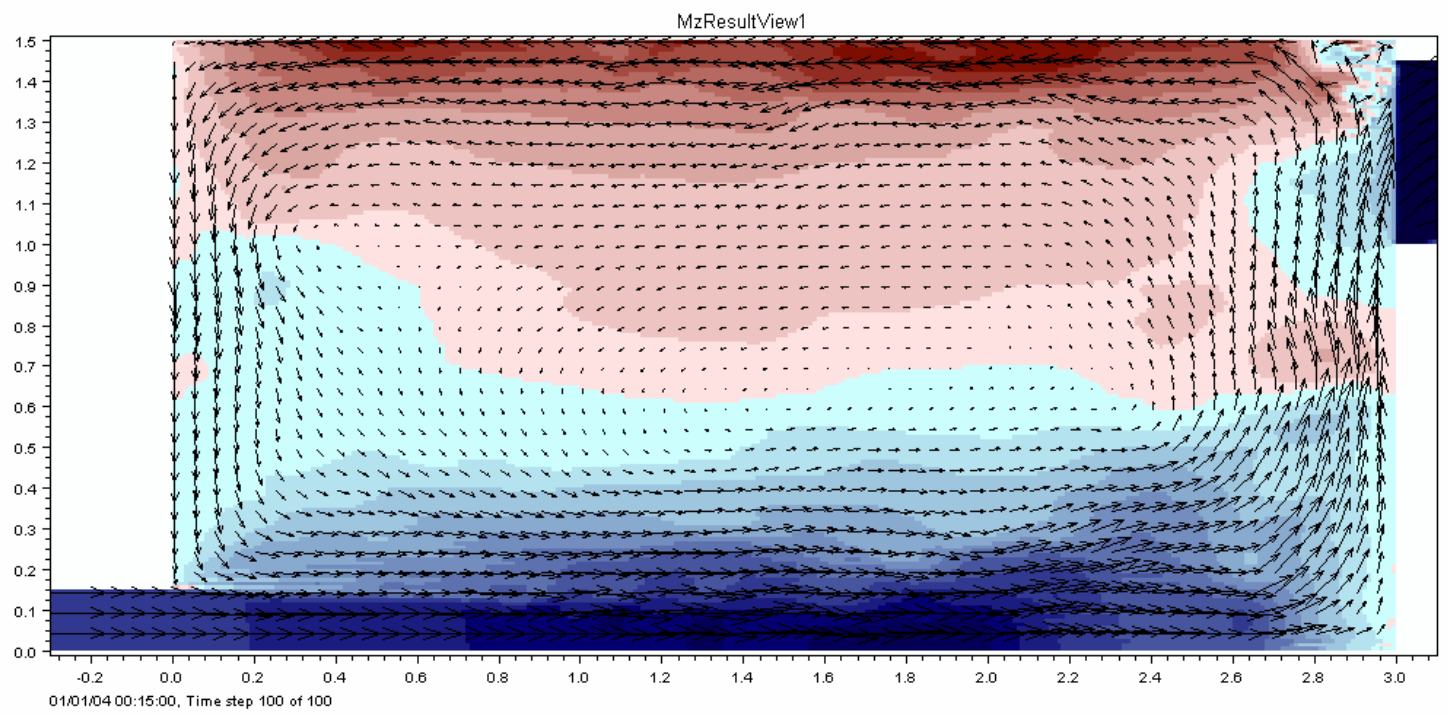

Figura 55 - Instante da simulação computacional para a Configuração 1, referente a $15 \mathrm{~min}$ de escoamento.

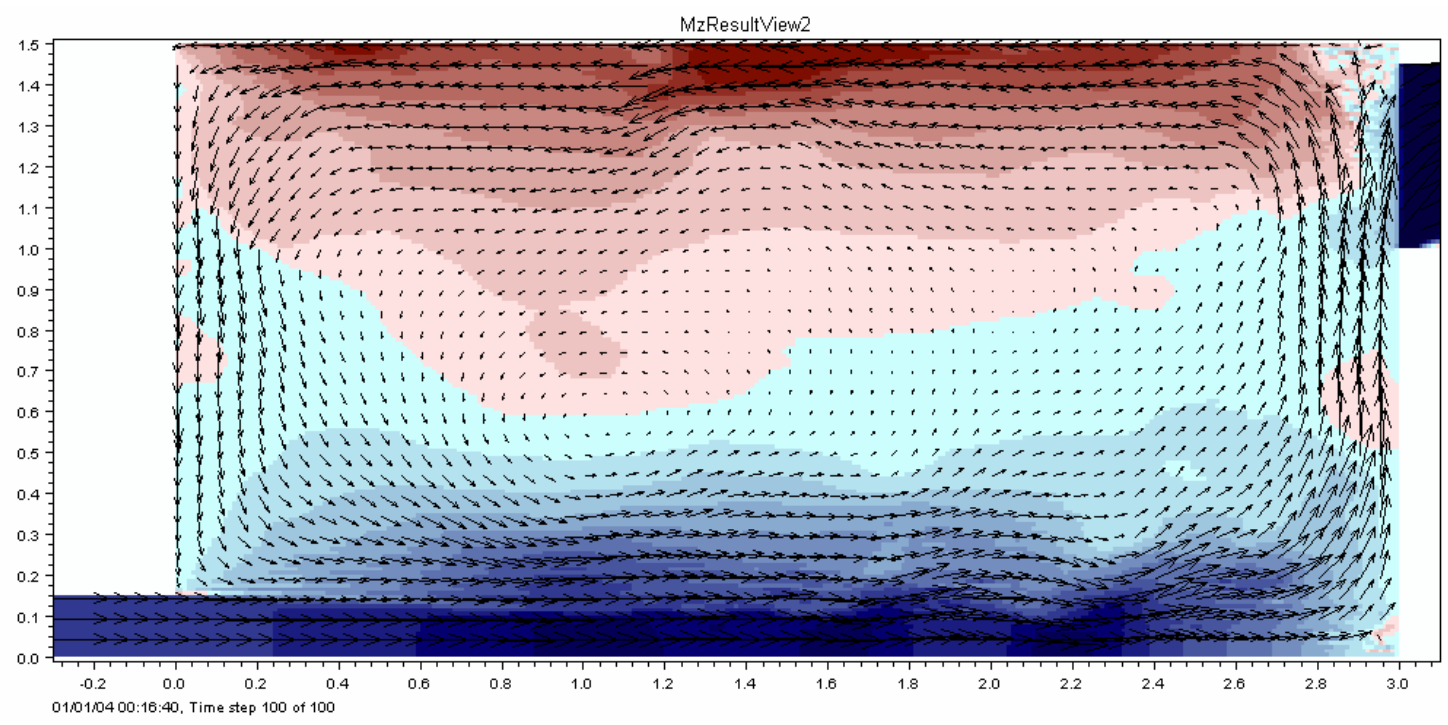

Figura 56 - Instante da simulação computacional para a Configuração 1, referente a $16 \mathrm{~min} 40$ s de escoamento. 


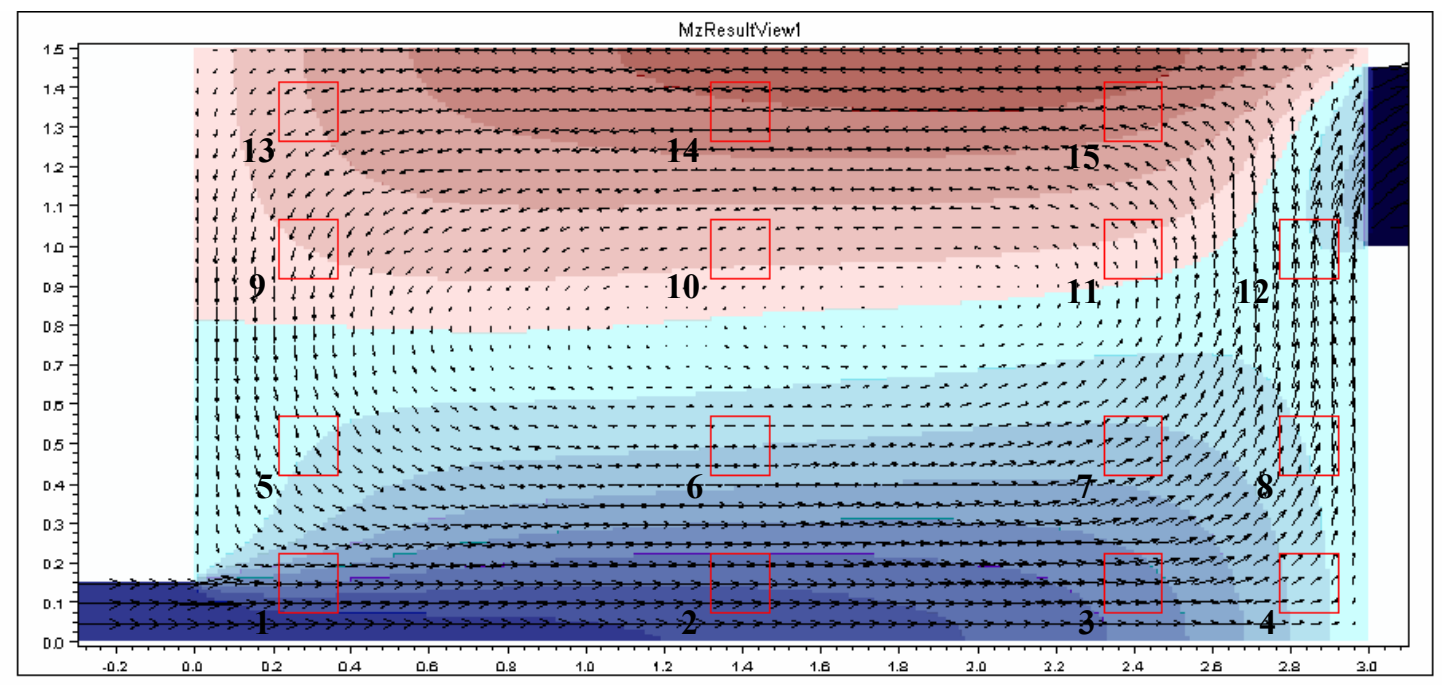

Figura 57 - Padrão médio do escoamento da Configuração 1.

$\mathrm{Na}$ Figura 57, nota-se semelhança da simulação com os resultados experimentais, mostrando uma grande zona de recirculação e o fluido que adentra a armadilha seguindo o caminho que passa pelas regiões $1,2,3,8$ e 12. Tanto para a direção dos vetores quanto para a magnitude da componente longitudinal da velocidade (de acordo com a escala de cores), tem-se boa representação do escoamento pela modelo.

No vídeo da simulação referente às Figuras 54-56, contido na PASTA 5_SIMULAÇÃO_VÍDEOS DO ESCOAMENTO_Configuração 1 do DVD, os vórtices de menor escala de comprimento, que são transportados na região de grande recirculação da armadilha, podem ser observados com clareza. Próximo às regiões 4 e 13, as pequenas recirculações de fluido, causadas pelas junções das paredes, mostraramse menores na simulação. Esse fato deve-se, provavelmente, à falta da condição de nãoescorregamento do fluido junto às paredes na simulação. Isso faz com que o escoamento proveniente dos canais afluentes chegue próximo às junções das paredes com velocidade máxima nas células adjacentes às paredes, portanto com maior inércia que o escoamento real, diminuindo assim as recirculações.

O escoamento médio da simulação realizada com modelagem da turbulência com o conceito de Smagorinsky se assemelha a um escoamento com viscosidade turbulenta constante, na faixa de $0,001 \mathrm{~m}^{2} / \mathrm{s}$ (mostrado mais adiante). Apenas como nota, essa simplificação, com uso de uma viscosidade turbulenta constante para todo o domínio, é apresentada por alguns autores, Olsen (2002) por exemplo, como opção de uma simulação mais simplificada e sem equacionamento para modelagem da 
turbulência. Obtém-se bons resultados com menor esforço computacional, quando se deseja analisar o comportamento médio do escoamento.

Observa-se na Figura 57 que existe transferência de quantidade de movimento, por difusão turbulenta, do fluido que entra pelo canal àquele mantido na grande zona de recirculação, alimentando seu movimento. Por outro lado, nota-se que os vetores velocidade apresentados nas regiões 1, 2 e 3 praticamente seguem a direção longitudinal da armadilha, iniciando uma mudança de direção apenas entre as regiões 3 e 4. Isso indica que as linhas de corrente do escoamento preferencial não divergem consideravelmente. Como o transporte advectivo é muito superior ao transporte difusivo de sedimentos, para o experimento em estudo, estima-se que o início do assoreamento siga o escoamento preferencial, próximo às paredes, sem muita difusão de sedimento no sentido transversal do escoamento.

Para apresentação neste texto de resultados quantitativos de velocidade instantânea, a Figura 58 traz gráficos da variação temporal da componente da velocidade instantânea no sentido longitudinal da armadilha, para experimento e simulação. Os gráficos referem-se ao ponto central da região 1 da Configuração 1 de escoamento. No gráfico experimental, 14 medidas de velocidade instantânea foram obtidas em um segundo, com uso de velocimetria laser. As linhas tracejadas na vertical representam as descontinuidades no processo de medição de velocidade, explicadas no item 4.1.2.1 Técnica de velocimetria a laser.

A velocidade média e o desvio padrão da velocidade instantânea em relação à média foram também calculados. O desvio padrão, porém, não deve ser tomado como critério na comparação, porque o número de medições de velocidade é diferente para experimento e simulação. Para os pontos centrais das demais regiões da Configuração 1 , os gráficos são mostrados no APÊNDICE C_FLUTUAÇÕES DE VELOCIDADE, para comparação. 

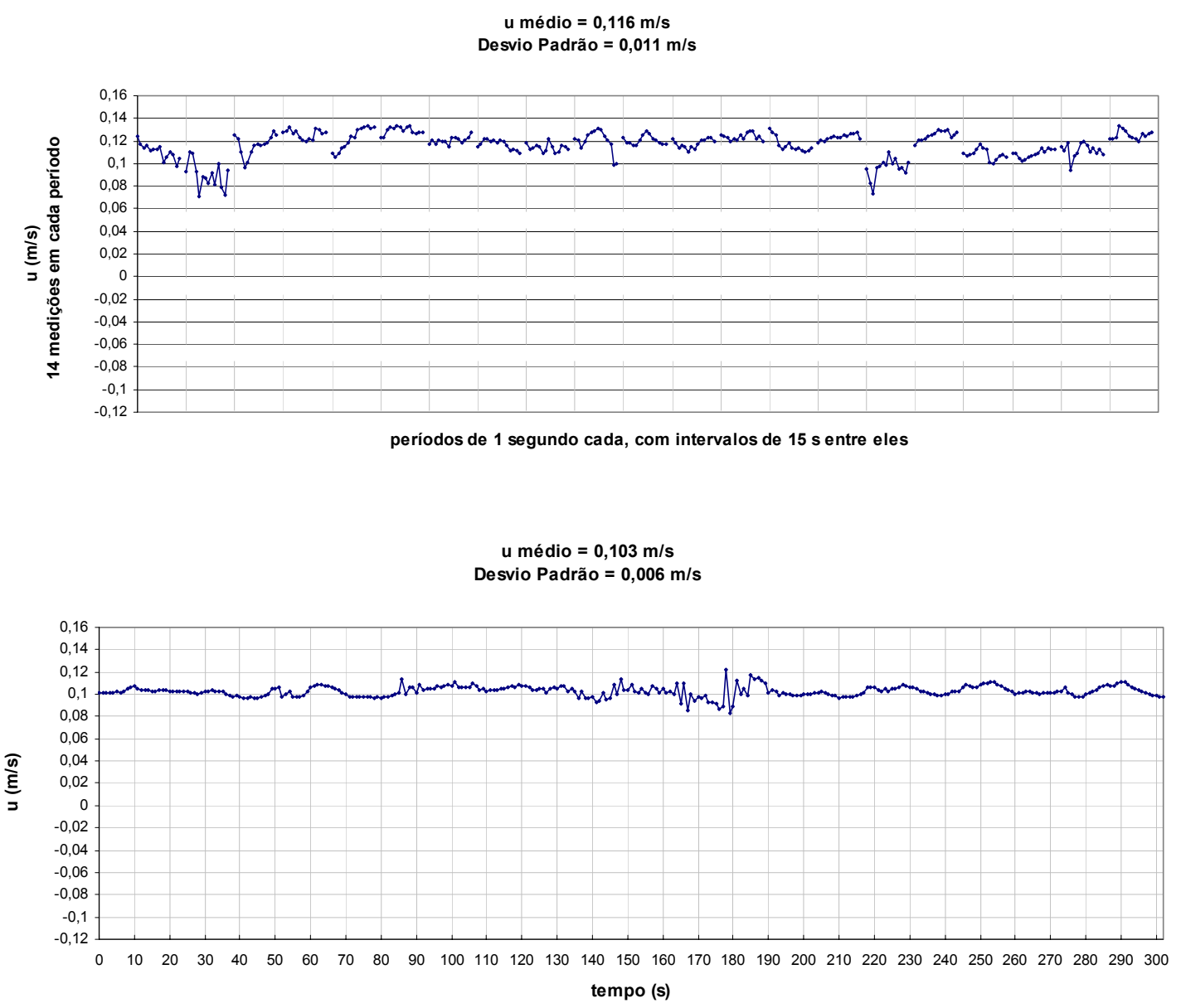

Figura 58 - Variação temporal da componente da velocidade instantânea no sentido longitudinal da armadilha, para um ponto central da região 1 na Configuração 1 do escoamento. $\mathrm{O}$ gráfico superior apresenta dados experimentais, e o inferior, o resultado simulado.

A relação entre a velocidade experimental e a velocidade simulada para o ponto central de cada região da Configuração 1 é mostrada na Figura 59. Como se trata de uma comparação pontual, portanto rigorosa, de velocidades e não de uma comparação de velocidades médias em uma seção do escoamento, pode-se obter resultados bem diferentes, devido aos gradientes de velocidade. Para a região 8, por exemplo, a velocidade média experimental chegou a 1,68 vez a velocidade simulada. Apesar da diferença de resultados, se considerada cada região como um todo (Figuras 45-52) e não apenas seu ponto central, nota-se boa semelhança entre experimento e simulação. 


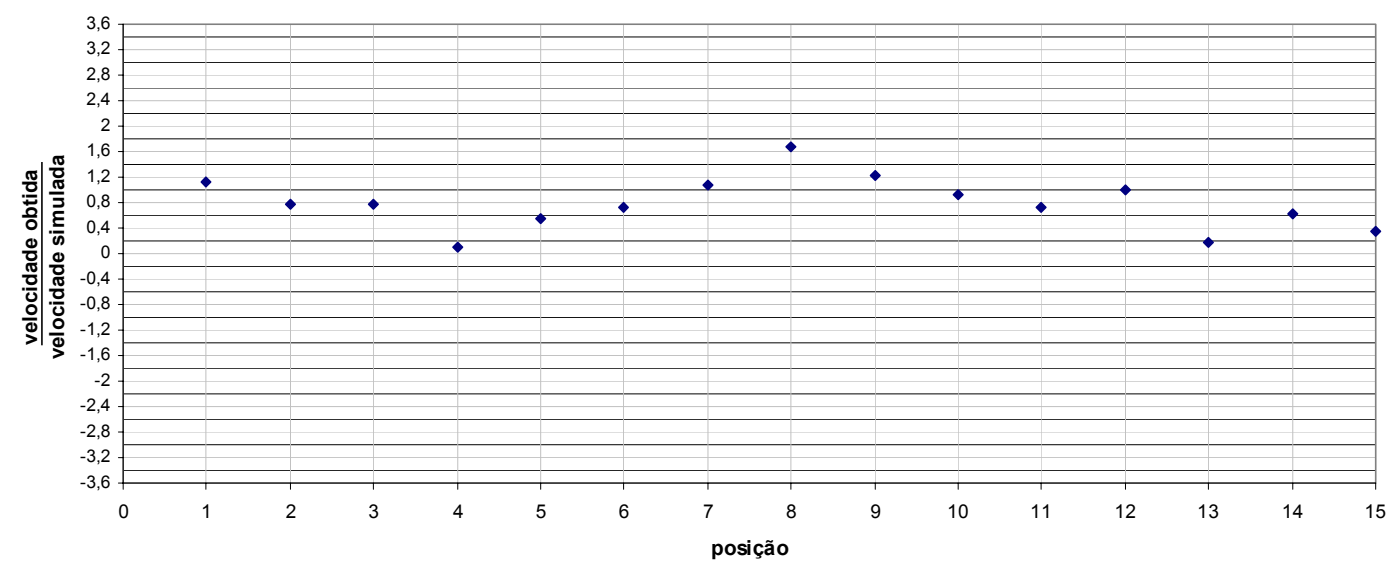

Figura 59 - Relação entre a velocidade média experimental e a simulada, para o ponto central de cada região da Configuração 1 de escoamento.

A simulação hidrodinâmica apresentada, com o conceito de Smagorinsky para modelagem da turbulência, é usada para dar início à simulação do assoreamento, com a Configuração 1 de escoamento.

\subsubsection{Configuração 2}

Os resultados referentes a experimento e simulação do escoamento para dois canais afluentes são apresentados a seguir.

\subsubsection{Experimento}

A Configuração 2 de escoamento teve o segundo canal aberto e descarregando uma vazão de $2 \mathrm{~L} / \mathrm{s}$, assim como o canal 1 . O padrão do escoamento, como visto a seguir, é diferente daquele encontrado para a Configuração 1. A Configuração 2 foi usada neste trabalho apenas para testar a capacidade do programa MIKE $21 \mathrm{C}$ em simular diferentes escoamentos de água com superfície livre, e pode ser usada em trabalhos seguintes, de assoreamento na armadilha.

Obedecendo à mesma seqüência de apresentação dos resultados da Configuração 1, primeiramente exibe-se os campos experimentais de velocidade média para cada região (Figuras 60-67) e, com base nestes, um esboço geral do campo de velocidade média em toda a armadilha (Figura 68). A escala de cores permanece aquela da Figura 21, para a componente longitudinal da velocidade. Na seqüência, encontram-se os resultados simulados, com três campos de velocidade instantânea e o campo simulado de velocidade média, este último comparado ao experimental. 

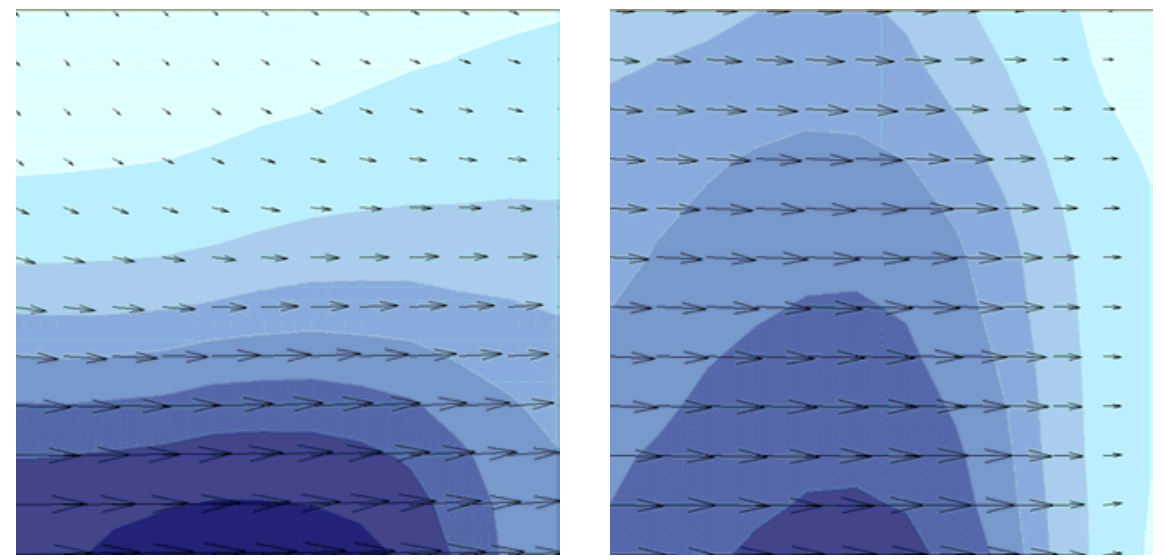

Figura 60 - Campos de velocidade média das regiões 1 e 2, respectivamente, para a Configuração 2 do escoamento.

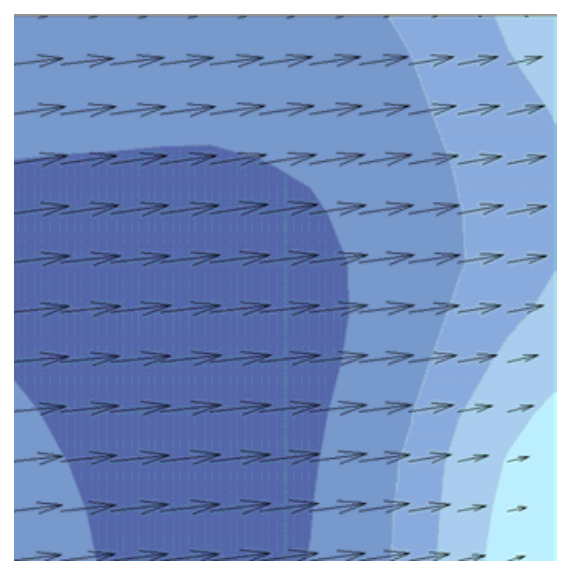

Figura 61 - Campos de velocidade média das regiões 3 e 4, respectivamente, para a Configuração 2 do escoamento.
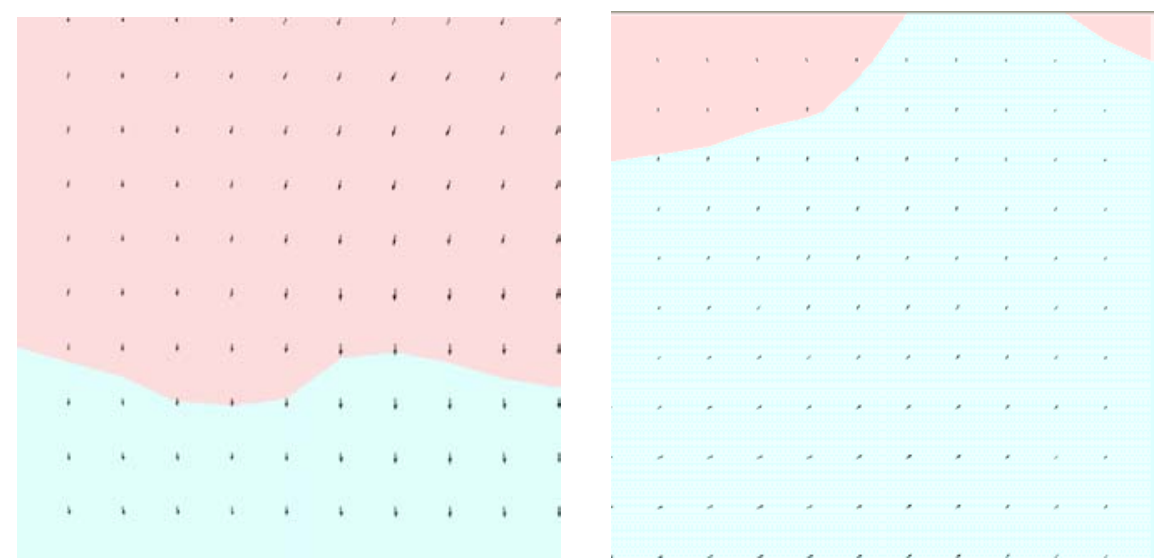

Figura 62 - Campos de velocidade média das regiões 5 e 6 , respectivamente, para a Configuração 2 do escoamento. 

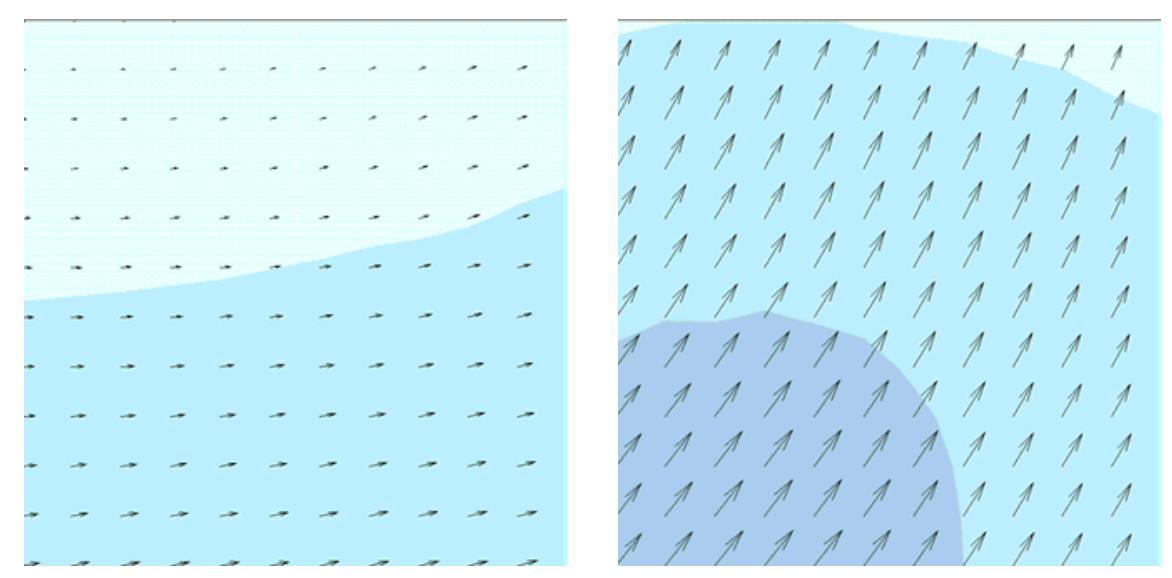

Figura 63 - Campos de velocidade média das regiões 7 e 8 , respectivamente, para a Configuração 2 do escoamento.
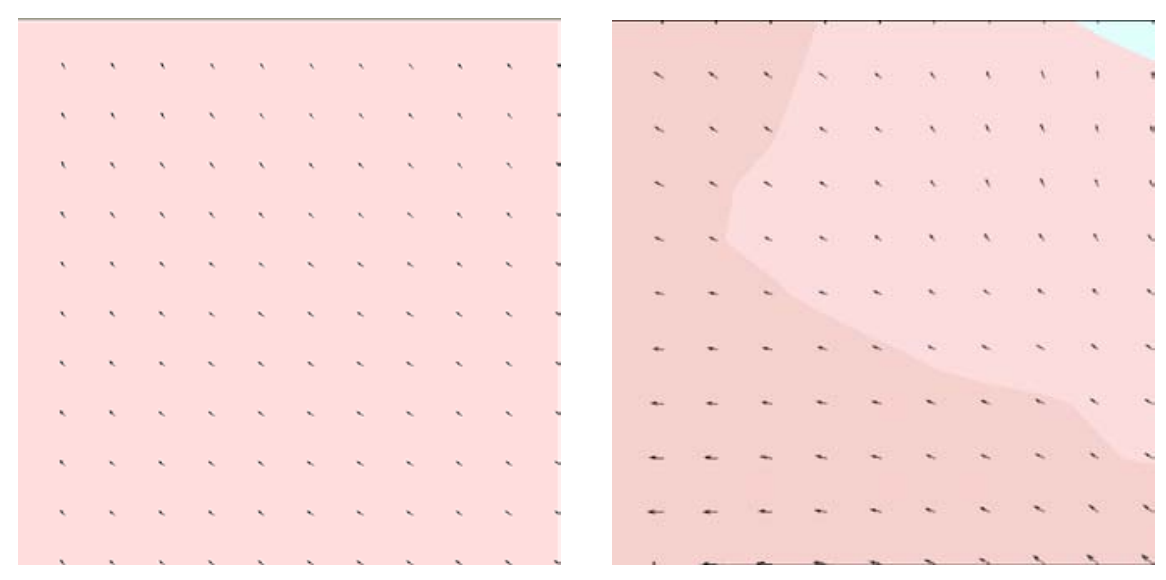

Figura 64 - Campos de velocidade média das regiões 9 e 10, respectivamente, para a Configuração 2 do escoamento.
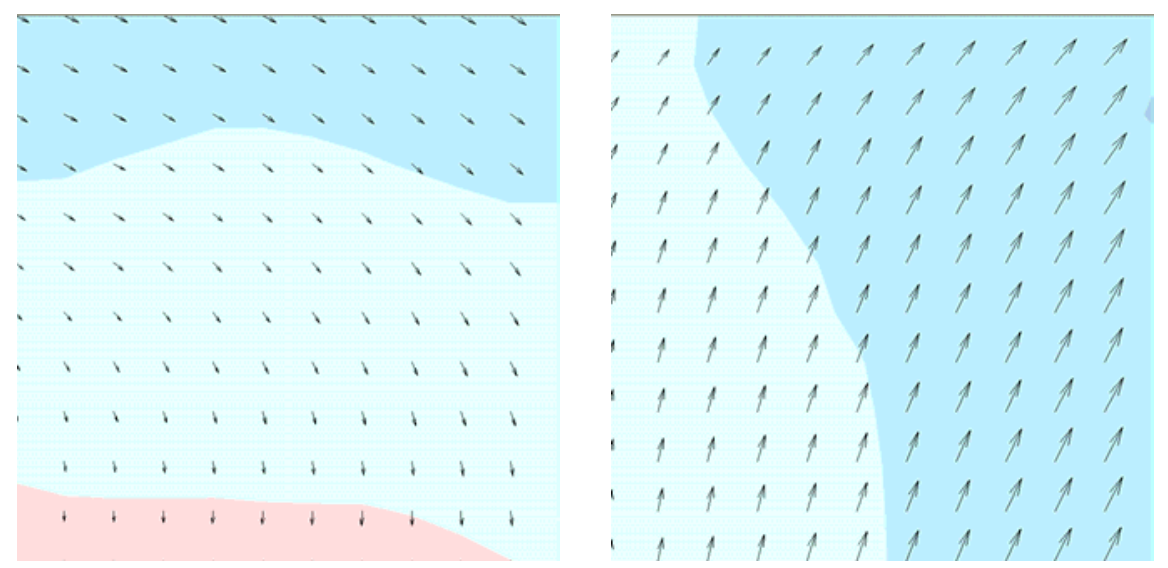

Figura 65 - Campos de velocidade média das regiões 11 e 12, respectivamente, para a Configuração 2 do escoamento. 

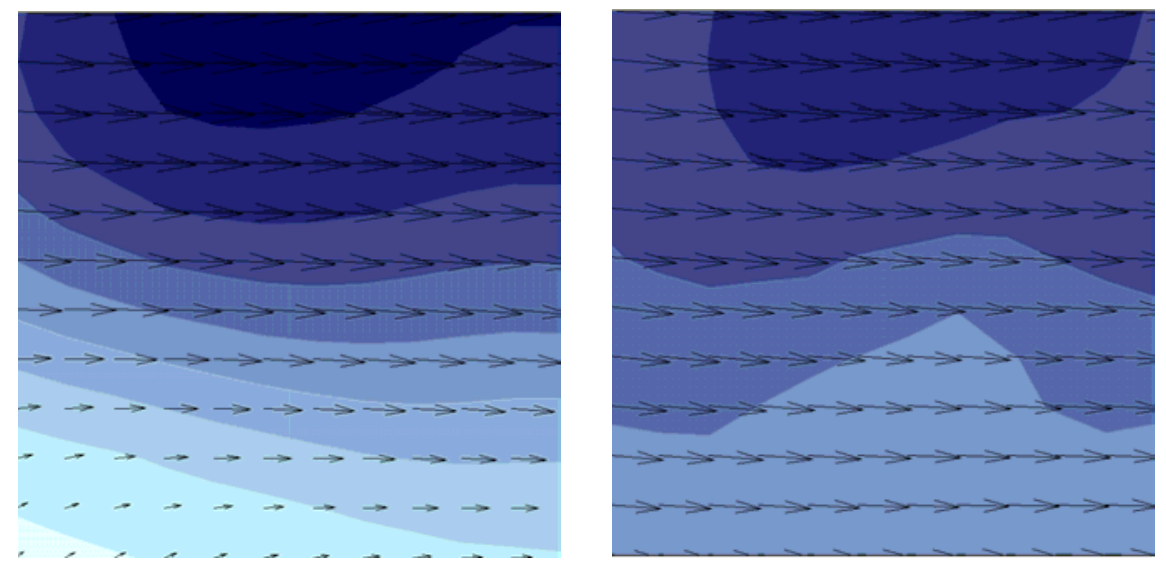

Figura 66 - Campos de velocidade média das regiões 13 e 14, respectivamente, para a Configuração 2 do escoamento.

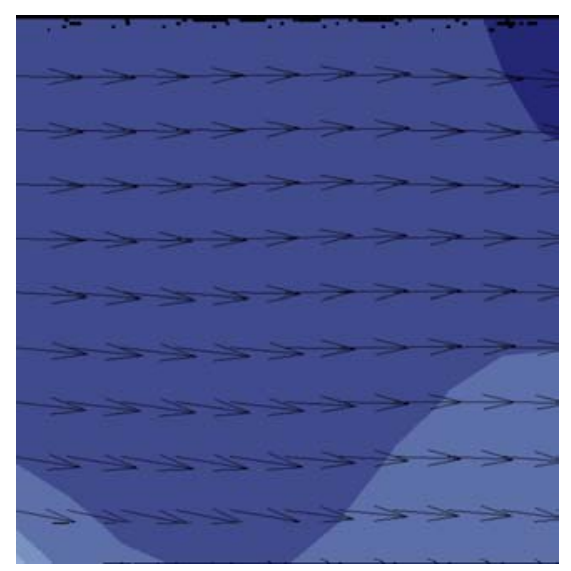

Figura 67 - Campos de velocidade média da região 15, respectivamente, para a Configuração 2 do escoamento.

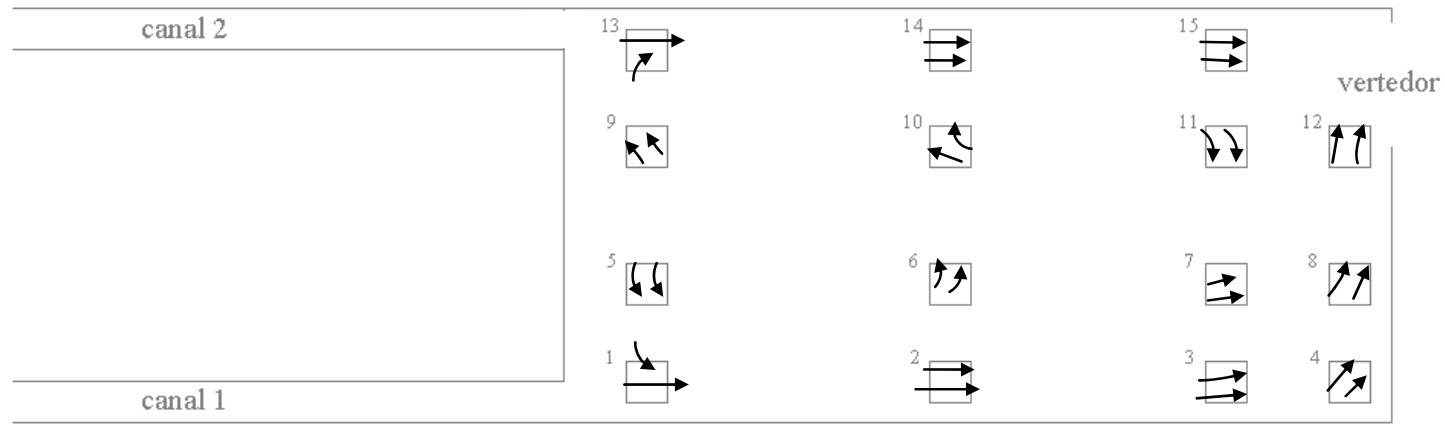

Figura 68 - Padrão do escoamento médio na armadilha, para a Configuração 2.

Com base nos campos de velocidade média (Figuras 60-67) e na Figura 68, observa-se que o padrão do escoamento em toda a armadilha não é bem identificado. Seria necessário um maior número de regiões analisadas com a técnica de velocimetria a laser. Porém, com o auxílio dos campos de velocidade instantânea e do campo de velocidade média simulados, ilustrados nas Figuras 69-72, o padrão do escoamento para 
a Configuração 2 se torna mais claro e a semelhança entre campos experimental e simulado pode ser observada.

\subsubsection{Simulação}

Da mesma forma como feito para a Configuração 1, partiu-se com o fluido em repouso na armadilha até que o escoamento atingisse regime permanente, a partir de 80000 passos. As Figuras 69-71 mostram instantes da simulação da Configuração 2, para 80000, 90000 e 100000 passos no tempo, referindo-se respectivamente a $13 \mathrm{~min}$ $20 \mathrm{~s}, 15 \mathrm{~min}$ e $16 \mathrm{~min} 40 \mathrm{~s}$ de escoamento. Diferentemente do escoamento com apenas um canal, na Configuração 2 o escoamento retorna (para a esquerda, em tons de vermelho) por um caminho no centro da armadilha, que oscila com o tempo. Essa variação do escoamento instantâneo é mostrada na PASTA 5_SIMULAÇÃO_VÍDEOS DO ESCOAMENTO_Configuração 2, no DVD.

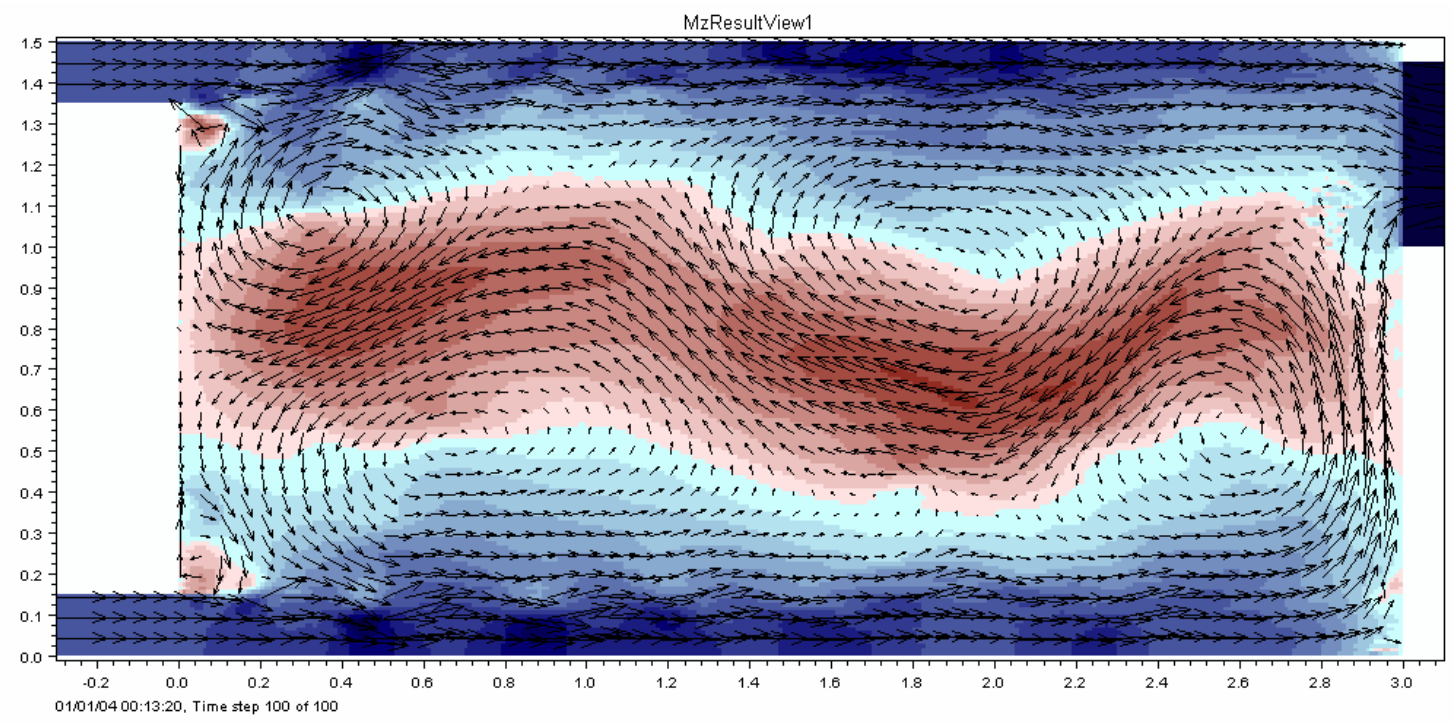

Figura 69 - Instante da simulação computacional para a Configuração 2, referente a $13 \mathrm{~min} 20 \mathrm{~s}$ de escoamento. 


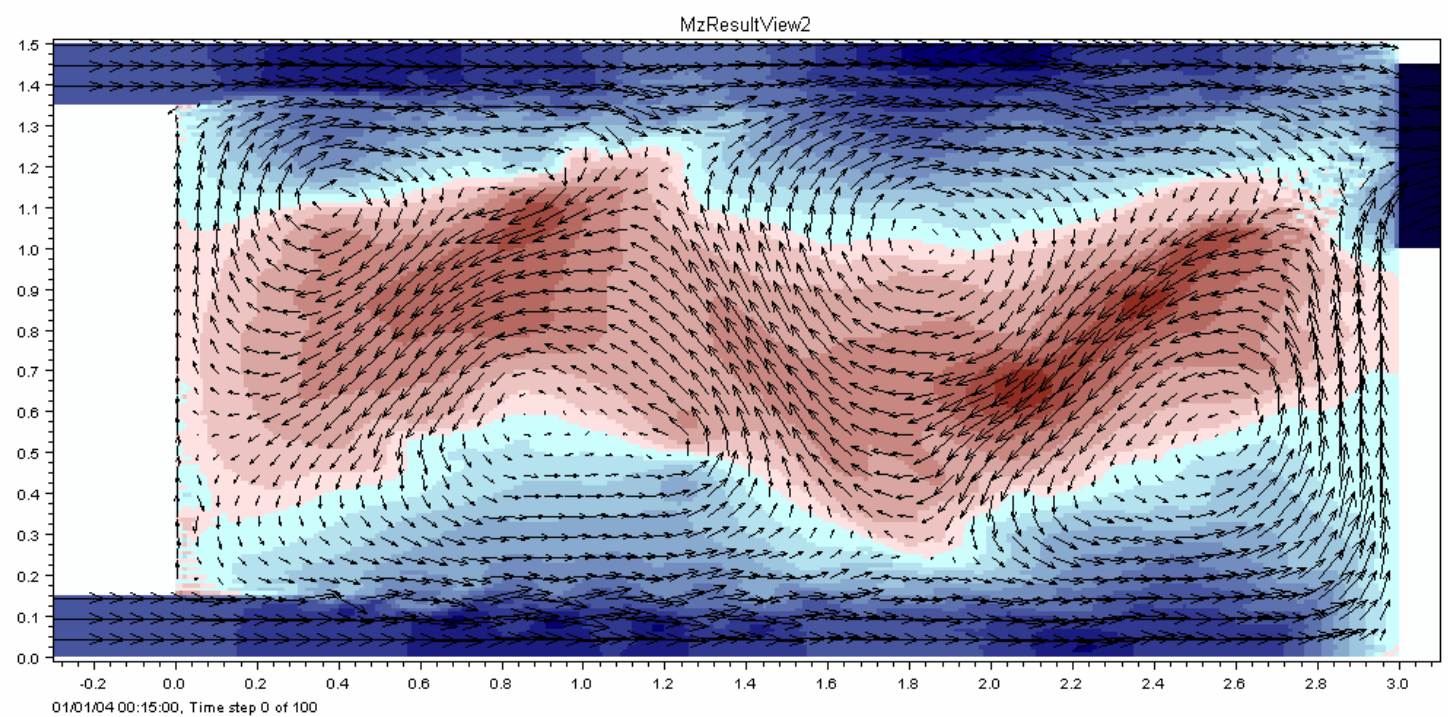

Figura 70 - Instante da simulação computacional para a Configuração 2, referente a $15 \mathrm{~min}$ de escoamento.

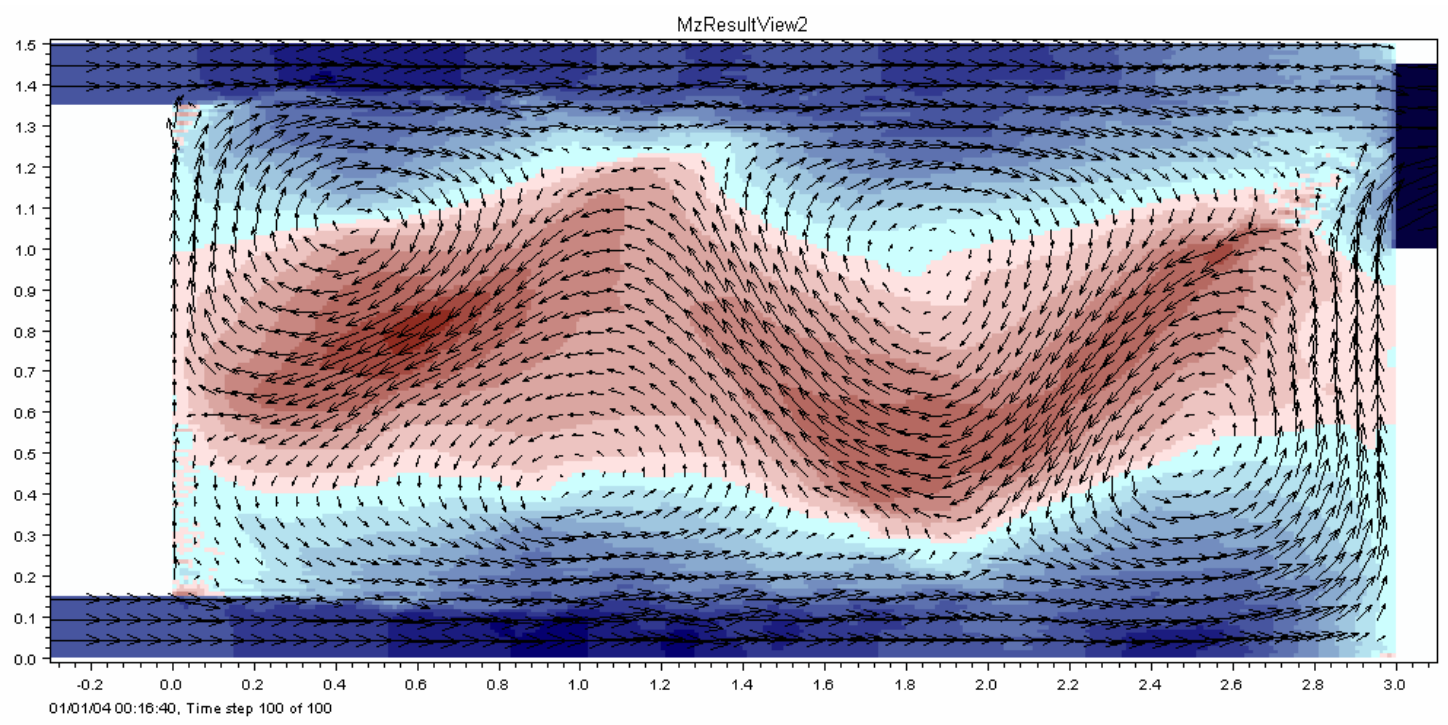

Figura 71 - Instante da simulação computacional para a Configuração 1, referente a $16 \mathrm{~min} 40 \mathrm{~s}$ de escoamento.

O escoamento médio, produzido a partir dos dados instantâneos e ilustrado na Figura 72, se assemelha ao obtido em laboratório e auxilia no entendimento dos resultados experimentais para as regiões analisadas. Observa-se até mesmo a boa representação, na simulação, dos campos de velocidade experimentais em regiões centrais da armadilha (regiões 6, 10 e 11), onde o escoamento é mais instável. 


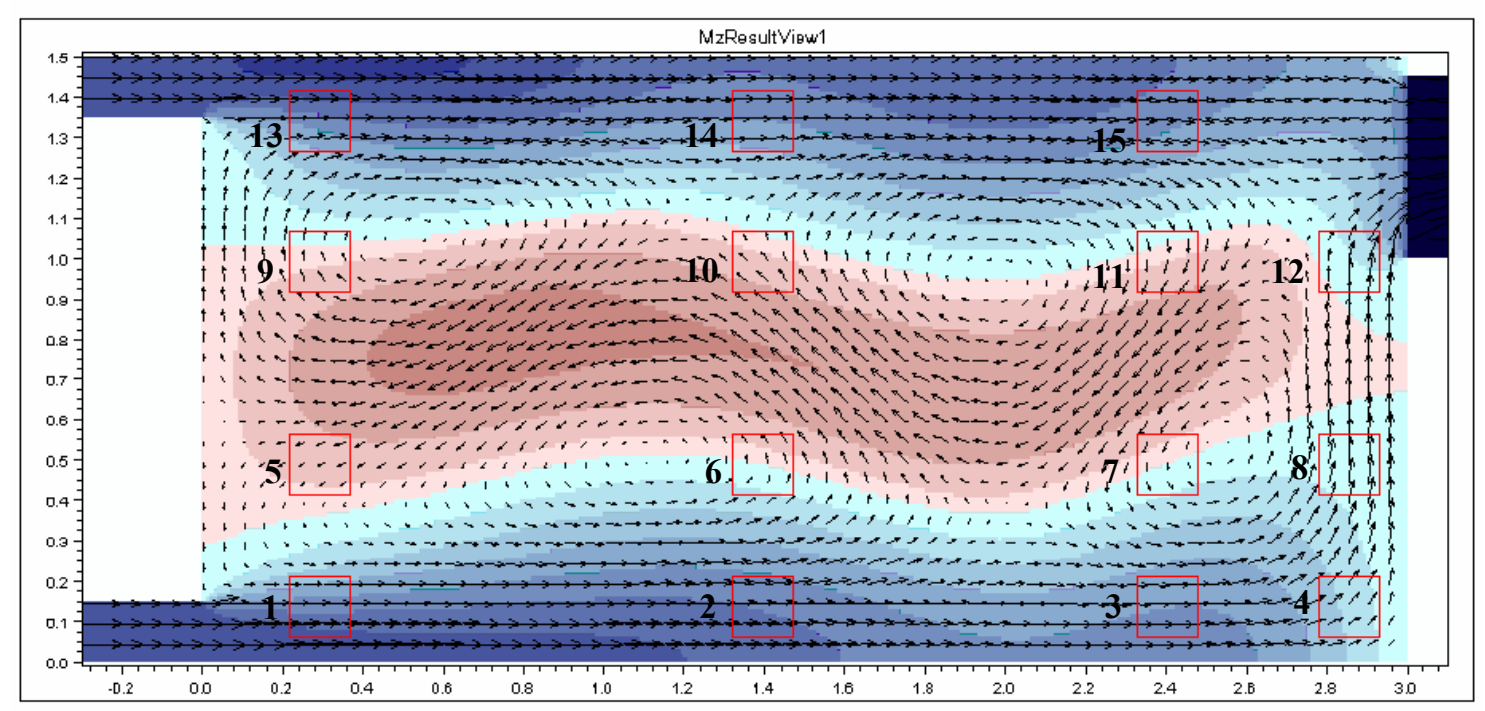

Figura 72 - Padrão médio do escoamento da Configuração 2.

Exceção acontece para a região 7. No campo simulado, encontra-se uma recirculação de fluido no sentido anti-horário, com observação do escoamento da direita para a esquerda (em tom de vermelho) na parte superior da região. No campo experimental, o escoamento neste sentido não está presente. No entanto, com um pequeno deslocamento da região 7 para baixo $( \pm 15 \mathrm{~cm})$, na Figura 72 , mostra-se que o campo de velocidade média obtido experimentalmente nessa região está presente na simulação.

Os gráficos da variação temporal da componente da velocidade instantânea no sentido longitudinal da armadilha foram colocados no APÊNDICE C. Com base no padrão do escoamento experimental, apresentado na Figura 68, conclui-se que um trabalho mais extenso de laboratório, com maior número de regiões experimentais analisados com velocimetria a laser, seria necessário para identificação do padrão médio do escoamento, caso não houvesse o auxílio da simulação computacional. Esse fato reforça a importância do uso conjunto de trabalhos experimentais e numéricos, no estudo de fenômenos físicos. 


\subsection{Assoreamento}

Apresenta-se o assoreamento realizado em laboratório e sua modelagem numérica com o programa MIKE 21C.

\subsubsection{Experimento}

Iniciou-se o assoreamento após 30min de escoamento apenas de água, para estabelecimento do regime permanente. Como as condições do escoamento eram favoráveis à deposição de areia, mesmo para a maior velocidade no canal, este foi assoreado totalmente nas primeiras $4 \mathrm{~h}$ do experimento (Figuras 73-75). A partir daí, o equilíbrio entre deposição e erosão foi atingido no canal, para altura média espacial de assoreamento variando entre $8 \mathrm{~cm}$ e $10 \mathrm{~cm}$ e superfície de água em torno de $12 \mathrm{~cm}$ (medida a partir do fundo horizontal da armadilha), e toda a descarga de areia passou a contribuir para o assoreamento na armadilha.

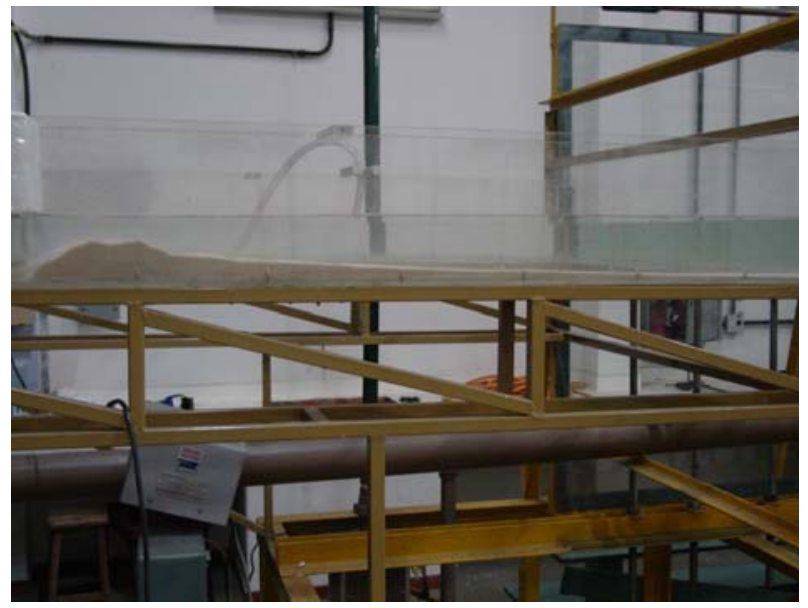

Figura 73 - Assoreamento do canal no $1^{\circ}$ dia, com $30 \mathrm{~min}$ de experimento.

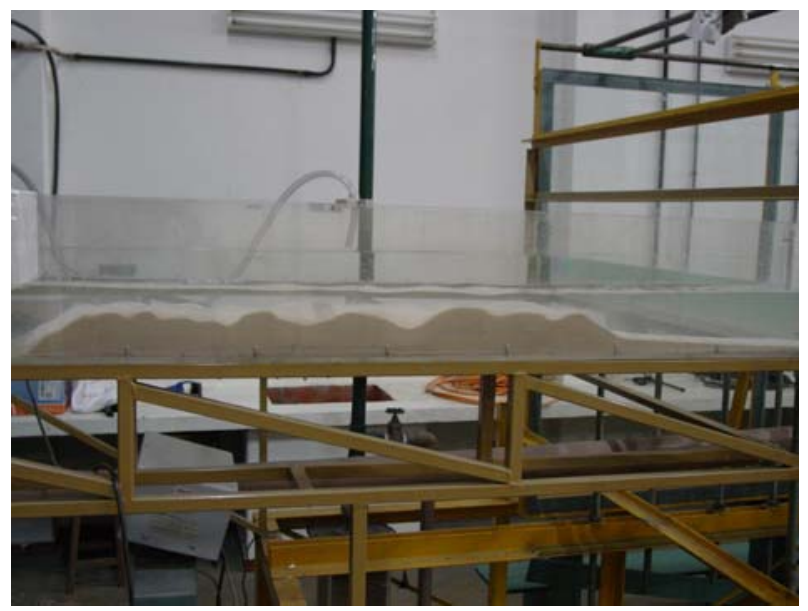

Figura 74 - Assoreamento do canal no $1^{\circ}$ dia, com $2 \mathrm{~h}$ de experimento. 


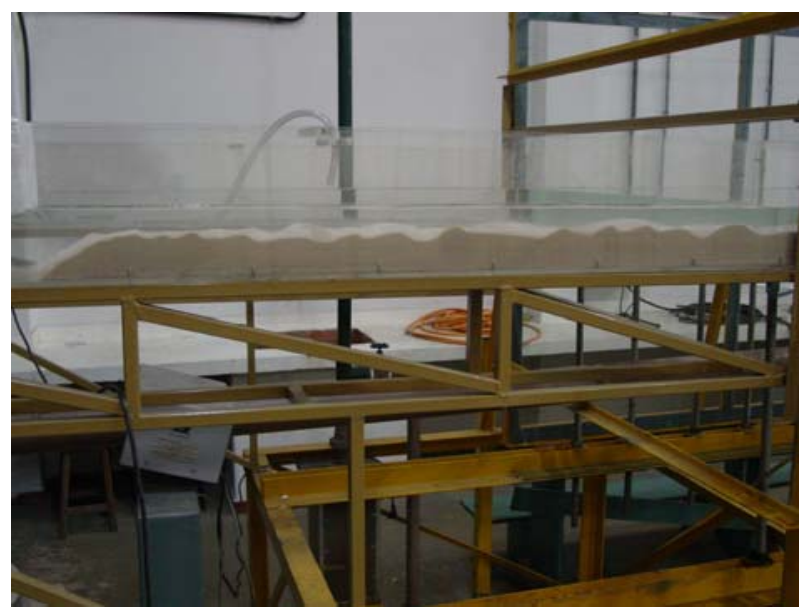

Figura 75 - Assoreamento do canal no $1^{\circ}$ dia, com 4 h de experimento.

Com 30min de experimento, uma pequena deposição de areia se inicia na entrada da armadilha. A deposição segue a direção longitudinal da armadilha, sem difusão relevante, como previsto a partir da análise do campo de velocidade para a Configuração 1 de escoamento, anterior ao assoreamento. A Figura 76 ilustra o exposto.

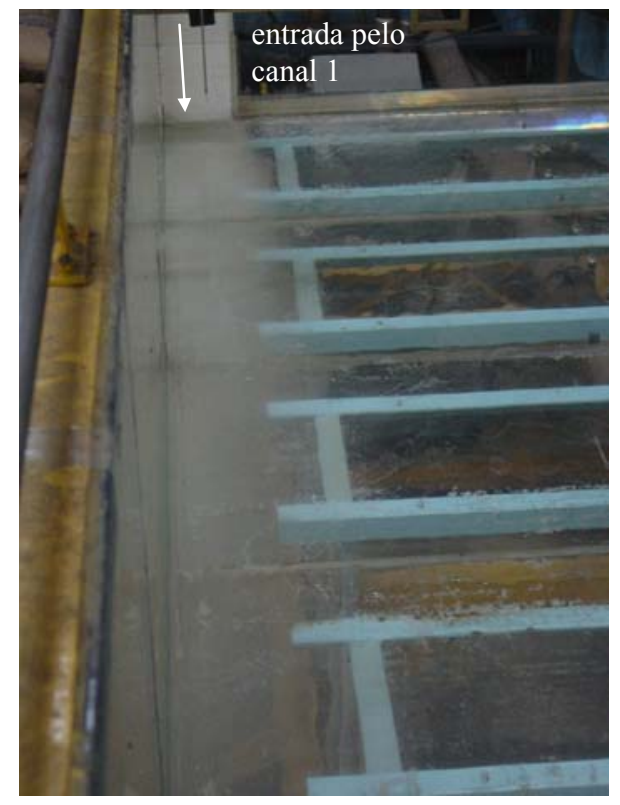

Figura 76 - Assoreamento da armadilha no $1^{\circ}$ dia, com $30 \mathrm{~min}$ de experimento.

Até $4 \mathrm{~h}$ de experimento, a deposição de areia acontece junto às paredes, contornando a área da armadilha, sem deposição no seu centro. Esse fato corrobora os resultados experimentais e simulados do padrão do escoamento para o início do assoreamento, apresentados na seção 5.1. Nesses resultados, as linhas de corrente do escoamento proveniente do canal não divergem ao entrarem na armadilha, portanto 
seguindo praticamente paralelas, junto às paredes, sem tomar um caminho mais curto até o vertedor, passando pelo centro da armadilha. O assoreamento para $4 \mathrm{~h}$ encontra-se na Figura 77.

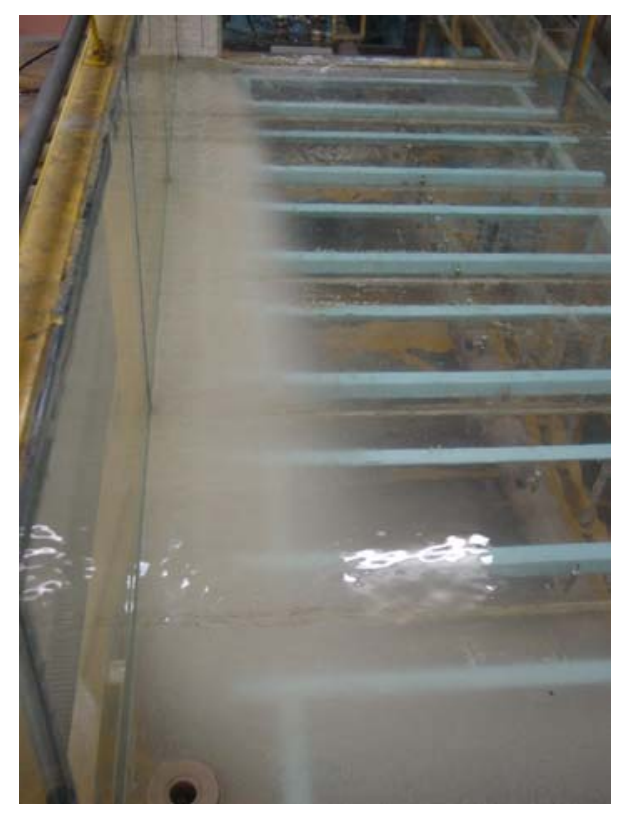

Figura 77 - Assoreamento da armadilha no $1^{\circ}$ dia, com $4 \mathrm{~h}$ de experimento.

A partir de 4h, o padrão da deposição de areia se modifica. Com o canal assoreado em toda sua extensão, a intensidade turbulenta aumenta em muito, se comparada àquela do início do experimento. Essa alta intensidade pôde ser percebida visualmente, pela agitação da superfície da água, no seu escoamento sobre as dunas de areia.

Com a alta intensidade turbulenta, o escoamento, ao entrar na armadilha, difunde maior quantidade de movimento e se comporta, em média, como o escoamento de um fluido de maior viscosidade. Dessa forma, as linhas de corrente se divergem na entrada da armadilha, para que o fluido se movimente de forma mais semelhante a "um sólido", em direção ao vertedor. A divergência das linhas de corrente na entrada da armadilha faz com que o sedimento, transportado preponderantemente por advecção, se distribua de forma mais homogênea e não mais apenas no sentido longitudinal da armadilha. $O$ padrão da deposição de areia toma, a partir daí, uma forma arredondada. É importante notar que essa transição para uma alta intensidade turbulenta e um novo padrão de deposição de areia não é instantânea; porém, aconteceu no experimento em um período de tempo curto se comparado às $72 \mathrm{~h}$ de trabalho. O assoreamento para $5 \mathrm{~h}$ e $10 \mathrm{~h}$ é mostrado nas Figuras 78 e 79, respectivamente. Na Figura 78, o assoreamento para 5h é registrado de um ponto sob a armadilha, para melhor observação do novo padrão de deposição. Na Figura 80, mostra-se um detalhe do assoreamento para 10h. 


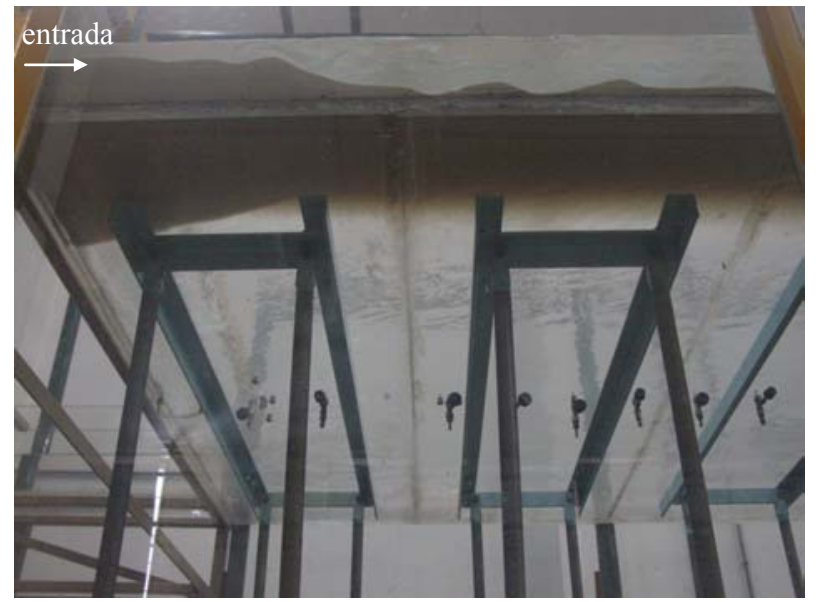

Figura 78 - Assoreamento da armadilha no $2^{\circ}$ dia, com 5 h de experimento. Vista sob o fundo.

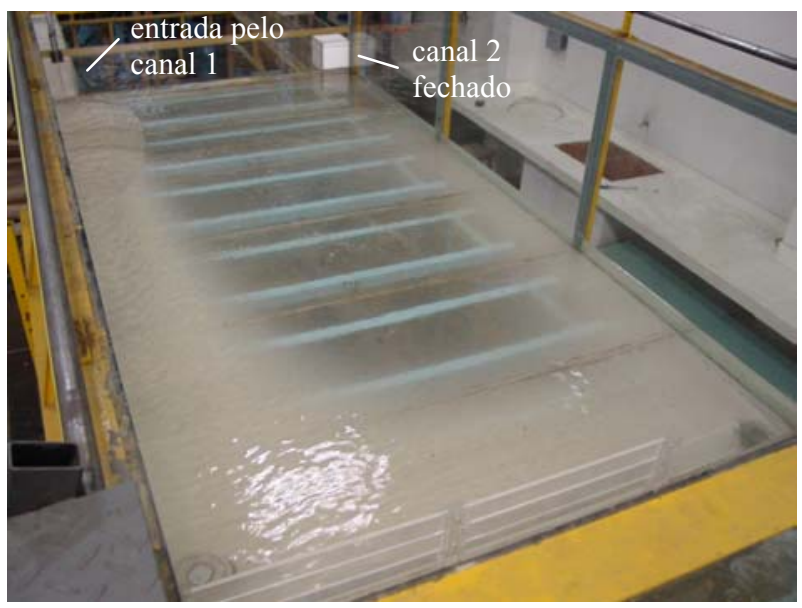

Figura 79 - Assoreamento da armadilha no $3^{\circ}$ dia, com $10 \mathrm{~h}$ de experimento.

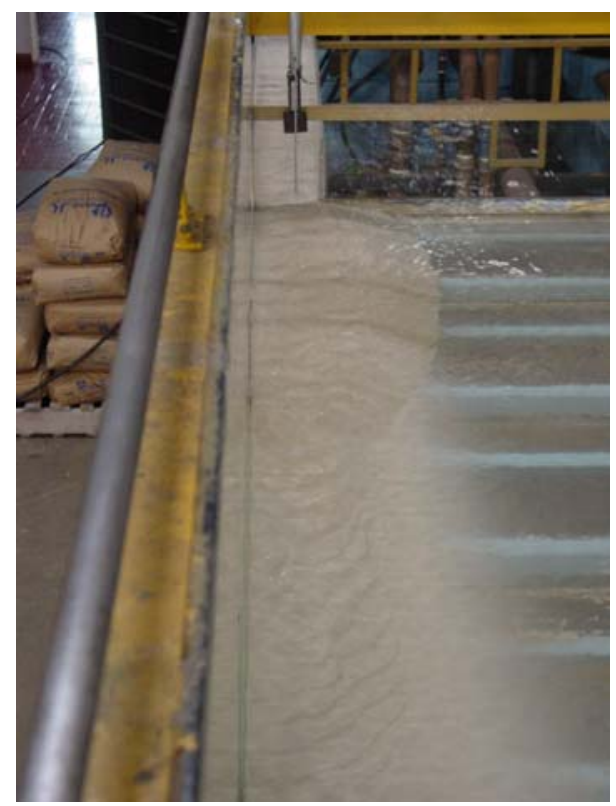

Figura 80 - Detalhe do assoreamento da armadilha no $3^{\circ}$ dia, com $10 \mathrm{~h}$ de experimento. 
A progressão do experimento até seu final mostra que o padrão do assoreamento não se altera de forma significativa. A formação arredondada, porém mais extensa no sentido longitudinal da armadilha, se expande, como nas Figuras 81-85, para os instantes referentes a $25 \mathrm{~h}, 50 \mathrm{~h}$ e $72 \mathrm{~h}$. Nessas figuras, fotos da armadilha de diferentes ângulos são apresentadas, para melhor apreciação do experimento.

É interessante comentar que durante todo o processo de assoreamento, a deposição de sedimentos na base do vertedor, pouco observada através das fotos, foi quase nula, limitando-se a uma fina camada de areia.

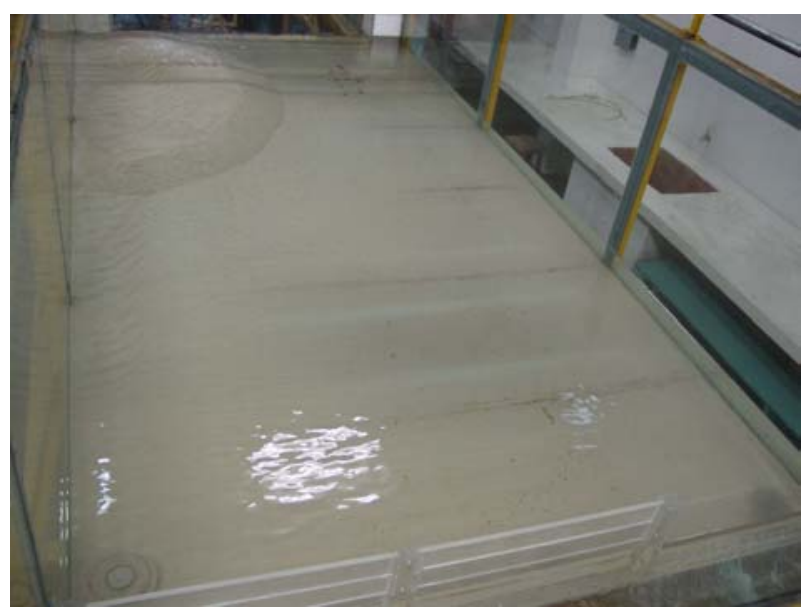

Figura 81 - Assoreamento da armadilha no $6^{\circ}$ dia, com $25 \mathrm{~h}$ de experimento.

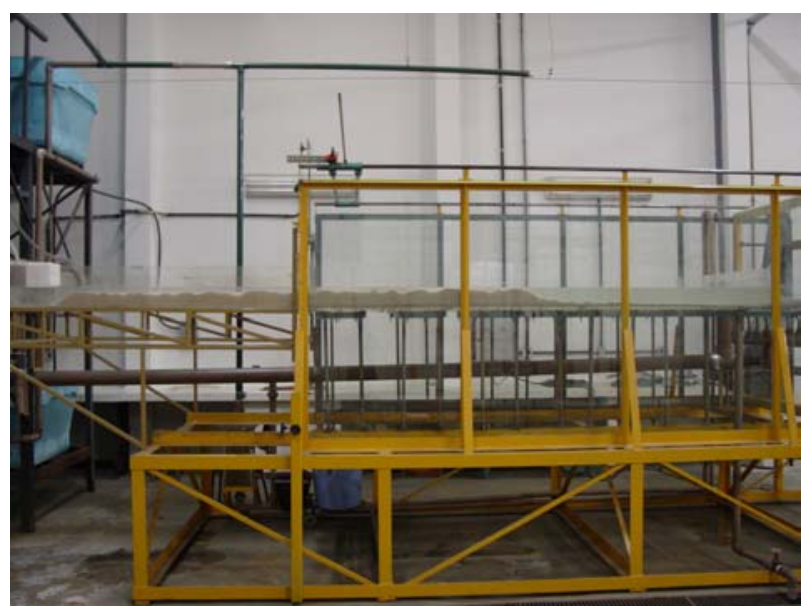

Figura 82 - Vista lateral da armadilha e do canal, com $25 \mathrm{~h}$ de experimento. 


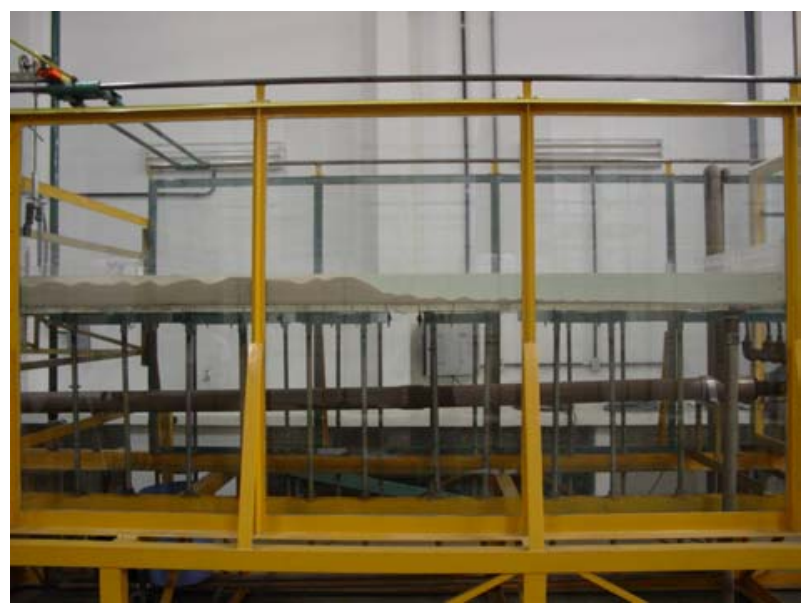

Figura 83 - Vista lateral da armadilha, com $25 \mathrm{~h}$ de experimento.

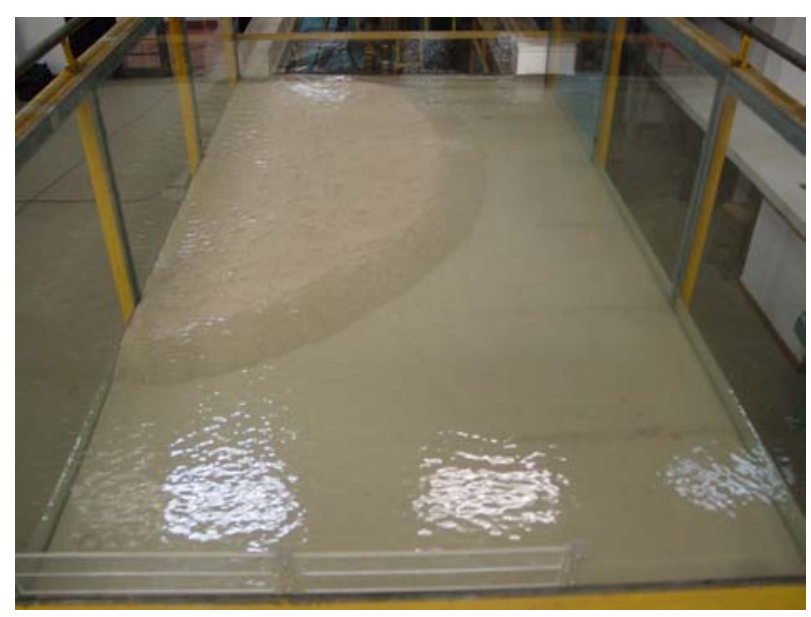

Figura 84 - Assoreamento no $9^{\circ}$ dia, com 50h de experimento.

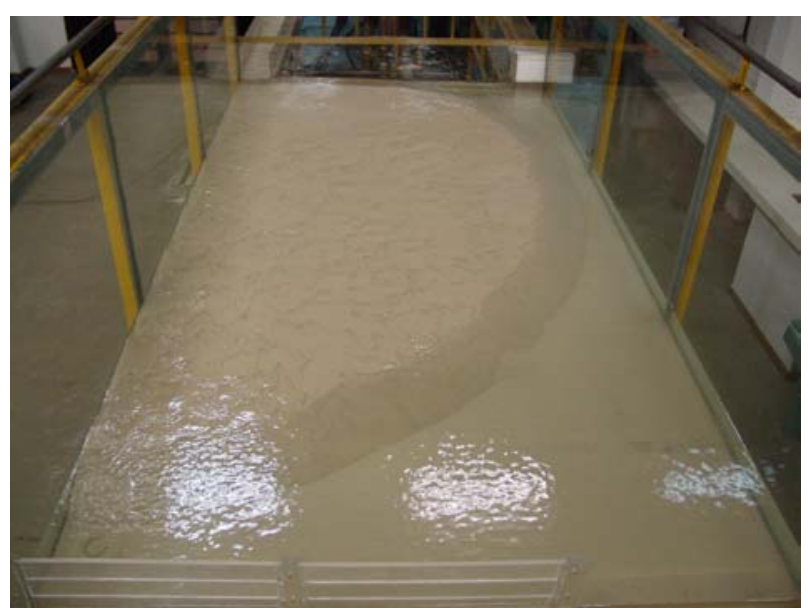

Figura 85 - Assoreamento no $11^{\circ}$ dia, com $72 \mathrm{~h}$ de experimento. 
O equilíbrio entre deposição e erosão foi atingido, em média, na armadilha com uma altura de assoreamento superior à do canal, entre $9 \mathrm{~cm}$ e $11 \mathrm{~cm}$, devido à menor velocidade do escoamento e conseqüentemente menor capacidade de transporte de sedimento. Vistas laterais do canal e da armadilha são mostradas nas Figuras 86 e 87, com $72 \mathrm{~h}$ de experimento, para visualização desse fato.

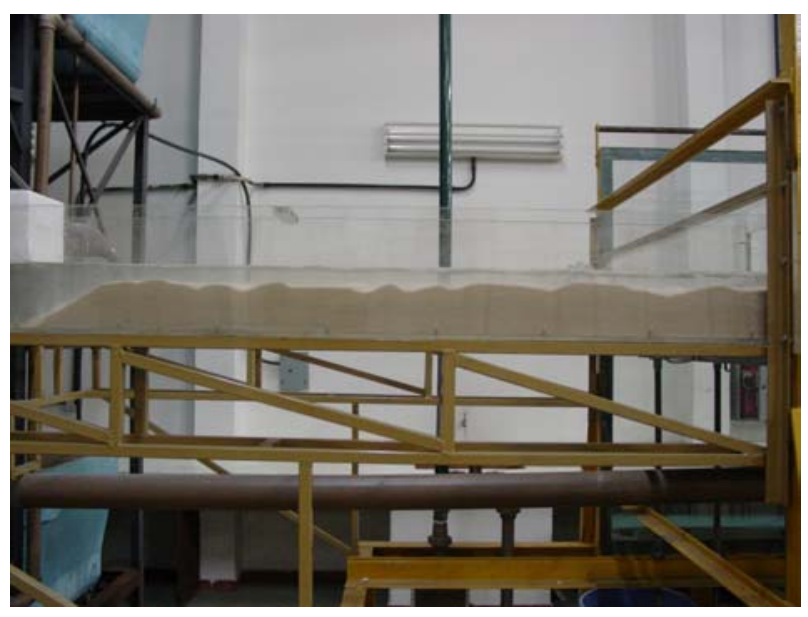

Figura 86 - Altura de equilíbrio entre deposição e erosão de areia no canal, para as condições do experimento.

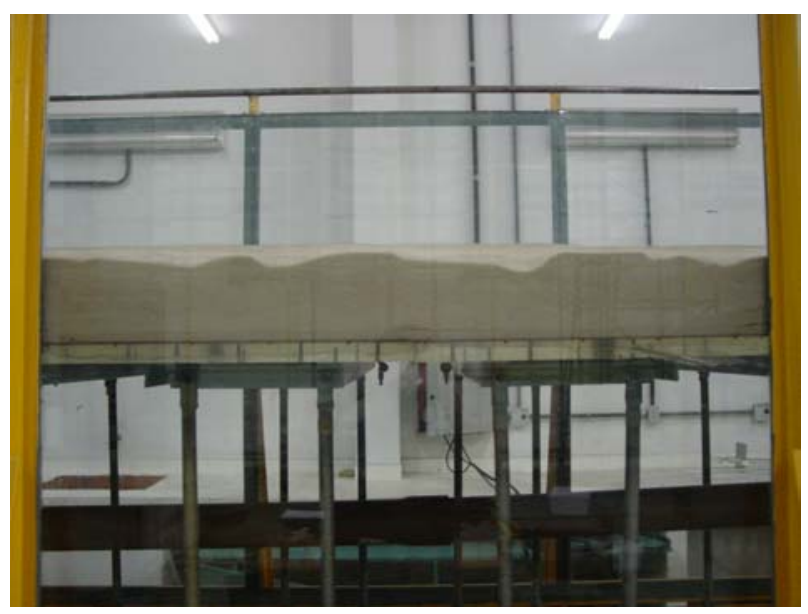

Figura 87 - Altura de equilíbrio entre deposição e erosão de areia na armadilha, para as condições do experimento.

Quando se atingiu $72 \mathrm{~h}$ de experimento, o assoreamento chegou próximo à tubulação de esvaziamento da armadilha, motivo pelo qual foi interrompido. Além disso, tinha-se já um assoreamento quase completo da armadilha, suficiente para que uma simulação do fenômeno fosse testada. A armadilha então foi esvaziada e a formação da areia depositada pôde ser mais bem observada. Ravinas foram formadas, 
mostrando a dispersão do escoamento na entrada da armadilha. A formação das ravinas apenas não aconteceu em uma região à esquerda do canal (do ponto de vista de montante), logo na entrada da armadilha. Uma formação praticamente plana e lisa de assoreamento, com altura em torno de $11 \mathrm{~cm}$, mantinha o escoamento de uma fina lâmina de água em baixa velocidade, como pôde ser observado durante o trabalho experimental. A Figura 88 é ilustrativa do exposto.

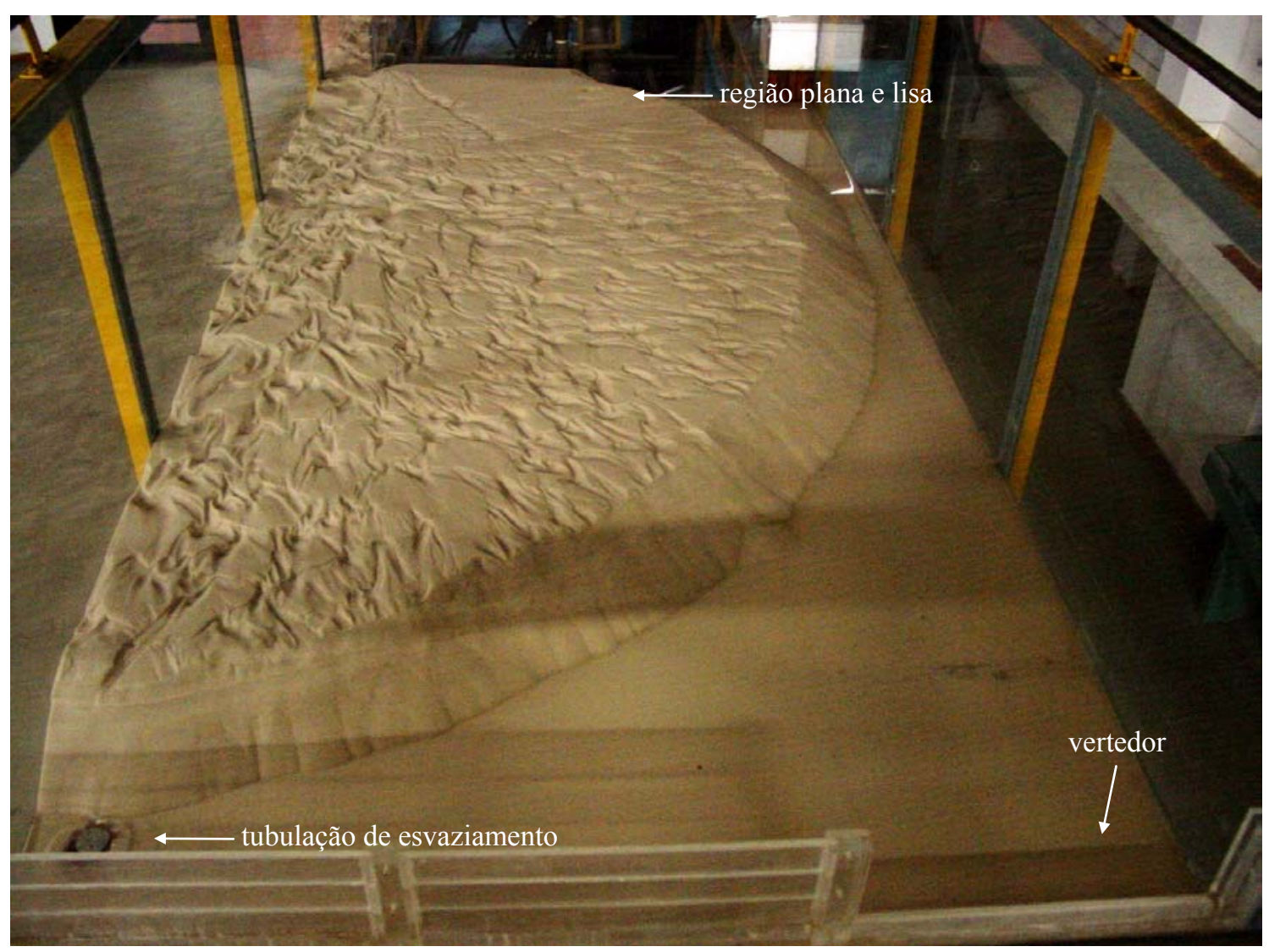

Figura 88 - Assoreamento final, com a armadilha esvaziada.

Na Figura 89, uma imagem da entrada da armadilha, vista de montante, registra a elevação do assoreamento na armadilha, com relação à altura de deposição no canal, devido à diminuição da capacidade de transporte do escoamento. 


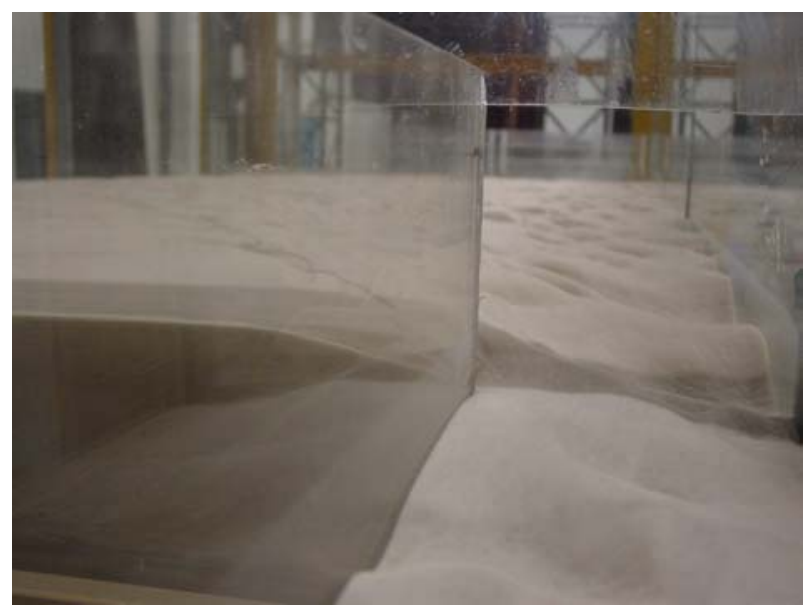

Figura 89 - Altura do assoreamento no canal, menor que no interior da armadilha

Todas as fotos obtidas durante o assoreamento e os vídeos com movimentação das dunas no canal e na armadilha encontram-se no DVD, em PASTA 3_EXPERIMENTO_FOTOS DO ASSOREAMENTO e PASTA 4_EXPERIMENTO_VÍDEOS DO ASSOREAMENTO, para melhor apreciação do trabalho experimental. 


\subsubsection{Simulação}

O assoreamento foi simulado com viscosidade turbulenta constante igual a $0,01 \mathrm{~m}^{2} / \mathrm{s}$. Para a simulação das primeiras quatro ou cinco horas de assoreamento, o ideal seria o uso do modelo de Smagorinsky, para cálculo da viscosidade turbulenta (Figura 90).

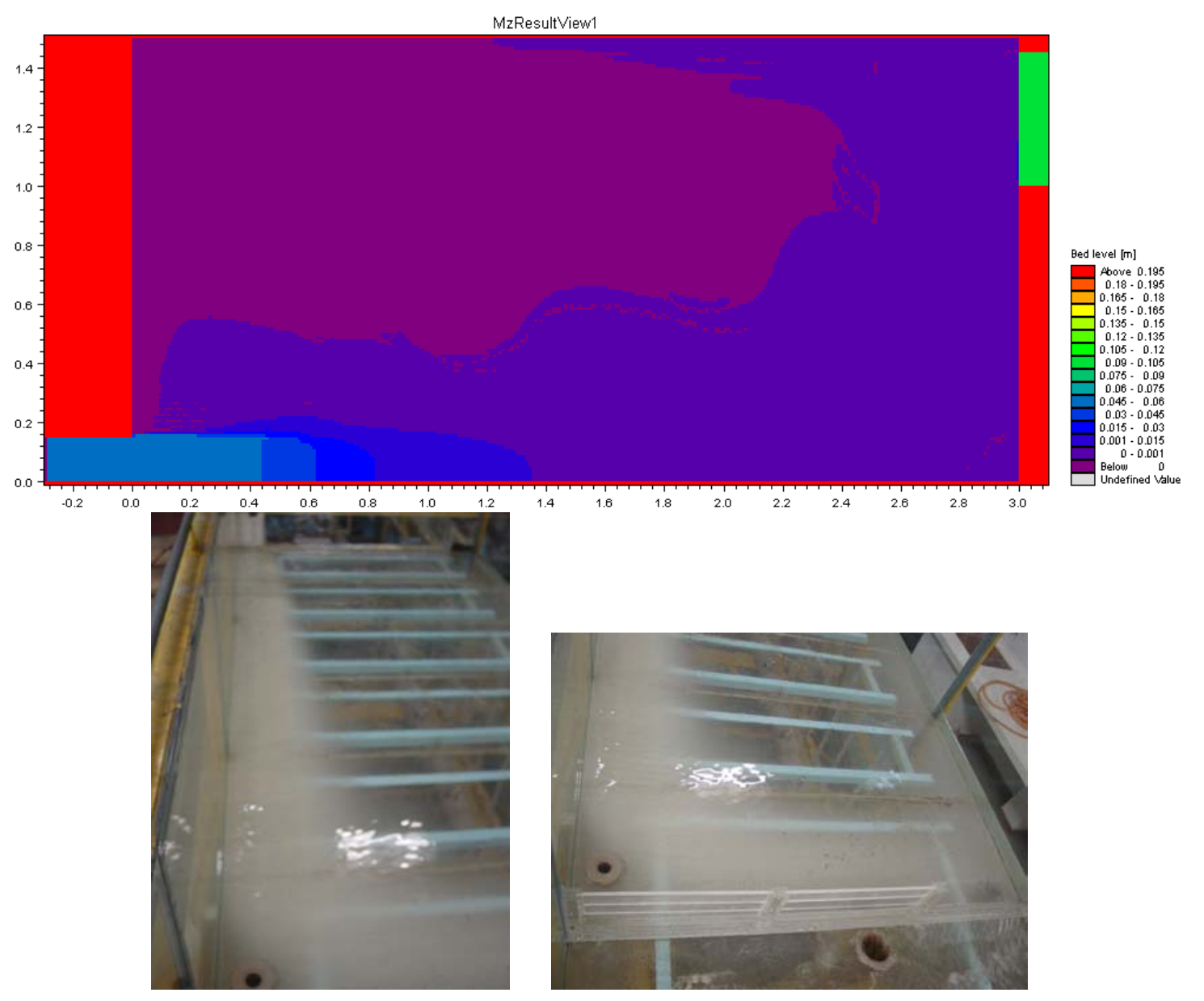

Figura 90 - Resultado de 4h30min de assoreamento, para experimento e simulação com modelo de turbulência de Smagorinsky.

Porém, em torno de quatro ou cinco horas de assoreamento experimental, o aumento da intensidade turbulenta, causado pela elevação do fundo e formação de dunas no canal e na entrada da armadilha, não foi captado pelo modelo de Smagorinsky, que continuou apresentando viscosidade turbulenta baixa, inferior à real. Com $15 \mathrm{~h}$ de assoreamento, por exemplo, notou-se na simulação que o modelo mantém a viscosidade turbulenta baixa, como mostrado nas Figura 91, com o campo de velocidade para esse instante. Houve uma mudança de direção do escoamento, devido ao assoreamento excessivo na região em vermelho na Figura 92, mas não houve divergência das linhas de corrente, o que representaria a alta viscosidade. Apesar de a forma da deposição de 
areia da Figura 92 ter semelhança com a realidade, a causa dessa formação é diferente para experimento e simulação. A baixa viscosidade na simulação faz com que essa semelhança desapareça rapidamente nas próximas horas de assoreamento.

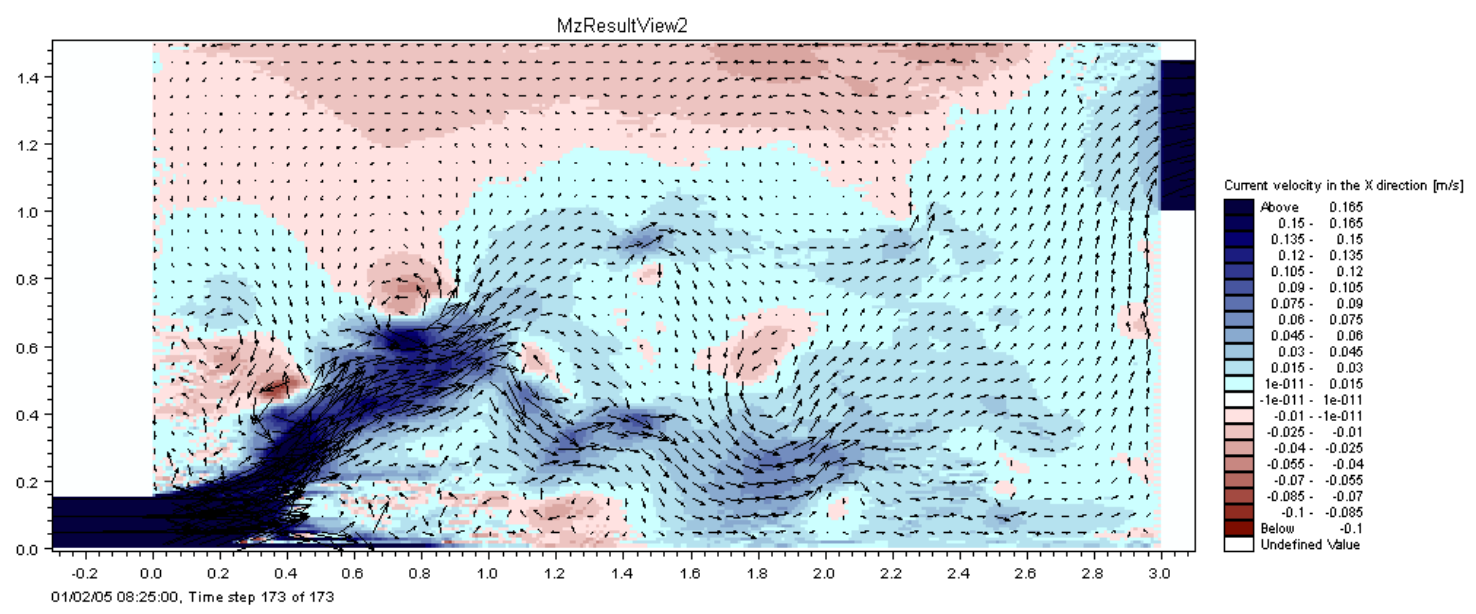

Figura 91 - Mudança de direção, na simulação, do escoamento proveniente do canal, sem divergência das linhas de corrente.

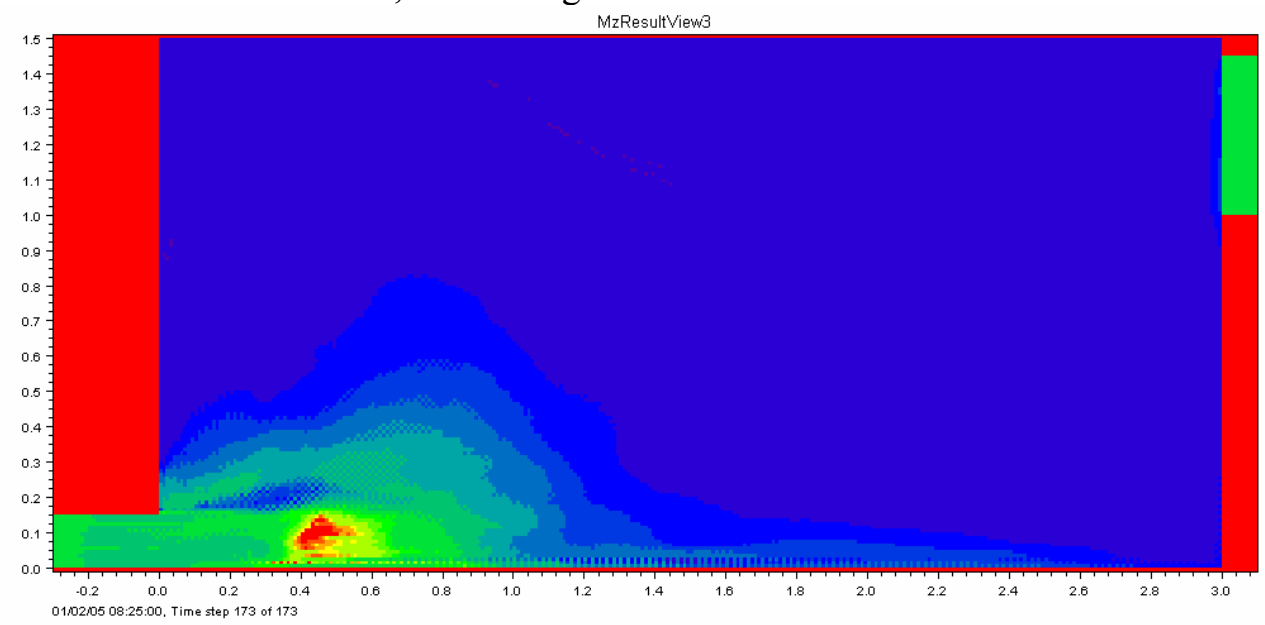

Figura 92 - Resultado de 15h de simulação do assoreamento, com modelo de Smagorinsky.

Uma tentativa de simulação foi realizada com uso do modelo de Smagorinsky para as 4 primeiras horas e sua seqüência com viscosidade constante de $0,01 \mathrm{~m}^{2} / \mathrm{s}$. Obteve-se resultados sem semelhança com os dados experimentais, provavelmente devido à mudança instantânea da viscosidade turbulenta. Uma mudança suave, com interrupção da simulação em vários momentos para ajuste da viscosidade, mostraria resultados mais próximos dos experimentais. Contudo, várias interrupções na simulação para ajuste de parâmetros não se justificam, dentro do objetivo deste trabalho.

Optou-se então por desenvolver a simulação com viscosidade turbulenta constante mais alta, igual a $0,01 \mathrm{~m}^{2} / \mathrm{s}$, dando menor importância à semelhança durante as primeiras 4h ou 5h. Buscou-se assim boa representação das demais horas de simulação (entre 5h e $72 \mathrm{~h}$ ), período mais longo e representativo do assoreamento. 
A diferença entre o padrão do escoamento com uso do modelo de Smagorinsky e o padrão com uso da viscosidade de $0,01 \mathrm{~m}^{2} / \mathrm{s}$ é ilustrada nas Figuras $93-96$, com padrões intermediários referentes às viscosidades de $0,001 \mathrm{~m}^{2} / \mathrm{s}$ e $0,05 \mathrm{~m}^{2} / \mathrm{s}$. Nota-se que a maior viscosidade ocasiona maior divergência das linhas de corrente na entrada da armadilha; Também, nota-se a semelhança do padrão do escoamento com viscosidade $0,001 \mathrm{~m}^{2} / \mathrm{s}$ e o padrão do escoamento médio com modelo de Smagorinsky, apresentado na Figura 57. Essa semelhança indica que o padrão do escoamento médio anterior ao assoreamento poderia ser representado por uma viscosidade constante. Com isso, a observação das flutuações da velocidade em torno de sua média não seria possível, mas poupar-se-ia trabalho computacional na ausência de um equacionamento para modelagem da turbulência.

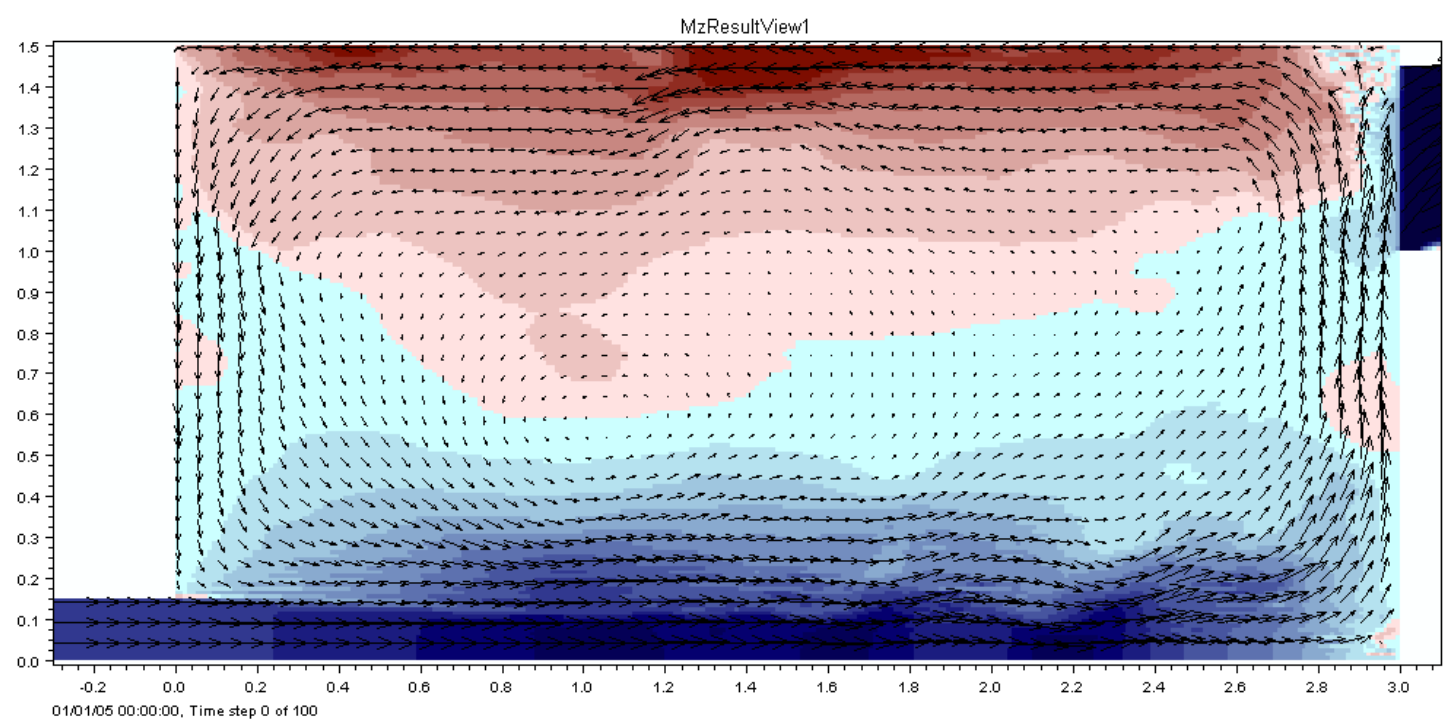

Figura 93 - Padrão instantâneo do escoamento simulado com modelo de turbulência de Smagorinsky.

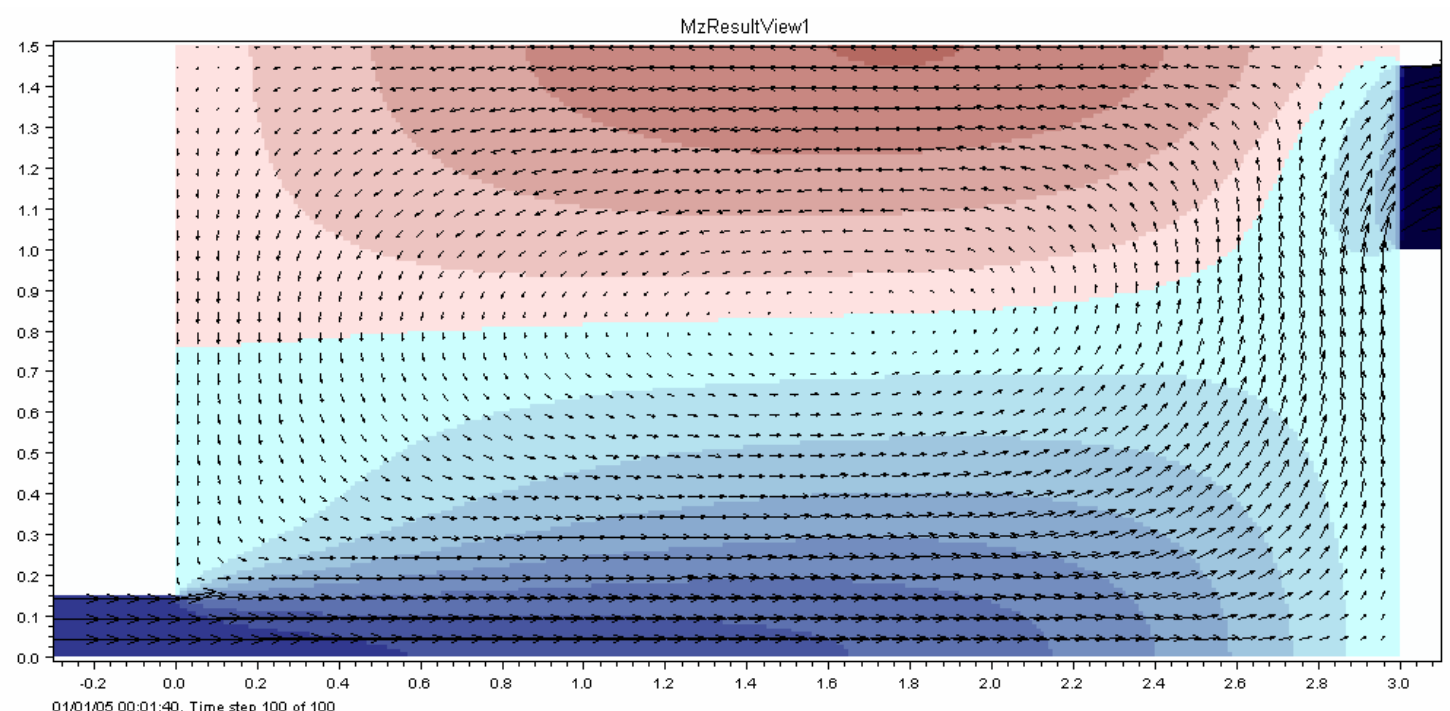

Figura 94 - Padrão do escoamento simulado com viscosidade turbulenta constante $0,001 \mathrm{~m}^{2} / \mathrm{s}$. 


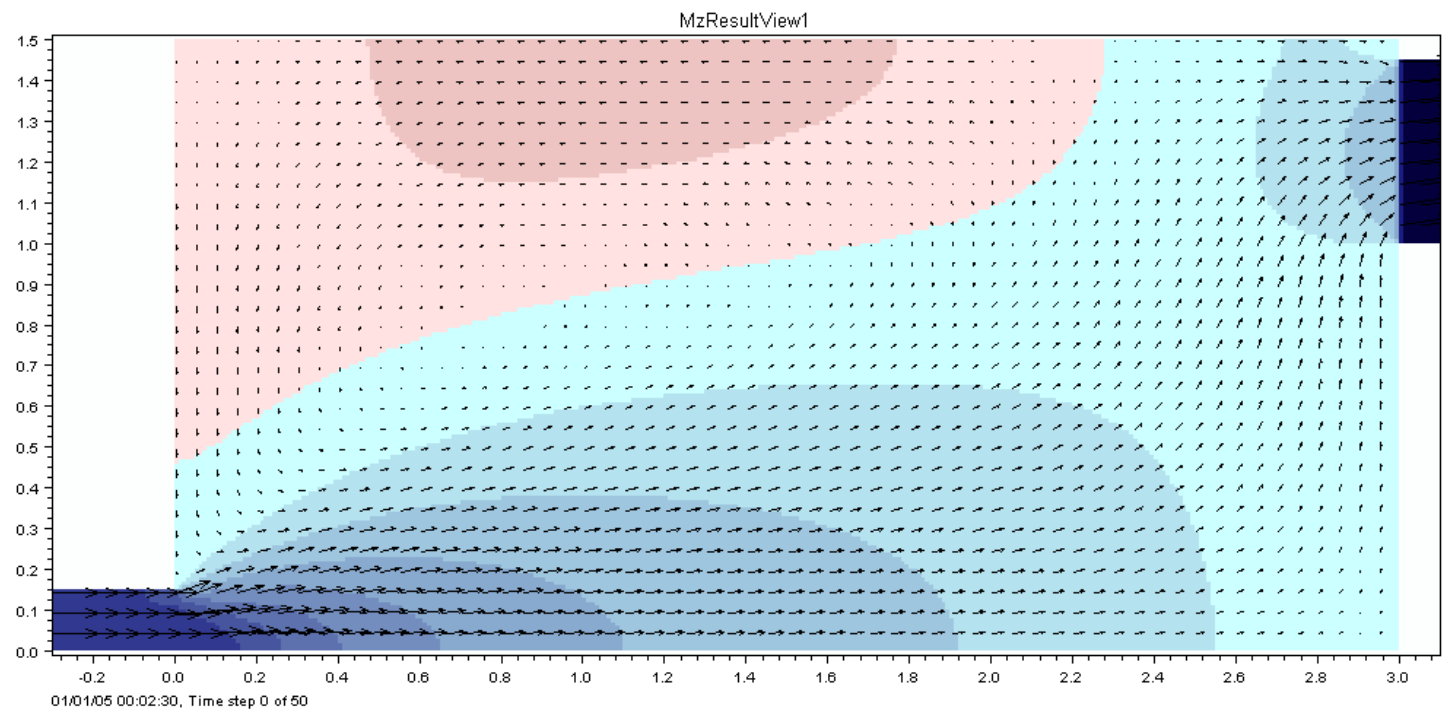

Figura 95 - Padrão do escoamento simulado com viscosidade turbulenta constante $0,05 \mathrm{~m}^{2} / \mathrm{s}$.

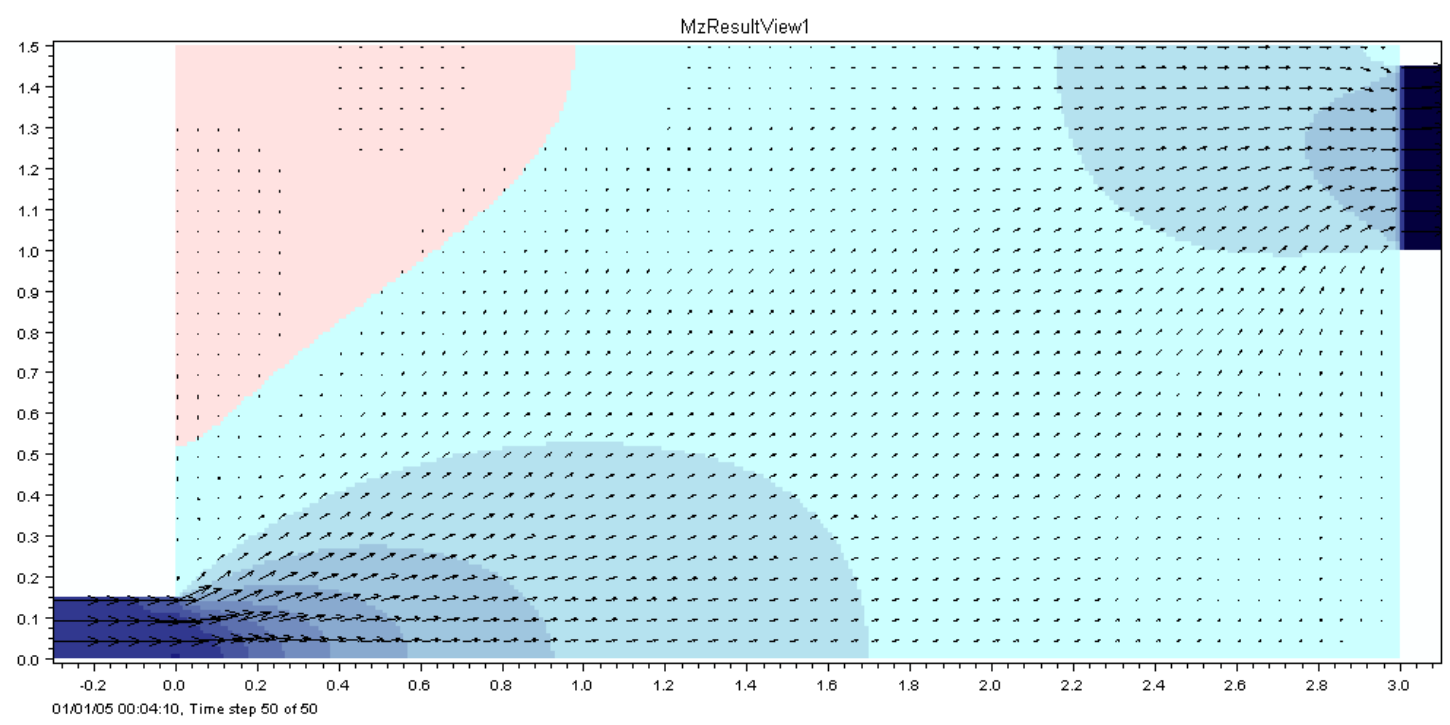

Figura 96 - do escoamento simulado com viscosidade turbulenta constante $0,01 \mathrm{~m}^{2} / \mathrm{s}$.

A divergência das linhas de corrente na entrada da armadilha, mostrada na Figura 96, auxilia na formação de um assoreamento mais arredondado e regular, como o ocorrido em laboratório. 


\section{Simulação final do assoreamento}

O resultado final do assoreamento simulado, com viscosidade turbulenta constante $0,01 \mathrm{~m}^{2} / \mathrm{s}$, é mostrado nas Figuras 97-104. Juntamente com as ilustrações de instantes da simulação, mostra-se imagens do assoreamento real para comparação imediata. Observase na Figura 98 que, mesmo com uma viscosidade turbulenta constante destinada a uma boa representação acima de 4 ou 5 horas de assoreamento, o início da simulação representou de forma considerável a deposição de areia na entrada da armadilha..

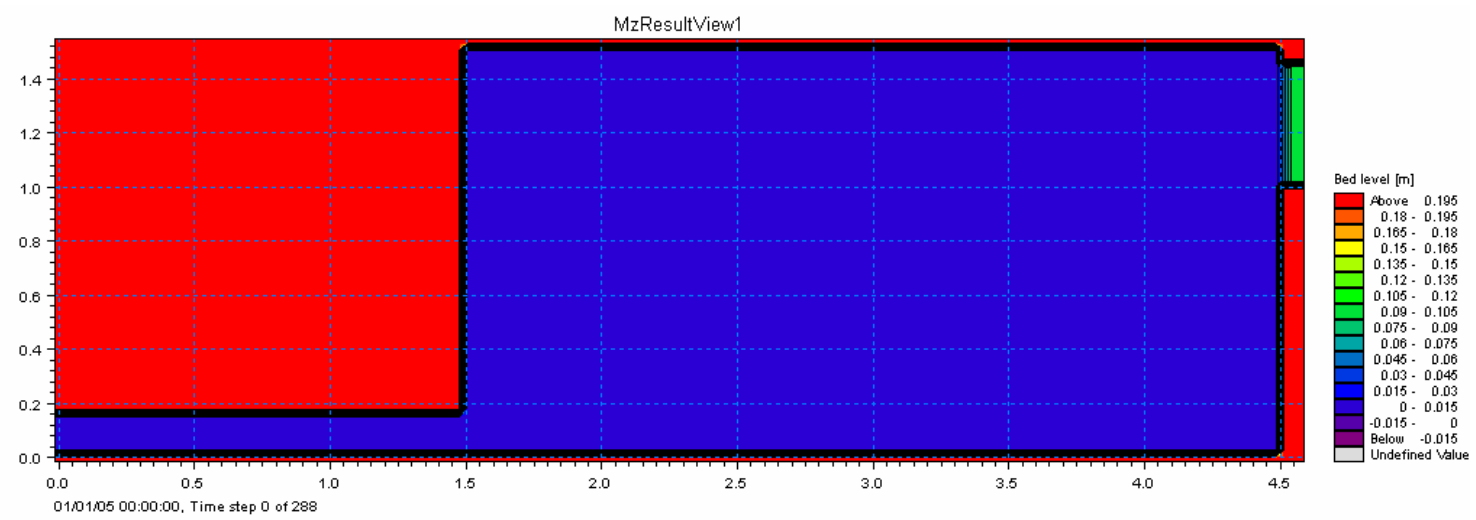

Figura 97 - Situação da armadilha, antes do assoreamento.

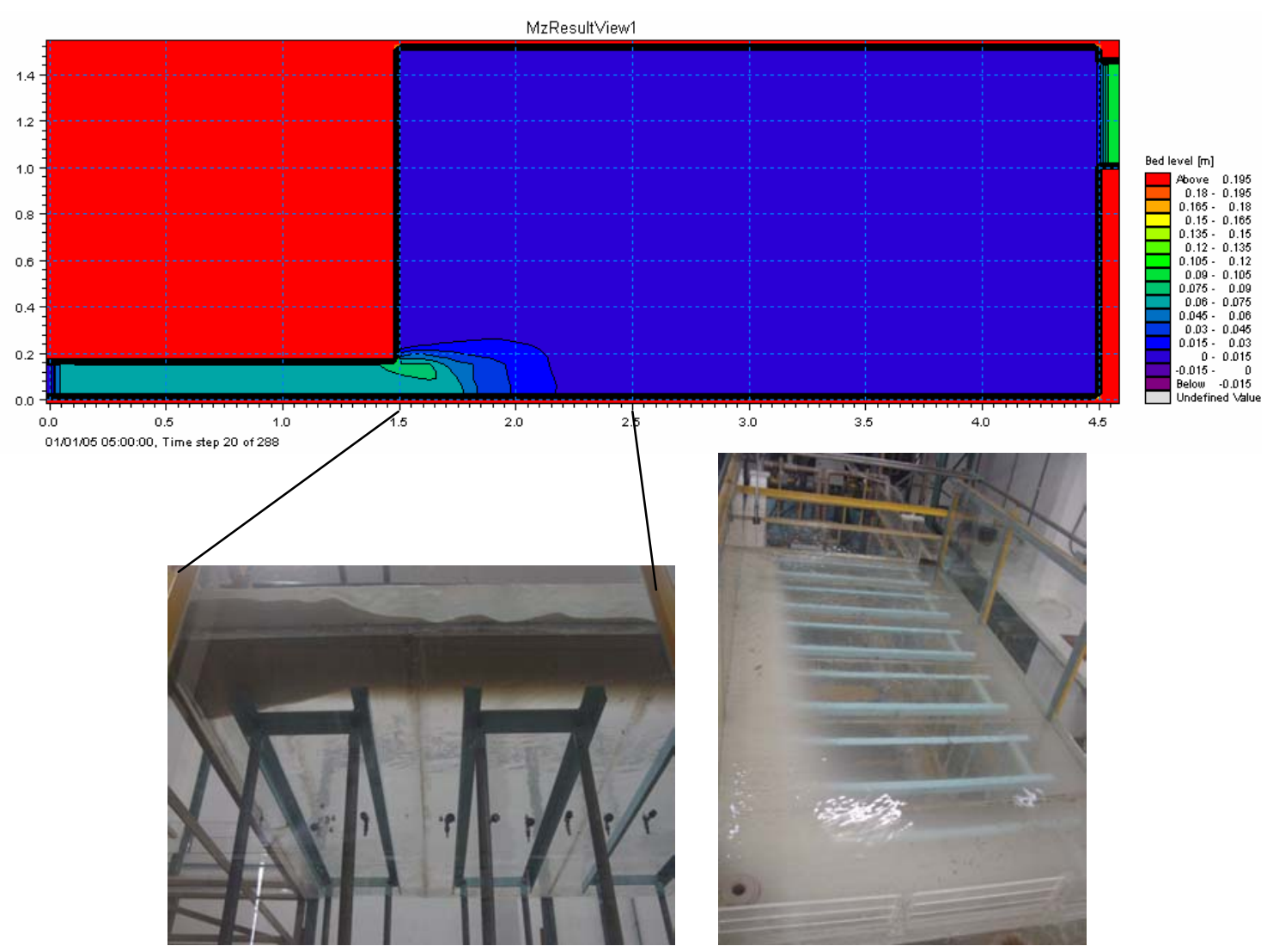

Figura 98 - Simulação e experimento para $5 \mathrm{~h}$ de assoreamento. As fotos trazem uma vista de um ponto sob a armadilha e uma vista superior da armadilha. As retas na cor preta localizam pontos da armadilha na ilustração da simulação. 
O assoreamento simulado com $10 \mathrm{~h}$ representa bem a realidade (Figura 99). É alongado, entrando na armadilha com altura entre $7,5 \mathrm{~cm}$ e $9,0 \mathrm{~cm}$, no primeiro $0,5 \mathrm{~m}$ do comprimento (sentido longitudinal da armadilha). De $0,5 \mathrm{~m}$ a $1,0 \mathrm{~m}$, eleva-se para uma altura entre $9,0 \mathrm{~cm}$ e $10,5 \mathrm{~cm}$. Essa elevação é notada na vista lateral do primeiro metro de comprimento da armadilha real. De $1,0 \mathrm{~m}$ a $1,5 \mathrm{~m}$ ocorre a diminuição do assoreamento tanto para simulação como para experimento, embora mais acentuada para este último. As vistas superior e inferior da armadilha auxiliam na observação do experimento nesse instante.

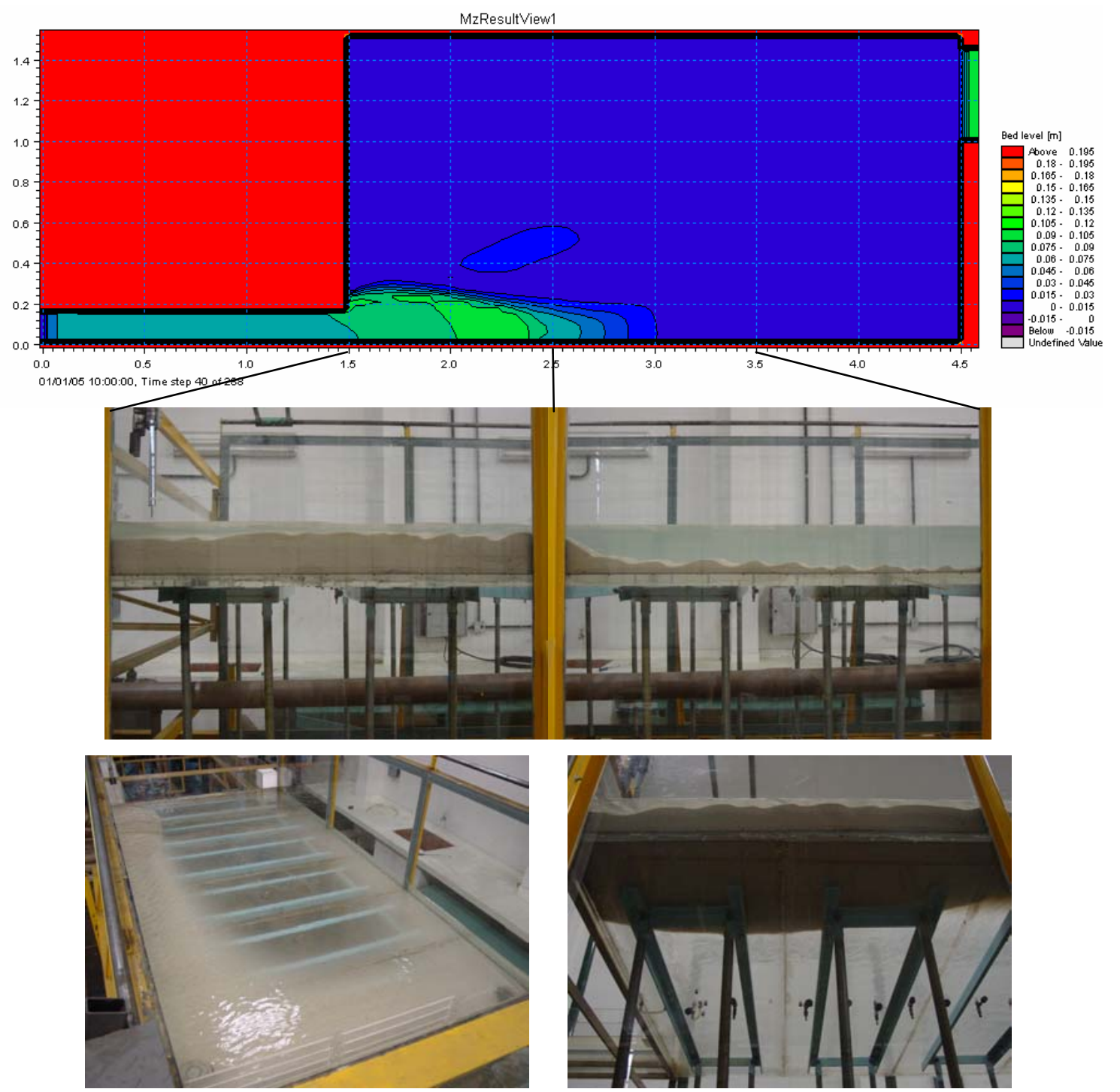

Figura 99 - Assoreamento com 10h. 
Com 20h, o assoreamento simulado apresenta-se arredondado, com talude (no contorno do assoreamento) íngreme no sentido transversal e mais suave no sentido longitudinal da armadilha. Sua semelhança com a situação experimental é observada na Figura 100.

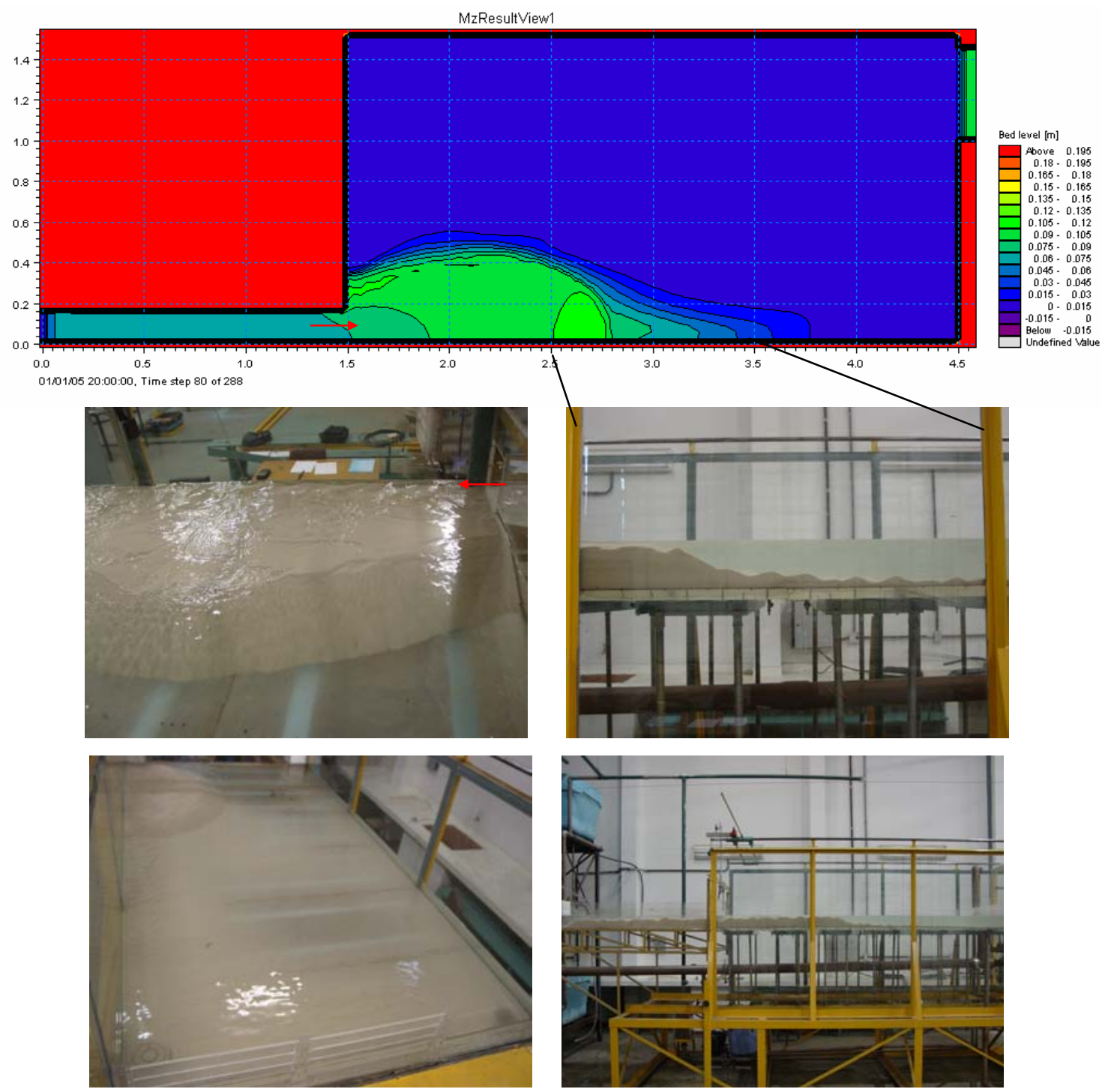

Figura 100 - Assoreamento com 20h. A seta vermelha localiza a ligação do canal com a armadilha.

Nas horas seguintes, a forma arredondada do assoreamento e sua altura máxima praticamente de mantêm, porém com expansão para dentro da armadilha. A declividade do talude em todo o contorno se torna um pouco mais suave na simulação, o que não acontece no experimento (situação ilustrada na Figura 101, com 30h). O assoreamento no canal aumenta sensivelmente em altura, pois a maior resistência ao escoamento imposta pelo maior volume de areia na armadilha causa uma sensível elevação da 
superfície da água no canal com diminuição da sua capacidade de transporte, até que o equilíbrio seja atingido novamente. A variação da altura da superfície da água durante o assoreamento simulado pode ser acompanhada em vídeo, no DVD.
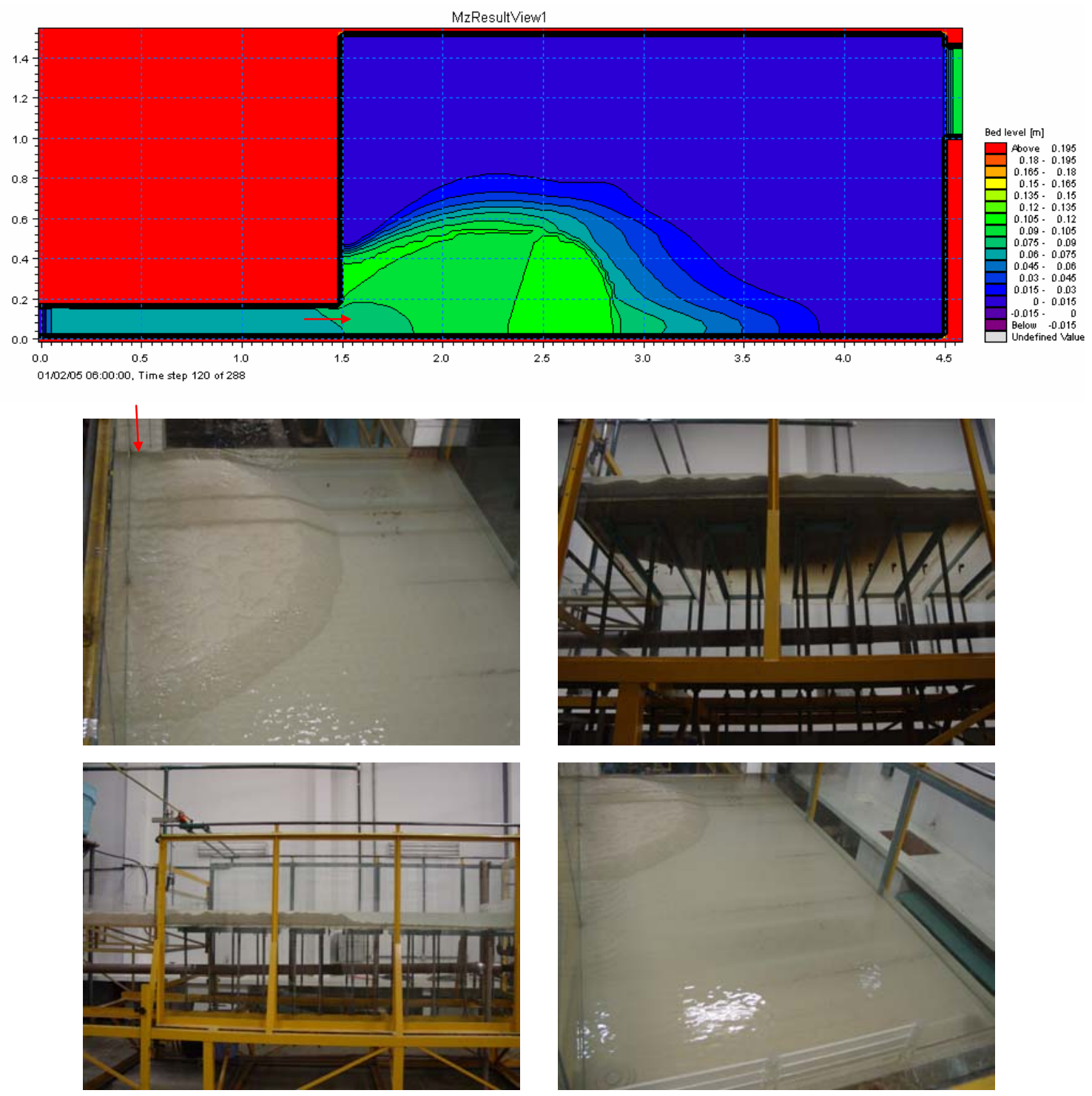

Figura 101 - Assoreamento com 30h.

Com 50h, a simulação expande o assoreamento preponderantemente no sentido transversal da armadilha, perdendo um pouco em extensão para a situação real (experimental). A declividade do talude no contorno permanece mais suave na simulação. A situação é ilustrada na Figura 102. 


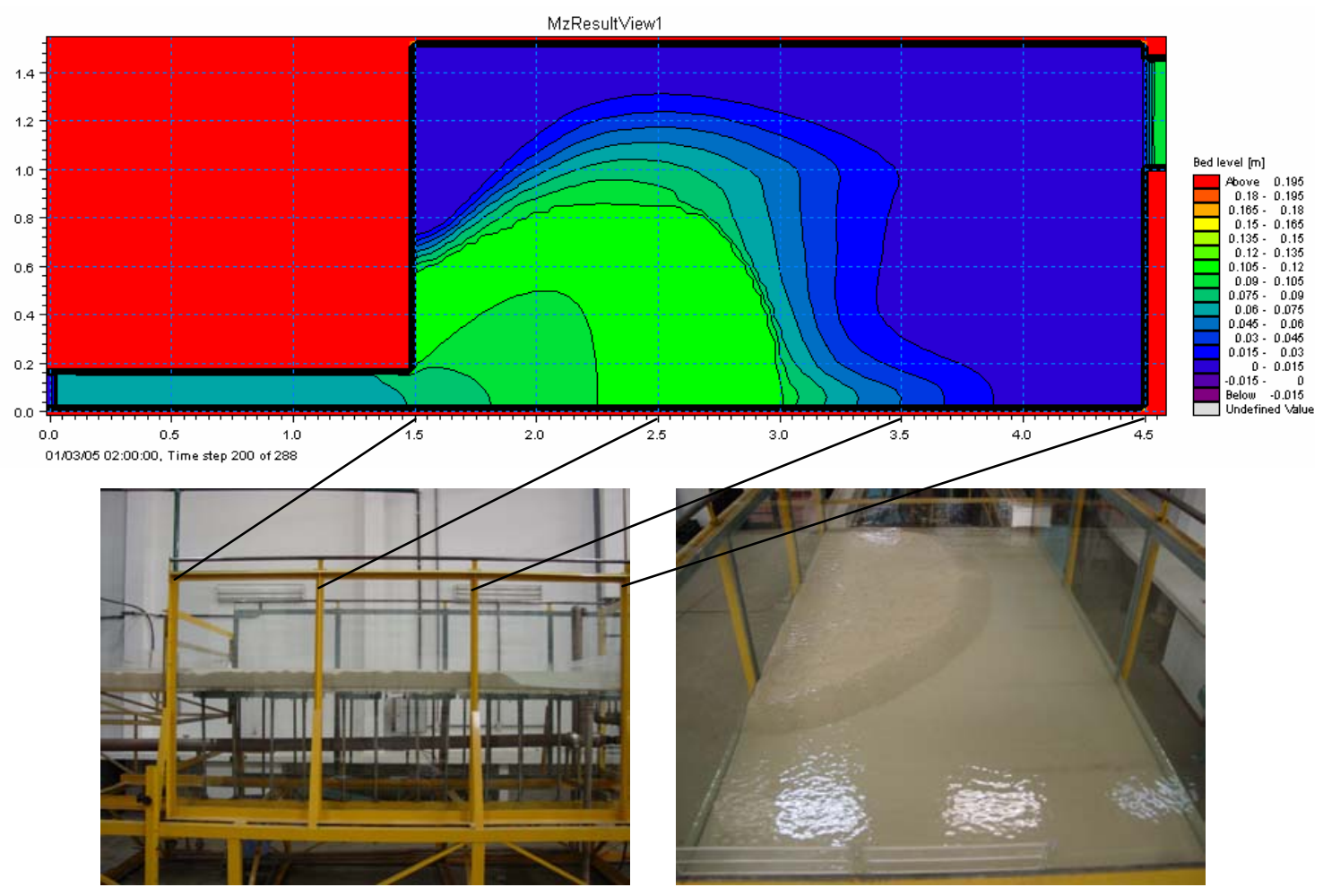

Figura 102 - Assoreamento com 50h

$\mathrm{Na}$ Figura 103, representativa de 60h, o assoreamento simulado passa novamente a ter uma expansão maior na direção longitudinal da armadilha, porém ainda inferior ao real. .
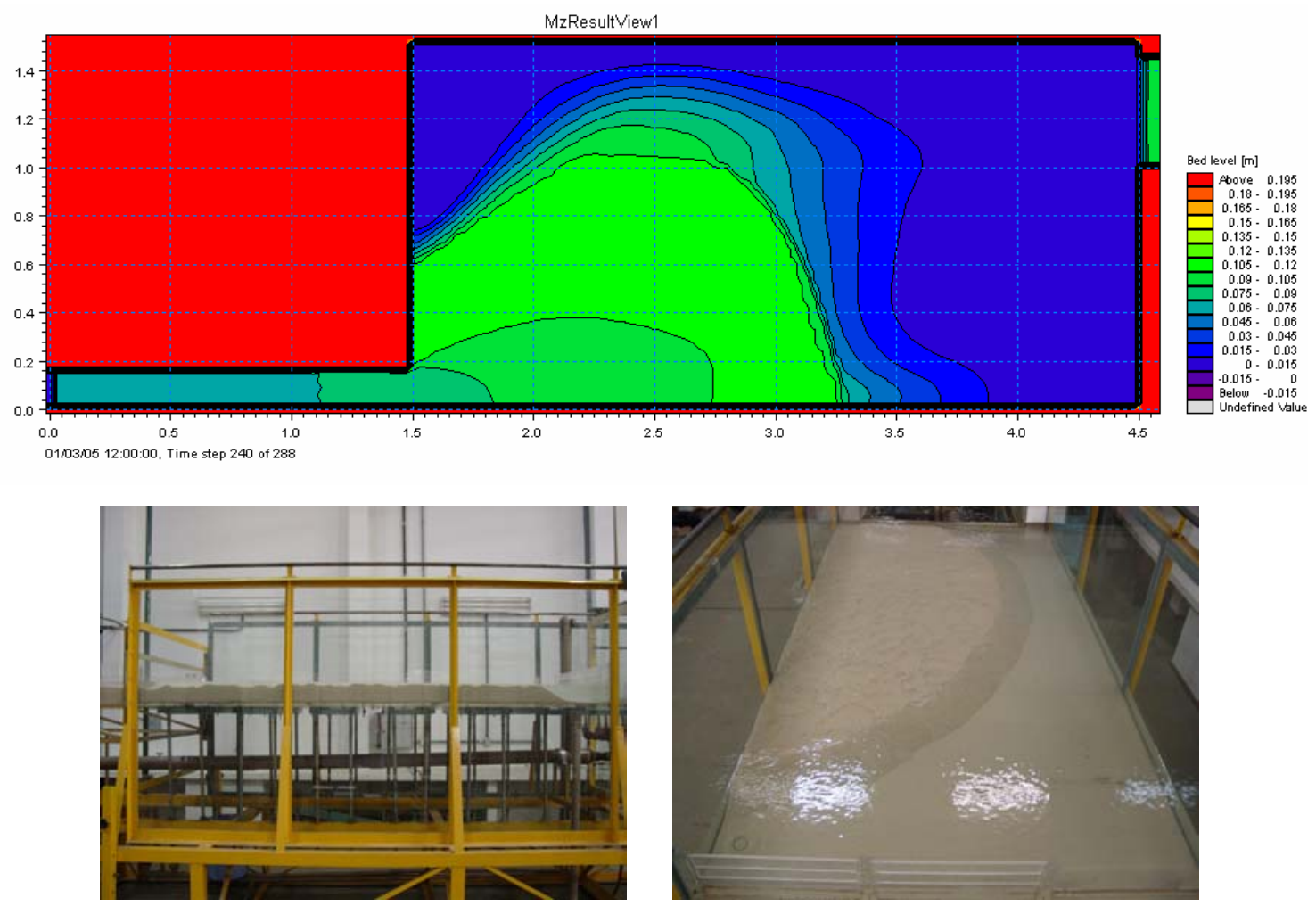

Figura 103 - Assoreamento com 60h. 
As últimas 12 horas da simulação mantiveram a expansão longitudinal do assoreamento. Seu resultado final, com $72 \mathrm{~h}$ e ilustrado na Figura 104, mostrou-se mais irregular, com taludes mais suaves no contorno e uma formação de areia de menores dimensões que o resultado experimental, tanto no sentido longitudinal quanto no sentido transversal da armadilha. Por outro lado, o assoreamento simulado tem forma arredondada e com uma grande região consideravelmente plana e horizontal, de altura entre $9 \mathrm{~cm}$ e $12 \mathrm{~cm}$, bem representativa do resultado experimental.

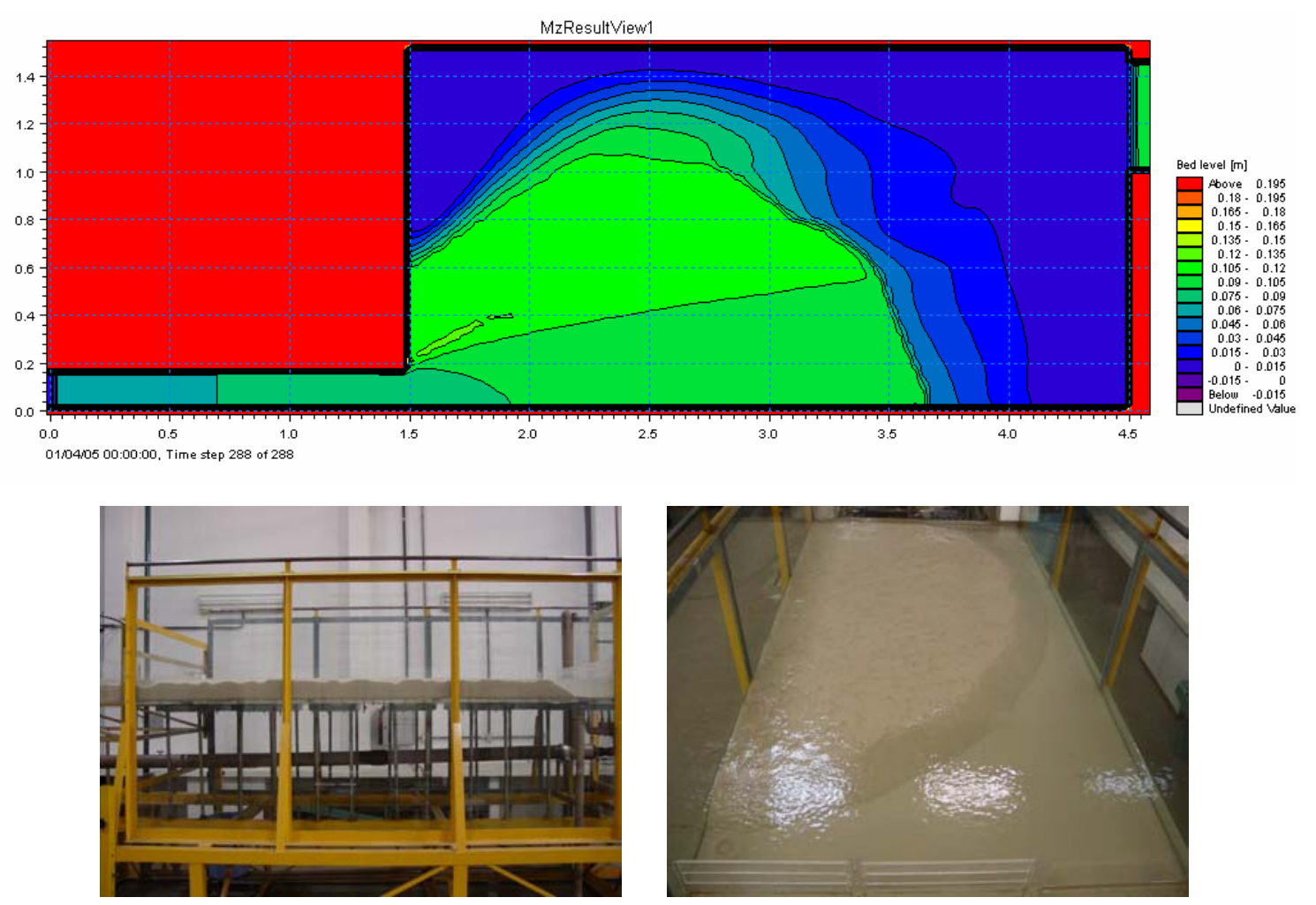

Figura 104 - Assoreamento com 72h.

Algumas visualizações tridimensionais do assoreamento simulado foram geradas, com uso do programa MATLAB, para os instantes referentes a $37 \mathrm{~h}$ (quando o experimento foi interrompido e iniciado no dia seguinte) e $72 \mathrm{~h}$ (final do experimento). Essas visualizações são mostradas nas Figuras 105 e 106, juntamente com as respectivas imagens do experimento. A escala de cores refere-se à elevação do fundo, na simulação. 

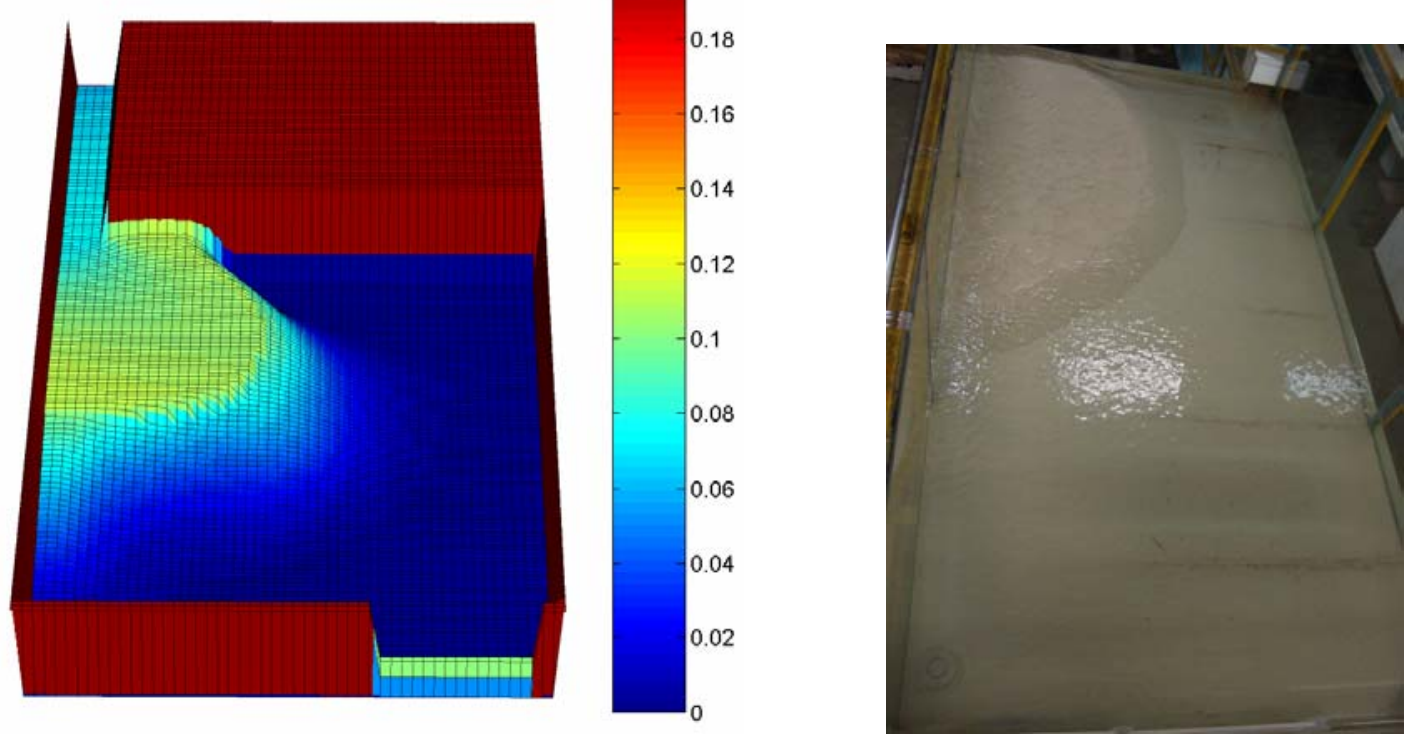

Figura 105 - Assoreamento com 37h. A unidade da escala é o metro.
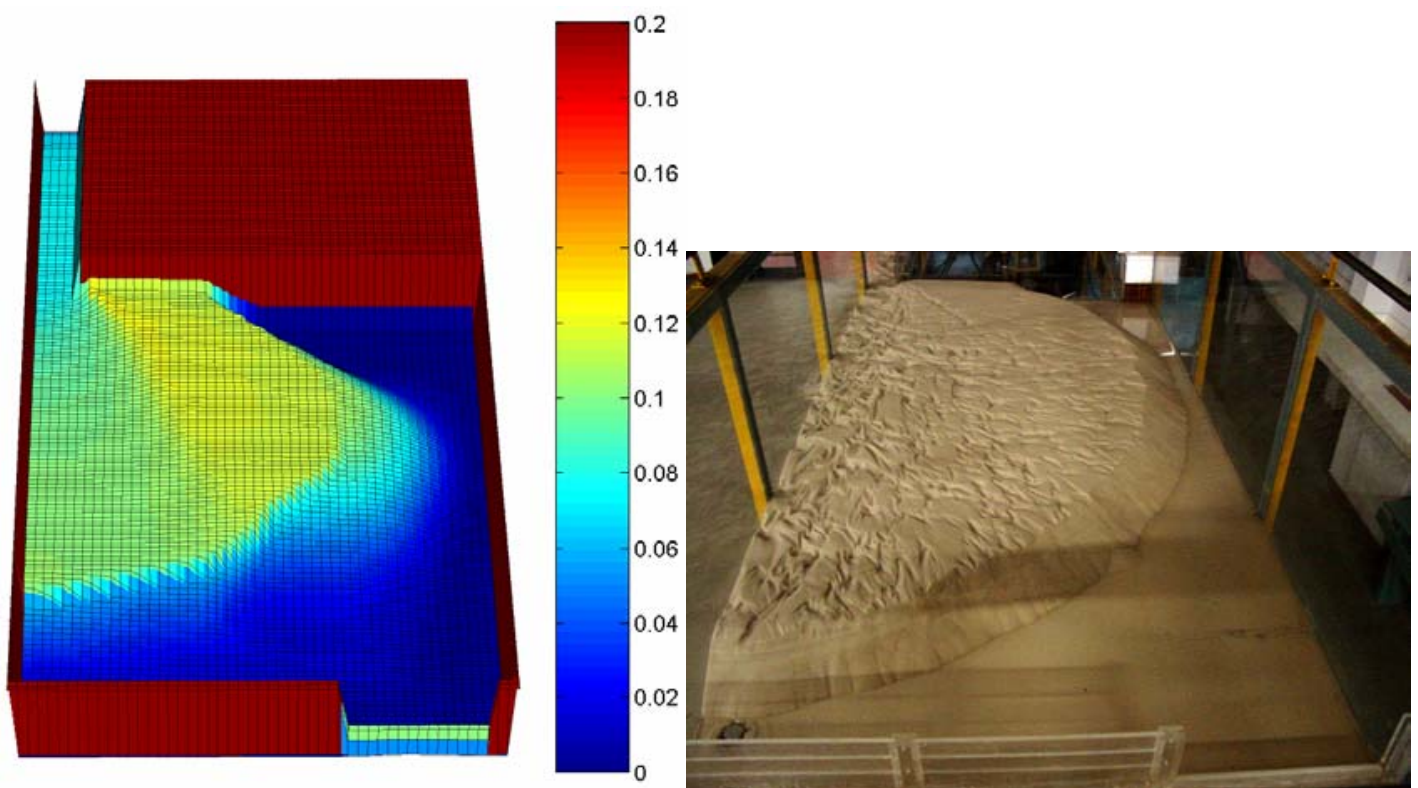

Figura 106 - Assoreamento com $72 \mathrm{~h}$

Com base no assoreamento final da Figura 106, faz-se uma comparação com relação ao padrão do escoamento. Na ilustração da simulação, tem-se uma região de altura referente à cor verde na escala, saindo do canal e se expandindo transversalmente, à medida que se caminha no sentido longitudinal da armadilha. Essa região define o escoamento preferencial, proveniente do canal, nas horas finais do assoreamento, como apresentado na Figura 107. Na imagem do experimento, ampliada na Figura 108, as ravinas formadas pelo escoamento mais intenso sobre o assoreamento concentram-se 
também nessa região. Supõe-se com essa análise que a simulação mantém boa representação nessa região não só do assoreamento, mas também do padrão do escoamento ao final do trabalho.

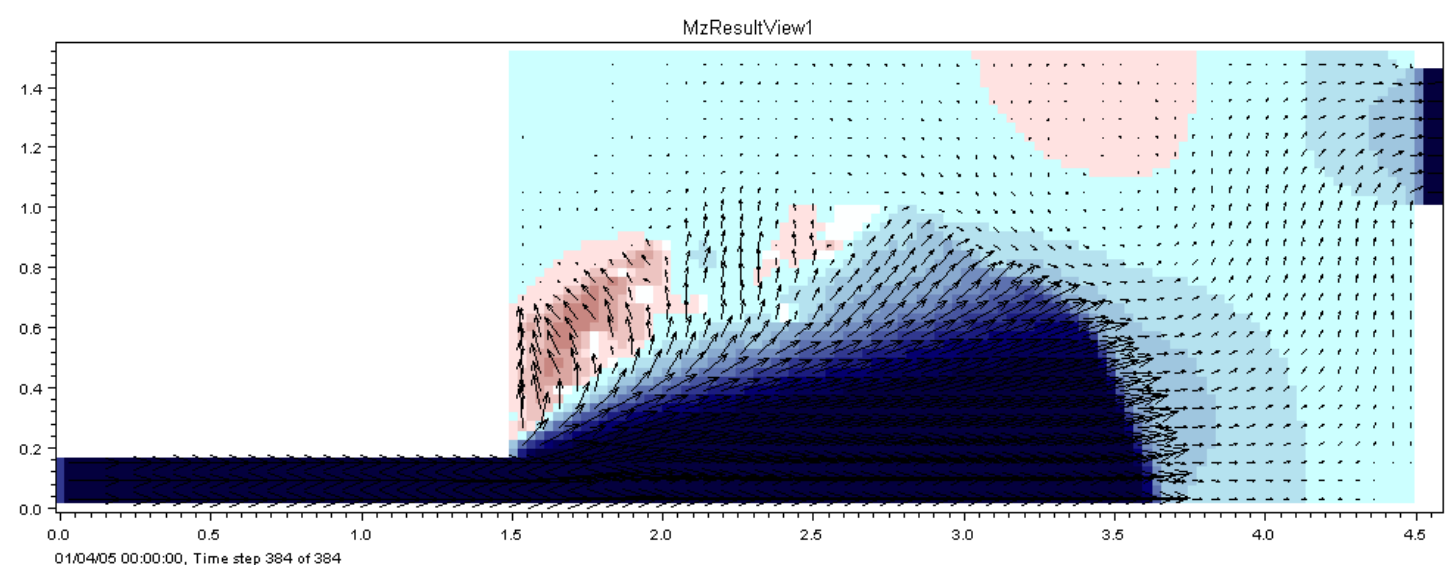

Figura 107 - Padrão do escoamento simulado para 72h.

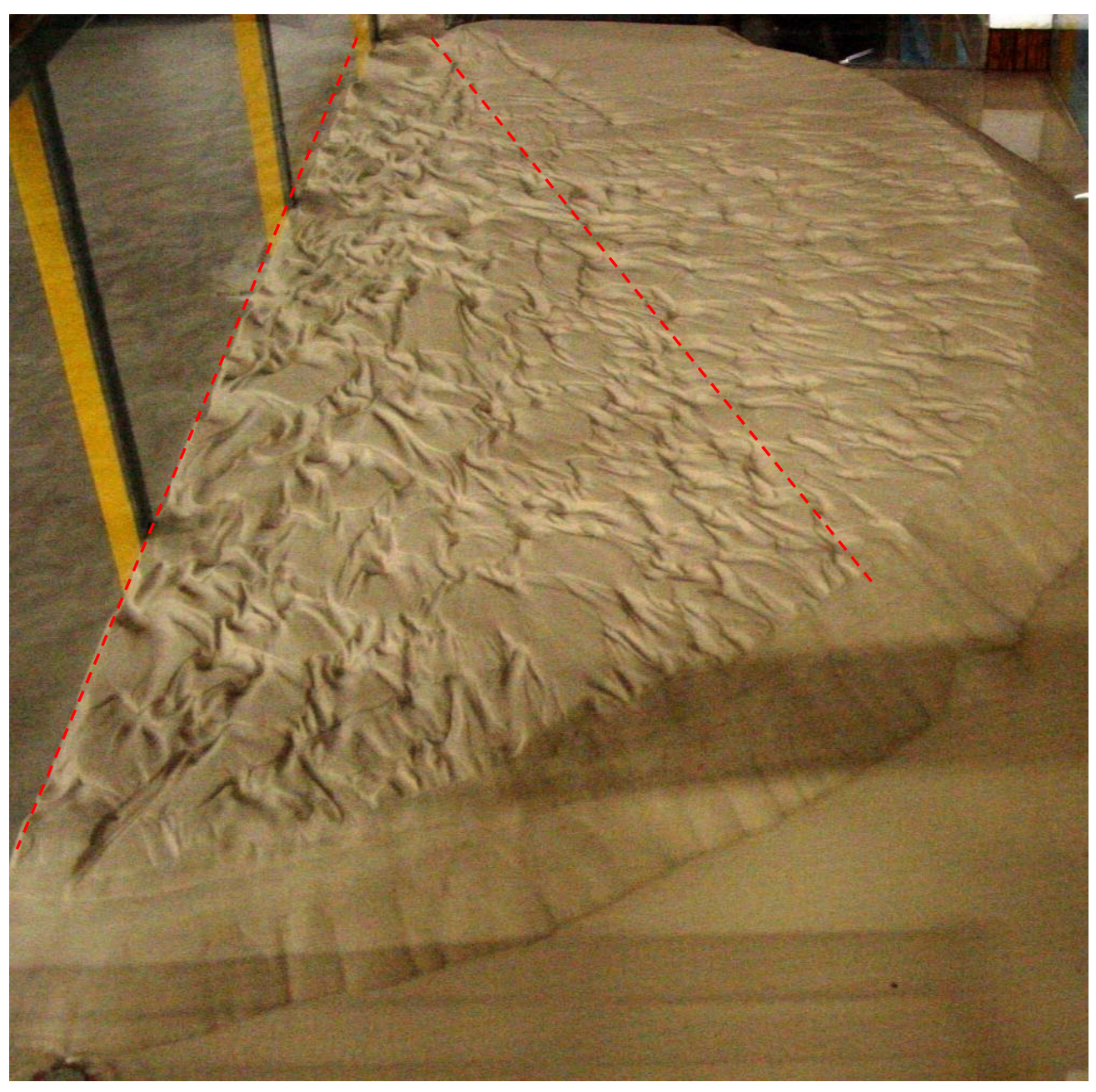

Figura 108 - Formação de ravinas mais intensa na região delimitada pelas linhas em vermelho. 
As regiões na cor branca na armadilha da Figura 107 representam células com assoreamento próximo à superfície da água, nas quais o processo de cálculo do escoamento foi interrompido. A altura de água nessas células é inferior a $0,002 \mathrm{~m}$.

\subsubsection{Comparação de seções transversais}

Quatro seções transversais do assoreamento para $37 \mathrm{~h}$ e $72 \mathrm{~h}$ foram representadas. Os gráficos experimentais não apresentam pontos discretos, pois foram feitos com base em observação visual durante o experimento, fotos tiradas de diferentes ângulos e apenas alguns pontos medidos para referência de altura. Para uma obtenção eficiente das seções transversais, seria necessário um sistema automatizado para medição rápida e detalhada do assoreamento, com captura da elevação das dunas e ravinas em toda a armadilha. Para a simulação, os pontos do gráfico representam a medida do assoreamento em cada célula da malha computacional. As seções transversais são localizadas na armadilha de acordo com a Figura 109.

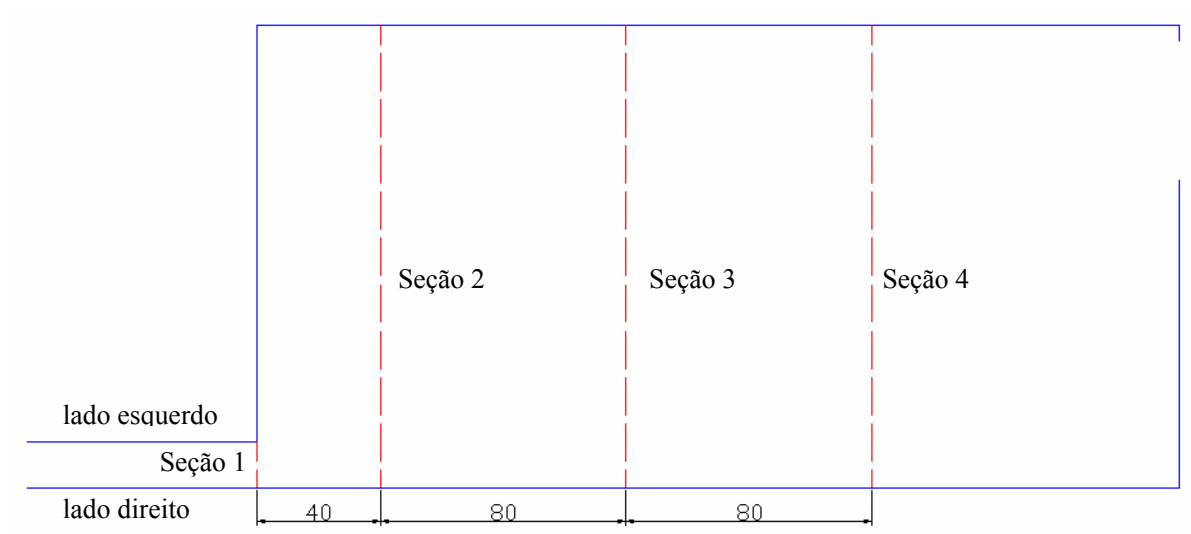

Figura 109 - Localização das seções transversais analisadas, do assoreamento na armadilha. Cotas em centímetros.

Para 37h, as seções transversais são apresentadas nas Figuras 110-113. Na Seção 1, Figura 110, ambos resultados mostraram maior assoreamento do lado esquerdo (lado esquerdo mostrado na Figura 109), na entrada da armadilha. 


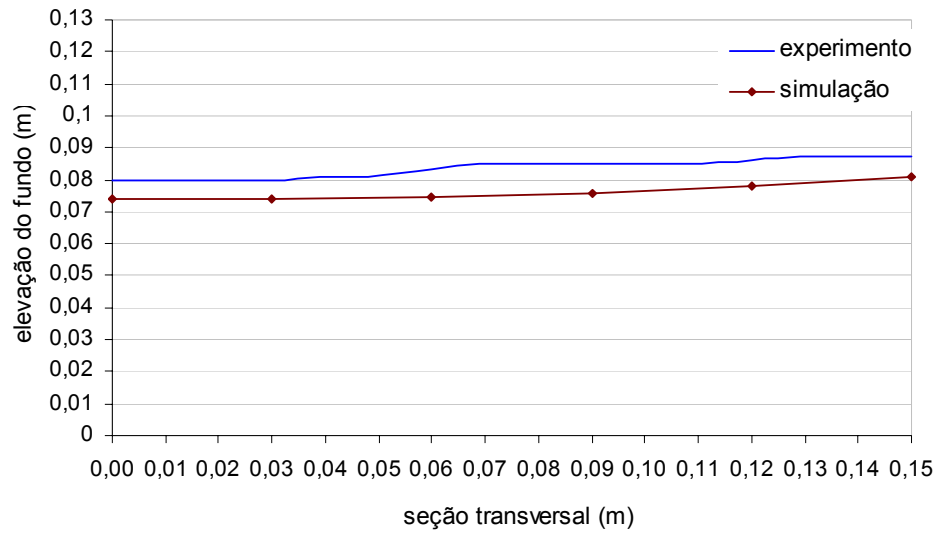

Figura 110 - Comparação Experimento x Simulação do assoreamento com 37h, na Seção 1.

Nas Figuras 111-113, o talude no contorno do assoreamento simulado apresenta declividade menos constante e mais suave.

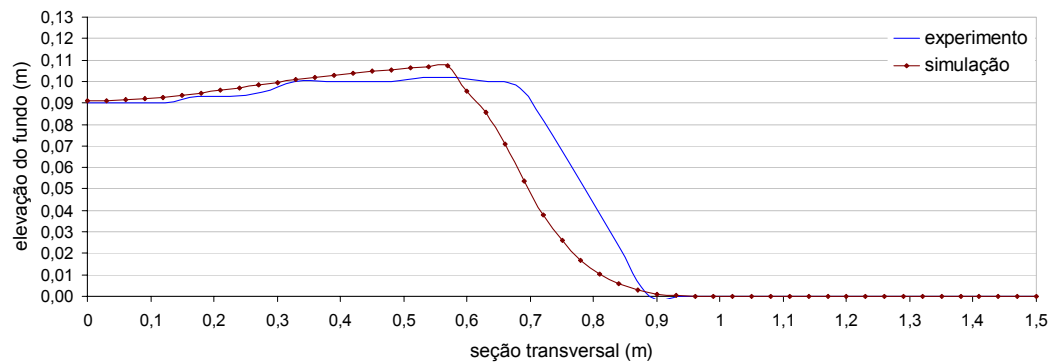

Figura 111 - Comparação Experimento x Simulação do assoreamento com 37h, na Seção 2.

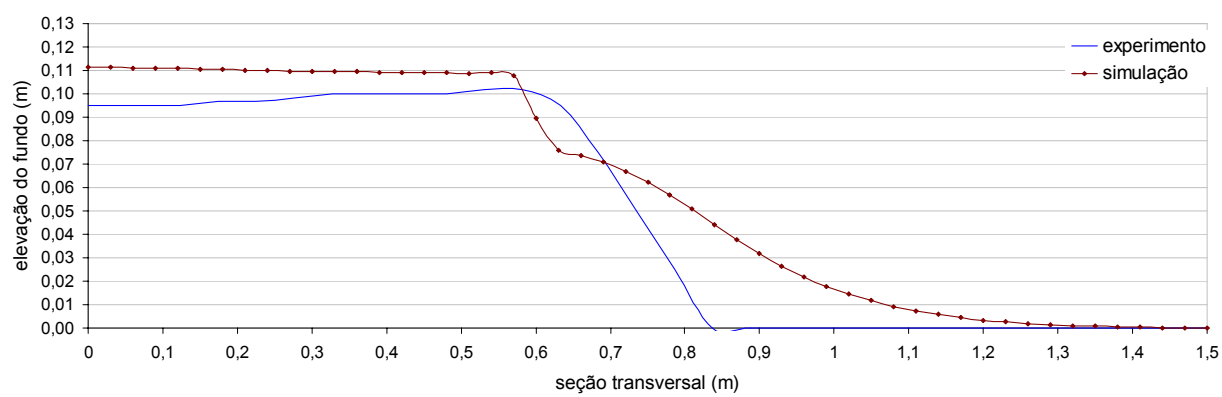

Figura 112 - Comparação Experimento x Simulação do assoreamento com 37h, na Seção 3.

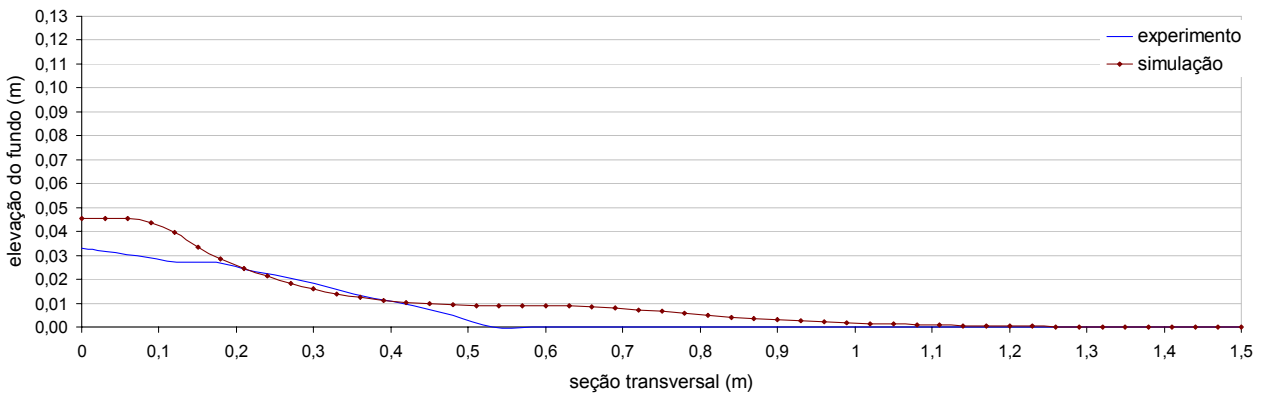

Figura 113 - Comparação Experimento x Simulação do assoreamento com 37h, na Seção 4. 
Em todas as seções transversais analisadas com $37 \mathrm{~h}$ de assoreamento, os resultados simulados foram considerados satisfatórios.

As seções referentes a 72h são ilustradas nas Figuras 114-117. A divergência entre os resultados a ser considerada se resume à forma da Seção 4, mais regular para o experimento. A superfície do assoreamento experimental é mais plana, horizontal e se expande mais para a esquerda. $\mathrm{O}$ talude no experimento apresenta-se mais regular, com praticamente a mesma declividade em todo o contorno da formação de areia

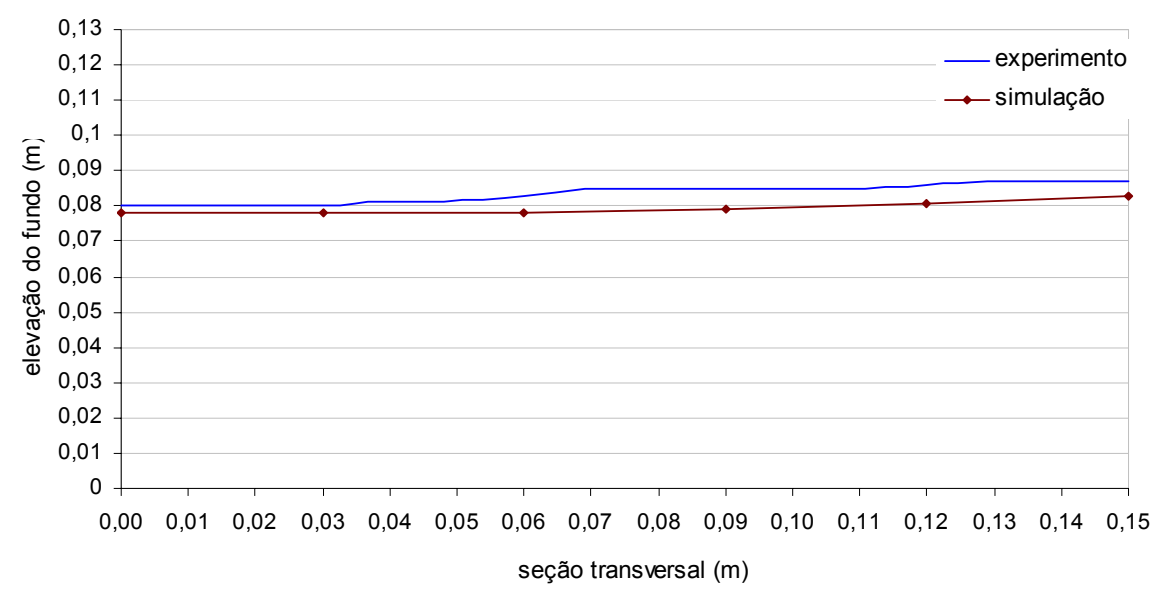

Figura 114 - Comparação Experimento x Simulação do assoreamento com 72h, na seção 1.

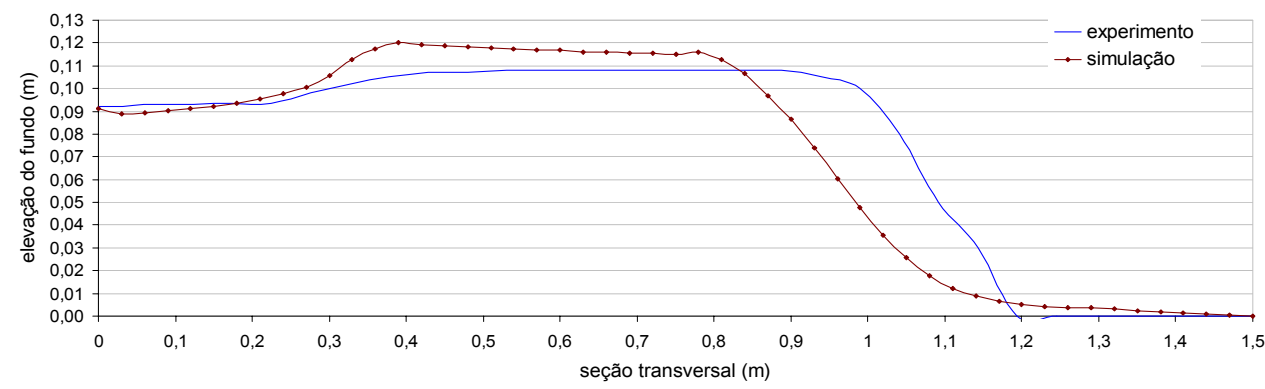

Figura 115 - Comparação Experimento x Simulação do assoreamento com 72h, na seção 2.

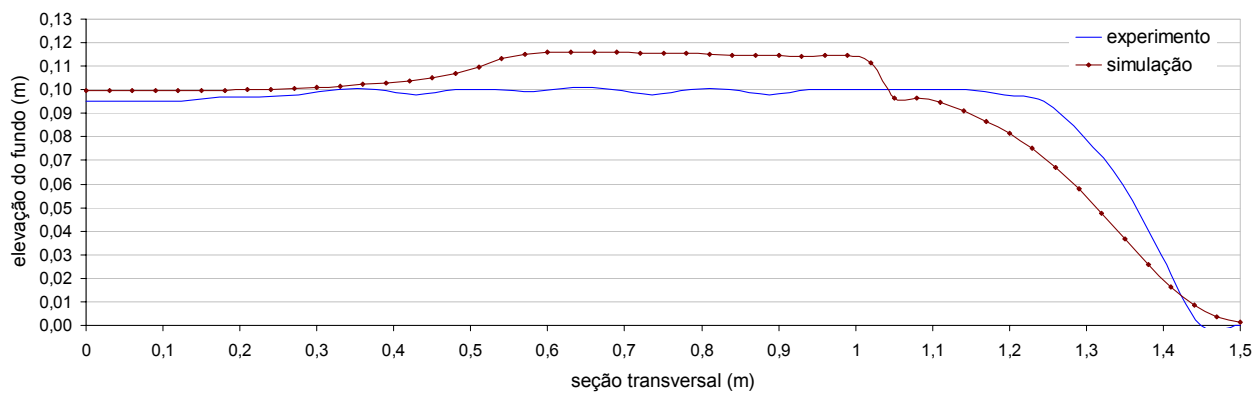

Figura 116 - Comparação Experimento x Simulação do assoreamento com 72h, na seção 3. 


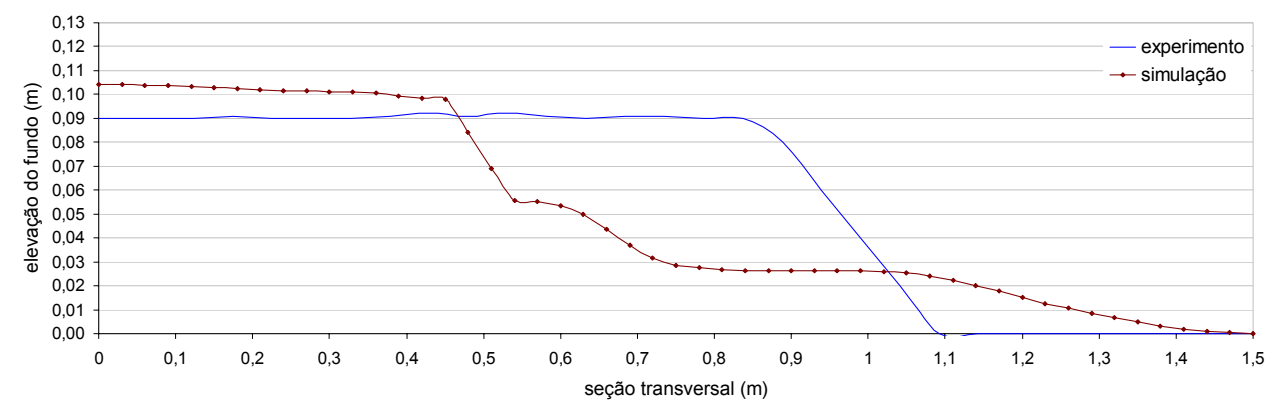

Figura 116 - Comparação Experimento x Simulação do assoreamento com 72h, na seção 4

O volume total do assoreamento também foi comparado para $72 \mathrm{~h}$. Para o experimento, coletou-se amostras da água na saída sobre o vertedor para análise dos sólidos em suspensão, de acordo com Standard Methods for Examination of Water and Wastewater, item 2540. O resultado foi uma concentração de $16,0 \mathrm{mg} / \mathrm{L}$ de sólidos suspensos (fixos + voláteis), para o final do experimento, na saída do vertedor. Essa descarga, caso fosse constante durante todo o experimento, acarretaria um volume de saída de $8,3 \mathrm{~kg}$ de areia. Porém, ao final do experimento, o volume de areia depositado na estrutura de recirculação da água (caixas de água e região a jusante do vertedor) mostrou-se desprezível. Dessa forma, considerou-se que todo o volume de areia usado no experimento foi depositado na armadilha (armadilha e canal de entrada); e seu volume foi calculado da forma:

Descarga que entra $=2 \mathrm{~g} / \mathrm{s}$

Tempo $=72 \mathrm{~h}=259200 \mathrm{~s}$

Massa total que entra $=$ descarga que entra $\mathrm{x}$ tempo $=518400 \mathrm{~g}=518,4 \mathrm{~kg}$ Massa específica aparente seca $=1760 \mathrm{~kg} / \mathrm{m}^{3}$

Volume total que entra $=$ massa que entra $/$ massa específica $=0,294545 \mathrm{~m}^{3}$

Vol $_{\text {experimental }}=0,294545 \mathrm{~m}^{3}$.

Para o assoreamento simulado, obteve-se Vol $_{\text {simulado }}=\mathbf{0 , 2 5 6 9 2 6 \mathbf { m } ^ { 3 }}$.

Com esses dados, tem-se como erro da simulação, para o volume final do assoreamento na armadilha:

Erro absoluto $=\mathrm{Vol}_{\text {simulado }}-\mathrm{Vol}_{\text {experimental }}=-0,037619 \mathrm{~m}^{3}$. 
Erro relativo $=\frac{\mathrm{Vol}_{\text {simulado }}-\mathrm{Vol}_{\text {exp erimental }}}{\mathrm{Vol}_{\text {exp erimental }}}=-0,127719=-12,77 \%$.

É provável que a simulação tenha apresentado maior transporte de sedimentos em suspensão, se comparada ao experimento, causando uma maior saída de volume de areia pelo vertedor.

As comparações de resultados apresentadas neste capítulo, tanto para o padrão do escoamento quanto para a deposição de areia na armadilha, comprovaram a capacidade do programa MIKE $21 \mathrm{C}$ de reproduzir o assoreamento experimental conduzido em laboratório.

Resultados consideravelmente diferentes de escoamento e assoreamento foram obtidos com pequenas variações nos parâmetros de entrada do programa, para as diversas simulações testadas até o resultado final. A calibração do modelo deve ser feita cuidadosamente, com base em dados de campo, modelagem física do problema ou experiência do simulador. Alguns resultados dessas simulações preliminares são apresentados no APÊNDICE D_RESULTADOS DE SIMULAÇÕES COM DIFERENTES PARÂMETROS DE ENTRADA NO PROGRAMA MIKE 21C, NÃO REPRESENTATIVOS DO EXPERIMENTO.

Os vídeos da simulação se encontram na PASTA 6_SIMULAÇÃO_VÍDEOS DO ASSOREAMENTO, no DVD. São eles:

- Assoreamento;

- Elevação da superfície da água;

- Hidrodinâmica durante o assoreamento. Este vídeo se inicia 24 antes do assoreamento, partindo com o fluido em repouso;

- Transporte de fundo na direção longitudinal;

- Transporte de fundo na direção transversal;

- Transporte em suspensão na direção longitudinal;

- Transporte em suspensão na direção transversal. 


\section{CONCLUSÕES}

\section{Referentes ao trabalho experimental}

A armadilha de sedimentos construída auxilia em pesquisas de transporte de sedimentos e assoreamento de reservatórios, proporcionando diferentes configurações de vazão nos canais afluentes, descarga de sedimento e abertura de vertedor.

As paredes em acrílico possibilitam observação, de diferentes pontos de vista, do transporte de sedimentos nos canais e da evolução do assoreamento na armadilha, permitindo melhor estudo desses processos.

O sistema de alimentação de areia desenvolvido mostrou-se eficiente em testes preliminares de assoreamento, apresentando uma descarga relativamente constante do material nos canais.

Apesar de aplicada a pequenas regiões do escoamento, a técnica de velocimetria a laser foi útil na determinação do padrão do escoamento médio na armadilha, para comparação e validação dos resultados simulados.

Com base nos campos de velocidade obtidos para várias regiões da armadilha, estimou-se o comportamento inicial do processo de assoreamento, comprovado experimentalmente.

Ao longo do processo do assoreamento, o comportamento hidrodinâmico varia consideravelmente. Por esse motivo, certo cuidado é necessário ao se estender as características iniciais do assoreamento para estimativa das demais horas desse processo.

A mudança do padrão do assoreamento, após algumas horas de experimentação, deveu-se ao aumento considerável da viscosidade turbulenta e da resistência ao escoamento. A alta difusão de quantidade de movimento, diretamente relacionada à viscosidade turbulenta, fez com que o escoamento médio se comportasse como de um fluido muito viscoso. Houve então divergência das linhas de corrente na entrada do 
reservatório e a areia, transportada preponderantemente por advecção, formou o assoreamento distribuído, de forma regular e arredondada.

\section{Com relação ao trabalho de simulação}

Os resultados da simulação hidrodinâmica para as duas configurações de vazão, com uso do modelo de turbulência de Smagorinsky, representaram bem o comportamento do escoamento na armadilha, quando comparados com os dados obtidos através da velocimetria a laser.

A comparação pontual de valores de velocidade média no centro de cada região analisada não apresentou bons resultados para avaliação do padrão do escoamento simulado. A comparação do campo de velocidade média em cada região como um todo trouxe resultados mais significativos para o trabalho.

Como o programa MIKE 21C apresenta resultados médios de assoreamento, sem o detalhamento das formas de fundo, o aumento da difusividade turbulenta ocasionado pela formação das dunas não é captado pelo modelo de turbulência de Smagorinsky. A modelagem do assoreamento foi, por esse motivo, realizada com uma viscosidade turbulenta constante, igual a $0,01 \mathrm{~m}^{2} / \mathrm{s}$.

Resultados consideravelmente diferentes de escoamento e assoreamento podem ser obtidos com pequenas variações nos parâmetros de entrada do programa. A calibração do modelo deve ser feita cuidadosamente, com base em dados de campo, modelagem física do problema ou experiência do simulador.

A simulação do assoreamento na armadilha foi bem sucedida, mostrando boa semelhança com o trabalho de laboratório. Porém, para que o programa seja usado de forma confiável para estimativa do assoreamento de reservatórios, outros trabalhos comparativos devem ser realizados, com execução de experimentos em laboratório ou uso de batimetrias relativas a vários anos de vida de reservatórios reais.

\section{Do trabalho como um todo}

Construiu-se uma armadilha de sedimentos em laboratório e adquiriu-se um programa computacional para reprodução numérica do assoreamento experimental. Os experimentos e as simulações realizadas mostraram a eficiência dessas ferramentas e credenciam sua utilização em trabalhos seguintes. 
Alguns "passos em falso" foram dados ao longo do trabalho, como o desenvolvimento de uma simulação hidrodinâmica com modelo de Smagorinsky que não foi ao final usada no assoreamento e a falta de uma técnica eficiente de medição instantânea do assoreamento em toda a armadilha. $\mathrm{Na}$ realidade, esses passos evidenciaram ser este um trabalho inicial, de uma série envolvendo a armadilha e o programa MIKE 21C, que descreve suas falhas, transmite experiência e faz sugestões para que a metodologia desenvolvida seja aperfeiçoada e contribua para novas pesquisas envolvendo assoreamento de reservatórios. 


\section{SUGESTÕES PARA TRABALHOS FUTUROS}

Sugere-se aos trabalhos seguintes modificações no equipamento construído, realização de experimentos em laboratório e de simulações com o programa MIKE 21C que possam auxiliar na melhor compreensão do processo do assoreamento de reservatórios. Algumas sugestões também são feitas para que dificuldades encontradas na metodologia deste trabalho sejam minimizadas futuramente. Sugere-se então:

- A realização de assoreamento experimental e simulado para a Configuração 2 apresentada neste trabalho, cujo padrão do escoamento já está determinado;

- menores descargas de sedimento, no caso da mesma vazão de água ser adotada, para que o equilíbrio no transporte de sedimentos seja atingido com menor altura do assoreamento na armadilha. O trabalho computacional é dificultado quando o assoreamento se aproxima muito da superfície da água;

- variação da geometria da armadilha, com inclusão de declividade no fundo e retirada de ângulos vivos, para maior semelhança com reservatórios reais;

- desenvolvimento de uma metodologia eficiente para medição do assoreamento em toda a armadilha, ao longo do tempo;

- uso de traçadores para visualização do escoamento durante a evolução do assoreamento. Deve-se, porém, modificar a tubulação de recirculação de água para que o volume do fluido que contenha o traçador seja descartado após sua saída pelo vertedor, não retornando à armadilha;

- simulações de escoamento e assoreamento em reservatórios reais, desde que dados históricos de vazão, descarga de sedimentos e batimetria estejam disponíveis para comparação com os resultados computacionais. 


\section{REFERÊNCIAS BIBLIOGRÁFICAS}

ALAMY FILHO, J. E.; SCHULZ, H. E. (2005). Simulação de escoamento sobre forma de fundo complexa utilizando o método de fronteira imersa. In: SIMPÓSIO BRASILEIRO DE RECURSOS HÍDRICOS, 16, nov. João Pessoa, PB.

ALVIM, A. M. (1987). Modelo matemático bidimensional de assoreamento em reservatórios. 154 p. Dissertação (Mestrado) - Departamento de Hidráulica e Saneamento, Escola de Engenharia de São Carlos, Universidade de São Paulo, São Carlos.

AUPOIX, B. (1984). Eddy viscosity subgrid scale models for homogeneous turbulence. Macroscopic Modelling of Turbulent Flow, Lecture Notes in Physics, Proc. SophieAntipolis, França.

BARBOSA, A. A. (1999). Correntes de densidade em reservatórios. 278 p. + apêndice. Tese (Doutorado) - Departamento de Hidráulica e Saneamento, Escola de Engenharia de São Carlos, Universidade de São Paulo, São Carlos.

BOTELHO, D. A. (2000). Em direção à determinação da circulação e transporte de constituintes no reservatório Billings. 130 p. + apêndices. Dissertação (Mestrado) Departamento de Hidráulica e Saneamento - Área: Ciências da Engenharia Ambiental, Escola de Engenharia de São Carlos, Universidade de São Paulo, São Carlos. 1999.

CARVALHO, N.O. (1994). Hidrossedimentologia prática. Rio de Janeiro: CPRM.

CEHPAR - CENTRO DE HIDRÁULICA E HIDROLOGIA PROF. PARIGOT DE SOUZA (1981). Projeto HL-59. Estudos hidráulicos em modelo reduzido do aproveitamento hidrelétrico de Ilha Grande: relatório n.5: projeto, construção e calibragem do modelo destinado à avaliação das modificações do leito no canal esquerdo do rio. Curitiba: dez. 1981. 
CHANG, H. H. (1988). Fluvial processes in river engineering. Nova Iorque: John Wiley \& Sons.

CHANG, H. H. (1993). Fluvial 12 - Mathematical model for erodible channels - User's manual. San Diego.

CHANG, H. H.; Harrison, L. L.; Lee, W.; TU, S. (1996). Numerical modeling for sediment-pass-through reservoirs. Journal of Hydraulic Research, v.122, n.7, jul.

CHANG, H. H. (1998). Fluvial processes in river engineering. 2.reed. Malabar, Flórida: Krieger Publishing Company.

CHELlA, M. R.; OTA, J. J.; POVH, P. H. Simulação física do transporte de sedimentos e assoreamento em reservatórios. In: SIMPÓSIO BRASILEIRO DE RECURSOS HÍDRICOS, 15., 2003, Curitiba. Anais... 1 CD.

COGOLLO, P. R. J.; VILLELA, S. M. (1988). Mathematical model for reservoir silting. In: PORTO ALEGRE SYMPOSIUM OF SEDIMENT BUDGETS, proceedings..., dez 1988, Porto Alegre: IAHS Publication, n. 174.

COLLISCHONN, W.; MERTEN, G. H. (2001). Análise de estabilidade de um rio no Pantanal utilizando um modelo matemático de transporte de sedimentos. In: ENCONTRO NACIONAL DE ENGENHARIA DE SEDIMENTOS - Caracterização quali-quantitativa da produção de sedimentos, 4, 2001, Santa Maria. Anais.... p.131-154.

COPEL. (1999). Relatório ambiental: Usina Hidrelétrica Melissa. Curitiba.

DEMUREN, A. O. (1989). Calculation of sediment transport in meandering channels. In: TECH SESSION A - IAHR CONGRESS, 23, proceedings..., International Association for Hydraulic Research, Delft, Holanda.

DEMUREN, A. O. (1991). Development of a mathematical model for sediment transport in meandering rivers. Report. n.693, Institute for Hydromechanics, University of Karlsruhe, Karlsruhe, Alemanha.

DEMUREN, A. O.; RODI, W. (1986). Calculation of flow and pollutant dispersion in meandering channels. Journal of Fluid Mechanics, Cambridge, U. K., 172, 63-92.

DHI (2004). MIKE 21C Scientific reference manual. Horsholm, Dinamarca. 
DHI (2005). MIKE 21C river hydrodynamics and morphology. Horsholm, Dinamarca.

DHI WATER AND ENVIRONMENT (2005). Horsholm, Dinamarca. Apresenta de forma resumida validações e aplicações do programa MIKE 21C. Disponível em: $<$ www.dhisoftware.com $>$. Acesso em 02 de outubro.

ENGELUND, F. AND HANSEN, E. (1967). A monographh on sediment transport in alluvial streams, Teknisk Forlag, Danish Technological University, Copenhague, Dinamarca.

ENGELUND, F.; FREDSØE, J. (1976). A sediment transport model for straight alluvial channels. Nordic Hydrology, v.7, n.5.

FAN, J.; MORRIS, G. L. (1992). Reservoir sedimentation. I: Delta and density current deposits.

FREAD, D. L. (1991) The NWS DAMBRK model: Theoretical background and user documentation. Hydrologic Research Laboratory. Office of Hydrology. National Weather Service, NOAA. Silver Spring, Maryland. 123p.

FREAD, D. L. (1993). Flow routing. In: Maidment, Handbook of Hydrology. McGrawHill, New York.

FRIEDRICH, M. F.; OTA, J. J. (2003). Modelagem computacional de escoamento fluvial: estudo de sensibilidade de parâmetros e condições de contorno. In: SIMPÓSIO BRASILEIRO DE RECURSOS HÍDRICOS, 15, 2003, Curitiba - PR, p. 23-27, nov.

GAILANI, J.; ZIEGLER, C. K.; LICK, W. (1991). Transport of suspended solids in the Lower Fox River. Journal of Great Lakes Reservoirs, v.17, n.4, p.479-494.

GALAPPATTI, R. (1983). A depth-integrated model for suspended transport. Report n.83-7, comm. on hydraulics, Department of Civil Engineering, Delft University of Technology.

GESSLER, D.; HALL, B.; SPASOJEVIC, M.; HOLLY, F.; POURTAHERI, H.; RAPHELT, N. (1999). Application of 3D mobile bed, hydrodynamic model. Journal of Hydraulic Engineering, v.125, n.7, jul. 
GUO, Q.; JIN, Y. (2002). Modeling nonuniform suspended sediment transport in alluvial rivers. Journal of Hydraulic Engineering, v.128, n.9, set.

HORIUTI, K. (1987). Comparison of conservative and rotational forms in large-eddy simulation of turbulent channel flow. Journal of Computational Physics, n.71, p.34-370.

IKEDA, S. (1980). Incipient motion of sand particles on slopes. Report of Foundation Engineering \& Construction Engineering, Saitama University, Japão.

JANSEN, P.H.; BENDEGOM, L. van; BERG, J. van den; VRIES, M. de; ZANEN, A. (1979). Principles of River Engineering. Pitman Publishing, 1979.

KOCH, F.G. (1980). Bed level computation for axis-symmetric curved channels. Report R567-1X/W308 part1, Delft Hydraulic Laboratory.

LANE, E.W. (1953). Progress report on studies on the design of stable channels by the Bureau of Reclamation. In: ASCE - IRR. AND DRAIN DIV., proceedings..., v.79.

LEONARD, A. (1974). Energy cascades in large-eddy simulations of turbulent fluid flows. Advances in Geophysics, n.18, p.237-247.

LICK, W.; LICK, J.; ZIEGLER, C. K. (1994). The resuspension and transport of finegrained sediments in Lake Irie. Journal of Great Lakes Reservoirs, v.20, n.4, p.599-612.

LILLY, D. K. (1966). On the application of the eddy viscosity concept in the inertial subrange of turbulence. NCAR Manuscript No. 123, National Center for Atmospheric Research, Colorado.

LIN, B. L.; FALCONER, R. A. (1996). Numerical modelling of three-dimensional suspended sediment for estuarine and coastal waters. Journal of Hydraulic Research, Delft, Holanda, v.34, n.4, p.435-456.

LOPES, S. J. L. (1978). Mathematical modeling of sediment deposition in reservoirs. Hydrology Papers, Colorado State University, Fort Collins, Colorado, jul.

Meyer-Peter, E. and Müller, R. (1948). Formulas for bed load transport. In: CONGRESS IAHR, 2, 1948, Estocolmo, proceedings..., v.2, paper 2. 
MOHAMMAD, A.G. (2000). Books reviews: silting and desilting of reservoirs, by Dan G. Batuca and Jan M. Jordaan. Journal of Hydraulic Engineering, New York, v.126, n.11, p.874-875, nov.

MOLINO, B.; GRECO, M.; ROWAN, J. S. (2001). A 2-D reservoir routing model: sedimentation history of Abbeystead Reservoir, U. K. Water Resources Management, v.15, p.109-122.

NICKLOW, J. W.; MAYS, L. W. (2000). Optimization of multiple reservoir networks for sedimentation control. Journal of Hydraulic Engineering, v.126, n.4, abrl.

ODGAARD, A. J.; BERGS, M. A. (1988). Flow process in a curved alluvial channel. Water Resources Research, v.24, n.1, p.45-56.

OLESEN, K.W. (1987). Bed topography in shallow river bends. Faculty of Civil Engineering, Delft University of Technology, Report 87-1.

OLSEN, N. R. B. (1999). Two-dimensional numerical modelling of flushing processes in water reservoirs. Journal of Hydraulic Research, v.37, n.1.

OLSEN, N. R. B.; KJELLESVIG, H. M. (1999). Three-dimensional numerical modelling of bed changes in sand trap. Journal of Hydraulic Research, v.37, n.2.

OLSEN, N. R. B. (2002). A three-dimensional numerical model for simulations of sediment movements in water intakes with multiblock option - user's manual. Disponível em <www.bygg.ntnu.no/ñilsol/cfd>. Acesso em 23 dez.

PAZ, A. R.; SCHETTINI, E. B. C.; VILlanUEVA, A. O. N. (2003). Simulação hidrodinâmica bidimensional do Banhado do Taim (RS). In: SIMPÓSIO BRASILEIRO DE RECURSOS HÍDRICOS, 15, p.23-27, nov. Curitiba - PR.

RIJN, L. C. van. (1984). Part I: Bed load transport. Journal of Hydraulic Engineering, v.110, out.

RIJN, L. C. van. (1984). Part II: Suspended load transport. Journal of Hydraulic Engineering, v.110, nov.

RIJN, L. C. van. (1986). Mathematical modeling of suspended sediment in nonuniform flows. Journal of Hydraulic Engineering, v.112, n.6, p.433-455. 
RIJN, L. C. van (1987). Mathematical modeling of morphological process in the case of suspended sediment transport. Delft Hydr. Communication No. 382.

ROZOWSKII, I.L. (1957). Flow of water in bends of open channels. English translation: Israel Progr.For Scientific Transl. Jerusalem, 1961.

SCHNITTER, N.J. A history of dams: the useful pyramids. Rotterdam: A.A.Balkema, 1994.

SILVA, S. V. Características de escoamentos decorrentes de diferenças de densidades. 2002. 284 p. Tese (Doutorado) - Departamento de Hidráulica e Saneamento, Escola de Engenharia de São Carlos, Universidade de São Paulo, São Carlos. 2002.

SLOFF, C. J.; JAGERS, H. R. A.; KITAMURA, Y. K. Study on the channel development in a wide reservoir. Proc. $2^{\text {nd }}$ Intern. Conf. on Fluvial Hydraulics, River Flow 2004, June 23-25, Napels, Italy, p.811-819.

SMAGORINSKY, J. (1963). General circulation experiment with the primitive equations. Monthly Weather Review, v.91, n.3, p.99-164.

SMITH, N.A.F. A history of dams. London: Peter Davies, 1971.

SOUZA, L. B. S. Estudo da estrutura turbulenta em escoamentos gerados por grades oscilantes. 2002. 102 p. + apêndice. Dissertação (Mestrado) - Departamento de Hidráulica e Saneamento, Escola de Engenharia de São Carlos, Universidade de São Paulo, São Carlos. 2002.

TALMON, A. M. (1992). Bed topography of river bends with suspended sediment transport. Tese (Doutorado) - Delft University of Technology, Holanda, 1992.

UNIVERSIDADE DE SÃO PAULO (2002). Diretrizes para elaboração de dissertações e teses na EESC-USP. 3.ed., São Carlos.

VRIEND, H. J. (1981), Steady flow in shallow channel bends. comm. on Hydraulics 813, Department of Civil Engineering, Delft University of Technology, Holanda.

WANG, S. S. Y.; ADEFF, S. E. (1986). Three-dimensional modelling of river sedimentation process. In: INTERNATIONAL SYMPOSIUM ON RIVER SEDIMENTATION, 3, proceedings..., University of Mississippi, Mississippi. 
WU, W.; RODI, W.; WENKA, T. (2000). 3D numerical modeling of flow and sediment transport in open channels. Journal of Hydraulic Engineering, v.126, n.1, p. 4-15, jan.

ZIEGLER, C. K.; NISBET, B. S (1994). Fine-grained sediment transport in Pawtuxet River, Rhode Island. Journal of Hydraulic Engineering, v.120, n.5, p.561-576.

ZIEGLER, C. K.; NISBET, B. S. (1995). Long-term simulation of fine-grained sediment transport in large reservoir. Journal of Hydraulic Engineering, v.121, n.11, nov. 


\section{APÊNDICES}

Apêndice: "Texto ou documento elaborado pelo autor, de acordo com a NBR 14724/2002, a fim de complementar sua argumentação" (Universidade de São Paulo, 2002).

São apresentados a seguir: 
APÊNDICE A

Organização dos vídeos e fotos no DVD.

PASTA 1_EXPERIMENTO_VÍDEOS DO ESCOAMENTO.

PASTA 2_EXPERIMENTO_VÍDEOS DOS CAMPOS DE VELOCIDADE INSTANTÂNEA.

PASTA 3_EXPERIMENTO_FOTOS DO ASSOREAMENTO.

PASTA 4_EXPERIMENTO_VÍDEOS DO ASSOREAMENTO.

PASTA 5_SIMULAÇÃO_VÍDEOS DO ESCOAMENTO.

PASTA 6_SIMULAÇÃO_VÍDEOS DO ASSOREAMENTO. 


\section{APÊNDICE B}

\section{Arquivo gerado pelo programa VISIFLOW.}

$\mathrm{O}$ arquivo refere-se a um campo de velocidade instantânea da região 1, da configuração 1 do escoamento, gerado a partir de um par de imagens obtidas com técnica de velocimetria a laser. Um total de 9420 arquivos nesse padrão foram trabalhados.

As colunas apresentam, respectivamente, as coordenadas em x, em y, o módulo do vetor velocidade (em m/s) e o seu ângulo de inclinação (em radianos).

VISIFLOW ASCII Velocity data file:

Start of header data; Number of vectors $=$ Randomly positioned data $=0$ Number of columns $=12$ Number of rows $=12$

Vector grid separation $=11800$

Area left corner $=0.000000$

Area right corner $=177006.508800$

Area bottom corner $=\quad 0.000000$

Area top corner $=187700.652040$

Number of peaks $=1$

Number of microns $/$ xpixel $=\quad 184.381780$

Number of microns/ypixel $=\quad 184.381780$

Macro factor $=\quad 1.000000$

Time separation $=66666.670000$

Flow variable $=$ none

$\begin{array}{llll}23600 & 23600 & 0.009012 & -3.099445 \\ 35400 & 23600 & 0.019111 & -3.076444 \\ 47200 & 23600 & 0.037513 & -3.069662 \\ 59000 & 23600 & 0.063037 & -3.077339 \\ 70800 & 23600 & 0.059848 & -3.063779 \\ 82600 & 23600 & 0.031386 & -3.005870 \\ 94400 & 23600 & 0.021842 & -2.987347 \\ 106200 & 23600 & 0.015186 & -2.993603 \\ 118000 & 23600 & 0.014250 & -3.045632\end{array}$




$\begin{array}{llll}129800 & 23600 & 0.009383 & -3.042568 \\ 141600 & 23600 & 0.010417 & -3.056079 \\ 153400 & 23600 & 0.012266 & -3.037853 \\ 23600 & 35400 & 0.023296 & -3.119704 \\ 35400 & 35400 & 0.035364 & -3.087970 \\ 47200 & 35400 & 0.061504 & -3.059273 \\ 59000 & 35400 & 0.070641 & -3.036376 \\ 70800 & 35400 & 0.071306 & -3.015815 \\ 82600 & 35400 & 0.052443 & -2.983485 \\ 94400 & 35400 & 0.045321 & -2.967054 \\ 106200 & 35400 & 0.035448 & -2.972675 \\ 118000 & 35400 & 0.025744 & -3.009641 \\ 129800 & 35400 & 0.023630 & -3.048307 \\ 141600 & 35400 & 0.028156 & -3.055838 \\ 153400 & 35400 & 0.034628 & -3.050457 \\ 23600 & 47200 & 0.054236 & -3.134604 \\ 35400 & 47200 & 0.051021 & -3.109427 \\ 47200 & 47200 & 0.076972 & -3.078057 \\ 59000 & 47200 & 0.085426 & -3.051566 \\ 70800 & 47200 & 0.090323 & -3.008644 \\ 82600 & 47200 & 0.091700 & -2.973112 \\ 94400 & 47200 & 0.083836 & -2.964061 \\ 106200 & 47200 & 0.068591 & -2.980114 \\ 118000 & 47200 & 0.041068 & -3.055049 \\ 129800 & 47200 & 0.045462 & -3.068132 \\ 141600 & 47200 & 0.065576 & -3.056747 \\ 153400 & 47200 & 0.069019 & -3.068672 \\ 23600 & 59000 & 0.081311 & -3.134342 \\ 35400 & 59000 & 0.077395 & -3.126286 \\ 47200 & 59000 & 0.105505 & -3.111368 \\ 59000 & 59000 & 0.105564 & -3.075643 \\ 70800 & 59000 & 0.104919 & -3.013124 \\ 82600 & 59000 & 0.106914 & -2.976839 \\ 94400 & 59000 & 0.100598 & -2.972657 \\ 106200 & 59000 & 0.088309 & -2.999388 \\ 118000 & 59000 & 0.067322 & -3.060421 \\ 129800 & 59000 & 0.079227 & -3.096073 \\ 141600 & 59000 & 0.075657 & -3.120510 \\ 153400 & 59000 & 0.076444 & -3.122586 \\ 23600 & 70800 & 0.110854 & -3.126149 \\ 35400 & 70800 & 0.123579 & -3.120734 \\ 47200 & 70800 & 0.123664 & -3.101592 \\ 59000 & 70800 & 0.123749 & -3.067297 \\ 70800 & 70800 & 0.119261 & -3.002256 \\ 82600 & 70800 & 0.120417 & -2.977181 \\ 94400 & 70800 & 0.118048 & -2.976310 \\ 106200 & 70800 & 0.112429 & -3.006368 \\ 118000 & 70800 & 0.104460 & -3.075285 \\ 129800 & 70800 & 0.094321 & -3.110648 \\ 141600 & 70800 & 0.072526 & -3.136116 \\ 153400 & 70800 & 0.090218 & -3.137985 \\ 23600 & 82600 & 0.129111 & -3.103842 \\ 35400 & 82600 & 0.135327 & -3.096696 \\ 47200 & 82600 & 0.134195 & -3.074114 \\ 59000 & 82600 & 0.134636 & -3.042645\end{array}$




$\begin{array}{llll}70800 & 82600 & 0.133257 & -2.993430 \\ 82600 & 82600 & 0.132951 & -2.977101 \\ 94400 & 82600 & 0.130779 & -2.975824 \\ 106200 & 82600 & 0.125885 & -2.997483 \\ 118000 & 82600 & 0.117178 & -3.041906 \\ 129800 & 82600 & 0.110640 & -3.111150 \\ 141600 & 82600 & 0.103611 & 3.137033 \\ 153400 & 82600 & 0.102745 & 3.108250 \\ 23600 & 94400 & 0.135095 & -3.095602 \\ 35400 & 94400 & 0.141524 & -3.075581 \\ 47200 & 94400 & 0.140577 & -3.053510 \\ 59000 & 94400 & 0.140854 & -3.024778 \\ 70800 & 94400 & 0.138912 & -2.980919 \\ 82600 & 94400 & 0.137626 & -2.972884 \\ 94400 & 94400 & 0.136907 & -2.972187 \\ 106200 & 94400 & 0.132678 & -2.992058 \\ 118000 & 94400 & 0.125767 & -3.037051 \\ 129800 & 94400 & 0.120380 & -3.124038 \\ 141600 & 94400 & 0.117788 & 3.105934 \\ 153400 & 94400 & 0.120121 & 3.046181 \\ 23600 & 106200 & 0.139031 & -3.080537 \\ 35400 & 106200 & 0.144510 & -3.054747 \\ 47200 & 106200 & 0.143702 & -3.033936 \\ 59000 & 106200 & 0.143888 & -3.009558 \\ 70800 & 106200 & 0.142234 & -2.981711 \\ 82600 & 106200 & 0.140915 & -2.974952 \\ 94400 & 106200 & 0.139605 & -2.974735 \\ 106200 & 106200 & 0.136153 & -2.993508 \\ 118000 & 106200 & 0.130912 & -3.043247 \\ 129800 & 106200 & 0.128335 & -3.139234 \\ 141600 & 106200 & 0.128482 & 3.064761 \\ 153400 & 106200 & 0.129052 & 3.030281 \\ 23600 & 118000 & 0.140010 & -2.983060 \\ 35400 & 118000 & 0.142629 & -2.999349 \\ 47200 & 118000 & 0.144190 & -3.009373 \\ 59000 & 118000 & 0.147171 & -3.016479 \\ 70800 & 118000 & 0.146162 & -2.998221 \\ 82600 & 118000 & 0.145008 & -2.993122 \\ 94400 & 118000 & 0.143146 & -2.994718 \\ 106200 & 118000 & 0.139530 & -3.013509 \\ 118000 & 118000 & 0.136636 & -3.058556 \\ 129800 & 118000 & 0.137092 & 3.139204 \\ 141600 & 118000 & 0.136371 & 3.064363 \\ 153400 & 118000 & 0.136680 & 3.036325 \\ 23600 & 129800 & 0.137421 & -2.711094 \\ 35400 & 129800 & 0.140697 & -2.855294 \\ 47200 & 129800 & 0.145096 & -2.960229 \\ 59000 & 129800 & 0.151330 & -3.033441 \\ 70800 & 129800 & 0.150012 & -3.027346 \\ 82600 & 129800 & 0.149371 & -3.029695 \\ 94400 & 129800 & 0.148237 & -3.037239 \\ 106200 & 129800 & 0.145127 & -3.058367 \\ 118000 & 129800 & 0.143815 & -3.093190 \\ 129800 & 129800 & 0.141151 & 3.117804 \\ 141600 & 129800 & 0.132454 & 3.051346\end{array}$




$\begin{array}{llll}153400 & 129800 & 0.125096 & 3.016328 \\ 23600 & 141600 & 0.177501 & -2.068672 \\ 35400 & 141600 & 0.145363 & -2.842144 \\ 47200 & 141600 & 0.149761 & -2.978784 \\ 59000 & 141600 & 0.154874 & -3.068155 \\ 70800 & 141600 & 0.153532 & -3.053556 \\ 82600 & 141600 & 0.157246 & -3.082891 \\ 94400 & 141600 & 0.155433 & -3.100053 \\ 106200 & 141600 & 0.153267 & -3.118465 \\ 118000 & 141600 & 0.151840 & -3.138244 \\ 129800 & 141600 & 0.138479 & 3.109410 \\ 141600 & 141600 & 0.120822 & 3.054648 \\ 153400 & 141600 & 0.092448 & 2.942548 \\ 23600 & 153400 & 0.186308 & -2.011565 \\ 35400 & 153400 & 0.145385 & -2.844872 \\ 47200 & 153400 & 0.149319 & -2.965832 \\ 59000 & 153400 & 0.153833 & -3.057711 \\ 70800 & 153400 & 0.151633 & -3.070073 \\ 82600 & 153400 & 0.156031 & -3.090912 \\ 94400 & 153400 & 0.155869 & -3.112793 \\ 106200 & 153400 & 0.154690 & -3.134272 \\ 118000 & 153400 & 0.151581 & 3.131377 \\ 129800 & 153400 & 0.126701 & 3.082140 \\ 141600 & 153400 & 0.087389 & 2.944346 \\ 153400 & 153400 & 0.069263 & 0.696056\end{array}$

Código em linguagem FORTRAN para adequação dos arquivos do VISIFLOW ao formato usado nos programas de geração dos vídeos.

Program Calculo

character (len=25) :: arquivo_escrita

character $($ len=5) :: line

character $($ len $=50)::$ arquivo

character $($ len $=50)::$ conta_arquivo_txt, conta_diretorio_pos_txt, conta_diretorio_config_txt

integer $\quad: \mathrm{x}, \mathrm{y}$, conta_arquivo, aux, conta_diretorio_pos, conta_diretorio_config

real $\quad::$ modulo, angulo, $\mathrm{u}, \mathrm{v}$, divisao

! real $\quad:: \mathrm{Pi}=3.1415926535897932384626433832795028841972$

do conta_diretorio_config $=1,3,1$ ! Contador mais externo - Pastas config $(1,2$ e 3$)$

aux $=$ conta_diretorio_config

WRITE (UNIT=conta_diretorio_config_txt, fmt='(I0)') aux ! Transforma o contador em texto

do conta_diretorio_pos $=1,15,1$ ! Contador do meio - Pastas POS 1 ate Pos 45

aux $=$ conta_diretorio_pos

WRITE (UNIT=conta_diretorio_pos_txt, $\left.\mathrm{fmt}==^{\prime}(\mathrm{I} 0)^{\prime}\right)$ aux ! Transforma o contador das pastas Pos em texto 
arquivo_escrita $=$ 'config $1 / /$ trim $($ conta_diretorio_config_txt) $/ /$ ' - pos

'//trim(conta_diretorio_pos_txt)//'.txt'

OPEN (UNIT=12,FILE=trim(arquivo_escrita),STATUS='NEW') ! Cria arquivo de saida CONFIG X - POS Y.txt

WRITE $(12, *)$ '"VARIABLES="'"X"'","'Y"'","'u"'","'V"'"'"

do conta_arquivo $=1,30,1$ ! Contador interno -314 arquivos

aux = conta_arquivo

WRITE (UNIT $=$ conta_arquivo_txt, $\left.\mathrm{fmt}={ }^{\prime}(\mathrm{I} 3.3)^{\prime}\right)$ aux

arquivo $=$ 'config $1 / /$ trim $($ conta_diretorio_config_txt $) / / /$ pos ' \&

$/ /$ trim(conta_diretorio_pos_txt $) / / / / / /$ trim(conta_arquivo_txt) $/ /{ }^{\prime}$.asc'

WRITE $\left(6,{ }^{*}\right)$ 'Abrindo arquivo: ' , trim(arquivo)

OPEN (UNIT=11,FILE=trim(arquivo),STATUS='OLD')

WRITE $\left(12,{ }^{*}\right)$ 'ZONE T="'//trim(conta_arquivo_txt)//"',I=12,J=12'

line $="$

do while (line .ne. '-----')

$\operatorname{READ}(11, *)$ line

! WRITE $\left(6,{ }^{*}\right)$ 'Ignorando linha : ' , line

enddo

do while (line .ne. ' ')

$\operatorname{READ}\left(11,{ }^{*}\right.$, end $\left.=10\right) \mathrm{x}, \mathrm{y}$, modulo, angulo

divisao $=$ conta_arquivo

divisao $=$ divisao $/ 15$

if (int(divisao) $==$ divisao) then

$\mathrm{u}=0$

$\mathrm{v}=0$

else

$$
\mathrm{u}=\text { modulo } * \cos (\text { angulo })
$$

$\mathrm{v}=$ modulo $* \sin ($ angulo $)$

endif

! WRITE (6, *) ",x,',',y,,','modulo,',',angulo,' ->',u,v

WRITE $(12$, fmt='(I10,I10,F22.15,F22.15)') x,y,u,v

enddo

10

CONTINUE

CLOSE(UNIT $=11)$

! stop

end do

close (UNIT=12)

enddo

end do

END 


\section{APÊNDICE C}

\section{Flutuações de velocidade}

Gráficos da variação temporal da componente da velocidade instantânea no sentido longitudinal da armadilha, para experimento e simulação, referentes ao ponto central de cada região, das Configurações 1 e 2 de escoamento.

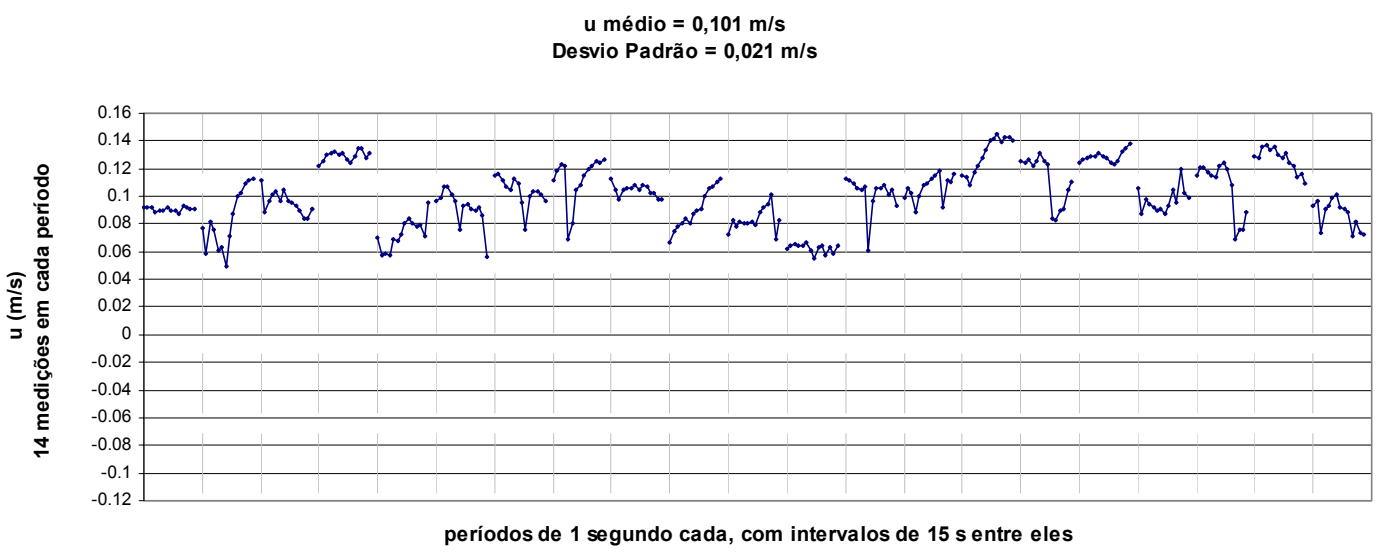

Experimento - Configuração 1 - região 2.

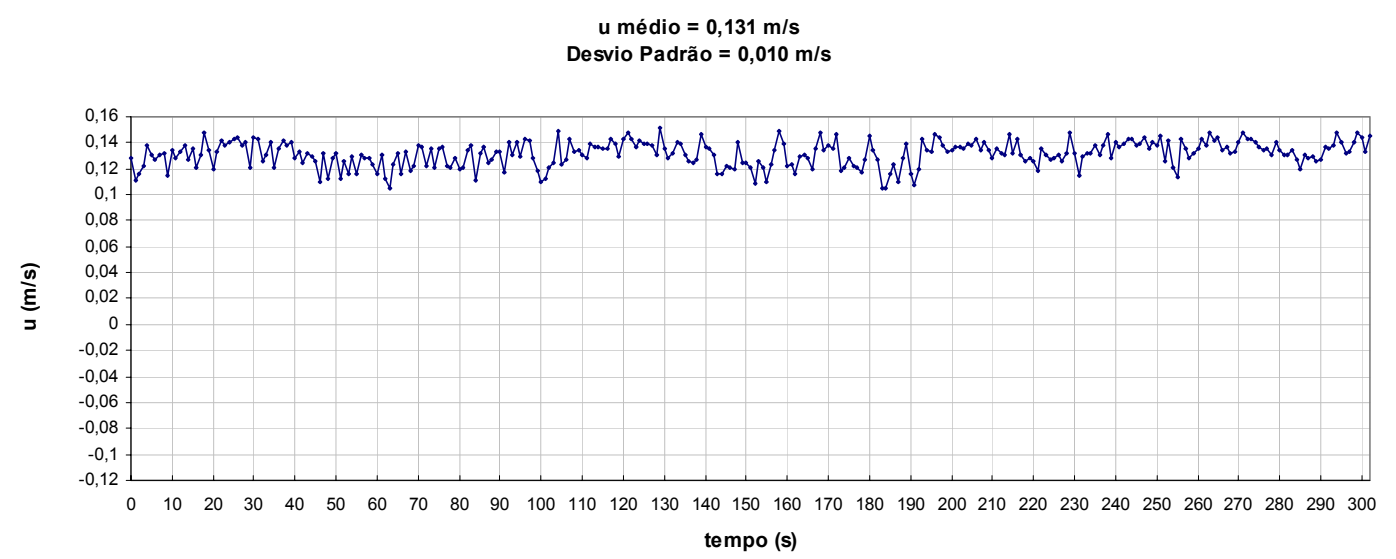

Simulação - Configuração 1 - região 2. 


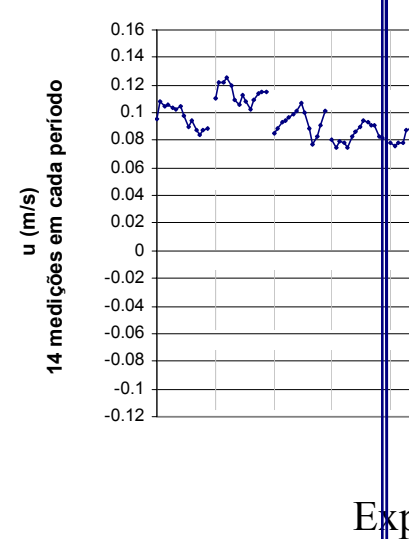




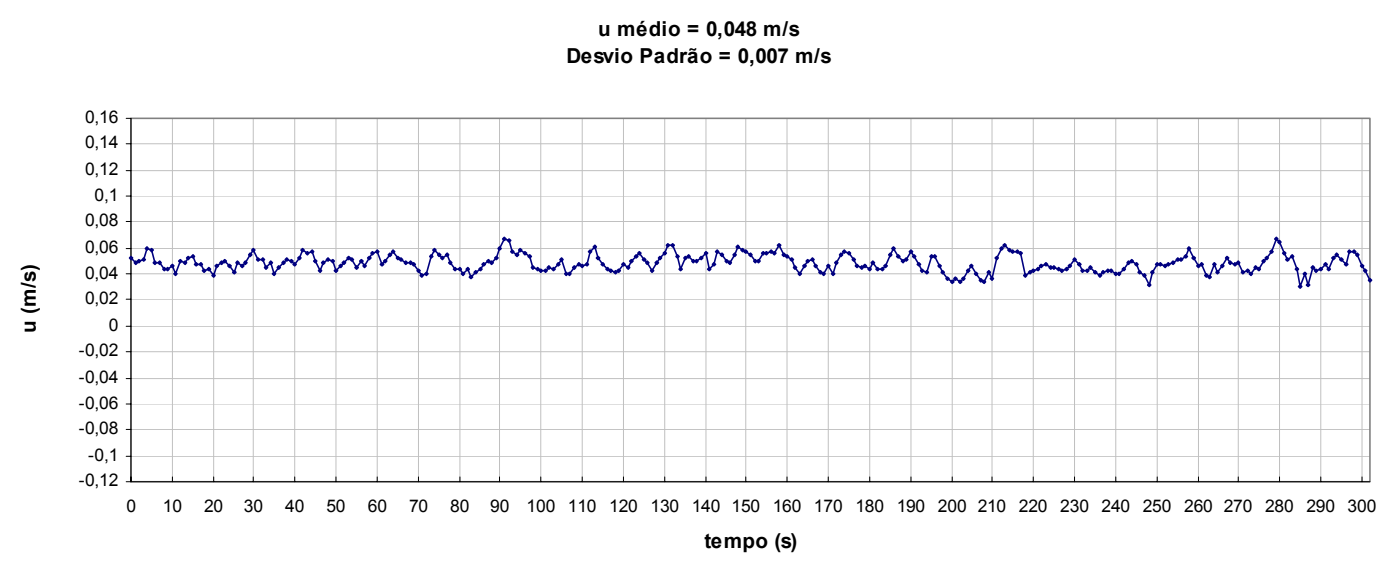

Simulação - Configuração 1 - região 4.

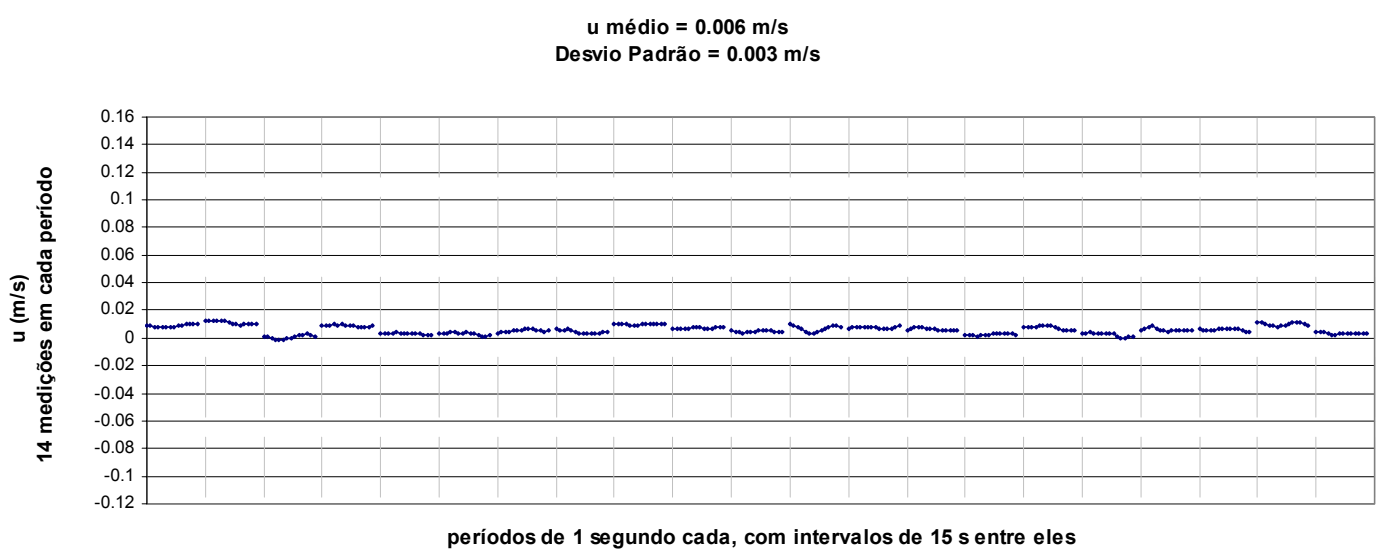

Experimento - Configuração 1 - região 5.

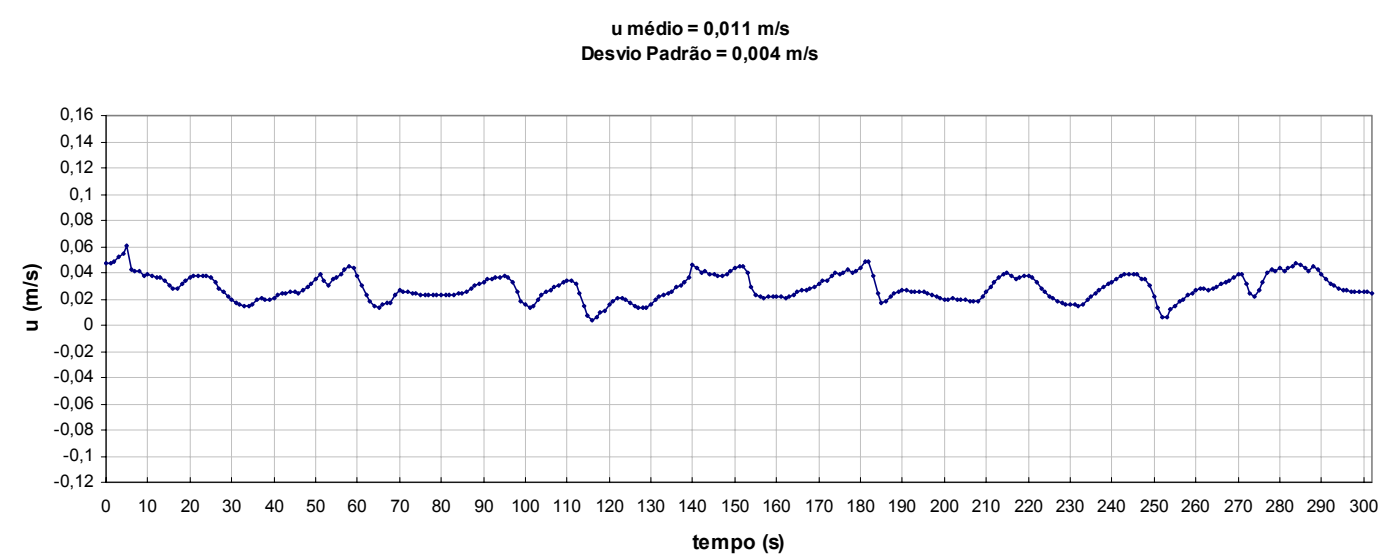

Simulação - Configuração 1 - região 5. 


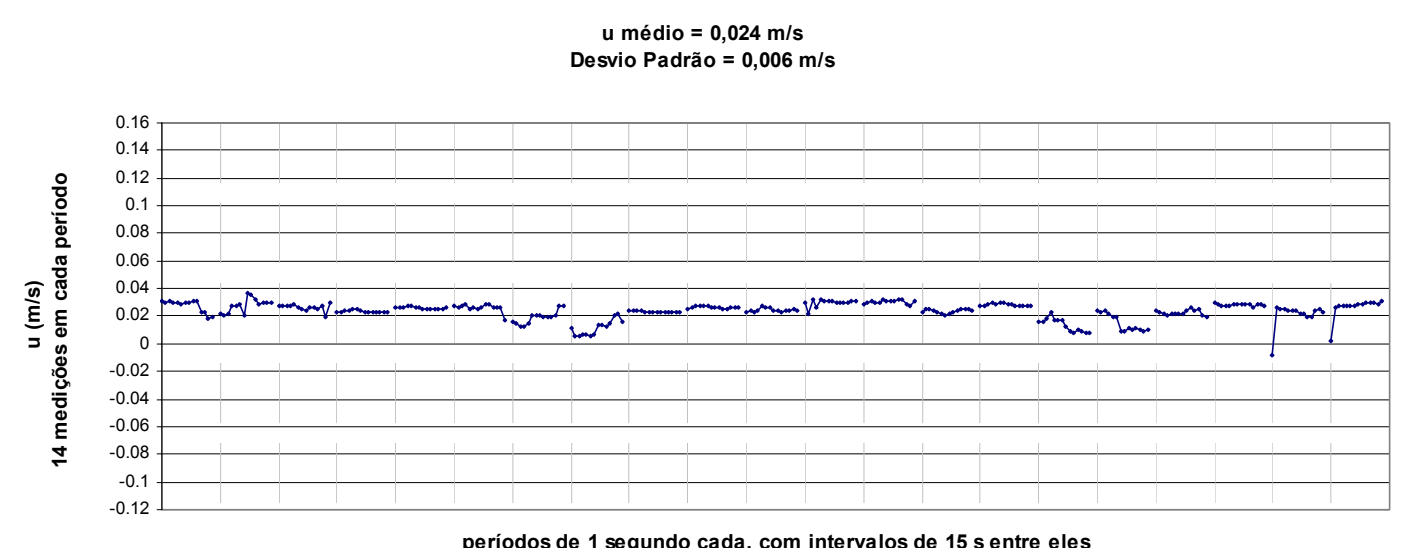

períodos de 1 segundo cada, com intervalos de 15 s entre eles

\section{Experimento - Configuração 1 - região 6.}

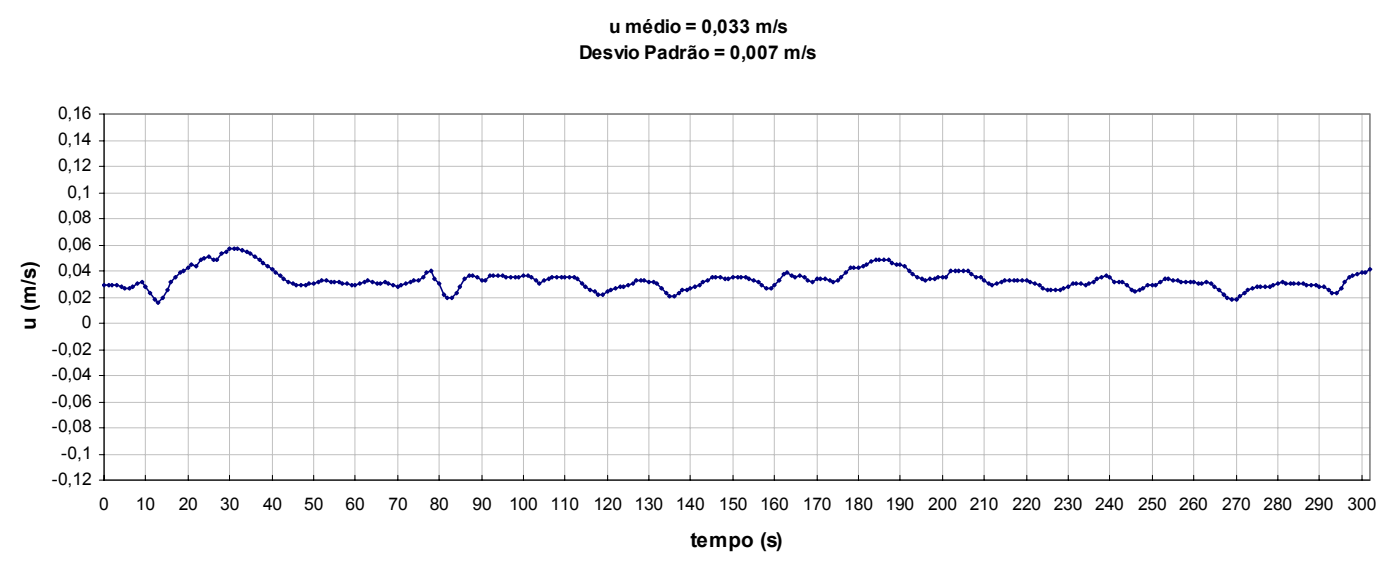

Simulação - Configuração 1 - região 6.

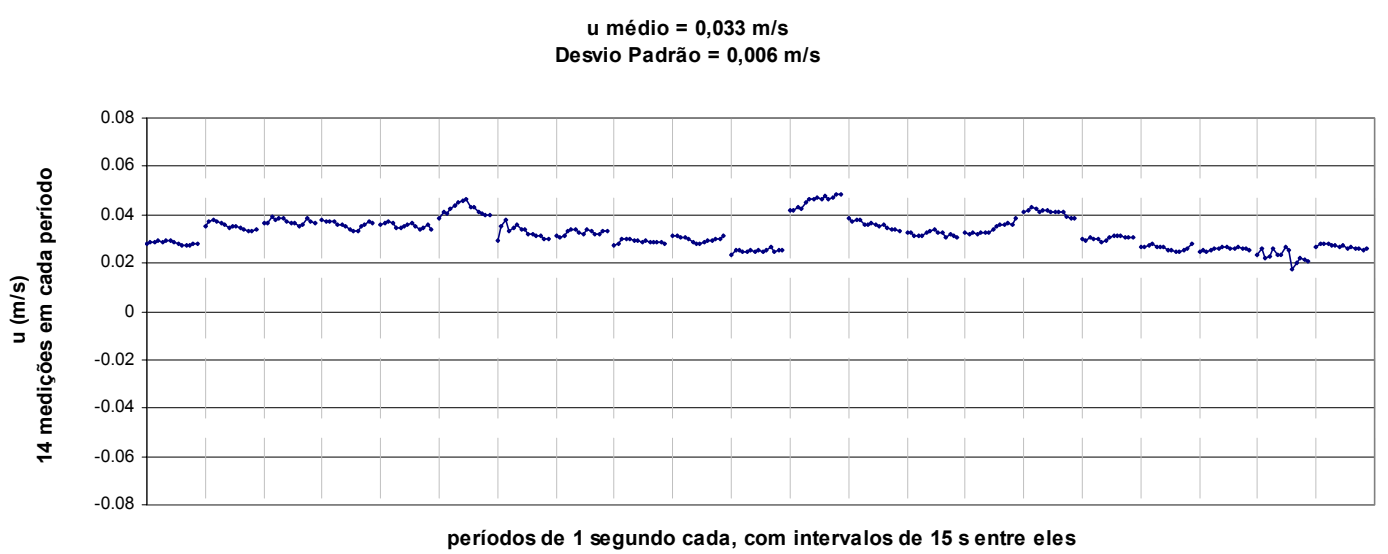

Experimento - Configuração 1 - região 7. 


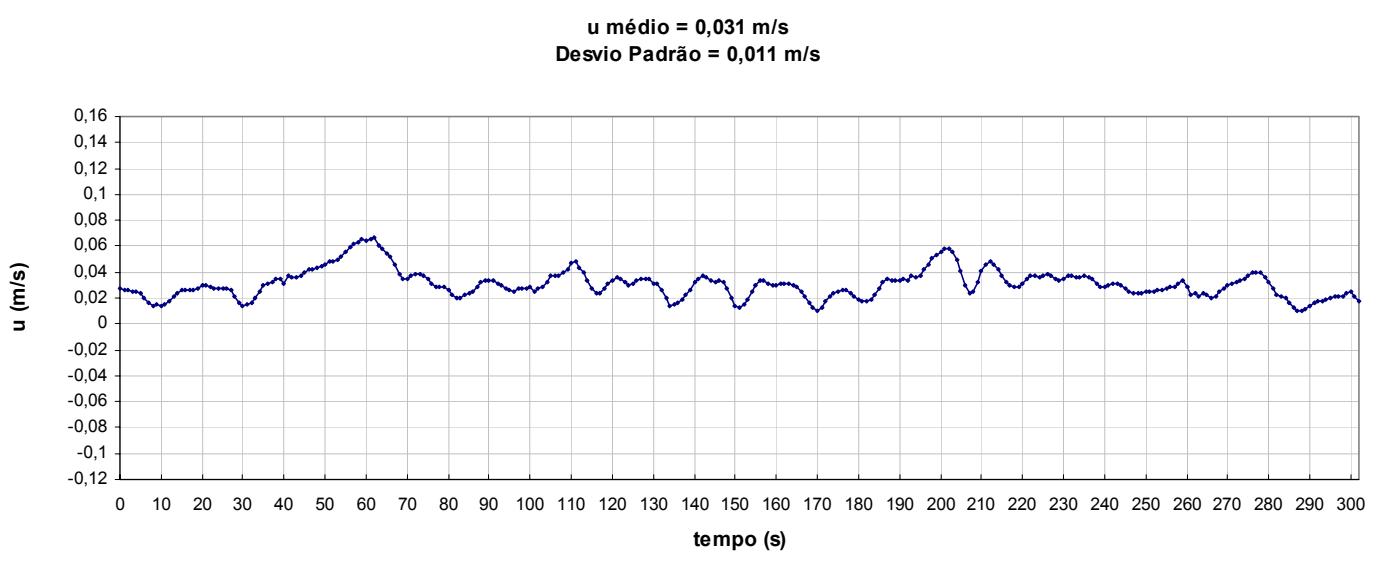

Simulação - Configuração 1 - região 7.

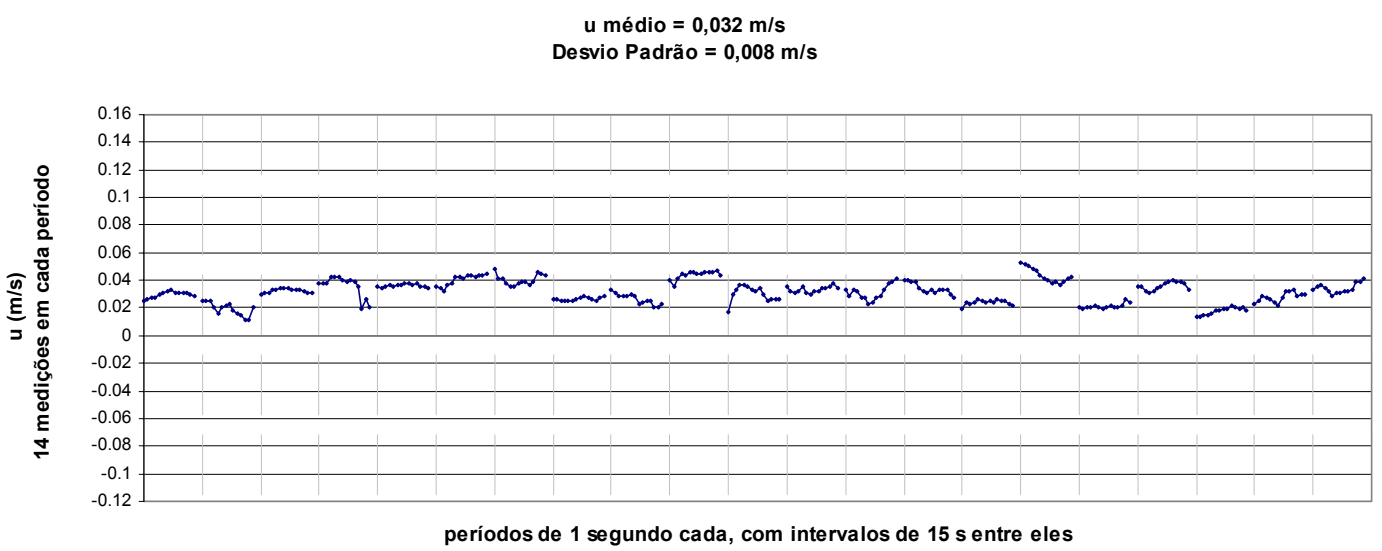

Experimento - Configuração 1 - região 8.

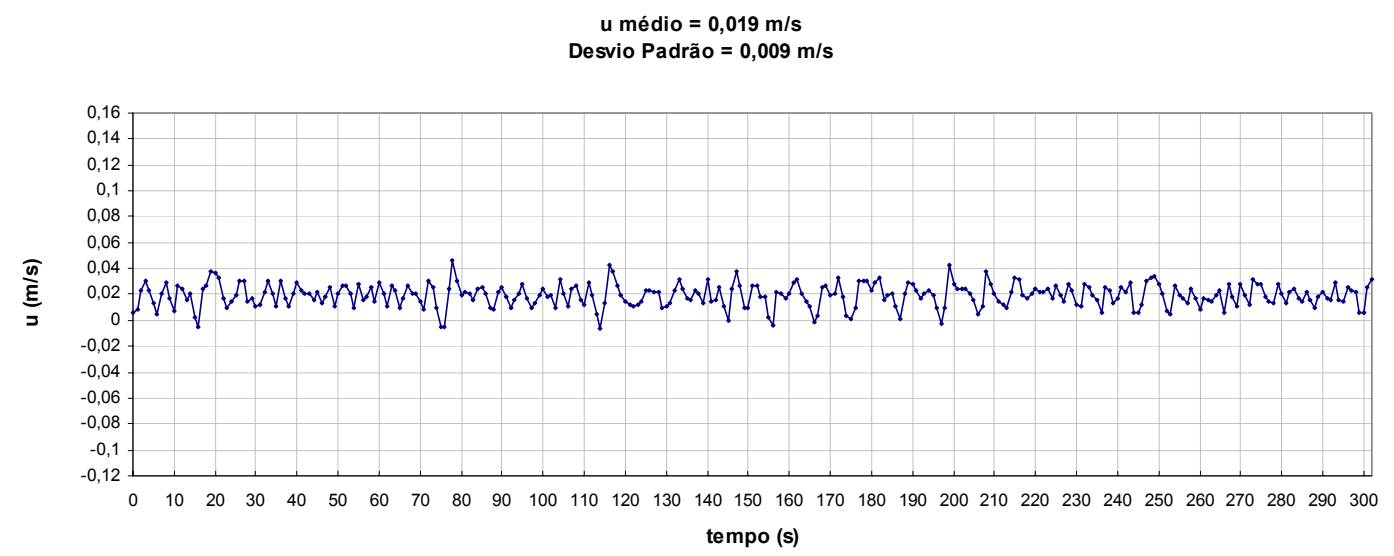

Simulação - Configuração 1 - região 8 . 


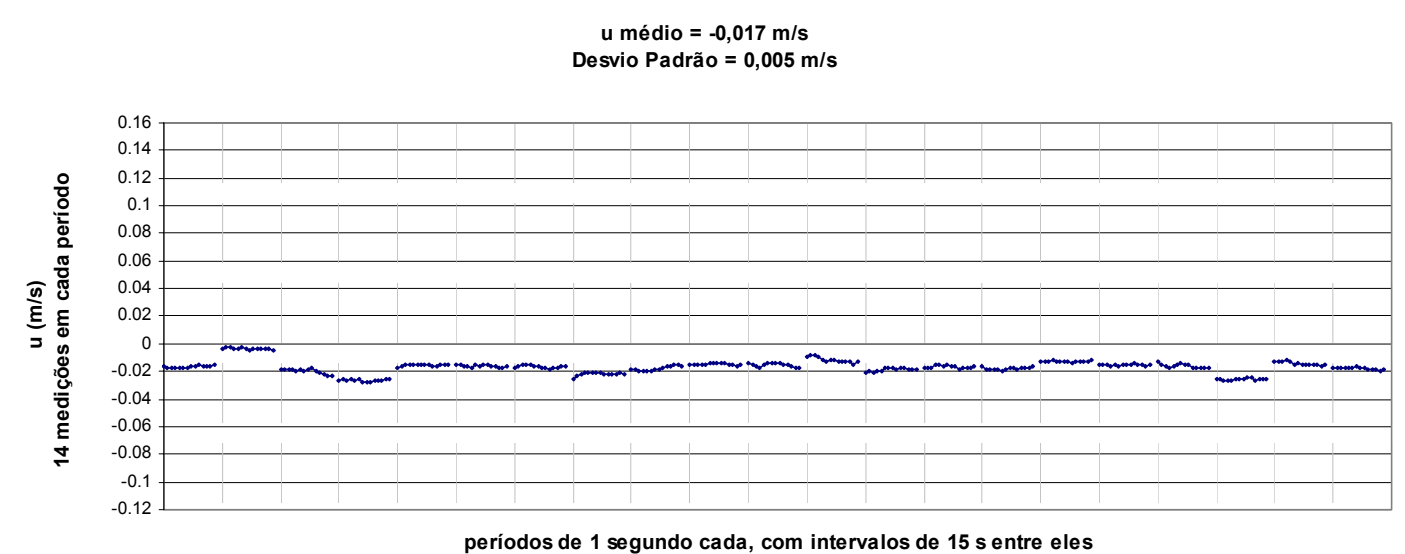

períodos de 1 segundo cada, com intervalos de 15 s entre eles

Experimento - Configuração 1 - região 9.

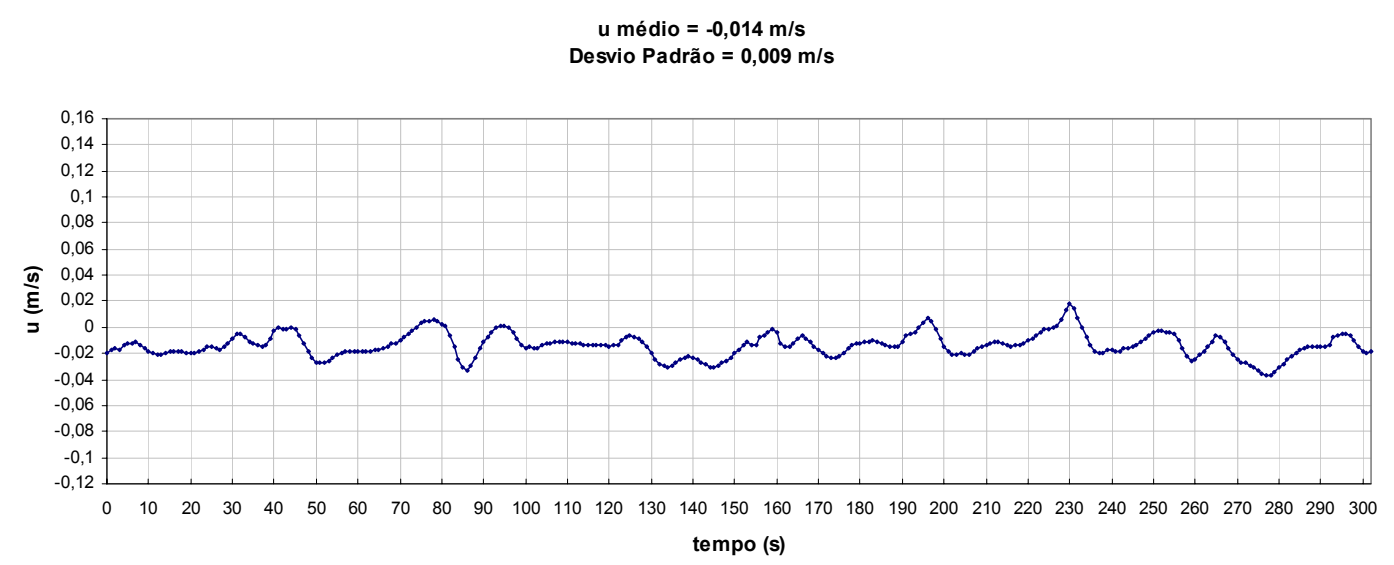

Simulação - Configuração 1 - região 9.

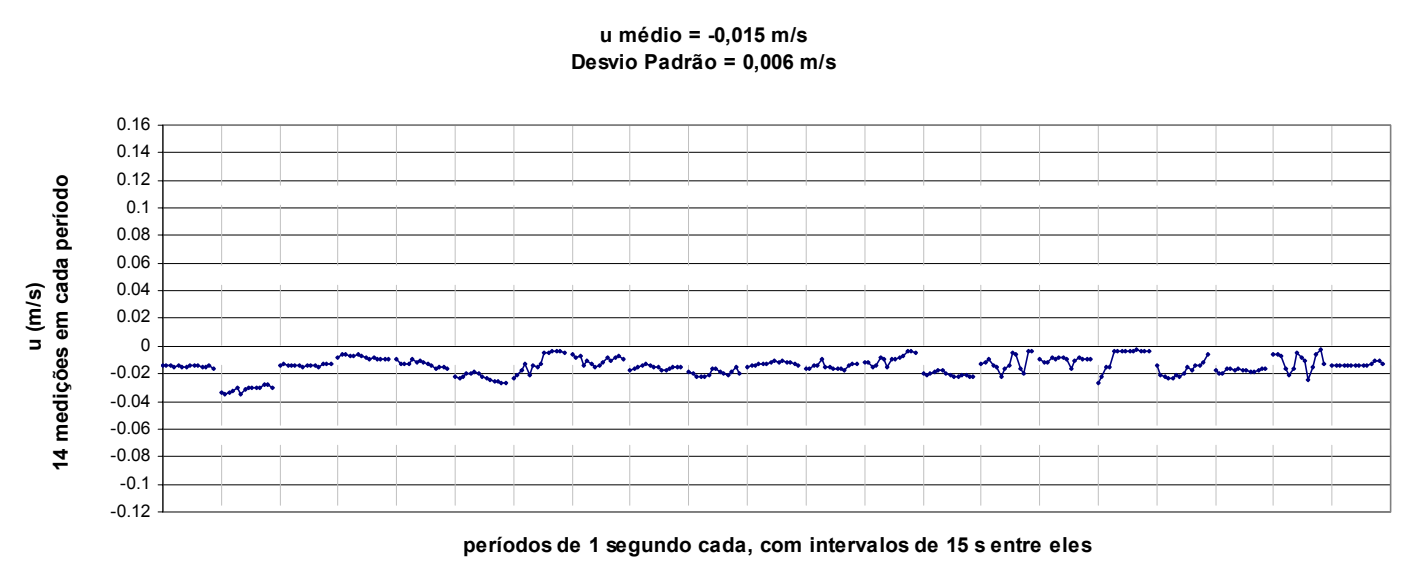

Experimento - Configuração 1 - região 10. 


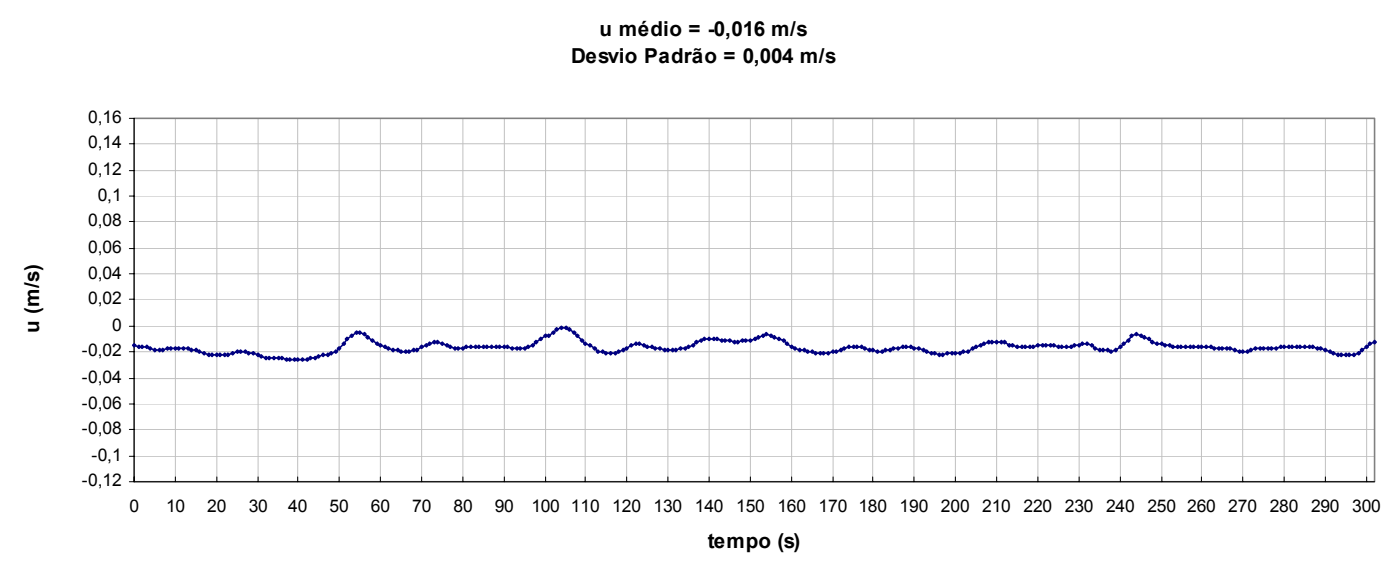

Simulação - Configuração 1 - região 10.

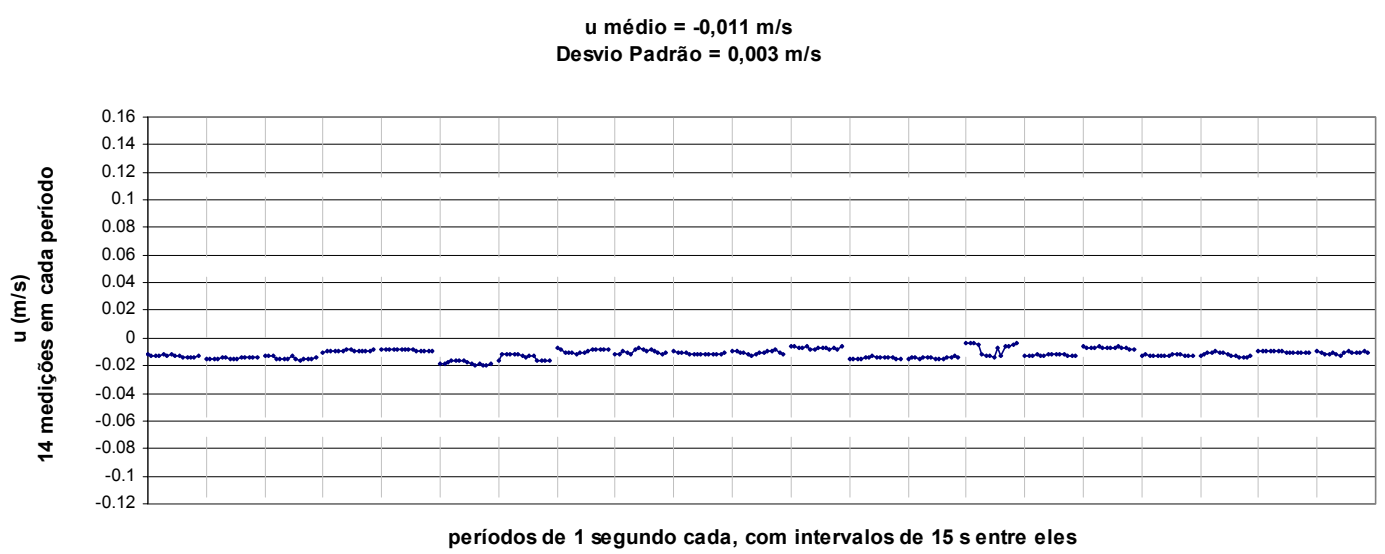

Experimento - Configuração 1 - região 11.

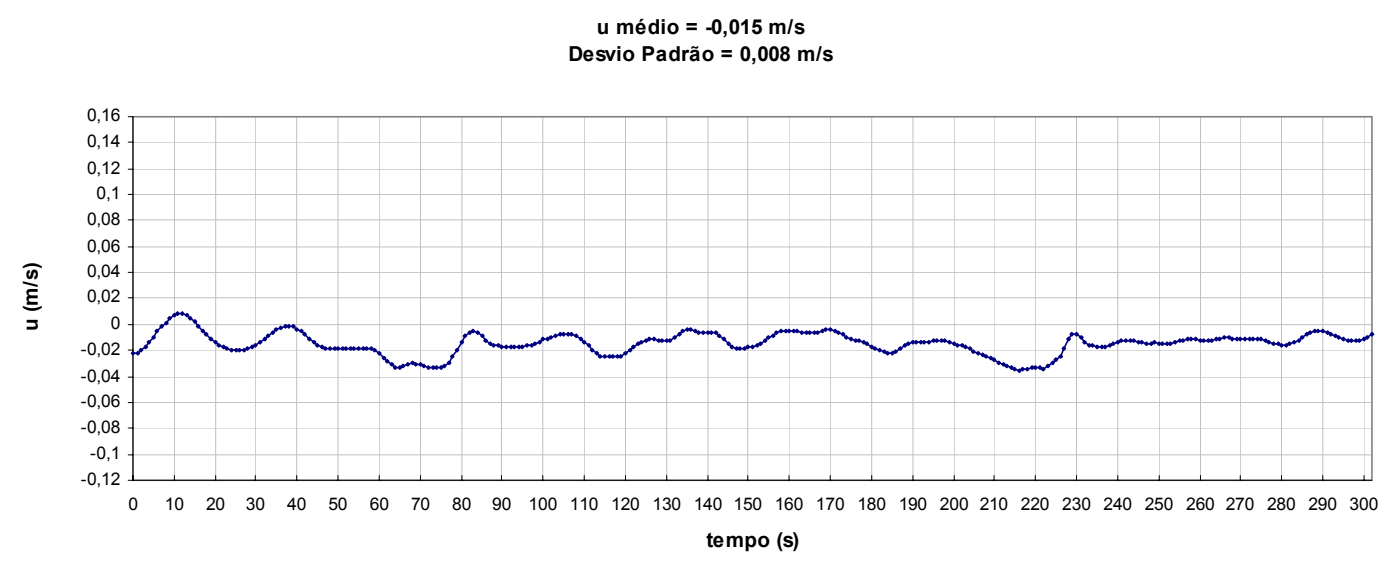

Simulação - Configuração 1 - região 11. 


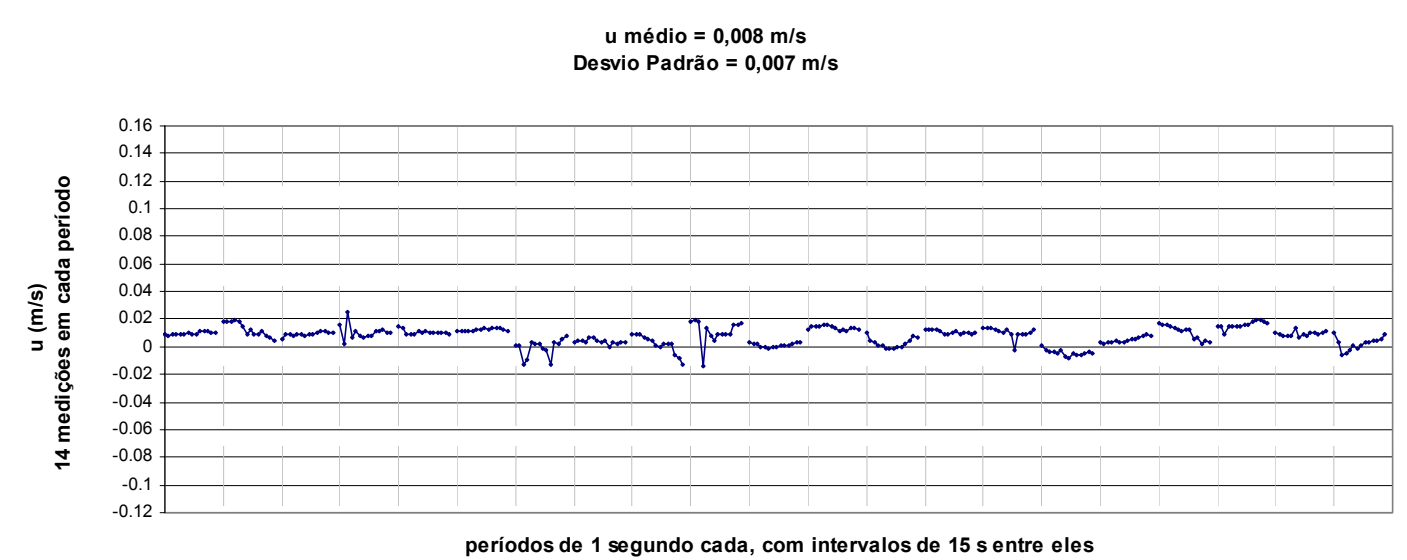

Experimento - Configuração 1 - região 12.

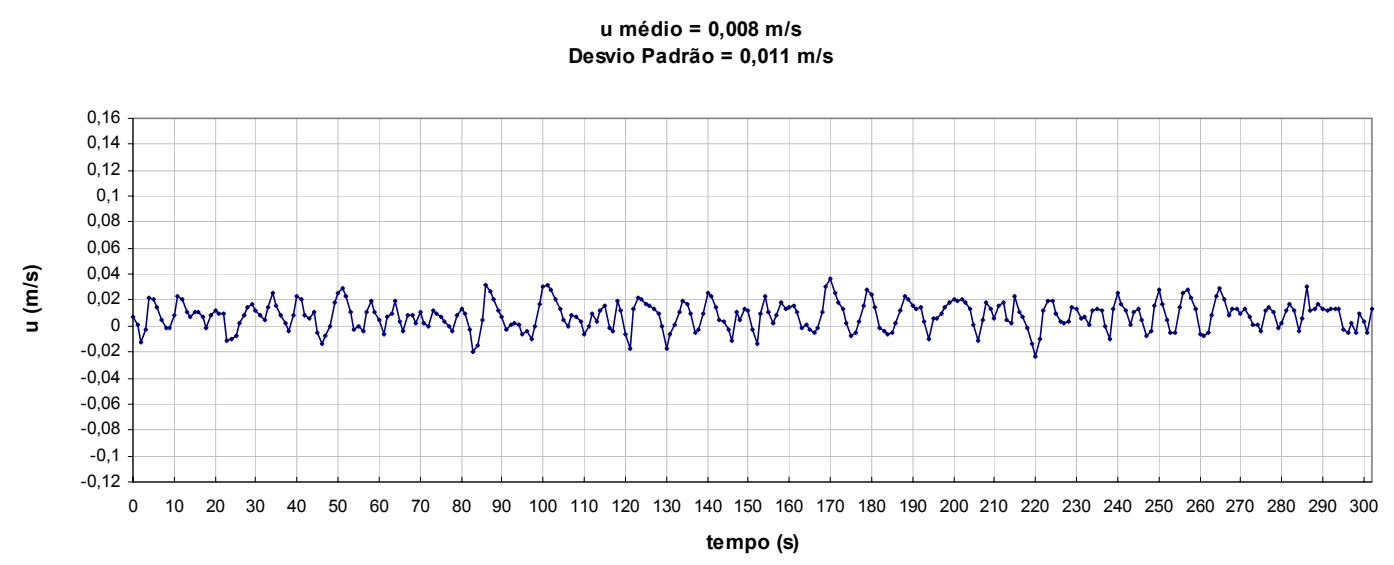

Simulação - Configuração 1 - região 12.

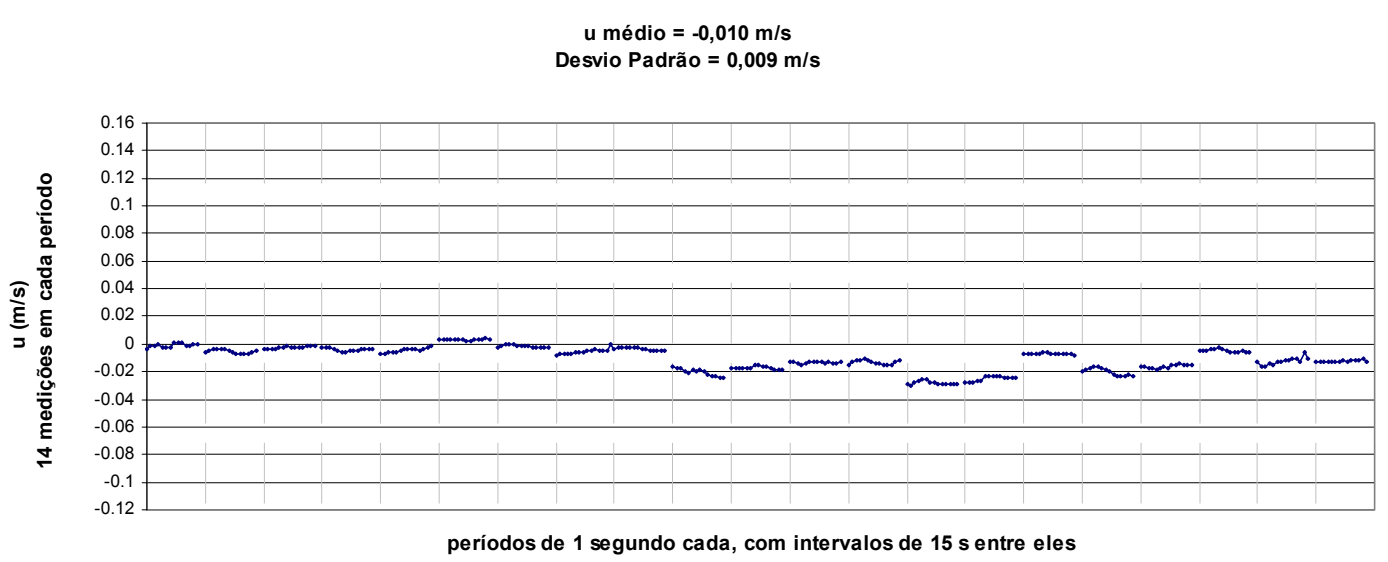

Experimento - Configuração 1 - região 13. 


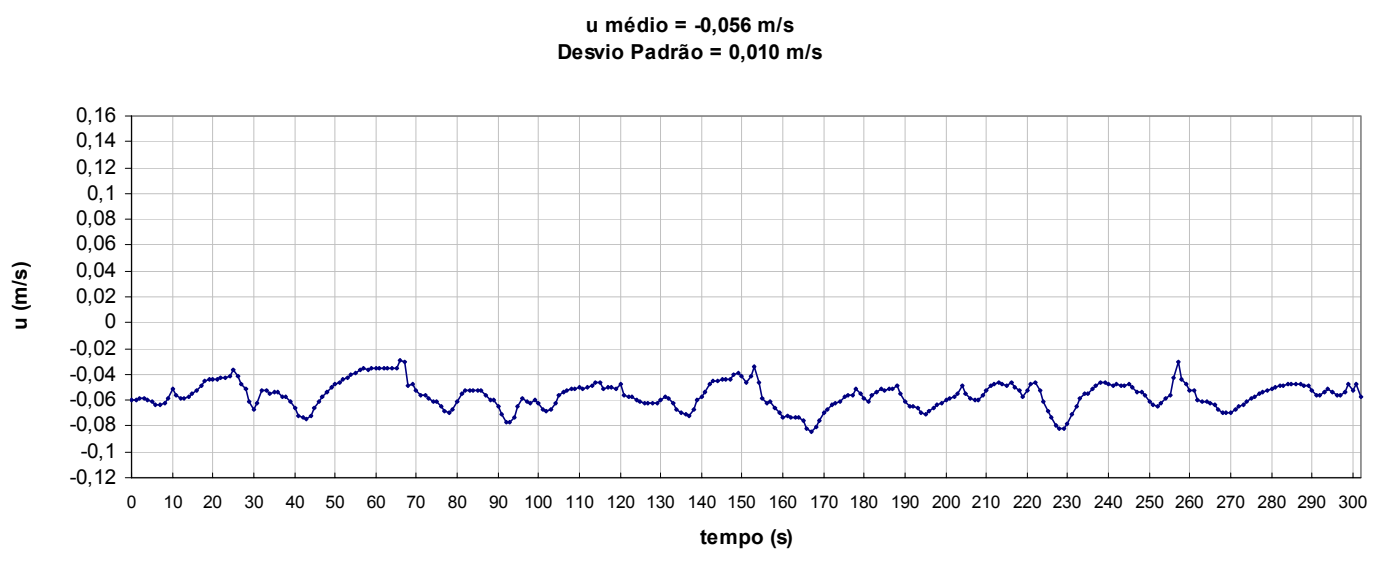

Simulação - Configuração 1 - região 13.

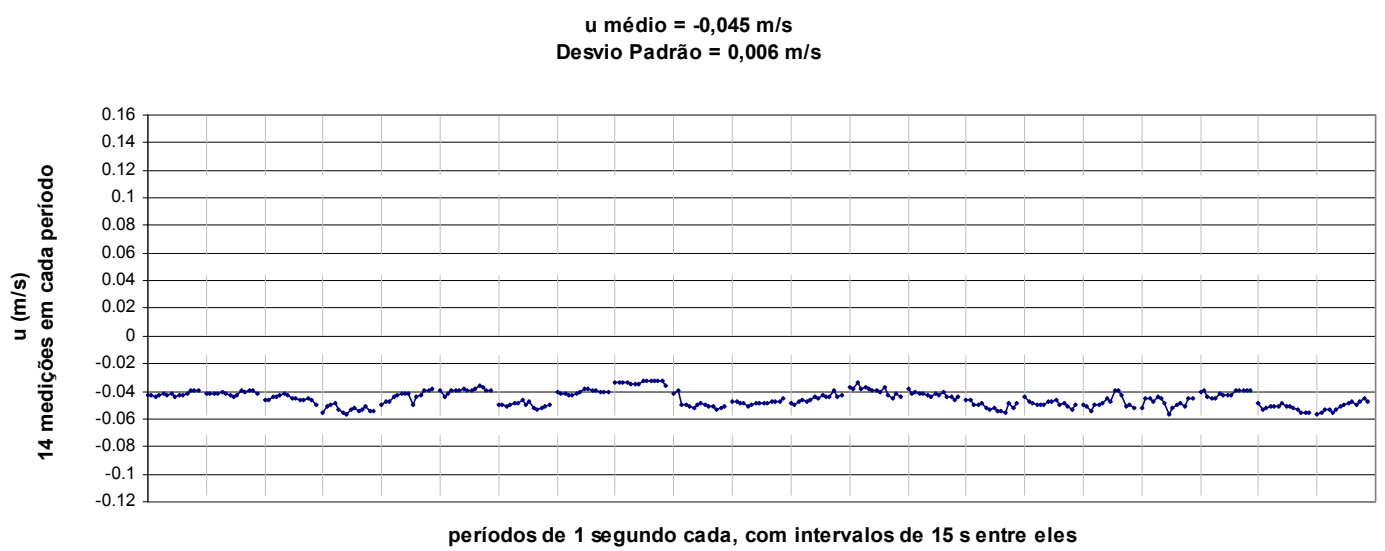

Experimento - Configuração 1 - região 14.

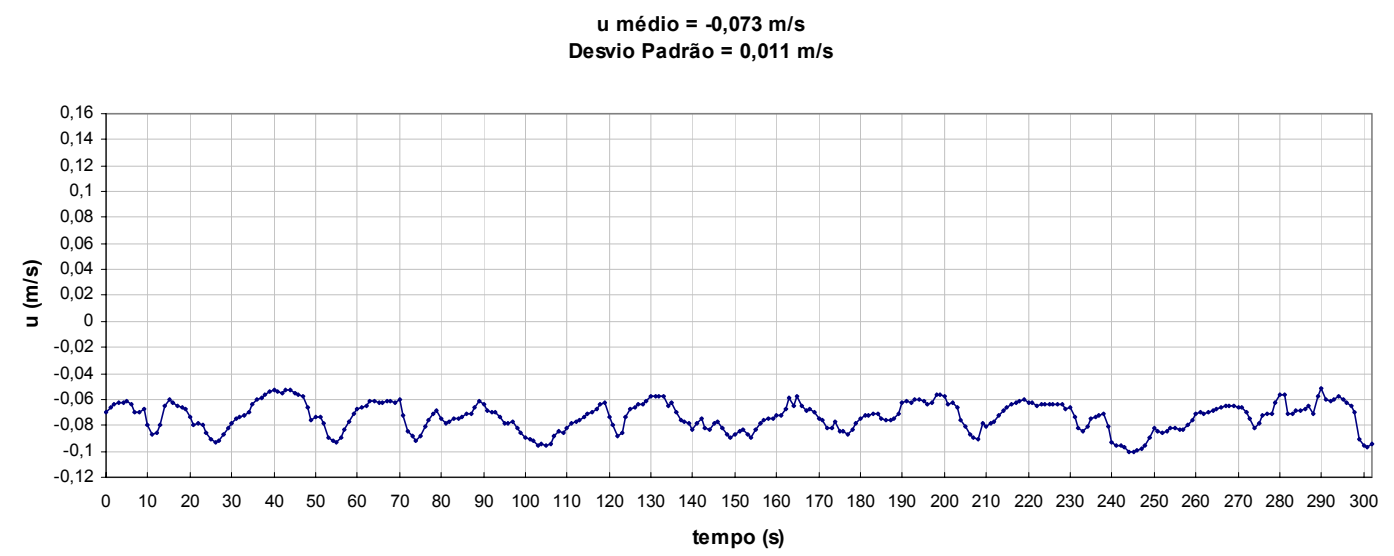

Simulação - Configuração 1 - região 14. 


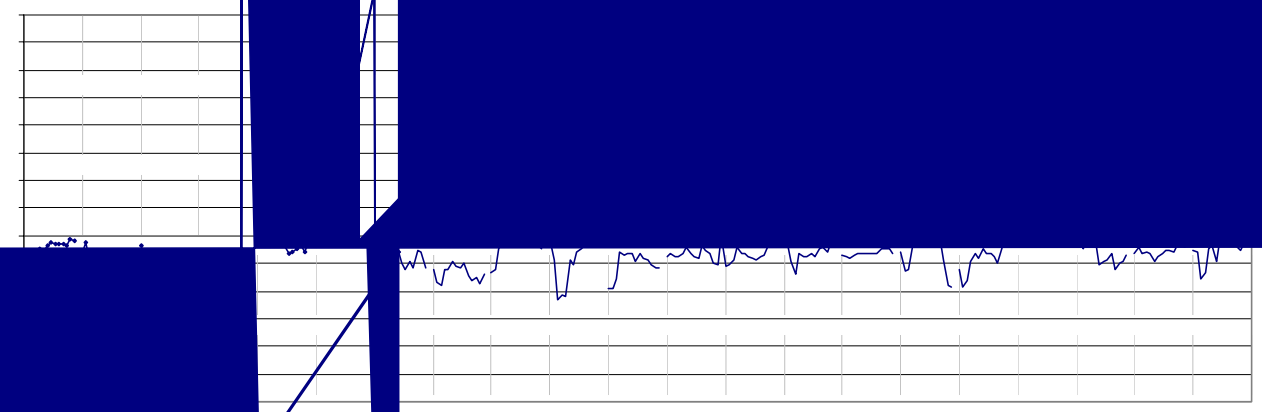




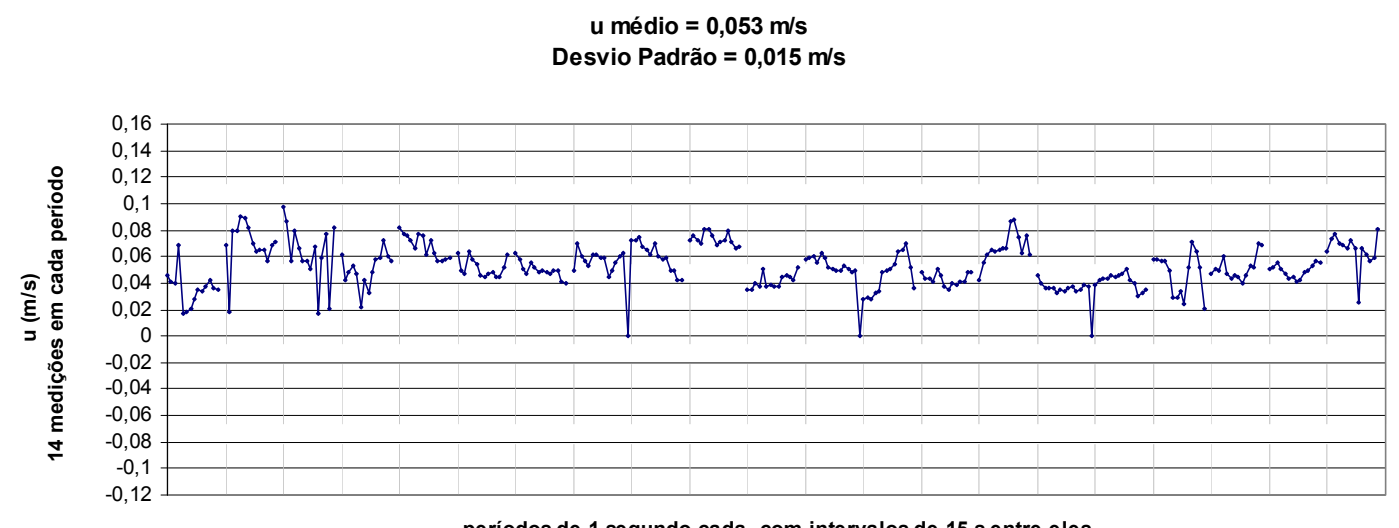

Experimento - Configuração 2 - região 1.

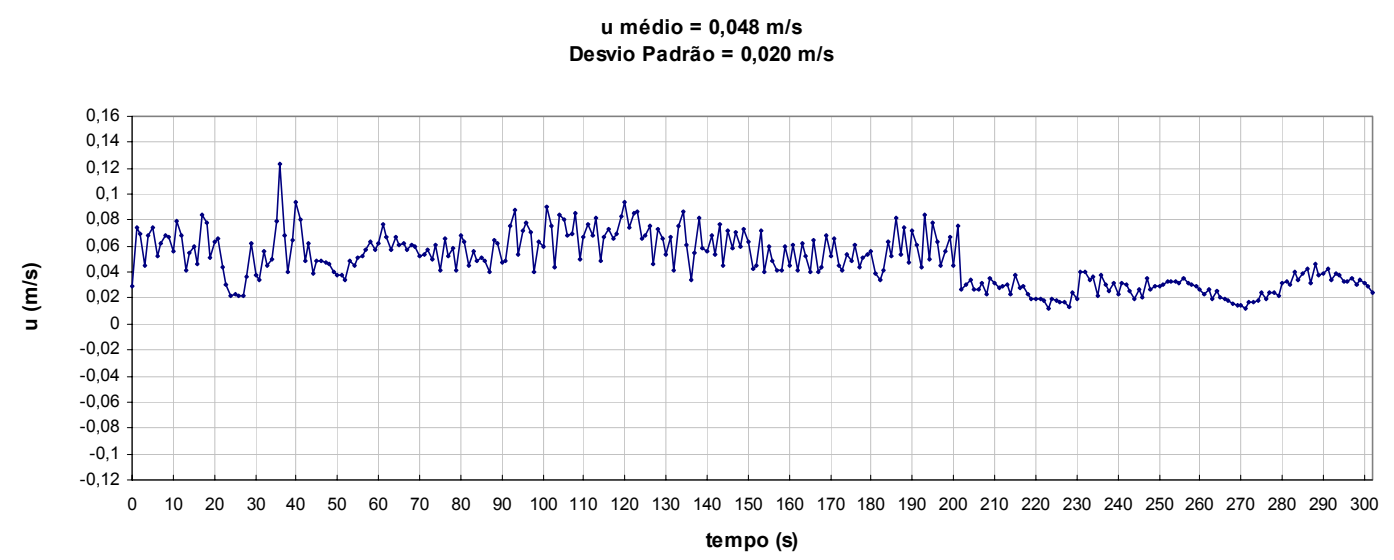

Simulação - Configuração 2 - região 1.

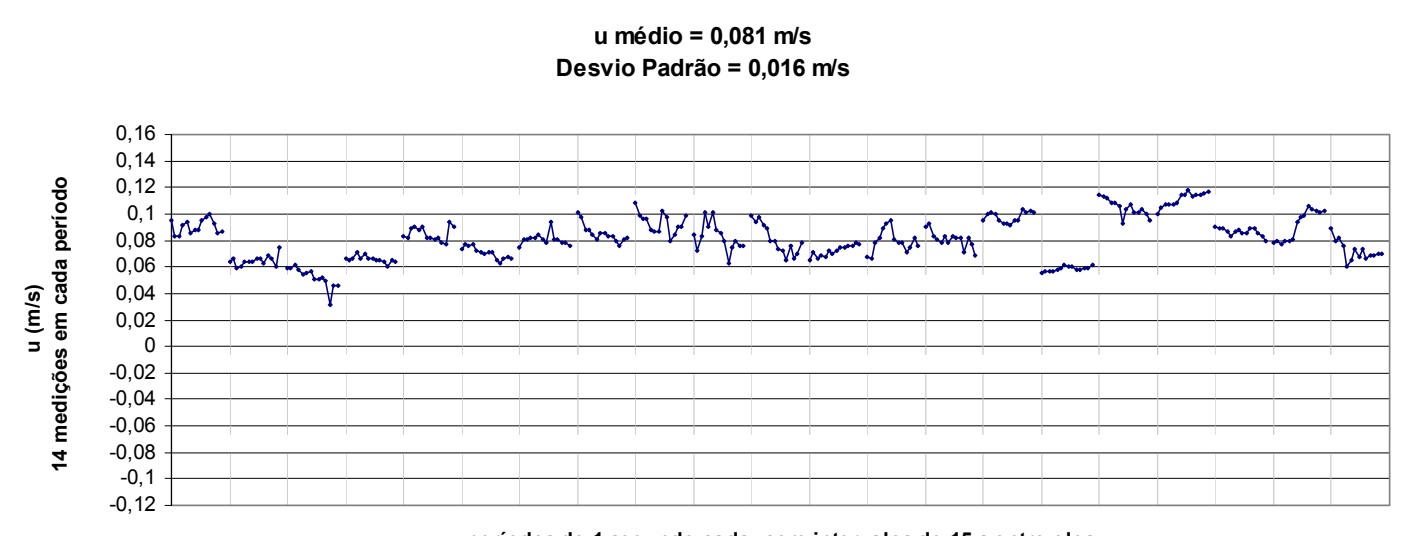

Experimento - Configuração 2 - região 2. 


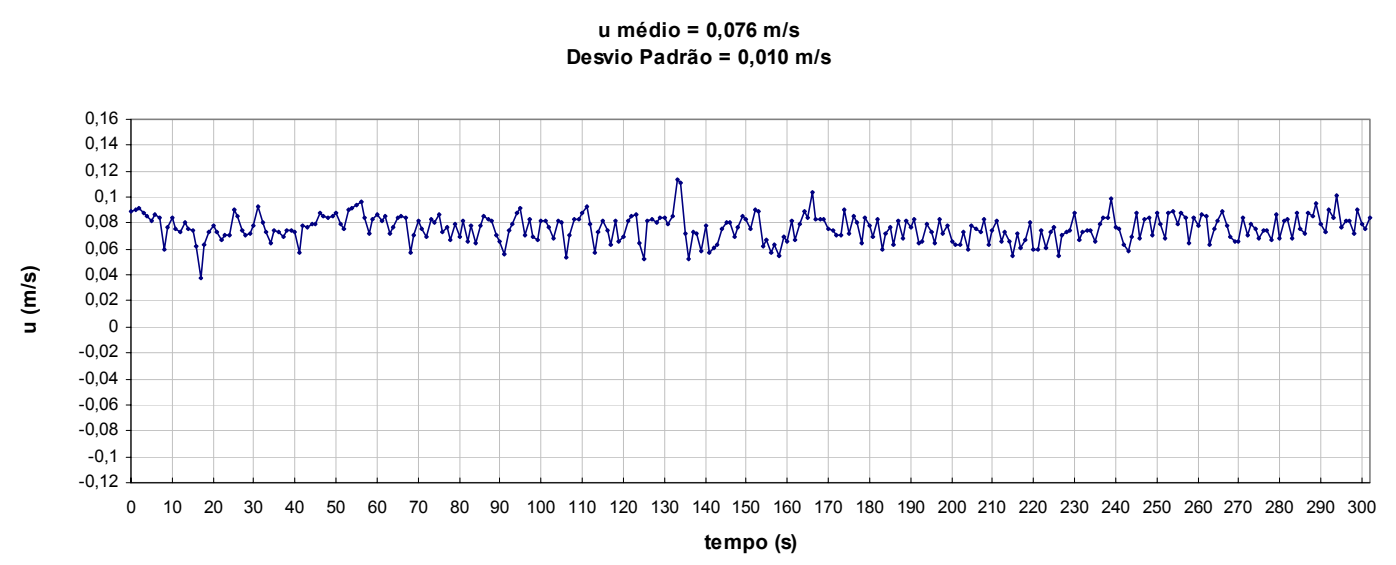

Simulação - Configuração 2 - região 2.

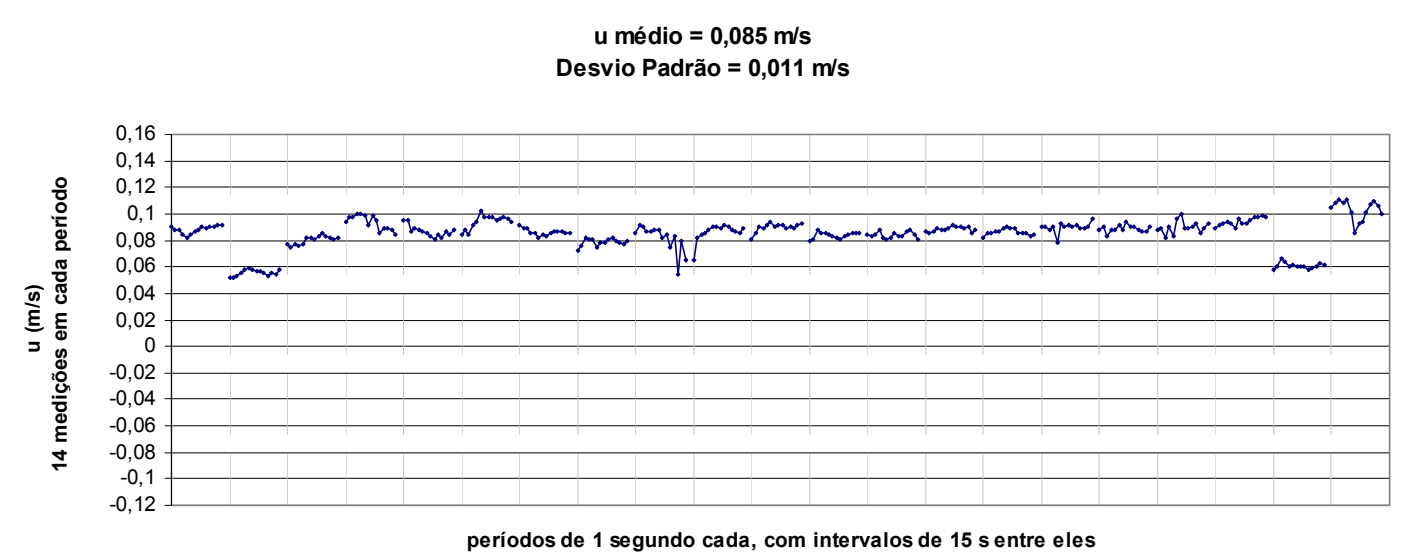

Experimento - Configuração 2 - região 3.

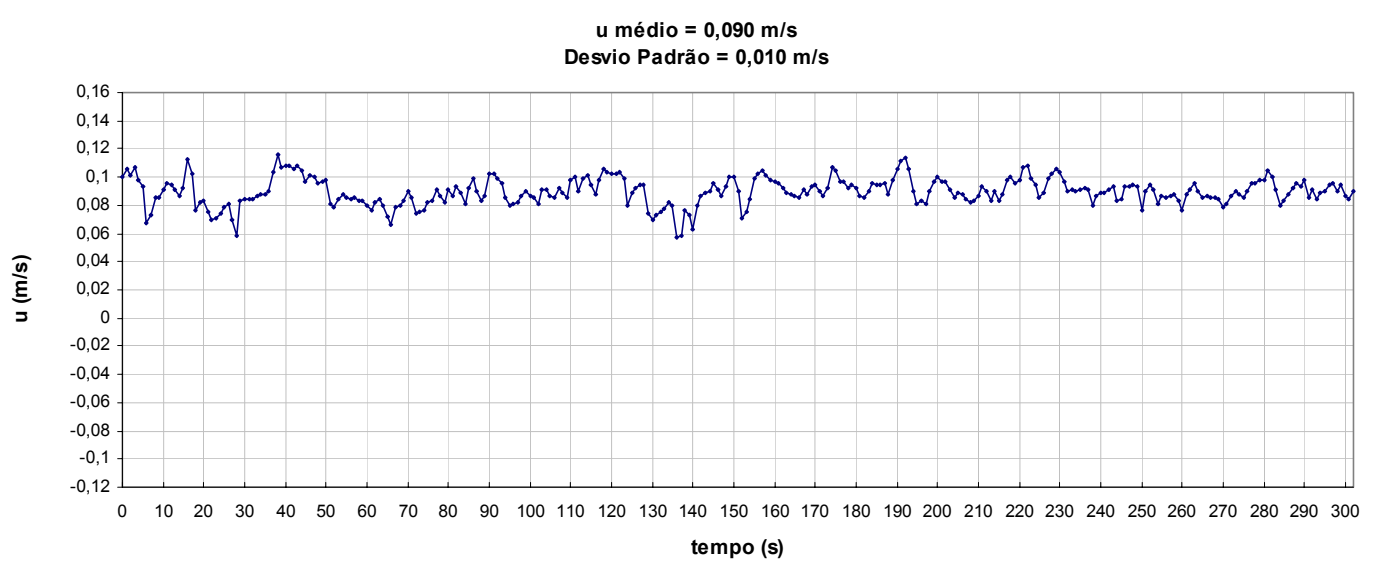

Simulação - Configuração 2 - região 3. 


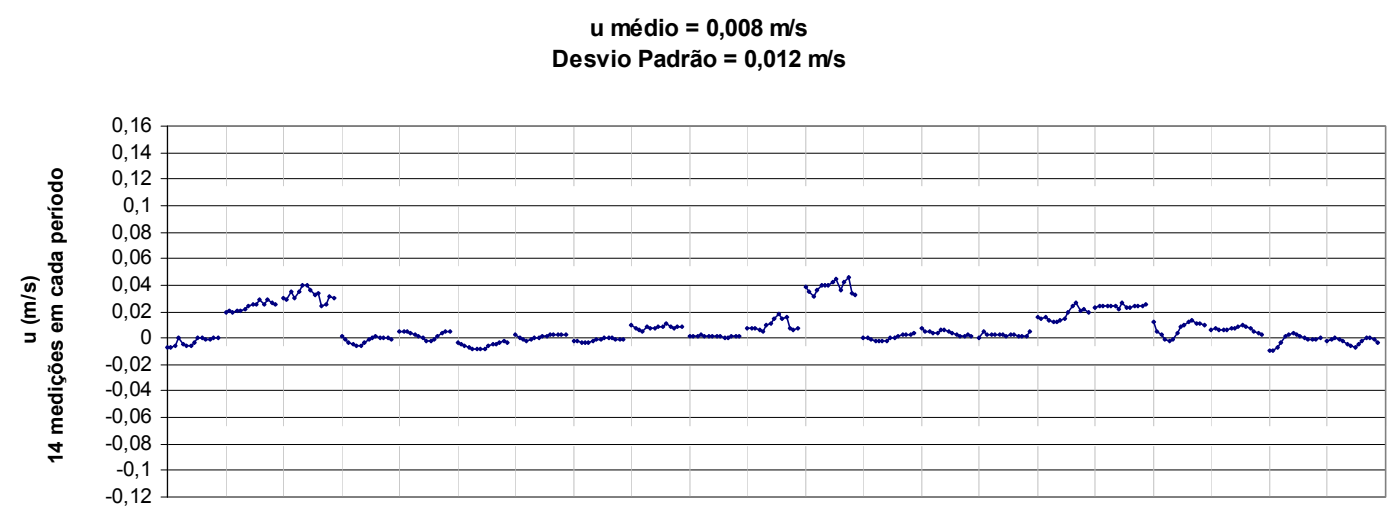

períodos de 1 segundo cada, com intervalos de 15 s entre eles

Experimento - Configuração 2 - região 4.

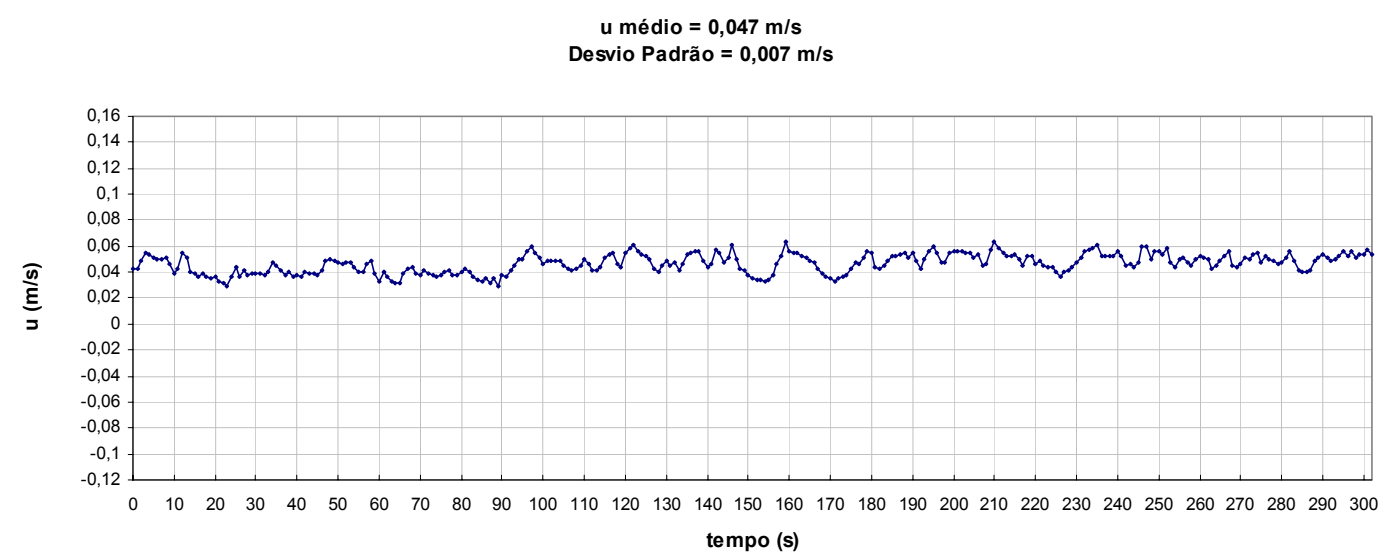

Simulação - Configuração 2 - região 4.

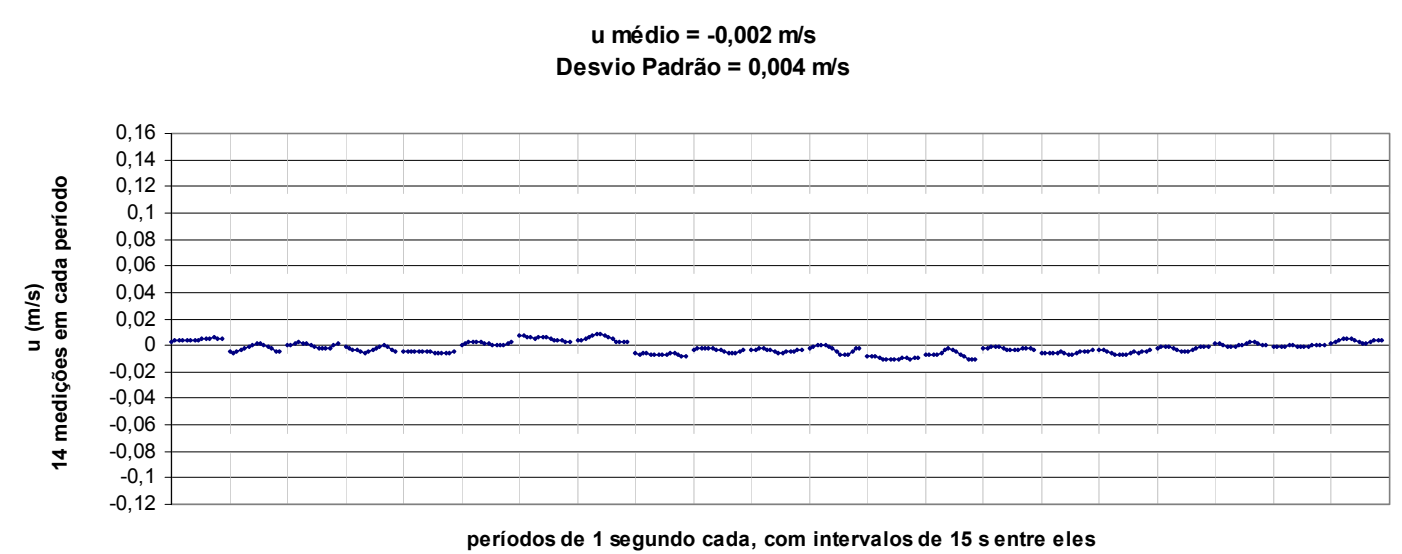

Experimento - Configuração 2 - região 5. 


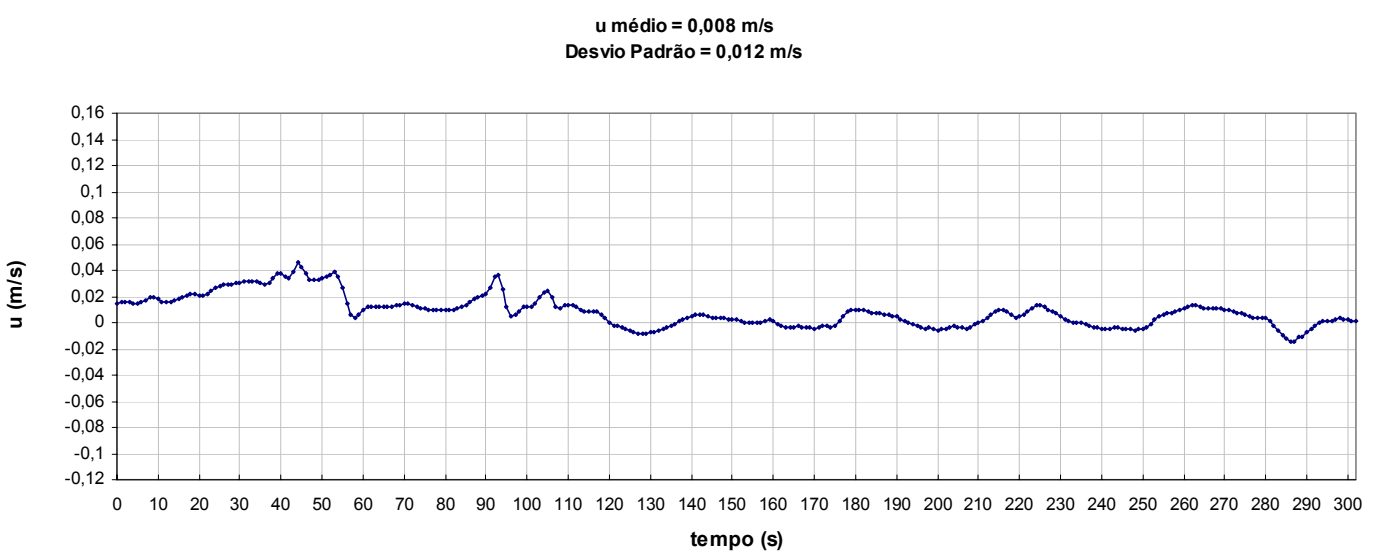

Simulação - Configuração 2 - região 5.

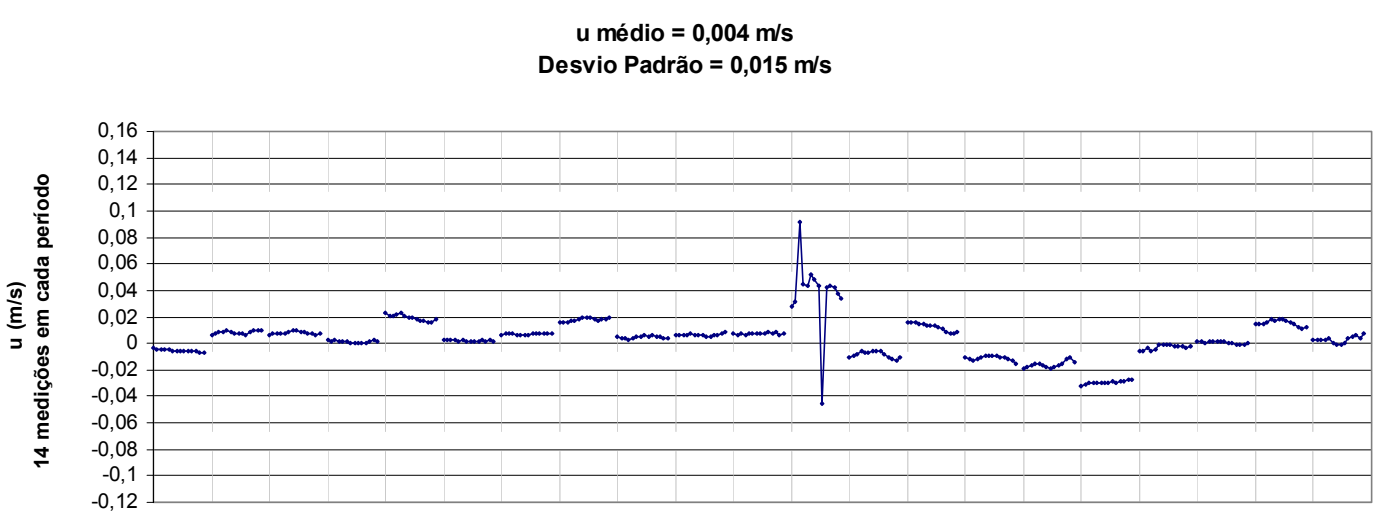

períodos de 1 segundo cada, com intervalos de 15 s entre eles

Experimento - Configuração 2 - região 6.

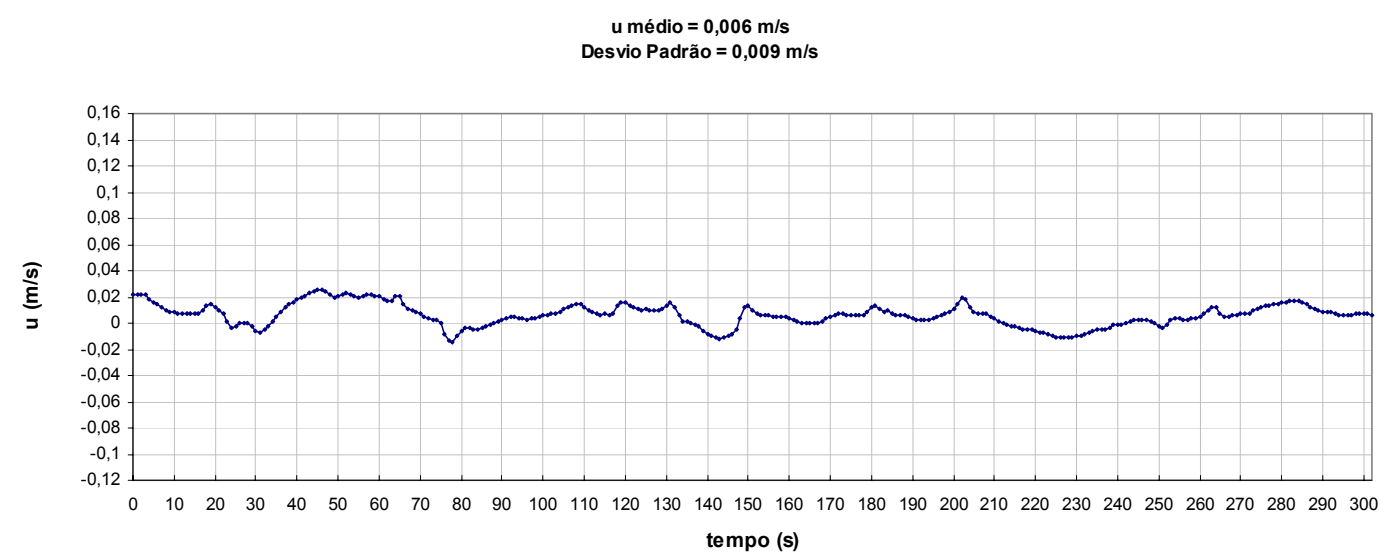

Simulação - Configuração 2 - região 6. 


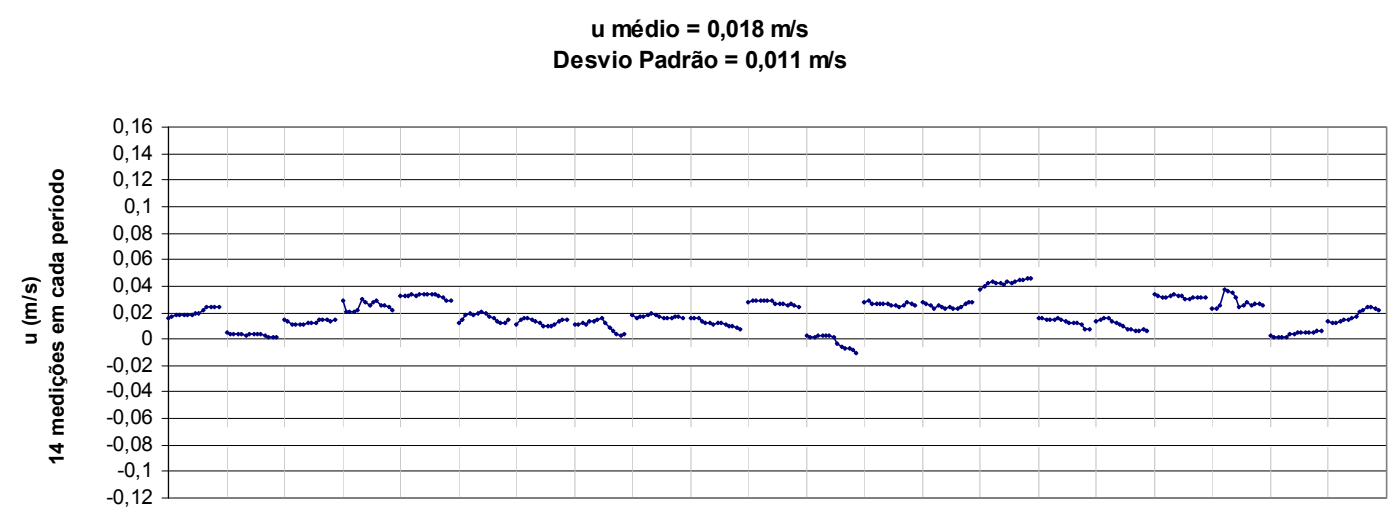

períodos de 1 segundo cada, com intervalos de 15 s entre eles

Experimento - Configuração 2 - região 7.

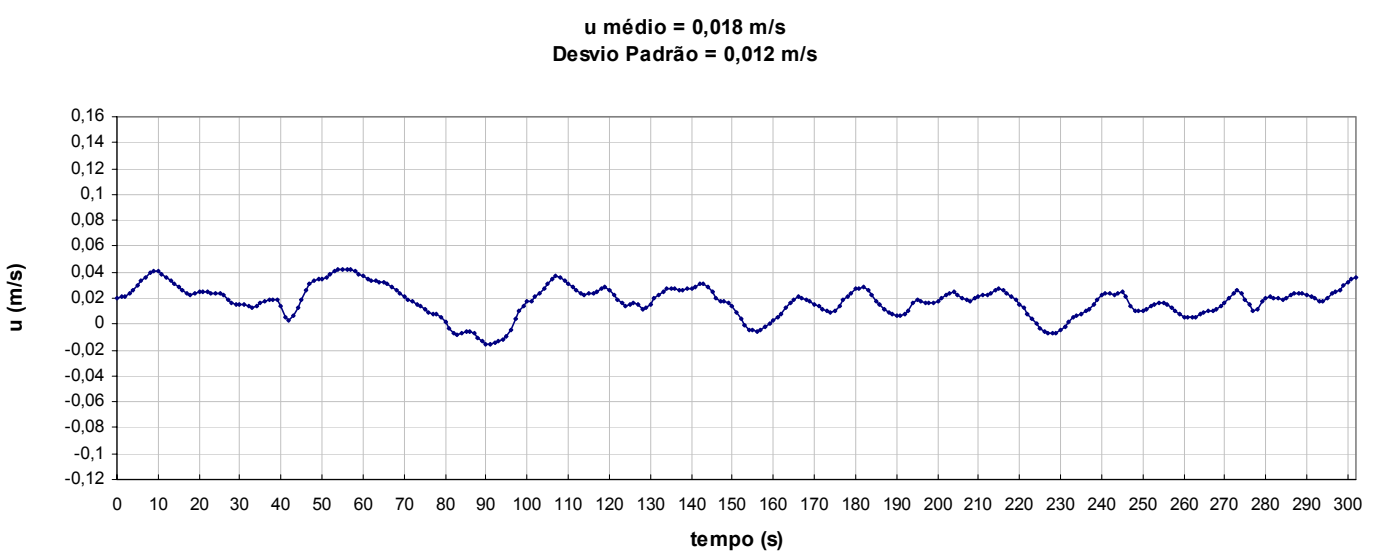

Simulação - Configuração 2 - região 7.

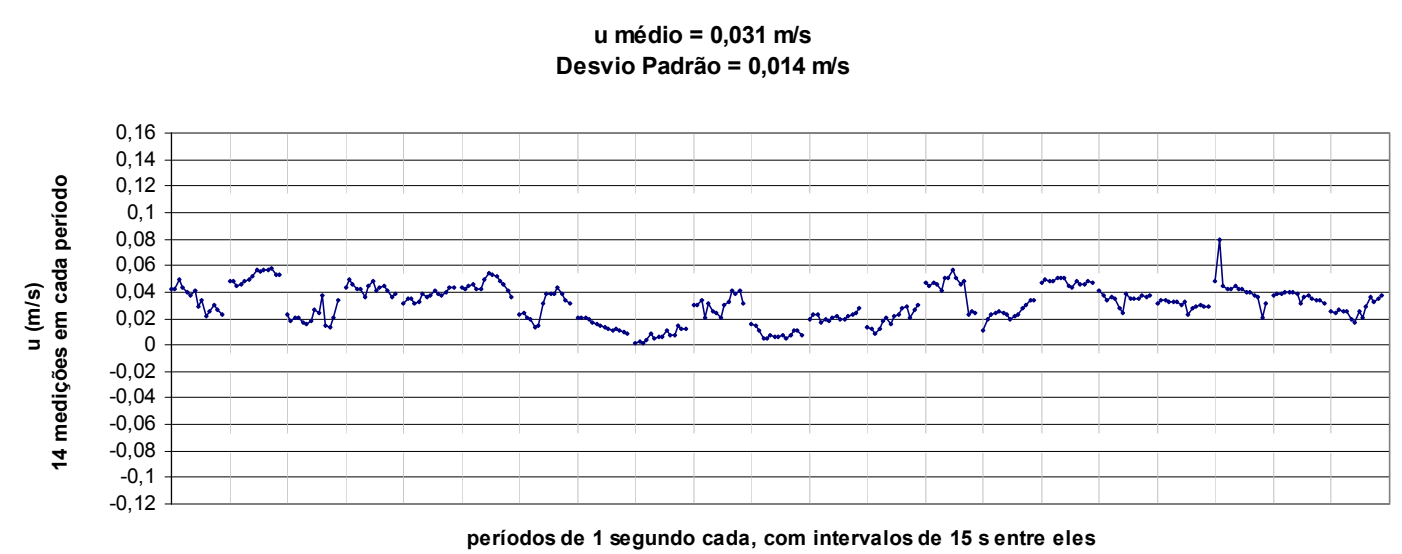

Experimento - Configuração 2 - região 8. 


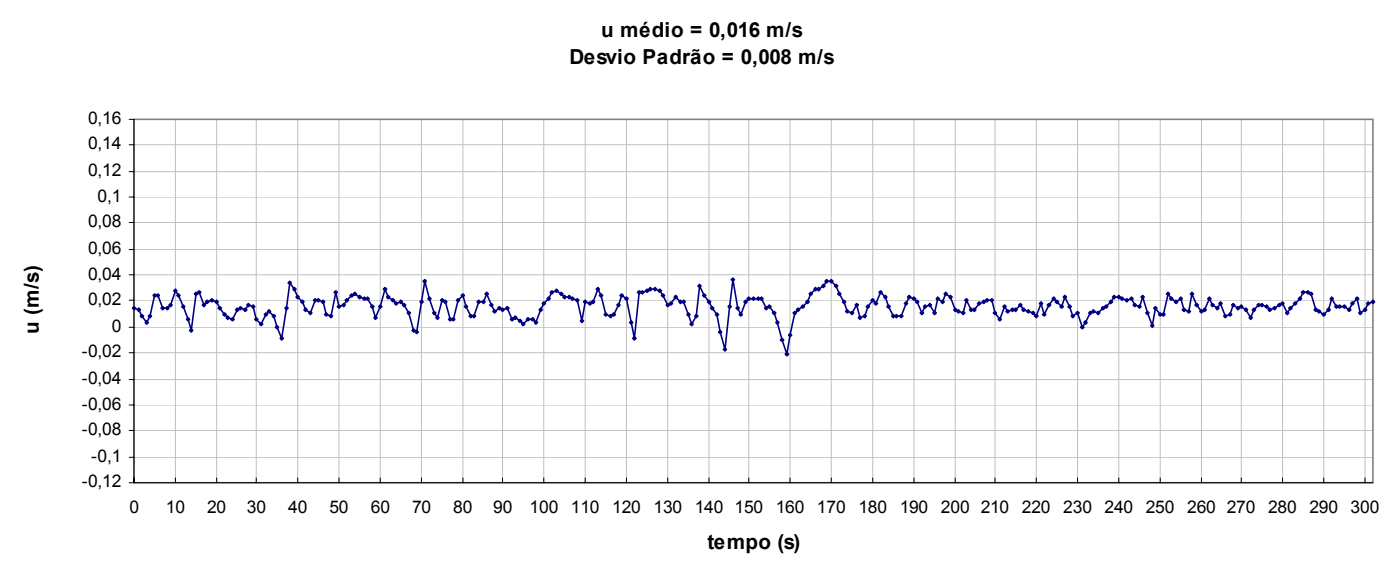

Simulação - Configuração 2 - região 8.

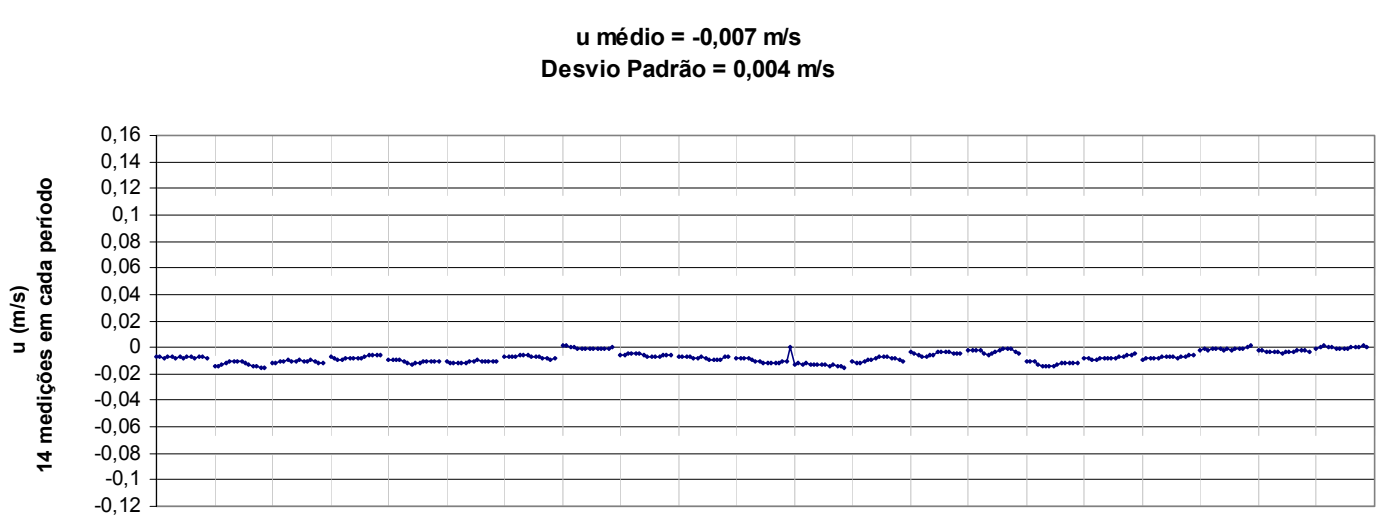

períodos de 1 segundo cada, com intervalos de 15 s entre eles

Experimento - Configuração 2 - região 9.

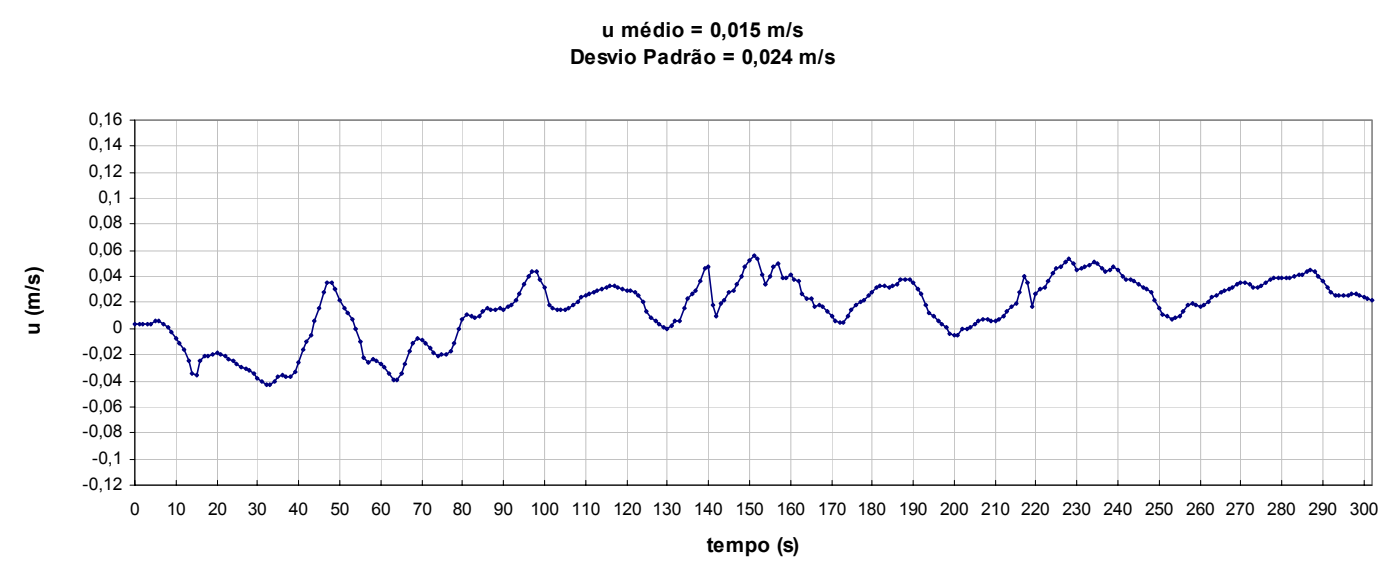

Simulação - Configuração 2 - região 9. 


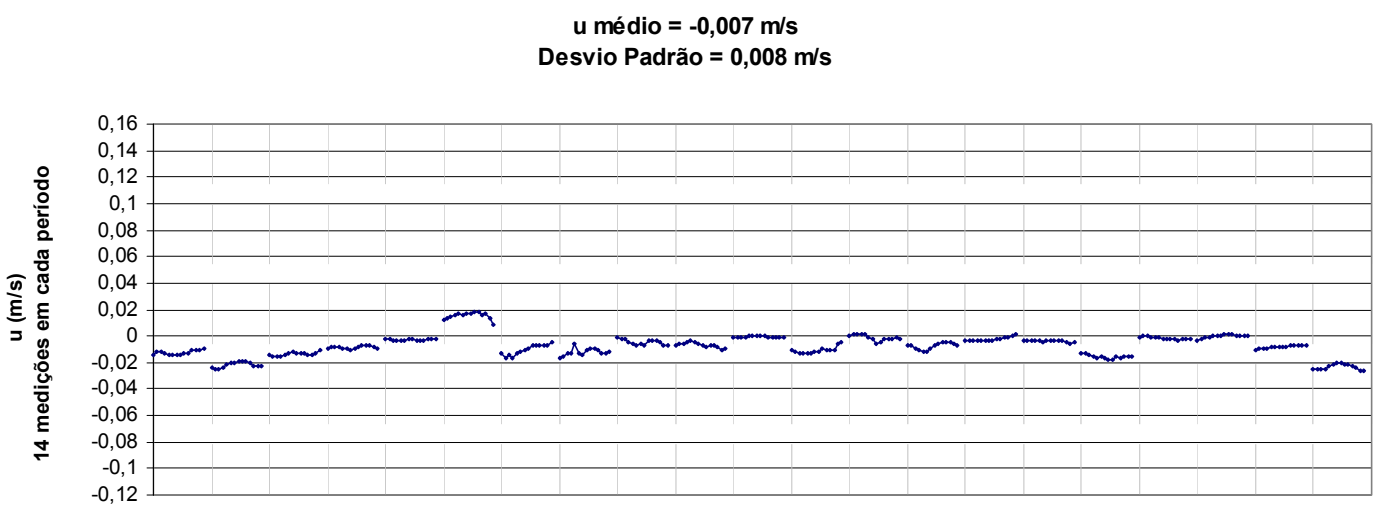

períodos de 1 segundo cada, com intervalos de 15 s entre eles

Experimento - Configuração 2 - região 10.

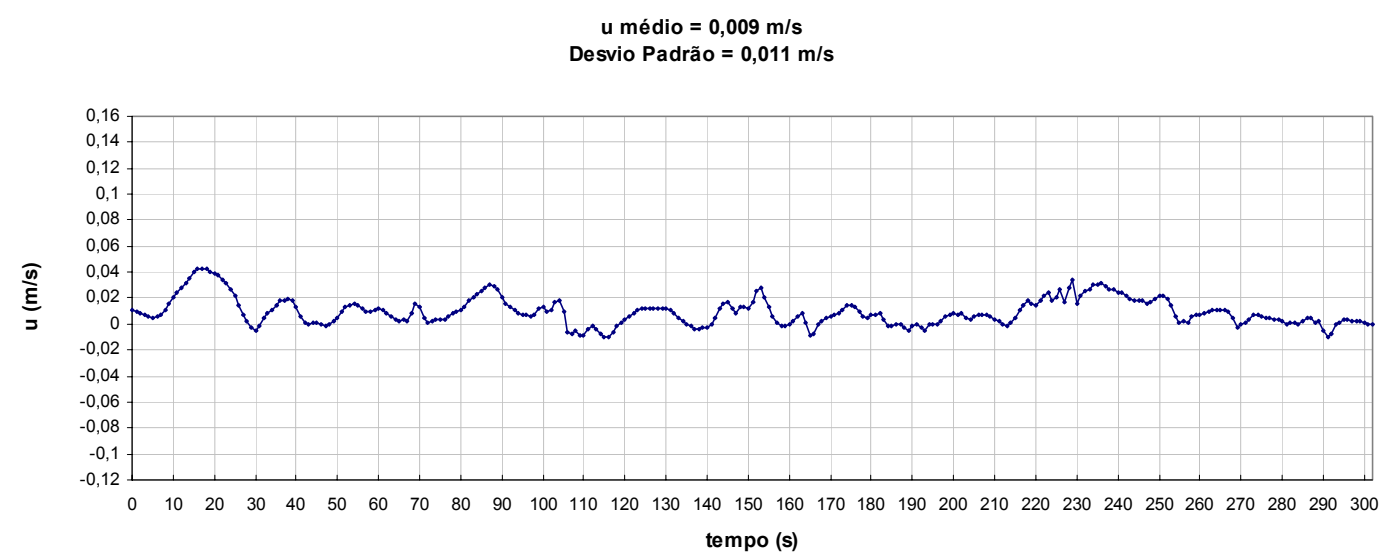

Simulação - Configuração 2 - região 10.

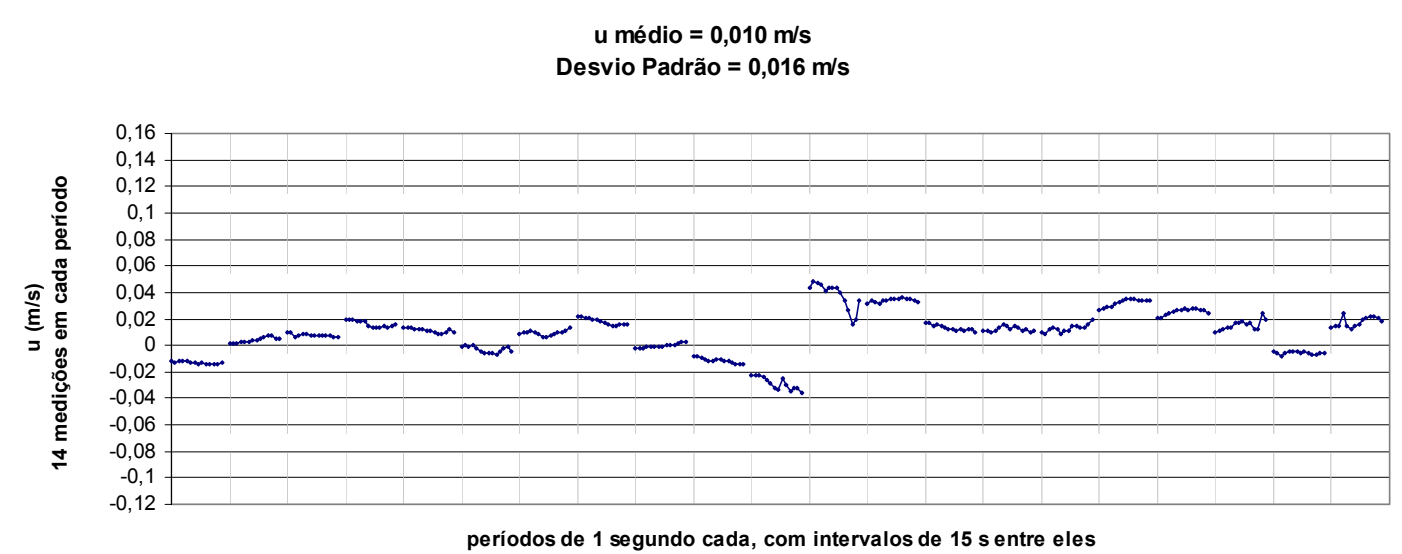

Experimento - Configuração 2 - região 11. 


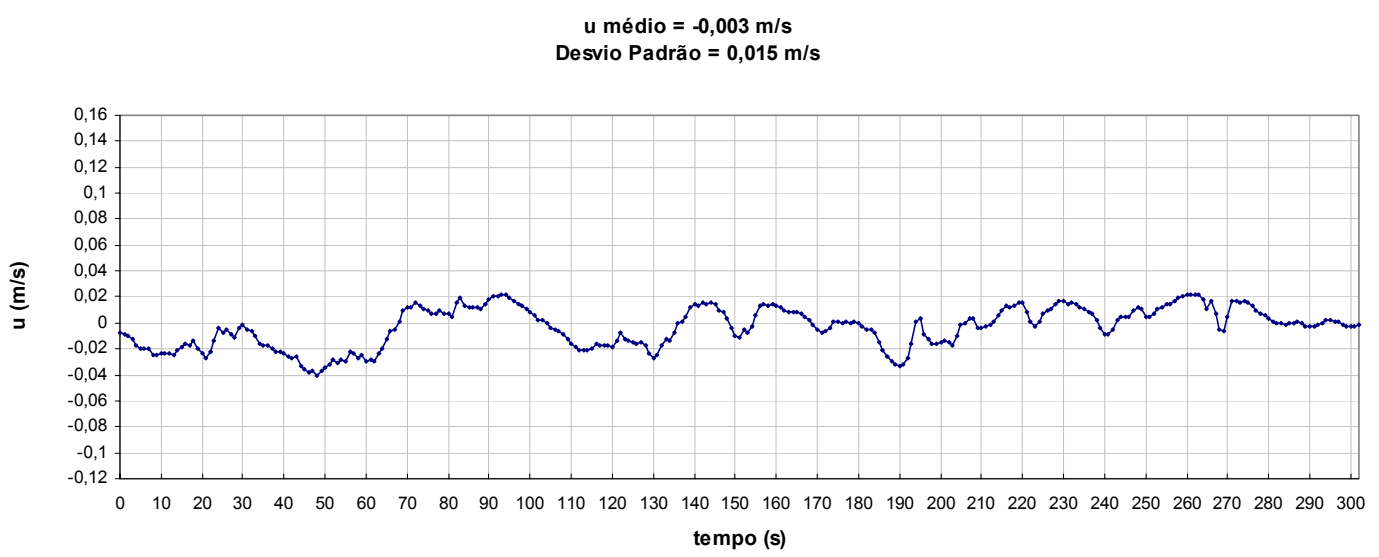

Simulação - Configuração 2 - região 11.

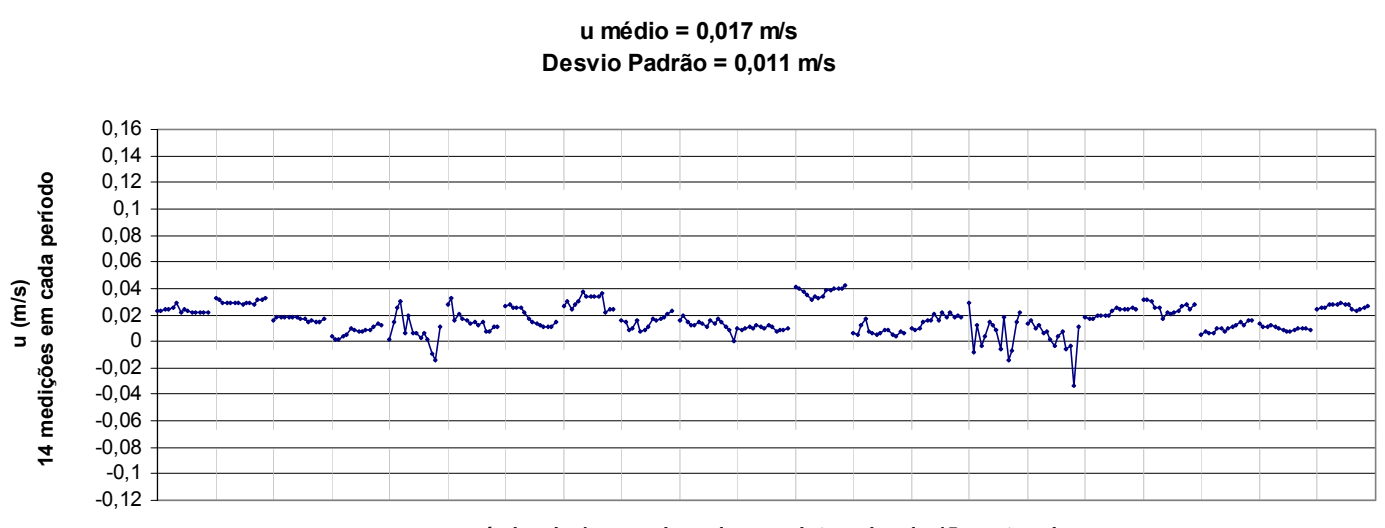

períodos de 1 segundo cada, com intervalos de 15 s entre eles

Experimento - Configuração 2 - região 12.

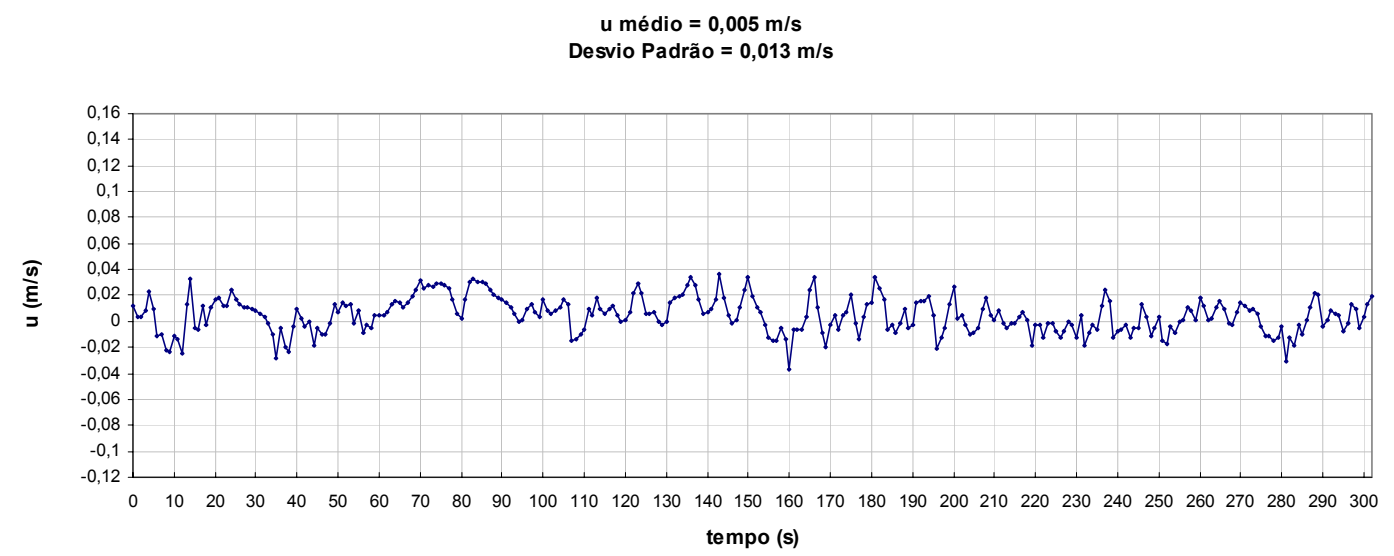

Simulação - Configuração 2 - região 12. 


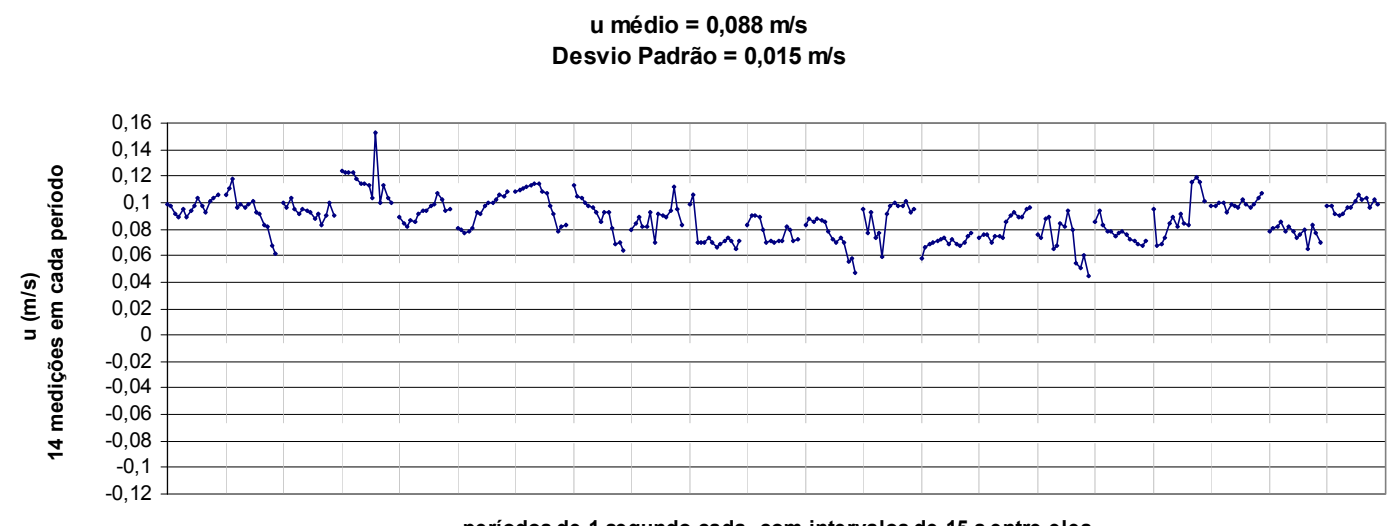

Experimento - Configuração 2 - região 13.

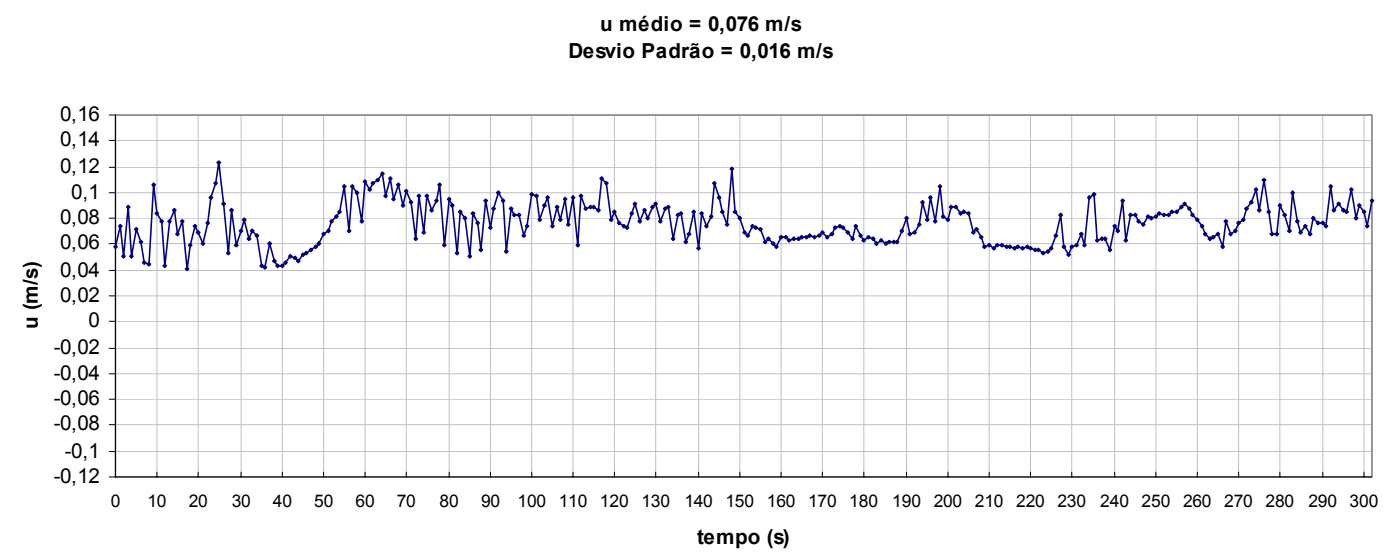

Simulação - Configuração 2 - região 13.

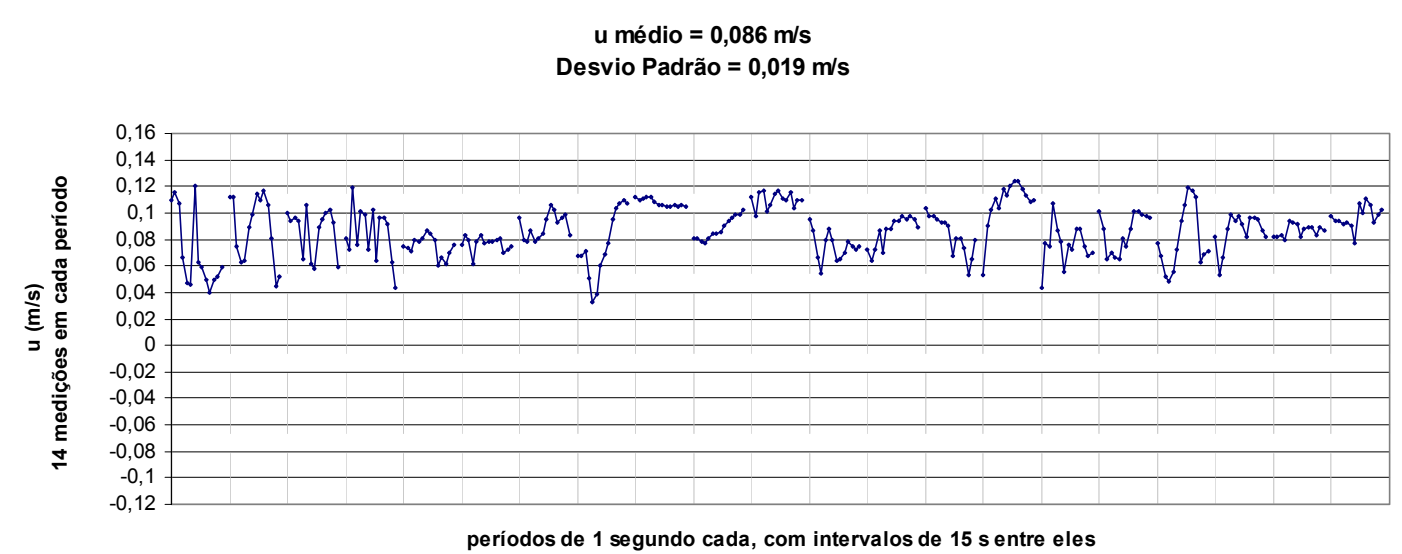

Experimento - Configuração 2 - região 14. 


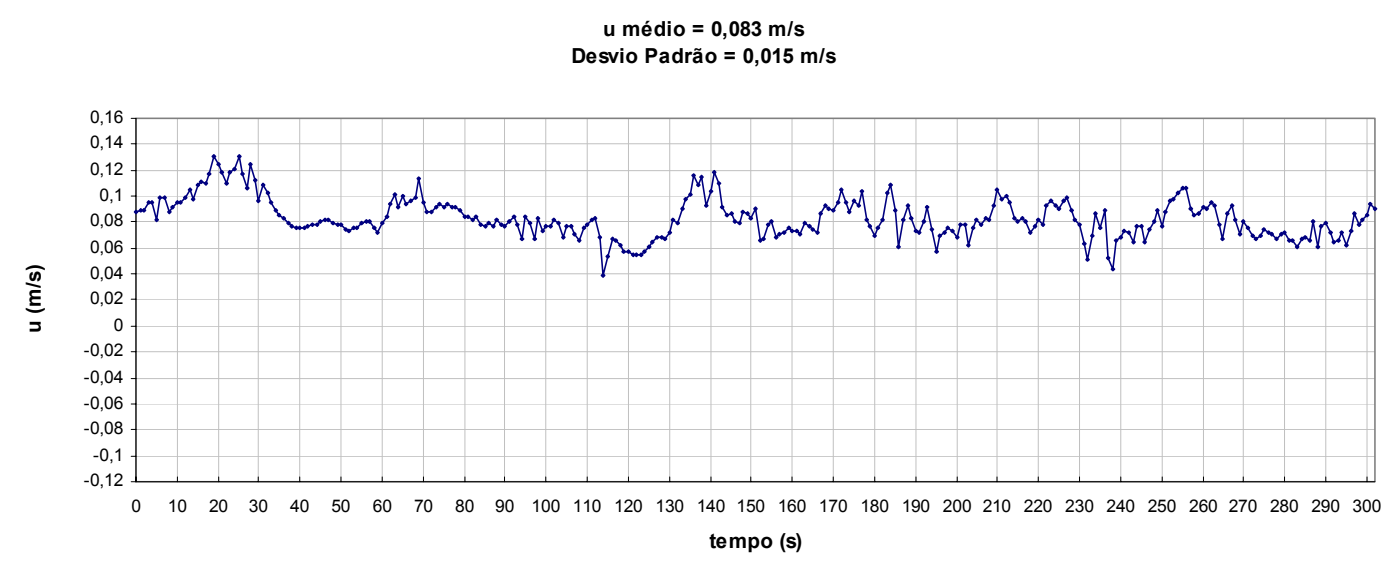

Simulação - Configuração 2 - região 14.

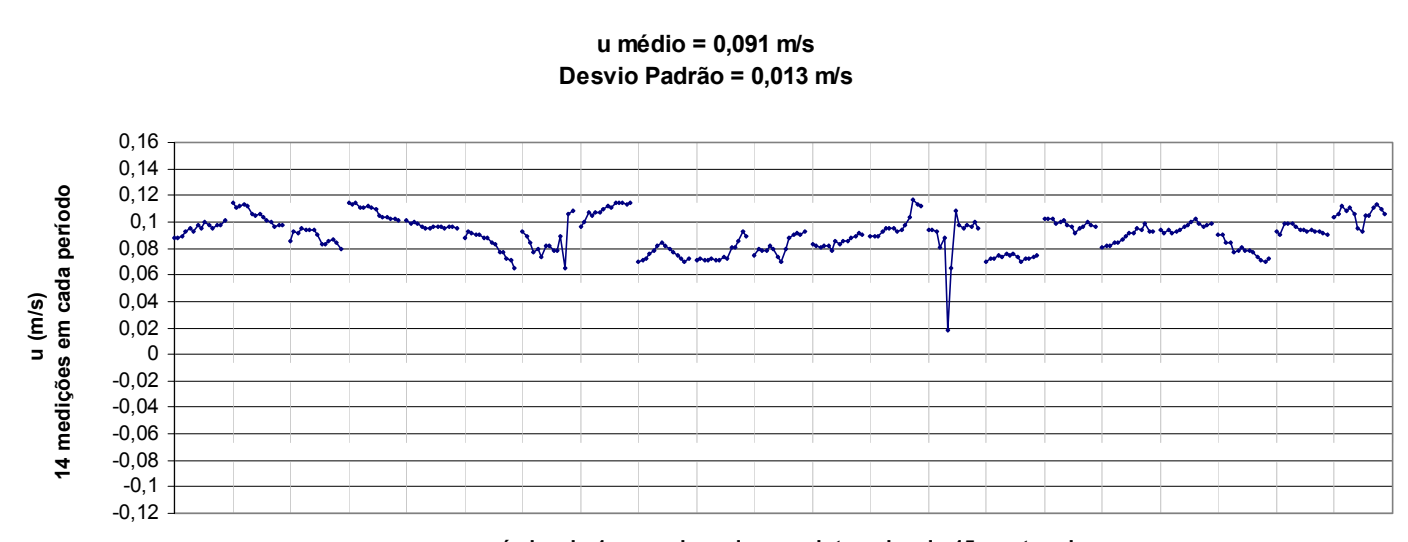

períodos de 1 segundo cada, com intervalos de 15 s entre eles

Experimento - Configuração 2 - região 15.

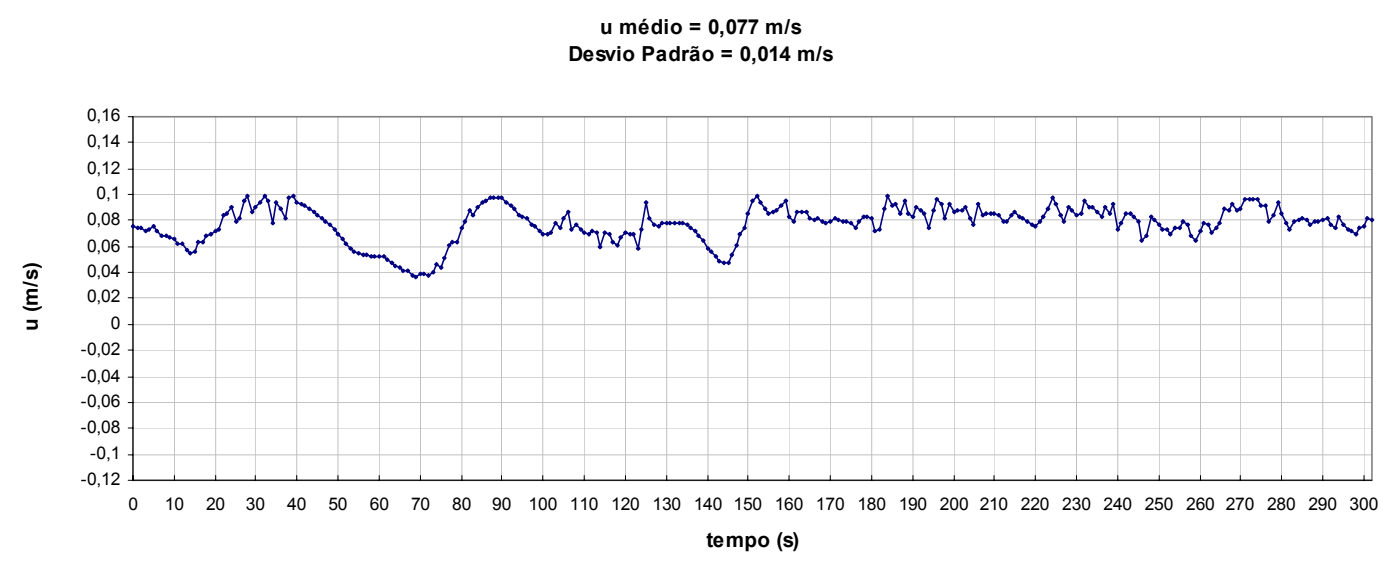

Simulação - Configuração 2 - região 15. 


\section{APÊNDICE D}

Resultados de simulações com diferentes parâmetros de entrada no programa MIKE 21C, não representativos do experimento.
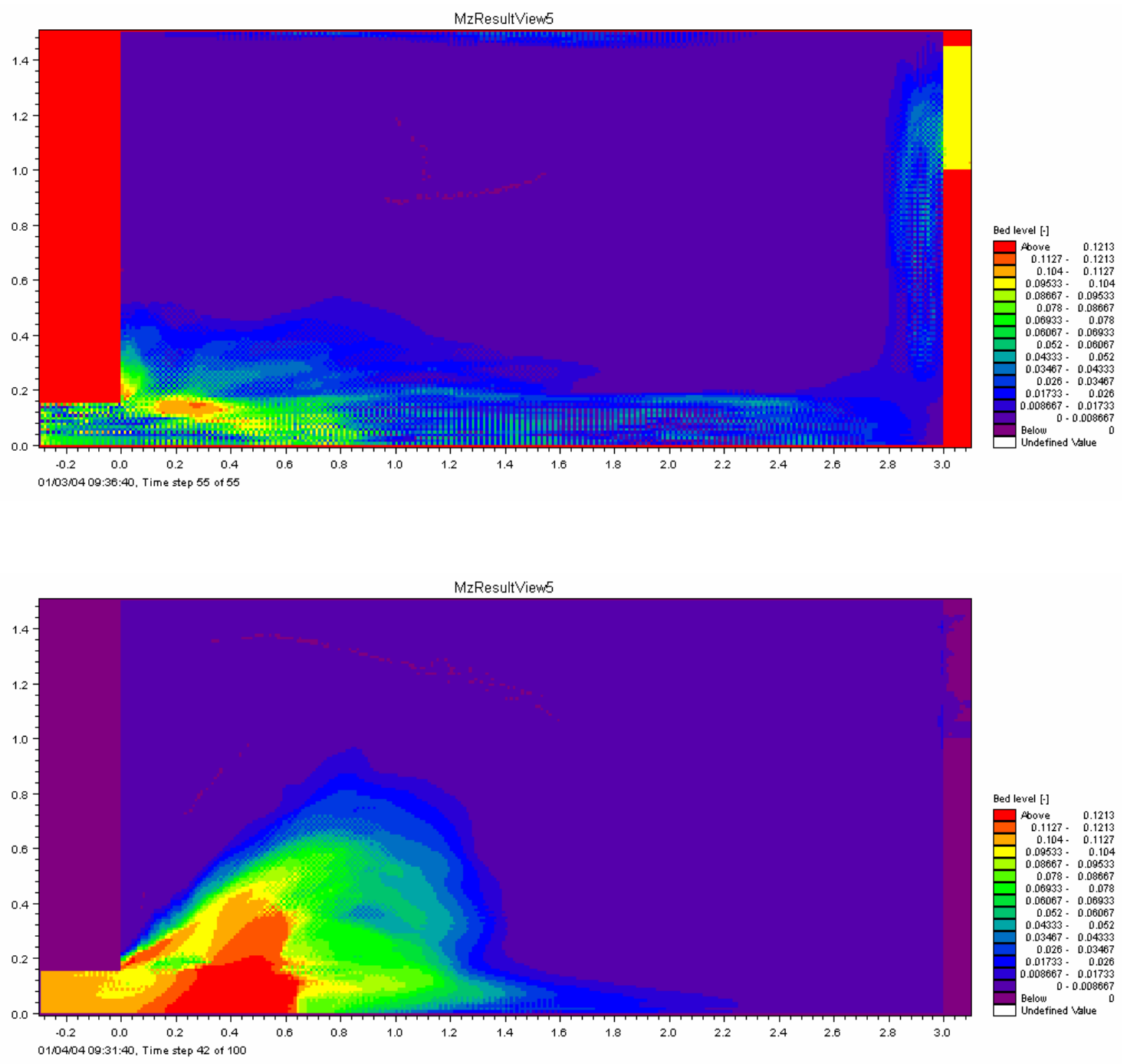
MzResultView3

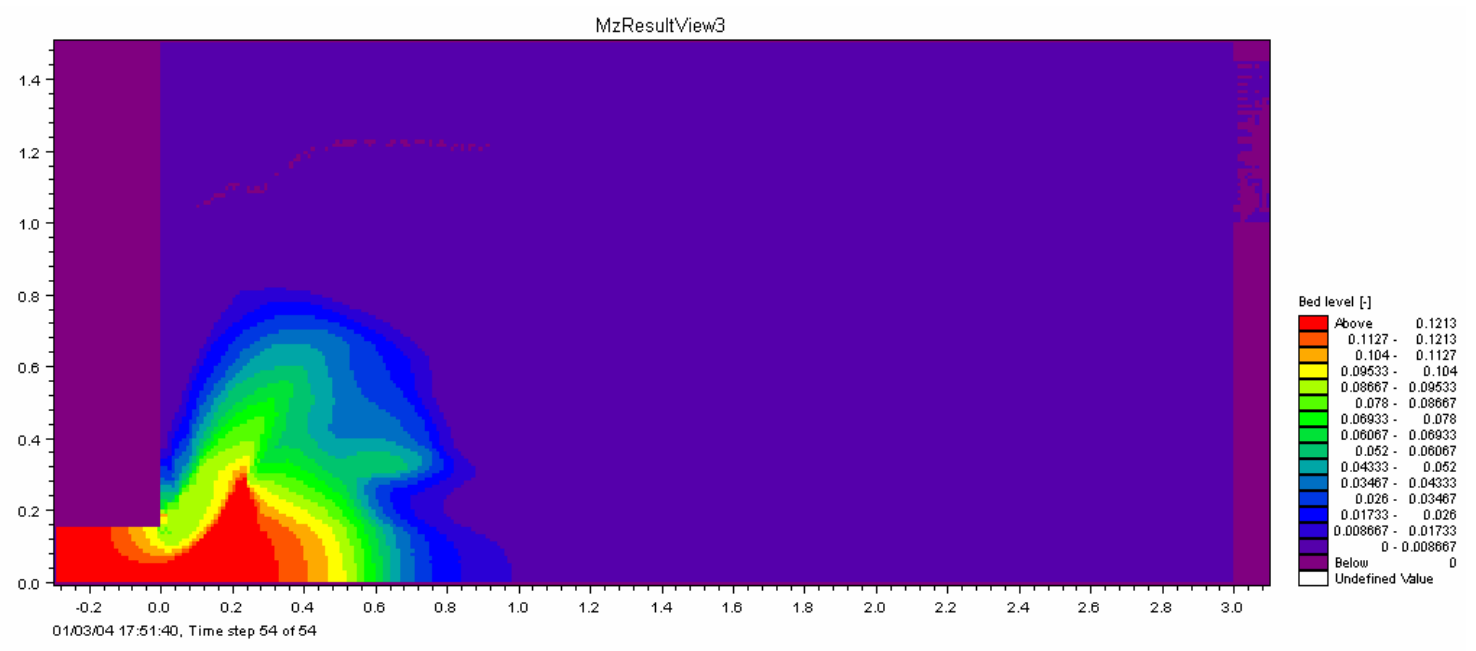

MzResultView2

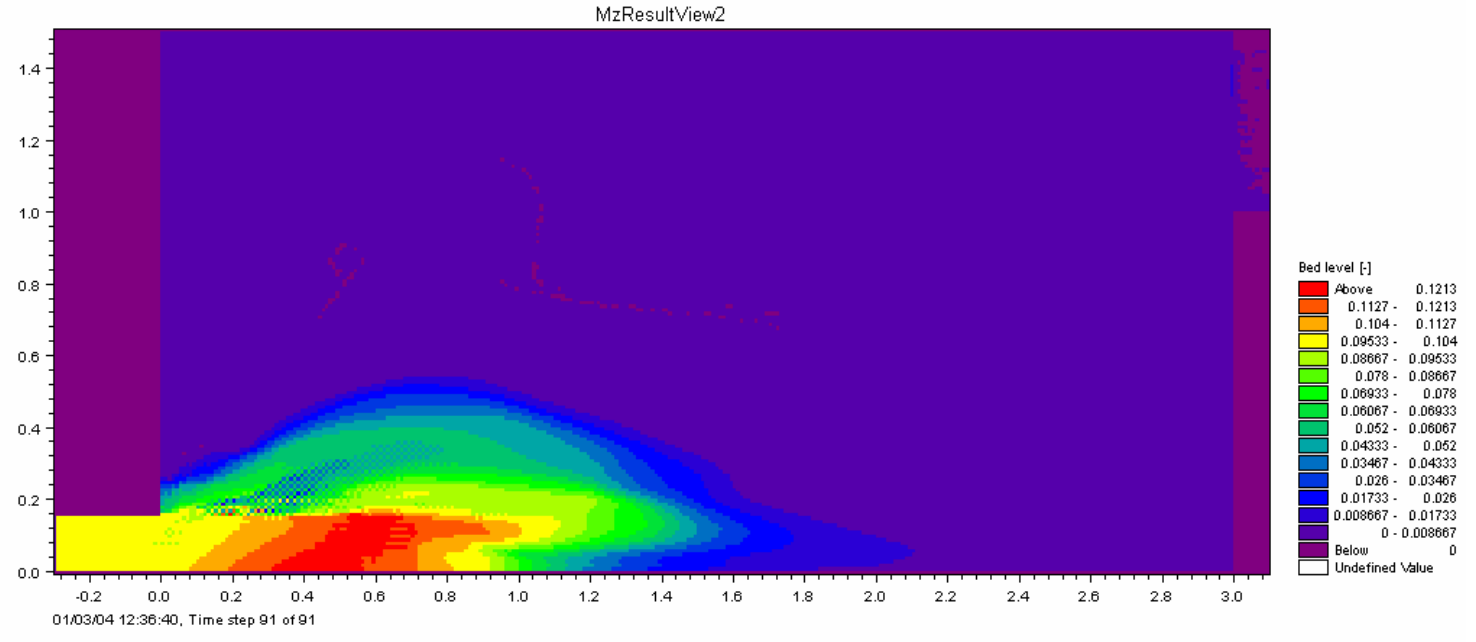

MzResultView5

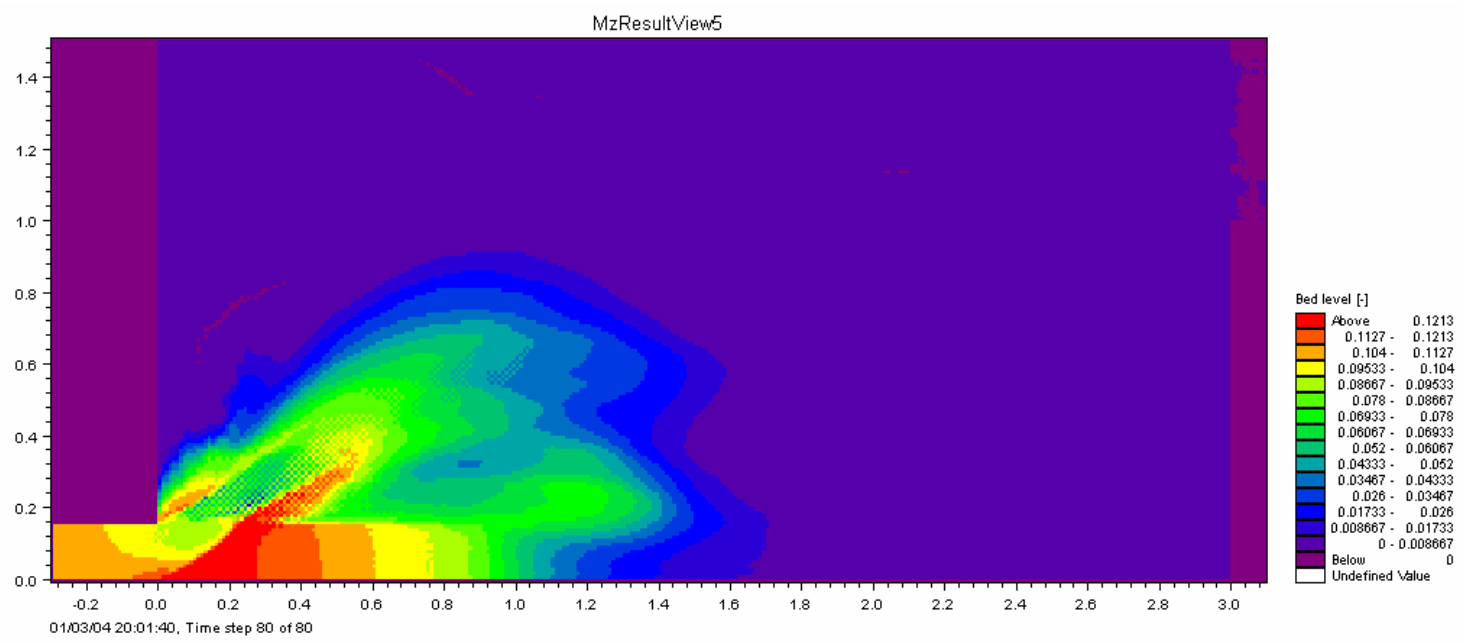




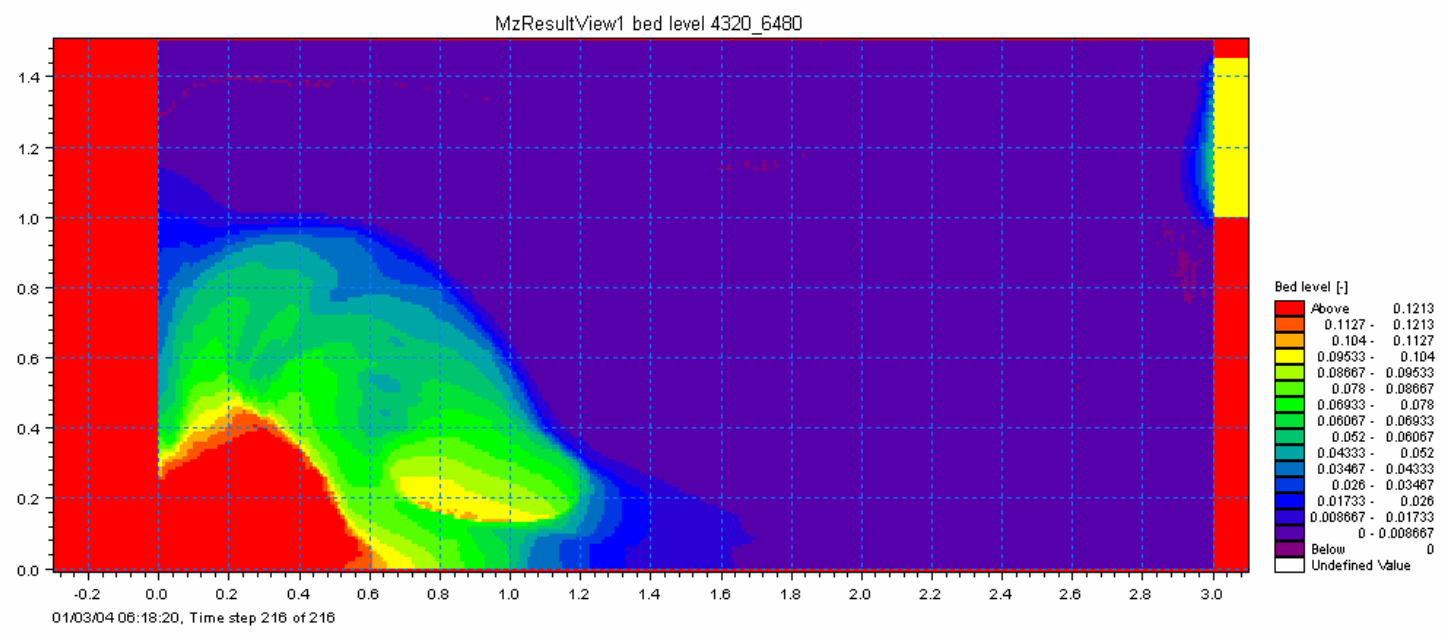

MzResultView1 bed level 64808640

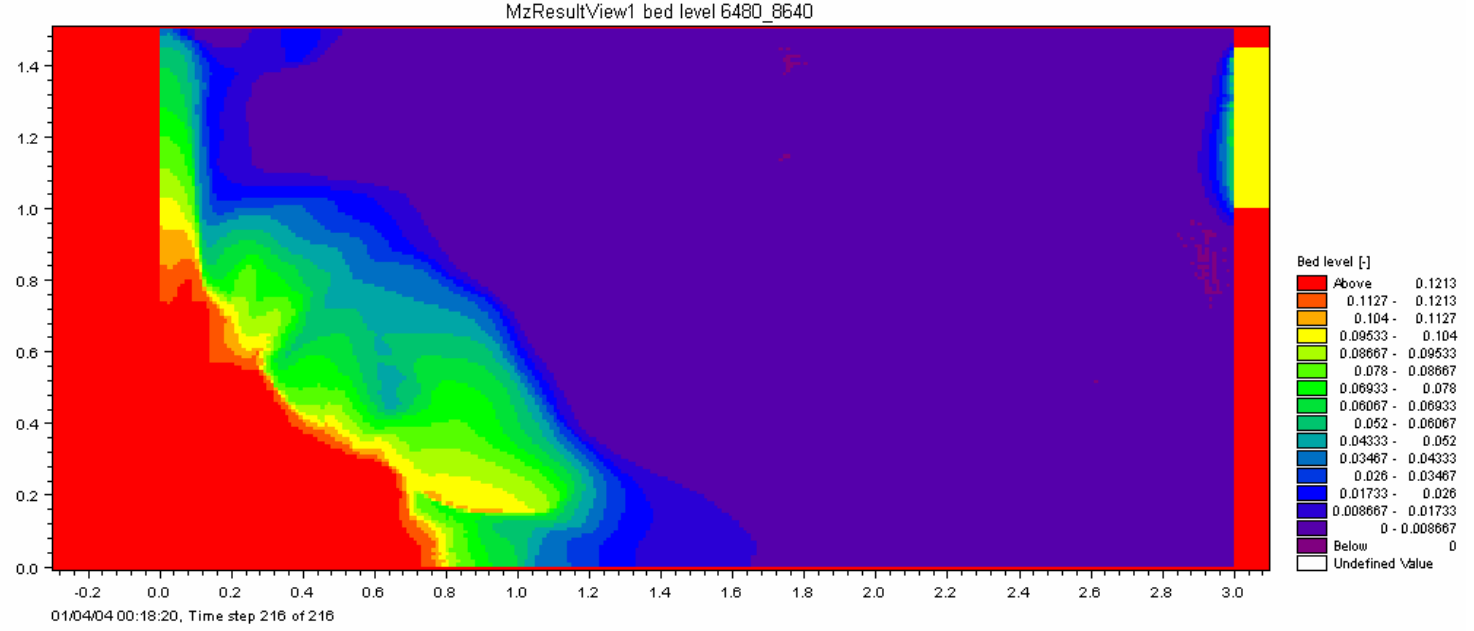

MzResultView1 bed level 21604320

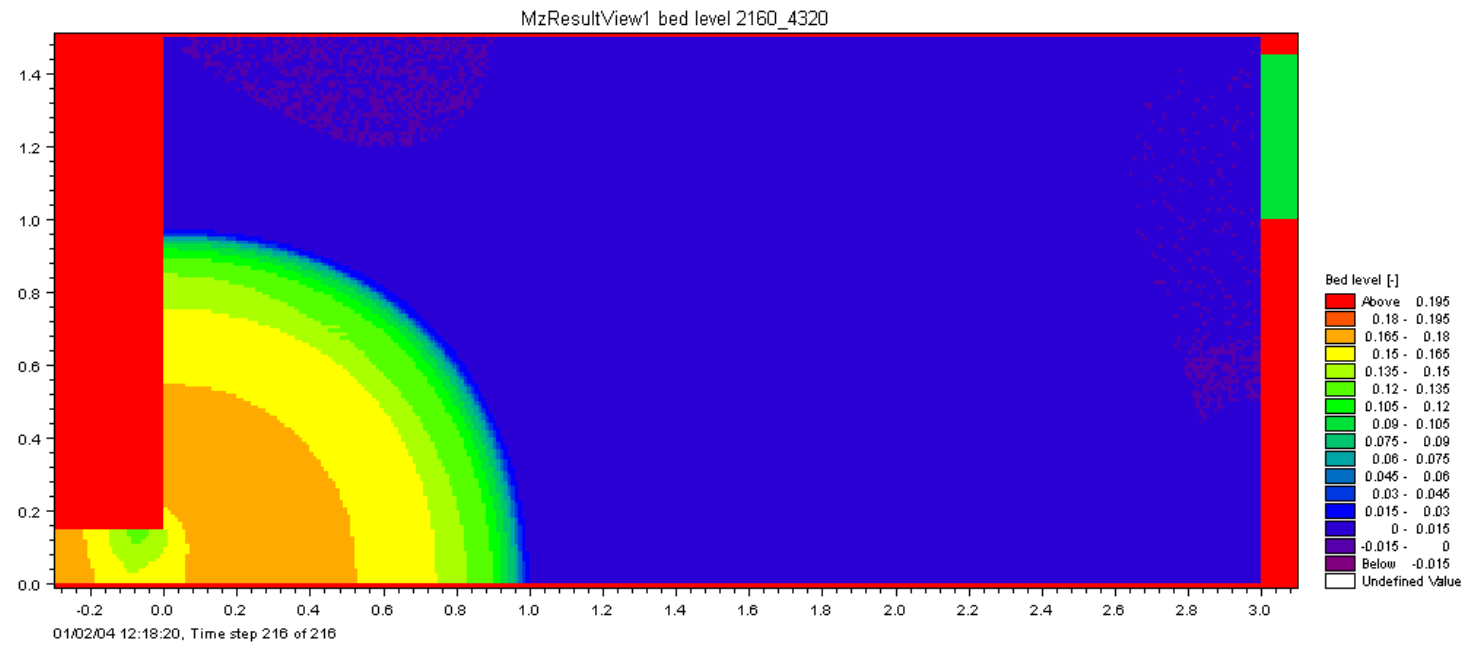


MzResultView1

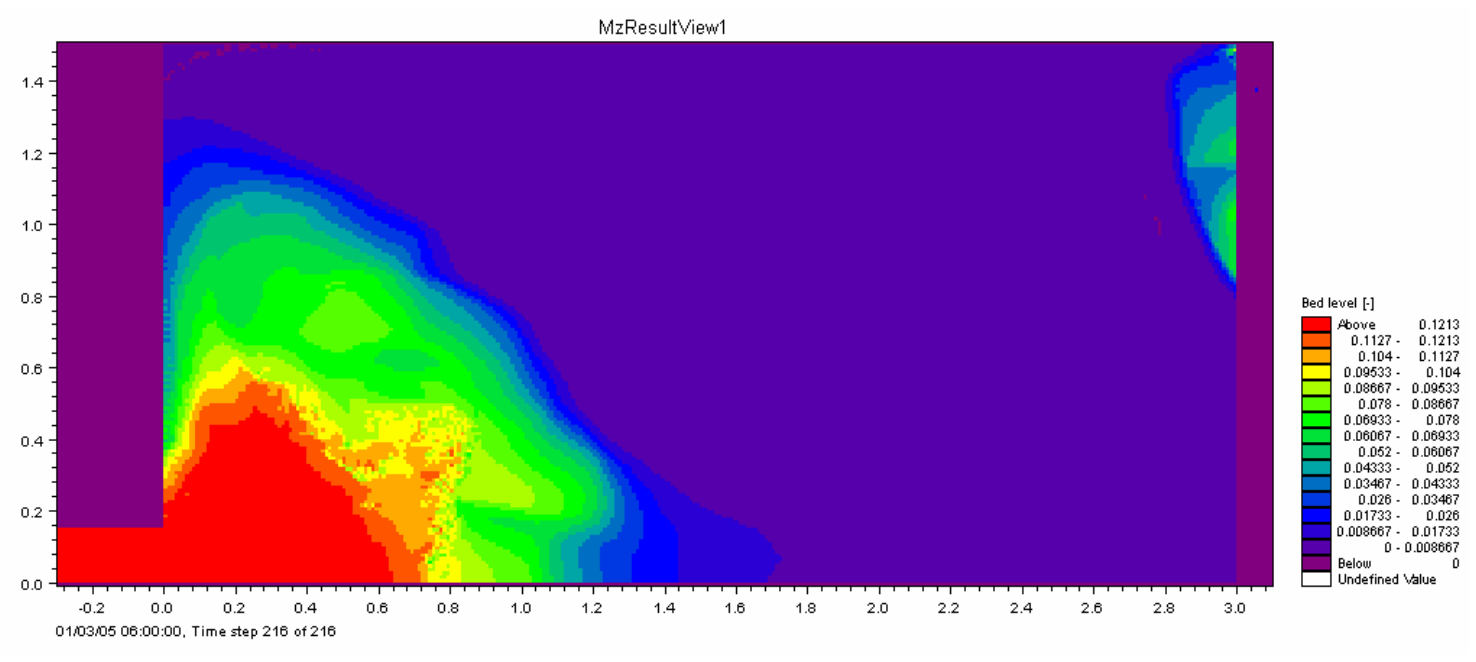




\section{ANEXO}

Anexo: "Texto ou documento não elaborado pelo autor, de acordo com a NBR14724/2002, que serve de fundamentação, comprovação e ilustração" (Universidade de São Paulo, 2002).

Reprodução do trabalho de Engelund and Fredsøe (1976). 
Nordic Hydrology, 7, 1976, 293-306

No part may be reproduced by any process without written permission from the author(s)

\title{
A Sediment Transport Model for Straight Alluvial Channels
}

\author{
Frank Engelund and Jørgen Fredsøe
}

Technical University of Denmark, Copenhagen

\begin{abstract}
The paper presents a simple mathematical model for sediment transport in straight alluvial channels. The model, which is based on physical ideas related to those introduced by Bagnold (1954), was originally developed in two steps, the first describing the bed load transport (Engelund 1975) and the second accounting for the suspended load (Fredsøe and Engelund 1976). The model is assumed to have two advantages as compared with empirical models, first it is based on a description of physical processes, secondly it gives some information about the quantity and size of the sand particles in suspension and the bed particles.
\end{abstract}

\section{Introduction}

One of the basic difficulties in sediment transport theory is the definition of bed load versus suspended load, and some authors have even tried to overcome the problem by disregarding any such distinction. However, there are several good reasons for maintaining it, mostly, of course, related to the nature of the physical processes. The authors would like to draw the attention to the fact that the instability of erodible beds which leads to the formation of sand dunes (or antidunes) can only be explained satisfactorily by a theory which clearly distinguishes between bed load and suspended load. It is found that transition between dunes and plane bed is very sensitive to a correct estimation of these transport rates (Engelund and Fredsøe 1974, Fredsøe and Engelund 1975, and Fredsøe 1976a). The stability analysis even gives an indication of one relevant way of defining the difference between the transport of bed load and 


\section{F. Engelund and J. Fredsøe}

suspension, respectively: The bed load is that part of the total load which accomodates to spatial changes in the tractive stress, so that spatial lag may be neglected, assuming inertia of the bed particles to be negligible. On the other hand, the suspended load responds with a certain lag, because the particles have to settle a certain distance before they become deposited. This lag depends on flow conditions and sediment properties and can be estimated from an equation of continuity.

Also in other problems in the field of river morphology and sedimentation a clear distinction between bed load and suspended load is important. For example it was found (Engelund 1976) that the transverse bed slope in river bends increases in linear proportion to the ratio $q_{S} / q_{B}$. Concerning the sedimentation of river navigation channels is, it was demonstrated (Fredsøe 1976b) that the rate of sedimentation for longitudinal currents is a function of the bed load, rather than of the total load. Further it might be mentioned that observations seem to indicate that the occurrence of meandering or braiding depends on the ratio $q_{S} / q_{B}$, so that the greater the relative amount of suspension is, the more pronounced is the tendency towards braiding. This tendency is until now not fully understood.

An obvious possibility is to define the bed load as the particles in the lowest layer of moving grains. Typically the particles move by rolling, sliding, or in short jumps. This definition is in accordance with the original definition by H. A. Einstein (1950): Bed load is the bed particles moving in the so-called "bed layer", defined as "a flow layer, 2 grain diameters thick, immediately above the bed."

In this treatise Einstein presented one of the first theoretical approaches to the problem of predicting theoretically the rate of bed load transport, applying theory of probability to account for the statistical variation of the forces acting on bed particles. If the magnitude of the instantaneous agitating forces on a certain bed particle exceeds the stabilizing forces, the particle is supposed to be eroded and to start moving along the bed, until it becomes deposited downstream at a location, where the magnitude of the instantaneous forces makes deposition possible. From such consideration Einstein found that the rate of bed load transport could be described by a relation between two non-dimensional quantities

$$
\Phi=\frac{q_{B}}{\sqrt{(s-1) g d^{3}}} \text { and } e=\frac{\tau_{0}}{(s-1) \circ g d}=\frac{U_{f}^{2}}{(s-1) g d}
$$

in which

$$
\begin{aligned}
q_{B}= & \text { rate of bed load transport in volume of material per unit time and unit } \\
& \text { width of the channel } \\
s \quad= & \text { relative density of sediment } \\
g= & \text { acceleration of gravity } \\
d= & \text { fall diameter of sediment particle } \\
\rho= & \text { fluid density } \\
\tau_{0}= & \text { bed shear stress (=tractive stress) }
\end{aligned}
$$




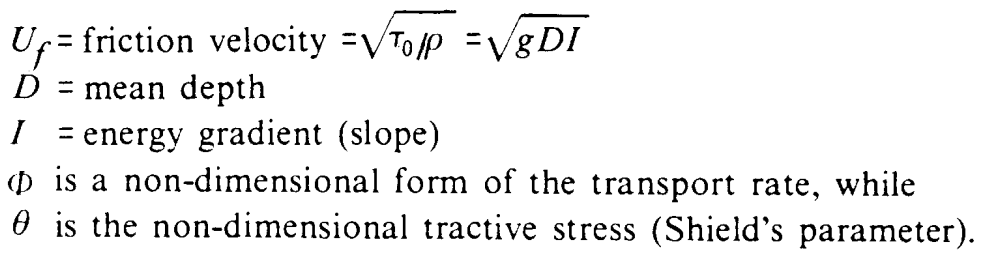

When calculating the transport rate of the suspended load Einstein applied the concentration distribution

$$
\frac{c}{c_{a}}=\left(\frac{D-y}{y} \frac{a}{D-a}\right)^{2}
$$

in which

$$
\begin{aligned}
& c=\text { concentration of suspended sediment (at } y \text { above the bed) } \\
& c_{a}=\text { concentration at reference level }(y=a) \\
& D=\text { depth of water } \\
& y=\text { distance from bed level } \\
& z=w / 0.4 U_{f} \text { (the Rouse number) where } w \text { is the settling velocity. }
\end{aligned}
$$

Eq. (2) was derived by Ippen and Rouse (1937) and experimentally verified by Vanoni (1946). It suffers from the drawback that $c_{a}$ usually cannot be predicted. The present paper suggests a method for calculation of $c_{a}$, based on a single dynamical principle. When $c_{a}$ is known the transport rate $q_{s}$ is found from

$$
q_{s}=\int_{a}^{D} c U d y
$$

$U$ being the mean flow velocity at the distance $y$ from the bed. Einstein's paper contains some excellent graphs which facilitate this calculation quite considerably.

In case the bed is covered by dunes the shear velocity $U_{f}$ should be replaced by

$$
U_{f}^{\prime}=\sqrt{g D^{\prime} I}
$$

in which the reduced depth $D^{\prime}$ is found from the equation (Einstein 1950)

$$
\frac{V}{U_{f}^{\prime}}=\frac{V}{\sqrt{g D^{\prime} I}}=6+2.5 \ln \frac{D^{\prime}}{k}
$$

where $k$ is the surface roughness, which is usually a little larger than the sediment size and may be taken as $2.5 \mathrm{~d}$ (Engelund and Hansen 1972). $V$ is the mean velocity of the flow.

R. A. Bagnold (1954) pointed out a short-coming of the previous theories by formulating the following paradox: Consider the ideal case of fluid flow over a bed of uniform, perfectly piled spheres in a plane bed, so that all particles are equally exposed, statistical variations due to turbulence being neglected.

When a gradually increasing tractive stress exceeds a critical value, all particles in the upper layer are peeled off simultaneously and are dispersed in the fluid. Hence the next layer of particles is exposed to the flow and should consequently also be peeled off. The result is that all subsequent underlying layers are also eroded, so that 


\section{F. Engelund and J. Fredsøe}

a stable bed could not exist at all, when the shear stress exceeds the critical value.

Bagnold explained the paradox by assuming that in a water-sediment mixture the total shear stress $\tau$ would be separated in two parts

$\tau=\tau_{F}+\tau_{G}$,

where $\tau_{F}$ is the shear stress transmitted by the intergranular fluid, while $\tau_{G}$ is the shear stress transmitted because of the interchange of momentum caused by the encounters of solid particles, i.e. tangential dispersive stress.

Hence, Bagnold's description of the physical process is, that when a layer of spheres is peeled off, some of the spheres may go into suspension while others will be transported as bed load. Thus a dispersive pressure on the next layer of spheres will develop and act as a stabilizing agency. Hence, a certain part of the total bed shear stress $\tau$ is transmitted as a grain shear stress $\tau_{G}$ and a correspondingly minor part as a fluid stress $\left(\tau_{F}=\tau-\tau_{G}\right)$. Continuing this argumentation, it is understood that exactly so many layers of spheres will be eroded that the residual fluid stress $\tau F$ on the first immovable layer is equal to the critical tractive stress $\tau_{c}$. Hence, the mechanism in transmission of a tractive shear stress $\tau$ greater than $\tau_{c}$ is the following: $\tau_{C}$ is transferred directly by fluid shear stress to the immobile bed while the residual stress $\tau-\tau_{C}$ is transferred to the moving particles and further from these to the fixed bed as a dispersive stress.

By theoretical and experimental research Bagnold developed the following expression for the dispersive shear stress due to the grain collisions

$$
F_{S}=0.013 \text { ps } \lambda^{2} d^{2}\left(\frac{d U}{d y}\right)^{2}
$$

where $\lambda$ is the so-called linear concentration, which is related to the volume concentration by the equation

$$
c=\frac{0.65}{(1+1 / \lambda)^{3}}
$$

and $y$ is the distance from the bed.

We shall later revert to an application of these expressions.

In recent publications (R. Fernandez Luque 1974, R. Fernandez Luque and R. van Beek 1976) certain modifications of Bagnold's ideas were suggested together with a consistent theory for the transport of bed load on a plane bed, considering the motion of individual particles. The theory is supported by a series of interesting experimental observations.

One of the basic issues is that close to incipient particle motion (i.e. small transport rates) only the topmost grains will be eroded, and the bed load will not effectively reduce the fluid part of the turbulent bed shear stress. This can also hardly be expected as, under these conditions, the bed load particles cover only a small portion of the bed surface, because only few particles will be in motion. According to the model of Fernandez Luque et al. the bed load particles reduce the maximum fluid shear stress at the bed surface to the critical value $\tau_{C}$ by exerting an average reaction 


\section{A Sediment Transport Model for Straight Alluvial Channels}

force on the surrounding fluid. Hence the bed load forms a "protection shield" at higher bed load concentrations, which controls the erosion rate. We shall revert to this idea later on.

The experiments presented by these authors are of special interest, because they avoid the complication of dune influence, as the observations were carried out for very small transport rates mostly before bed waves became appreciable.

\section{The Rate of Bed Load Transportation $q_{B}$}

In the following it is attempted to approach the bed load transportation problem by considering the motion of the individual particles. Information about the transport velocity of single particles has been obtained by experiments published by Meland and Normann (1966). These experiments were carried out with single spherical glass beads moving over a bed of rhombohedrally packed spherical beads. In some of the runs the moving single particle was of the same size as those of the bed, while in other cases the bed particles were either larger or smaller. Following these authors notation $d$ denotes the diameter of the migrating particle, while $k$ is the diameter of the bed particles.

On the basis of these measurements it is attempted to develop a semi-empirical law for the mean transport velocity $U_{B}$ of a particle moving as bed load. To this end we consider the most important forces determining the motion of an immersed particle:

1) The agitating forces, drag $F_{D}$ and lift $F_{L}$, and

2) the stabilizing forces, reduced gravity (immersed weight) and the frictional forces resulting from the occasional contacts between particle and bed.

An exact description of forces and particle motion is impossible due to the complex character of the phenomenon. What we can do is to establish a "model equation" containing the time-averaged quantities, and from this equation we can hope to obtain sufficient information to be able to identify the parameters necessary for a relevant description of the process.

The agitating forces may be represented in form of a drag

c $\frac{1}{2} \rho\left[\alpha U_{f}-U_{B}\right]^{2} \frac{\pi}{4} d^{2}$

in which $U_{f}$ and $U_{B}$ are the friction velocity and the migration velocity of the particle, respectively. $\alpha U_{f}$ is the flow velocity at a distance of about one or two grain diameter $d$ from the fixed bed. Assuming the validity of the ordinary velocity distribution in rough channels, $\alpha$ must be of the order of 6 to 10. The factor $c$ stands for the drag (and lift) coefficient, but as the time variation of the agitating forces differs considerably from that of the stabilizing forces, we can hardly expect the value of $c$ to be exactly equal to the static value. 


\section{F. Engelund and J. Fredsøe}

The frictional force acting on the particle is written as

$$
\rho g(s-1) \frac{\pi}{6} a^{3} \beta
$$

where $s$ is the relative density of the particles, and $\beta$ is the dynamic friction coefficient. Actually the gravity of the particle should be corrected for a small dynamic lift $F_{L}$. However, this may be done by changing the value of $c$.

The model equation then expresses the average equilibrium of agitating and stabilizing forces

$$
c \frac{1}{2} \rho\left(\alpha U_{f}-U_{B}\right)^{2} \frac{\pi}{4} a^{2}=\rho g(s-1) \frac{\pi}{6} d^{3} \beta,
$$

from which

$$
\frac{U_{B}}{U_{f}}=\alpha\left[1-\sqrt{\theta_{0} / \theta}\right]
$$

where $\theta$ is given by Eq. (1), and

$$
\theta_{0}=\frac{4 \beta}{3 \alpha^{2} c}
$$

$\theta_{0}$ is seen to be the limiting value of $\theta$ for which a particle located on the bed is just immobile. It is natural to relate this to the critical value $\theta_{\mathcal{C}}$ corresponding to Shield's criterion. As a particle lying on the bed is easier to move than a particle located in the bed, it must be expected that $\theta_{0}<\theta_{\mathcal{C}}$. A crude estimate can be obtained from Eq. (10) by insertion of the following values, partly obtained by the subsequent analysis:

$$
\beta=\tan 27^{\circ}, \quad \alpha=9, \quad c=0.6 \text {, }
$$

which gives $\theta_{0}=0.014$, which is between one half and one fourth of the generally accepted values of $\theta_{C}$.

It is probably better to evaluate $\theta_{0}$ by considering the experiments of Fernandez Luque et al., which indicated $\theta_{0}$ to be about half $\theta_{c}$, so that Eq. (9) may be written

$$
\frac{U_{B}}{U_{f}}=\alpha\left[1-0.7 \sqrt{\theta_{c} / \theta}\right]
$$

Comparison of this expression with Meland and Normann's result indicated that for suitable choice of $\theta_{c}$ and $\alpha=10$, a very good agreement is obtained, as demonstrated in Fig. 1. Fernandez Luque's results, also indicated in this figure, are more satisfactory in the sense that $\theta_{C}$ was measured directly and $U_{B}$ was determined as the mean transport velocity in a natural bed.

Eq. (11) was first suggested by Fernandez Luque and was checked by experiments with different slopes of the bed surface. It was found to hold irrespective of the inclination angle $\delta$, provided the proper value of $\theta_{c}$ was inserted. The experiments indicate that we must take

$$
\theta_{c}=\theta_{c, 0}[1+\tan \delta]
$$




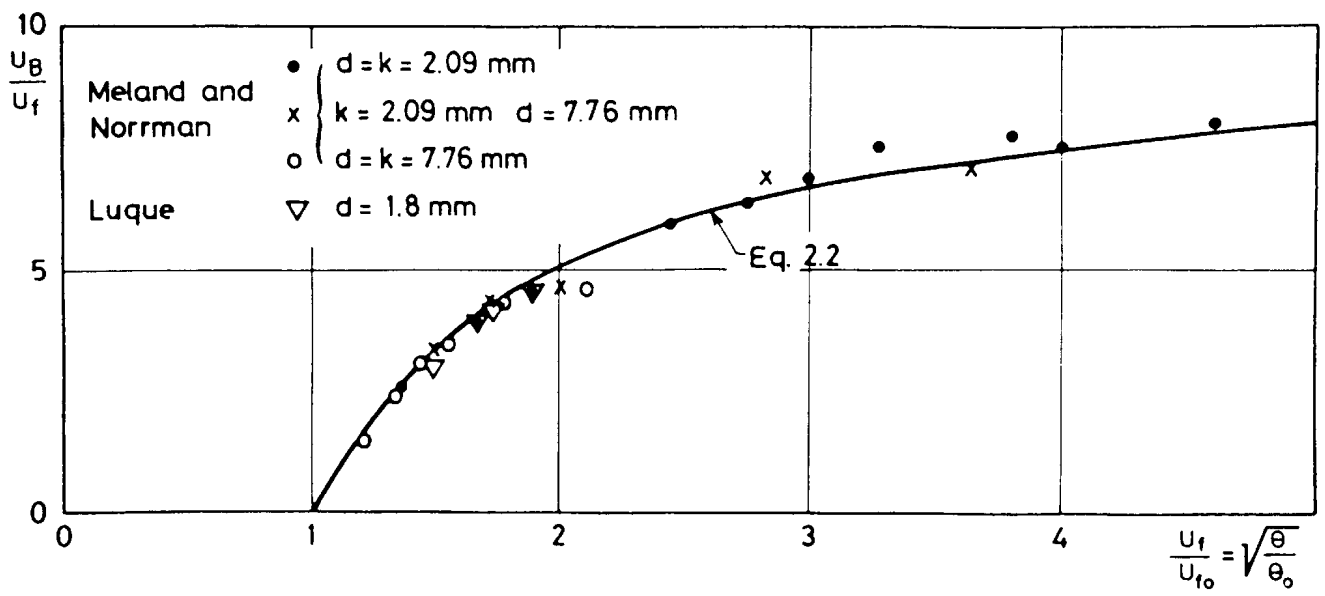

Fig. 1. Experiments of the transport velocity $U_{B}$ of bed load particles.

where $\theta_{\mathcal{C}},{ }_{0}$ is the value of $\theta_{\mathcal{C}}$ for horizontal bed. $\delta$ is positive when the particles move uphill.

For sand the value of $\alpha$ was found to be 9.3.

From the knowledge of mean particle velocity we can now derive an expression for the rate of bed load transport $q_{B}$ under the assumption that the bed load is the transport of a certain fraction $p$ (= probability) of the particles in a single layer. As the total number of surface particles per unit area is $1 / d^{2}$, we get

$$
q_{B}=\frac{\pi}{6} d^{3} \frac{p}{d^{2}} U_{B}
$$

or, after insertion of Eq. (11)

$$
q_{B}=9.3 \frac{\pi}{6} d p U_{f}\left[1-0.7 \sqrt{\theta} c^{/ \theta}\right]
$$

This is made non-dimensional by the divisor $\sqrt{(s-1) g d^{3}}$ (of Eq. (1)):

$$
\Phi_{B}=5 p(\sqrt{\theta}-0.7 \sqrt{\theta})
$$

From the experiments of Fernandez Luque et al. we can get some empirical information about $p$, because the measurements comprise $\phi_{B}, \theta$, and $\theta_{C}$. The result is given in Fig. 2, where the values of $p$ calculated from Eq. (13) are plotted against $\theta$. The experiments are particularly interesting because the transport rates were so small that all particles moved as bed load and without the disturbing effect of dunes and ripples. In case of larger transport rates this technique is no longer applicable, so that we must find other ways to obtain the necessary information.

Another useful series of data is that presented by Guy et al. (1966). For the present purpose, the evaluation of $p$, the experiments with sand size $d=0,93 \mathrm{~mm}$ are particularly suited as explained below. Because of the dune formations it is neccessary to divide the total shear stress in two components 


\section{F. Engelund and J. Fredsøe}

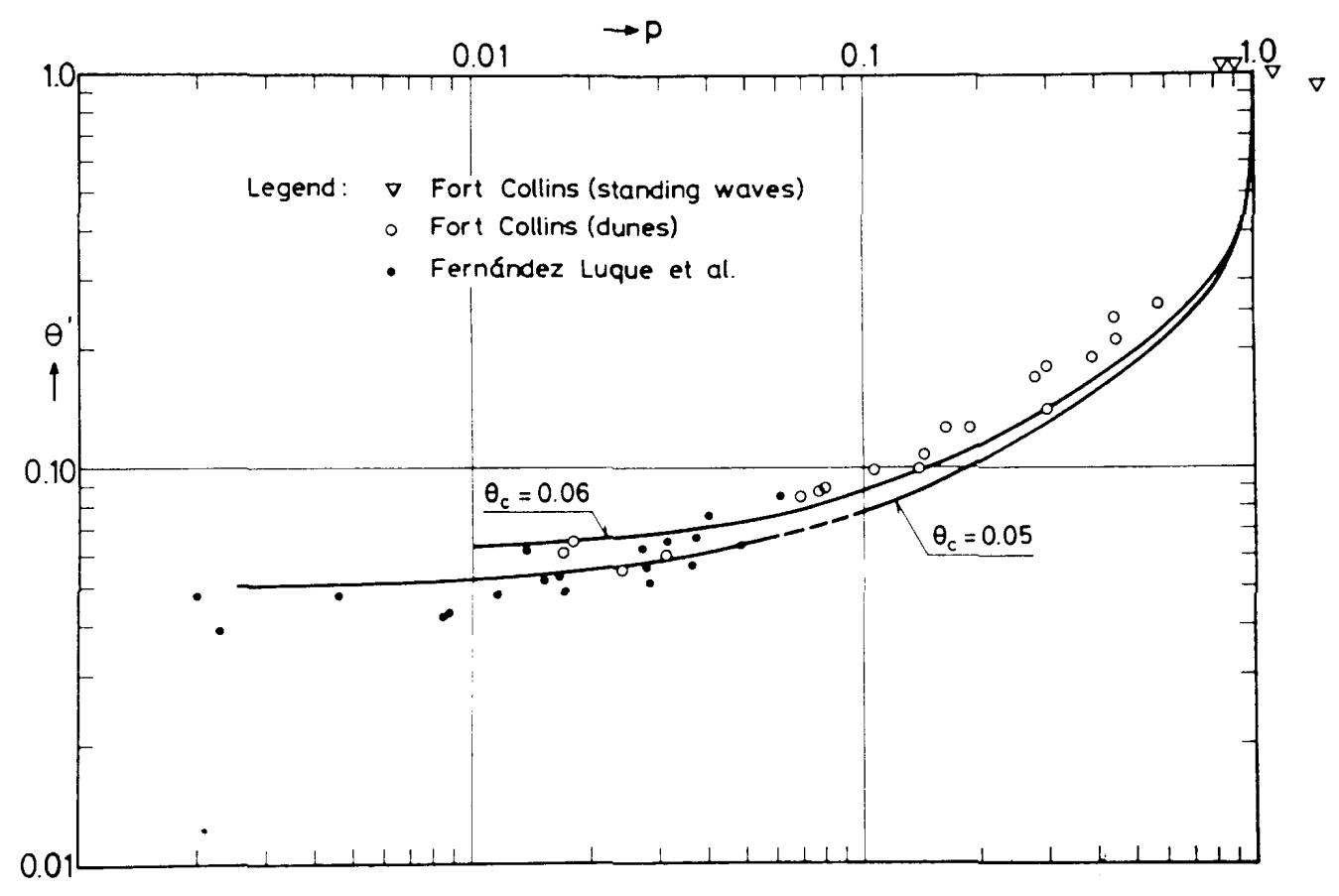

Fig. 2. The probability function $p$ versus $\theta^{\prime}$.

$$
\tau=\tau^{\prime}+\tau^{\prime \prime} \quad, \quad \frac{\tau^{\prime}}{\rho}=U_{f}^{\prime 2}
$$

where only the first term, which corresponds to the skin friction, is directly active in the bed load process. $\tau$ ' (or $U_{f}$ ) is calculated from Einstein's procedure of Eqs. (4) and (5). Similarily, we have the non-dimensional version of Eq. (13).

$$
\theta=\theta^{\prime}+\epsilon
$$

In all the expre.sions derived above, $\theta$ should consequently be substituted by $\theta^{\prime}$ in order to correct for the effect of dunes.

Another difficulty in applying ordinary flume data is that the total sediment load usually has a component of suspension, which has to be subtracted from the total load in order to obtain the bed load proper. The selected series of experiments has the particular advantage that the amount of suspended load was always a minor part of the total.

There are two different methods of evaluation of the bed load transport. The first one is to take the total load and subtract the measured suspended load. The second one is to consider the measured dune height $h$ and the migration velocity $a$ and then apply the equation

$$
q_{B} \simeq \frac{1}{2}(1-m) a h
$$




\section{A Sediment Transport Model for Straight Alluvial Channels}

where $m$ is the porosity of the sand bed.

Of course there is a considerable amount of uncertainty associated with both methods, which makes it so important to select experiments where the suspension is small. In the runs considered, the two methods were found to agree fairly well. Hence, after making an estimate of $\theta_{c}$ (e.g. by Shield's diagram), we can now calculate the value of $p$ from Eq. (13), substituting the calculated value of $\theta$ ' for $\theta$. The result of such an analysis is also shown in Fig. 2, where the Fort Collins points and Fernandez Luque's data are seen to form a fairly consistent picture.

Now we are able to make a first check on the above-mentioned assumption that only the part $\tau \dot{c}$ of the total shear stress $\tau$ is transferred directly to the immobile bed as skin friction, while the residual part $\tau-\tau_{\mathcal{C}}$ is carried as drag on the moving bed particles and indirectly transferred to the bed by occasional encounters. This idea leads to the equation

$$
\tau \neq \tau_{C}+n F_{D},
$$

where $F_{D}$ is the average drag on a single moving bed particle, while $n$ is the number of moving particles per unit area. If this expression is divided by $\rho g(s-1) d$, and $F_{D}$ is estimated as

$$
F_{D} \approx \rho g(s-1) \frac{\pi}{6} d^{3} \beta
$$

the resulting equation becomes

$$
\theta=\theta_{c}+\frac{\pi}{6} \beta\left(n d^{2}\right)=\theta_{c}+\frac{\pi}{6} \beta p
$$

From this $p$ can be determined, if $\theta_{c}$ and $\beta$ are known. From investigations of flow in meanders (Engelund 1975, Gottlieb 1976) the value of the dynamic friction angle $\varphi$ is known to be slightly smaller than the static (i.e. angle of repose), the value $\varphi=270$ being reasonable for ordinary sand. Taking $\theta_{c}=0.05$ we get

$$
\theta=0.05+0.2668 p \text {, }
$$

which is given in Fig. 2 for comparison with Fernandez Luque's experiments. The agreement is acceptable for small values of $\theta$, but for the larger values the curves fall below the Fort Collins data. The explanation for this seems to be that Eq. (15) is only valid as long as there is no suspension, a point we shall revert to later in greater detail.

The next problem is what happens at very large transport rates. In this extreme the argument leading to Eq. (15) does obviously not hold. If we stick to the model that the bed load is a single layer of particles, the maximum value of $p$ must be unity corresponding to a simultaneous motion of all particles in the layer.

In the Fort Collins series four runs (corresponding to "standing waves") are marked by triangles in Fig. 2. In these runs the transport rate was large but still largely occurring as bed load. The fact that they all gave values of $p$ close to unity is an experimental support for the idea that $p$ approaches unity for increasing values of $\theta$. 


\section{F. Engelund and J. Fredsøe}

If a limiting value of $p=1$ is accepted, the expression for $p$ has to be modified as for instance

$$
p=\left[1+\left(\frac{\frac{\pi}{6} \beta}{\theta-\theta_{c}}\right)^{4}\right]^{-1 / 4}
$$

which is about equal to Eq. (15) for $\theta$ close to $\theta_{c}$ and approaches unity for large values of $\theta$. Eq. (16) is given in Fig. 2 for $\theta_{C}=0.05$ and 0.06 .

\section{The Suspended Load}

For large values of $\theta^{\prime}$ the transfer of shear stress to the bed surface is no longer well described by Eq. (15), because it neglects the dispersive stress from the suspended load. In order to take account of this we have to introduce Bagnold's expression and write

$$
\tau^{\prime}=\tau_{c}+n F_{D}+F_{S},
$$

in which $F_{S}$ is the dispersive stress as given by Eq. (6), where a specific value of the velocity gradient will have to be inserted. Assuming the classical logarithmic velocity distribution to be at least approximately valid, we get

$$
\frac{d U}{d y}=\frac{2.5 U_{f}^{\prime}}{y}
$$

The dispersive stress acting on the bed must depend on this velocity gradient calculated for a value of $y$ about equal to one particle diameter $d$. The following calculations indicated that the value $y=1.73 d$ yielded the best agreement with observation of the actual amount of suspension, so that Eq. (17) becomes

$$
\tau^{\prime}=\tau_{c}+n E_{D}+0.027 \text { ps }\left(\lambda_{b} U_{f}^{\prime}\right)^{2},
$$

where $\lambda b$ is the linear concentration at bed level. In nondimensional form this equation becomes

$$
\theta^{\prime}=\theta_{c}+\frac{\pi}{6} B p+0.027 s \theta^{\prime} \lambda_{b}^{2}
$$

By Eq. (7) we can now calculate the corresponding volumetric bed concentration $c_{b}$ as

$$
c_{b}=\frac{0.65}{\left(1+1 / \lambda_{b}\right)^{3}}
$$

Hence this model provides a method for calculation of $c_{b}$ from the requirements of momentum transfer to the immobile sand surface if $p$ is known.

When $\theta$ becomes very large, corresponding to large suspended transport rates, we assume $p$ to be unity and find that 


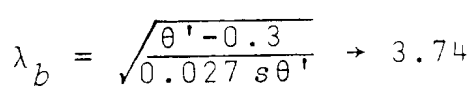

for ordinary sand with $s=2.65$. This corresponds to the volumetric bed concentration $c_{b}=0.32$, which is estimated to be a reasonable maximum value for suspended sediment in motion. Theoretically $c_{b}$ can be as large as 0.65 , but this corresponds to firm packing and does not allow free motion of the particles.

In the general case $c_{b}$ must be determined from Eqs. (19) and (20), assuming $p$ to be given by Eq. (16) (an illustrative example is given below). For fixed values of $\theta_{\mathcal{c}}, B$, and $s$, the bed concentration depends on $\theta^{\prime}$ only. This relationship is presented in Fig. 3 for $\theta_{c}=0.05, s=2.65$, and $\beta=\tan 27^{\circ}=0.51$. Note that $c_{b}$ becomes extremely small for $\theta^{\prime}<0.1$ and that it approaches 0.32 for large values of $\theta^{\prime}$.

To proceed further it is necessary to obtain an estimate of the size of the particles moving in suspension. This is achieved by means of the criterion

$$
w<0.8 U_{f}^{\prime},
$$

which states that only particles with a fall velocity $w$ smaller than this threshold value will move in suspension. When the distribution curve for $w$ is known it is possible to estimate the "effective fall velocity" for the suspended fraction (Raudkivi 1976). Criteria of the type (21) seem to be generally accepted (Middleton 1976).

When $w$ has been determined the transport rate of suspended load can be calculated from Eqs. (2) and (3), as described by Einstein (1950). The bed load transport is obtained from Eqs. (13) and (16).

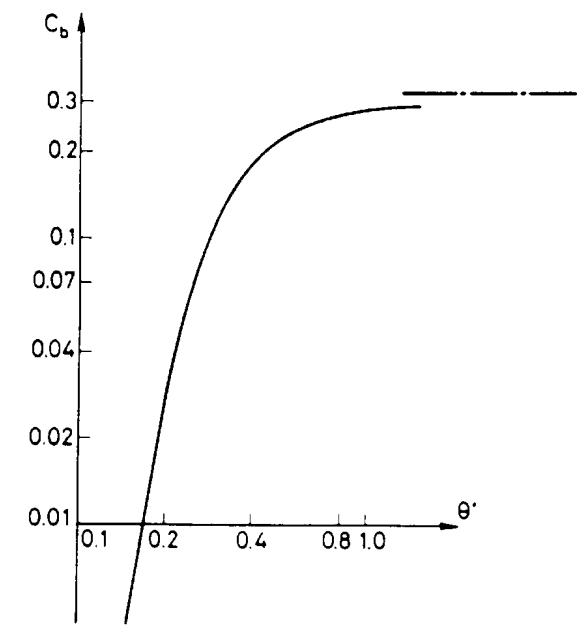

Fig. 3. Bed concentration $c_{b}$ versus $\theta^{\prime}$, assuming $\theta_{\mathrm{C}}=0.05$, $s=2.65$, and $B=0.51$. 


\section{F. Engelund and J. Fredsøe}

The problem is now how the theory can be controlled by comparison with experiments. It is well-known, that measurements of the transport rates of bed load and suspended load separately is difficult and always associated with considerable uncertainty. Likewise, the mean particle size of the suspended load is rather uncertain.

In adapting the Fort Collins data (Guy et al. 1966) we have tried to compare the calculated bed load transport rates with the measurements applying Eq. (14) (which is rather doubtful for large transport rates). Although the scatter is rather large, the general trend in the comparison is satisfactory. A similar remark applies to the suspended particle size.

The total rate of sediment transport, however, can be measured with good accuracy. Hence, the most significant test is to compare the total load with the theory, which is done in Fig. 4.

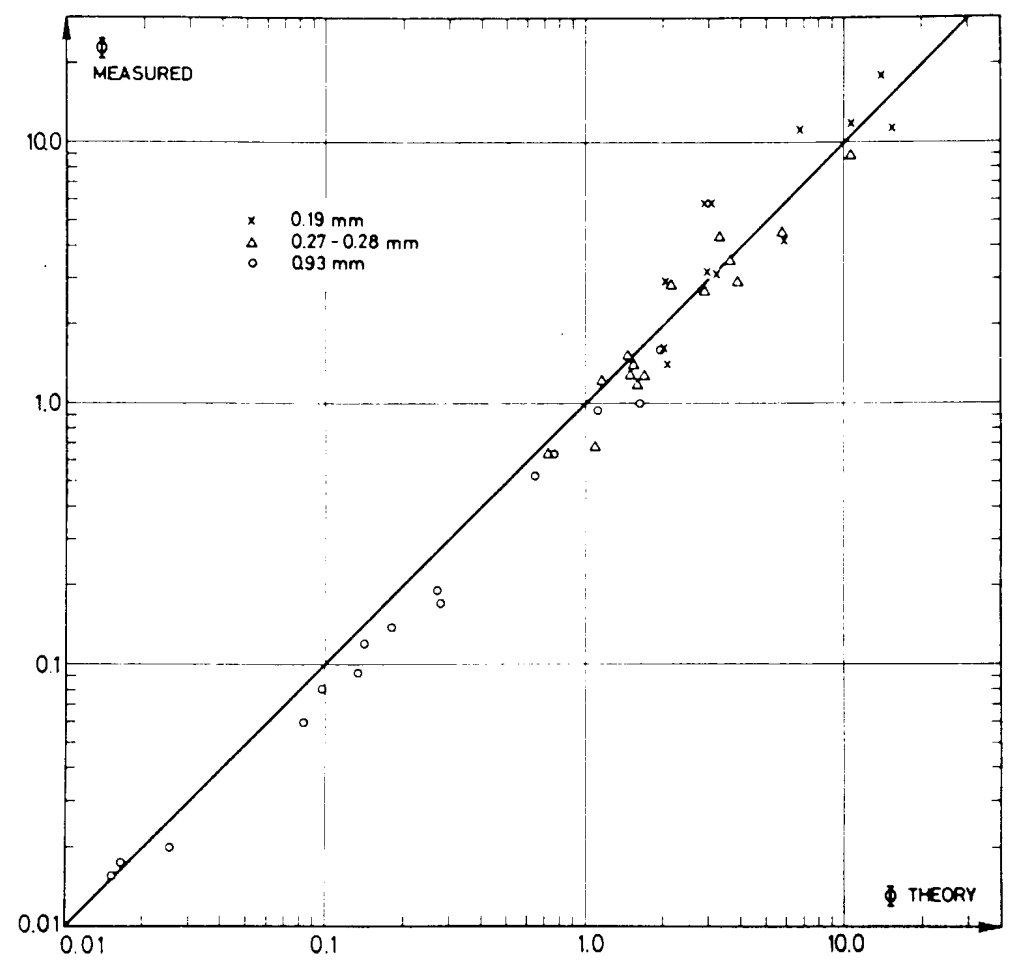

Fig. 4. Comparison between measured and calculated rates at total sediment transport. 


\section{Example}

As an illustrative example we consider run 21 from the Fort Collins report (Guy et al. 1966) from the series using sand with the mean fall diameter $d=0.28 \mathrm{~mm}$. The data for this run are:

$$
\begin{array}{ll}
\text { Slope } I & =0.00131 \\
\text { Depth } D & =0.326 \mathrm{~m} \\
\text { Mean velocity } V & =0.725 \mathrm{~m} / \mathrm{s} \\
\text { Temperature } T & =16 .{ }^{\circ} 5 \mathrm{C}
\end{array}
$$

The hydraulic roughness of the surface is estimated to $k=2.5 d$. Hence, from Eq. (5) we get $D^{\prime}=0.116 \mathrm{~m}$ and $U_{f}^{\prime}=0.0386 \mathrm{~m} / \mathrm{s}$. From this we find that

$$
\theta^{\prime}=\frac{D^{\prime} I}{(s-1) d}=0.329
$$

With $\theta_{c}=0.05$ and $\beta=0.51$ Eq. (16) gives $p=0.859$ and the non-dimensional rate of bed load transport is calculated from Eq. (13):

$$
\Phi_{B}=1.79
$$

If the same quantity is estimated from Eq. (14) we get $\varphi_{B}=1.22$. The critical fall velocity $w_{c}$ is (Eq. (21)) $0.8 U_{f}^{\prime}=0.031 \mathrm{~m} / \mathrm{s}$. From the distribution of particle fall velocity it is found that the mean fall velocity of the suspended part is about $w=$ $0.023 \mathrm{~m} / \mathrm{s}$, corresponding to a fall diameter of $0.20 \mathrm{~mm}$. The measured mean diameter of the suspended particles was in this case considerably smaller, about $0.16 \mathrm{~mm}$. (For the runs in general the agreement between measured and calculated particle sizes for the suspended material was better and no trend in the deviations was found).

The value of $z$ becomes

$$
z=\frac{w}{0.4 U_{f}^{\prime}}=1.49
$$

The lower limit a for the integral in Eq. (3) is taken as $a=2 d$.

According to Einstein (1950) Eq. (13) can be written as

$$
\Phi_{s}=11 . \overline{6} \cdot \theta^{\prime} c_{b}\left(\frac{a}{d}\right)\left[I_{1} \ln \frac{30 D}{k}+\cdot I_{2}\right] \text {, }
$$

where $I_{1}$ and $I_{2}$ are obtained from his diagrams as 0.40 and -2 , respectively. From Eqs. (19) and (20) or from Fig. $3 c_{b}$ is found to be 0.14 , so that the non-dimensional transport rate of suspended material becomes

$$
\Phi_{S}=1.94
$$

The total sediment transport rate thus becomes

$$
\Phi_{t}=\Phi_{b}+\Phi_{s}=3.73
$$

to be compared with the measured value 3.46 . 


\section{F. Engelund and J. Fredsøe}

\section{References}

Bagnold, R. A. (1954) Experiments on a gravity-free dispersion of large solid spheres in a Newtonian fluid under shear. Proc. Roy. Soc. London (A) 225, 49.

Einstein, H. A. (1950) The bed-load function for sediment transport in open channel flows. U.S. Dept. of Agriculture, Techn. Bulletin No. 1026.

Engelund, F. and Hansen, E. (1972) A monograph on sediment transport in alluvial streams. Technical Press, Copenhagen.

Engelund, F. and Fredsøe, J. (1974) Transition from dunes to plane bed in alluvial channels. Series Paper 4, Inst. Hydrodynamics and Hydraulic Eng., Tech. Univ. Denmark.

Engelund, F. (1974) Flow and bed topography in channel bends. J. Hyd. Div., ASCE, vol. 100, No. HY 11 .

Engelund, F. (1975) Steady transport of moderately graded sediment (part 2). Progress Report No. 35, Inst. Hydrodynamics and Hydraulic Eng., Tech. Univ. Denmark.

Engelund, F. (1976) Experiments in curved alluvial channel (part 2). Progress Report No. 38, Inst. Hydrodynamics and Hydraulic Eng., Tech. Univ. Denmark.

Fernandez Luque, R. (1974) Erosion and transport of bed sediment (Diss.), Krips Repro B. V. - Meppel.

Fernandez Luque, R., and van Beek, R. (1976) Erosion and transport of bed-load sediment. $J$. Hyd. Research, vol. 14 No. 2.

Fredsøe, J., and Engelund, F. (1975) Bed configurations in open and closed alluvial channels. Series Paper 8, Inst. Hydrodynamics and Hydraulic Eng., Tech. Univ. Denmark.

Fredsøe, J. (1976 a) Sediment inertia as cause of river antidunes. Discussion, J. Hyd. Div., ASCE, vol. 102 HY 1.

Fredsøe, J. (1976 b) Levelling of side slopes in river navigation channels. Progress Report No. 38, Inst. Hydrodynamics and Hydraulic Eng., Tech. Univ. Denmark.

Fredsøe, J., and Engelund, F. (1976): Bed concentration of suspended material. Progress Report No. 39, Inst. Hydrodynamics and Hydraulic Eng., Tech. Univ. Denmark.

Gottlieb, L. (1976) Three-dimensional flow pattern and bed topography in meandering channels. Series Paper 11, Inst. Hydrodynamics and Hydraulic Eng., Tech. Univ. Denmark.

Guy, H. P., Simons, D. B., and Richardson, E. V. (1966) Summary of alluvial channel data from flume experiments, 1956-61. U.S. Geological Survey professional paper 462 - I.

Meland, N., and Normann, J. O. (1966) Transport velocities of single particles in bed-load motion. Geografiska Annaler, Vol. 48, A.

Middleton, G. V. (1976) Hydraulic interpretation of sand size distributions. Journal of Geology, Vol. 84, pp. 405-426.

Raudkivi, A. J. (1976) Loose boundary hydraulics. 2. edition. Pergamon Press.

Rouse, H. (1937) Modern conceptions of the mechanics of turbulence. Trans. ASCE 102, pp. 463-543.

Vanoni, V. A. (1946) Transportation of suspended sediment by water. Trans. Am. Soc. Civ. Engrs., Vol. 111, pp. 67-133.

Received: 25 October, 1976

Address:

Institute of hydrodynamics and hydraulic engineering ISVA, Technical University of Denmark,

Bldg. 115,

2800-Lyngby, Denmark 